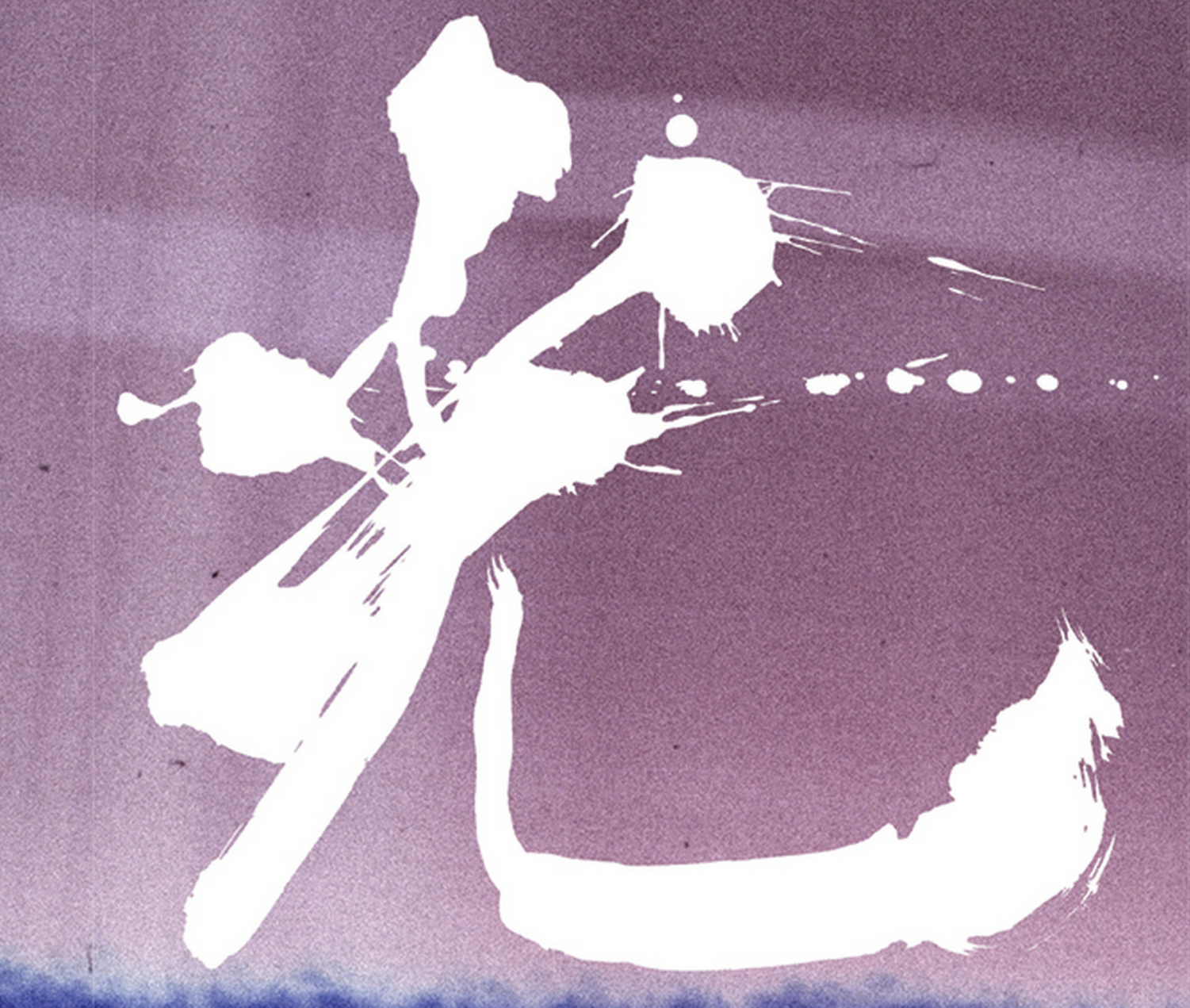

Brushed in Light

CALLIGRAPHY IN EAST ASIAN CINEMA

Markus Nornes 


\section{Brushed in Light}




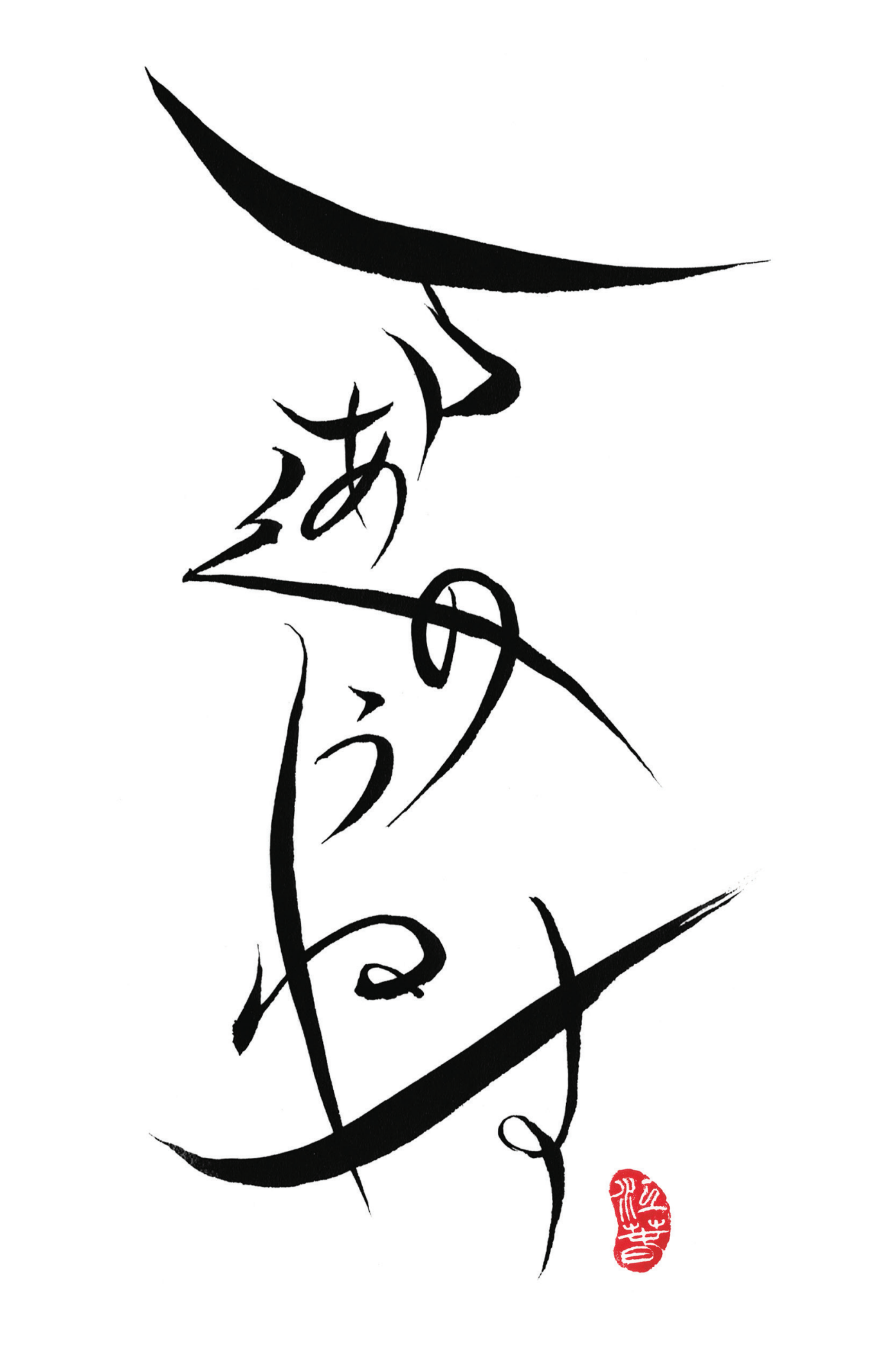


Brushed in Light CALLIGRAPHY IN EAST ASIAN CINEMA

Markus Nornes

University of Michigan Press Ann Arbor 


\section{(cc) BY-NC-ND}

This work is licensed under a Creative Commons Attribution-NonCommercial-NoDerivatives 4.o International License. Note to users: A Creative Commons license is only valid when it is applied by the person or entity that holds rights to the licensed work. Works may contain components (e.g., photographs, illustrations, or quotations) to which the rightsholder in the work cannot apply the license. It is ultimately your responsibility to independently evaluate the copyright status of any work or component part of a work you use, in light of your intended use. To view a copy of this license, visit http://creativecommons.org/licenses/by-nc-nd/4.0/

For questions or permissions, please contact um.press.perms@umich.edu

Published in the United States of America by the

University of Michigan Press

Manufactured in the United States of America

Printed on acid-free paper

First published February 2021

A CIP catalog record for this book is available from the British Library.

Library of Congress Cataloging-in-Publication data has been applied for.

DOI: https://doi.org/10.3998/mpub.11373292

ISBN: 978-o-472-13255-3 (hardcover : alk. paper)

ISBN: 978-0-472-90243-9 (OA e-book)

Frontispiece calligraphy of the author's name by Nishigaito Koshun. Cover calligraphy by Torii Haru, with 35mm filmstrip from the author's collection. Chapter number calligraphy by various ancient masters, mostly from stele rubbings. End credit title on page 145 from Mizoguchi Kenji's Downfall of Osen (Orizuru Osen, 1935).

This book is freely available in an open access edition thanks to TOME (Toward an Open Monograph Ecosystem) —a collaboration of the Association of American Universities, the Association of University Presses, and the Association of Research Libraries - and the generous support of the University of Michigan, TOME initiative. Learn more at the TOME website, available at: openmonographs.org

This work was supported by the Core University Program for Korean Studies through the Ministry of Education of the Republic of Korea and Korean Studies Promotion Service of the Academy of Korean Studies (AKS-2016-OLU-2240001). 
For td 


\section{Acknowledgments}

As I explain in my introduction, I first imagined this book as a dissertation. However, it was not until about ten years ago that I actually embarked on the project. I never imagined that it would be such a rich experience. I really shouldn't have waited so long. I have been humbled by the hospitality of all the scholars, calligraphers, art directors, and filmmakers I met across East Asia. It has been one exciting encounter after another.

My first stop was Japan where, thanks to an introduction from director Hara Kazuo, I met the great Akamatsu Hikozo and came away with the confidence that this book was actually possible. Over the years, I met some inspiring calligraphers in Japan, especially Nishigaito Koshun (who brushed my name in her distinctive style for this book's colophon), Yabe Chosho, Iida Reigiku, Itomi Keinan, Sisyu, and Takeda Soun. I enjoyed long conversations with filmmakers Adachi Masao, Matsumoto Toshio, Yoshida Kiju, Iimura Takahiko, in addition to scholars like Okada Mariko, Yoshimi Shunya, Akiyama Tamako, Ueno Toshiya, Sakamoto Hirofumi, Nakajima Seio, Yomota Inuhikoalso actress Okada Mariko, benshi Kataoka Ichiro, Oyama Yuki, Sasatake Yoshiyuki, Takahashi Ken at Toei, Wachi Yukiko from Kawakita Memorial Film Institute, and finally Okada Hidenori and Kamiya Makiko (National Film Archive of Japan). I especially want to thank Koizumi Hiroyasu for organizing a gathering of veteran art designers at the Association of Production Designers of Japan office. Art designers Imai Takashi, Nitta Takayuki and Ando Atsushi were particularly helpful, especially for guiding me through studio props departments in Japan.

In Taiwan, I was able to conduct research through the support of the 2011 Faculty Research Grant for Taiwan Studies, conducted by Education Division, Taipei Economic \& Cultural Office in Chicago. On the ground, I was particularly indebted to Wood Lin, Frances Huang, and Lin Wen-chi for helping me to set up the trip. I had inspiring meetings with calligraphers Chen Shih-hsien, Chao Yuhsiu and especially Tong Yang-tze. Many people shared their precious time, including Yu Kuo-ching (National Palace Museum), Liao Hsien-hao Sebastian, Chung Kuohua, Lee Yu-hwa (Fisfisa Media), Ru-Shou Robert Chen, Edmond Wong Kin-yip, Fu Syou-ling, Lee Yu-Hwa, Vivian Tsu-i Chiang, Rose Kuo-chen Chen, Wang Paizhang, and especially Angelika Wong. Meeting Hou Hsiao-hsien was a goal in life I can now take off the list. As you will discover in chapter 5 , he was both delightfully frank and unhelpful; this was the moment I discovered that directors are actually less interesting to talk to than art directors when it comes to calligraphy.

Korea was an eye-opening experience in so many ways. I would like to start with thanks to my interpreters Hansang Kim and Shinae Chu. They helped me talk to Park 
Sun-Young, Choi Ji-Woong (Propaganda), Gim Hogil and Yi Ye-Ho, Kim Tae-Uk (Namyangju Film Studio Props Department), Park Si-Young (Bitnanun), Kang Byung-in, Kim Hye-jin (Kkotsbom), and Sue Kim. I was also helped by Henry Em, Jung Hyunchang (KOFIC), Kim Soon-mo, Chung Chonghwa (KOFA), Kim Soyoung, Kim Ki-duk, Kim Dongwon, Byung Youngjoo and Lee Myungse.

In the United States and Europe, I benefited from the wisdom of Mark Cousins, Chris Berry, Yasuko Tsuchikane, $\mathrm{Xu}$ Bing, D. N. Rodowick, Stanley Cavell, Alexander Zahlten, Aaron Gerow, and Tom Lamarre (who knew what I was up to from the get go and that gave me great confidence). At the University of Michigan, many colleagues served as interlocutors and helped me in myriad ways, especially Natsu Oyobe, Youngju Ryu, Kevin Carr, Micah Auerbach, Sangjoon Lee, Reginald Jackson, Donald Lopez Jr., Ben Bross, Martin Powers, Shuen-fu Lin, Erin Brightwell, Xiaobing Tang, David Rolston, Johannes von Moltke, and Giorgio Bertellini. Many students helped me with my research, including Yuki Nakayama, Michael Arnold, Irhe Sohn, Sanako Fujioka, Emily Ho, Jini Kim, Wang Gerui, Haely Chang, Vesal Stoakley, Jihun Suk, and Juyeon Lee. My editor at University of Michigan Press, Christopher Dreyer, has been incredibly supportive. And at the Centers I could always count on Ena Schlorf, Yuri Fukazawa, and Do-hee Morsman for everything and anything that came up; they are incredible.

Hong Kong was, as always, an enervating and inspiring place. I was immeasurably helped by Elvis Mok, Justin Ng, Cyrus Ho Kim Hung, Wallace Chan Chi Ieong, Man Kit Wah Eva, Shu Kei, Johnson Chang (Chang Tsong-zung) and Valerie C. Doran of Hanart TZ Gallery, Emily SY Choi, Law Kar, Emily Yeh Yueh-yu, and Darrell Davis. I am always impressed by the archive in Hong Kong and the folks there-particularly Winnie Wy Fu, May Kwan Yuk Ng, and Angel On Ki Shing-helped me figure out who I should meet. Tit Leung Cheung helped me in so many ways, and it saddens me that he cannot take this book into hand; he was an enthusiastic supporter and great interlocutor and gifted me many wonderful experiences and memories.

In Shanghai, I had the invaluable guidance of Zhang Shujuan, who performed archive dives and networked for me while I was a visitor at Fudan University. This was upon the invitation of Lu Xinyu, two months that had an enormous impact on the project. On this trip, my encounters with Xiong Qi, Yang Ji, Riverstone and especially Xu Pengle of Shanghai Film Corporation felt fateful.

And in Beijing, I am grateful for the support of Wang Hongwei, Qin Zhenzhong, Li Gantian, Zhao Liang, Wang Wo, Cong Feng, Wang Haizhou, Jin Haina, and the calligraphers of the China Central Newsreel and Documentary Film Studio. I want to highlight my encounters with $\mathrm{Li}$ Xianting. As the following text will demonstrate, he had an enormous influence on my thinking about calligraphy.

When I look over these pages of names, I am truly humbled by everyone's support. My only Asian language is Japanese, so this book would have been truly impossible without everyone's help and advice. More than that, they all enriched my life in ways I never would have anticipated.

This book is dedicated to Tony Demko, whose place in Nakano-Fujimicho was my homey base camp. His friendship has been a bright light in my life. This project owes so much to his support.

Finally, I am endlessly grateful for the Institut française du Japon-Tokyo. I wrote the first draft of this book in their media center (great chairs!) and in their cafe (delicious coffee and pastries!). It was fun to write in a beautiful building designed by a Corbusier disciple, regularly bumping into friends on their way to catch a film.

This work was supported by the Core University Program for Korean Studies through the Ministry of Education of the Republic of Korea and Korean Studies Promotion Service of the Academy of Korean Studies (AKS-2016-OLU-2240001). I also benefitted from a summer visiting professorship at Fudan 
University's State Institute for Innovations in the Studies of Journalism, Communication and Mediated Society. Research and subvention grants were provided by the University of Michigan's Lieberthal-Rogel Center for Chinese Studies, Center for Japanese Studies, Nam Center for Korean Studies, the
University of Michigan Office of Research, and the College of Literature Science and the Arts. Research in Taiwan was conducted through the support of the 2011 Faculty Research Grant for Taiwan Studies, conducted by Education Division, Taipei Economic \& Cultural Office in Chicago. 


\section{Contents}

ACKNOWLEDGEMENTS

\section{INTRODUCTION}

Theorizing the Calligraph

The End

CHAPTER 1. Shufa/Seoye/Shodo

Calligraphy in the West

Shufa: In the Beginning Was the Law

Shodo: The Way of Japanese Calligraphers

Seoye: The Geopolitical Character

The Stench and Fragrance of Cinematic Calligraphy

CHAPTER 2. Transformations

The "Silent" Calligraph 33

Marginalizing Calligraphy $\quad 39$

The Analog Glyph of the Sound Era $\quad 41$

Bytes and Pieces-Calligraphy and Collage $\quad 46$

Collage and Time Travel in Chinese Cinema

CHAPTER 3. Defining Calligraphy 57

Cool Type $\quad 57$

Four Treasures $\quad 59$

$\begin{array}{lr}\text { Five Styles } & 69\end{array}$

Three Irreplaceables $\quad 73$

One Missing Ingredient $\quad 77$

The Last Word: Brush $\quad 80$ 
Hou Hsiao-hsien and Narrative Space $\quad 101$

Telling Time

Anchoring Space

Subtitling Calligraphy

CHAPTER 6. The Shimmering Smudge

The Knot

Corporeal Calligraphy

Reading the Moment

The Restlessness of the Calligraph

Digital materials related to this title can be found on the Fulcrum platform via the following citable URL: https://doi.org/10.3998/mpub.11373292 


\section{Introduction}

Had I been born Chinese, I would have been a calligrapher, not a painter.

-Pablo Picasso ${ }^{1}$

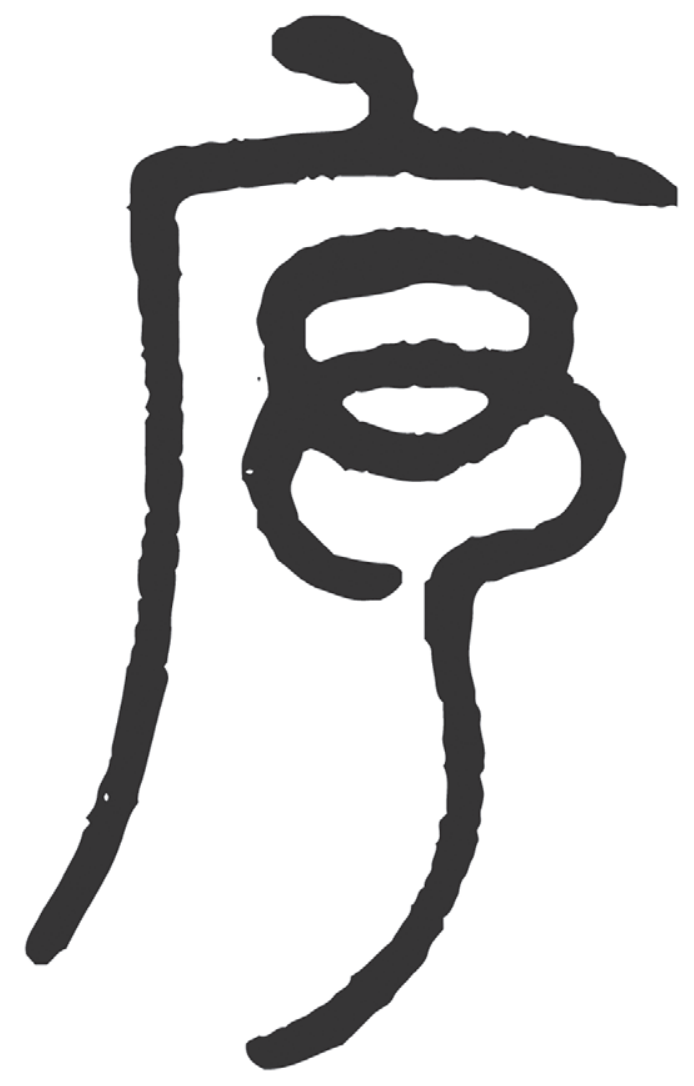

This quote from Picasso exemplifies the rapt fascination modern artists felt for the calligraphy of East Asia. Abstract expressionist painters like Franz Kline and Pierre Soulages integrated lessons from this distant practice into their own art works, mimicking the movements of calligraphers in their brushwork, playing with the broad contrast of black paint on white surface. Their affinities were both felt and real, but the Western artists were ultimately interested in calligraphy's abstraction. Soulages is exemplary here, as his bold black strokes very gradually took over his canvas until, at the end of his life, the underlying white was no longer visible. These late works cannot affiliate with calligraphy, having obliterated the spaces between lines.

Make no mistake, even conventional calligraphers trade in abstraction. Cursive forms of calligraphy, for example, easily edge toward illegibility for all but the highly trained artist or scholar. And then there are the characters themselves, some of which are pictographs abstracted from the visual world. But the complexities of this linguistic dimension of calligraphy are of little interest to those modern artists who emphasize calligraphy's material production and basic fascination for the line.

I must admit I shared these fascinations when I took notice of calligraphy in East Asian cinema. It was hard not to miss. Calligraphy is ubiquitous and is particularly prominent in prewar and period films. This is natural, con- 
sidering the place of the brushed word in both public and private space. As Chang Tsong-zung notes,

Imagine looking at an average Chinese town at the turn of the 2oth century, before the end of imperial rule. Whether entering from city gates, walking around the streets or taking detours into side alleys and private gardens, we would find calligraphic inscriptions as among the key elements of architectural decoration. Carved into wood or set into the architecture in brick or stone, calligraphy would appear centrally over the city gates, on beams and pillars of civil and religious buildings and as poetic decoration in residential and garden architecture. By contrast, a European city of equivalent significance from the same period would have had-instead of the ubiquitous poetic writingfigurative art, such as statues and paintings dominating civic and private buildings. ${ }^{2}$

The exteriors of films shot in the prewar period are documentary records of this built space decorated with characters, and set decorators for all period films go to great lengths to recreate it. And in contemporary cities, most of this carved calligraphy was replaced by photographic enlargements, neon, and lettering mimicking the calligraphic (Fig o.1). There is also calligraphic-looking graffito. Interiors are likewise decorated with calligraphy, and the cinema adds credit sequences, intertitles, all manner of props, and, more recently, cybernetic calligraphy. Once one takes notice of the brushed word in East Asian film, its utter ubiquity comes as a surprise.

When I took notice, I was struck by the sheer beauty of calligraphy at a time I myself was illiterate. Like Kline and company, I simply found it strikingly powerful and moving. This was something that my training in film studies was not terribly helpful for understanding and unpacking. But it was also thanks to this disciplinary grounding, notably in the heyday of cine-structuralism and semiotics, that
I took note of calligraphy's multifarious contributions to East Asian cinema. This project is a natural extension of my obsession with text on and in the image, which I previously explored in Cinema Babel: Translating Global Cinema. ${ }^{3}$

Perhaps it is no coincidence that my interest in calligraphy began at the same time as my study of subtitling. This was back in graduate school at the University of Southern California (USC) in the 1980s. Intent on studying East Asian cinema, I haunted the movie theaters of Little Tokyo and Chinatown. I rented pirated videos in Koreatown and Monterey Park. I began to take notice of the calligraphy in the films. It was everywhere. We even see this in the archive for cinema.

Calligraphy was an integral part of daily life for audiences through the 1940s. Letters, government documents, memos, signs, receipts, signatures, and more were rendered with brush and ink. During the immediate postwar era, the preferred writing tools became pens and pencils, followed much later by computers. While people are no longer daily producers of calligraphy, everyone studies it during their education. Furthermore, they remain daily consumers of calligraphy because of its integration into design, advertising and, yes, moving image media. Films are filled with calligraphy. So are their advertising campaigns. And there are also the graves (Fig 0.2).

As a spectator, you have undoubtedly taken calligraphy for granted. Indeed, when I have told people about this project, nearly all Westerners immediately respond, "Oh, you mean like Peter Greenaway's The Pillow Book (1996)." To be honest, this was a work I studiously avoided until after writing the book. Upon returning to the film, I find that Greenaway did little that hadn't been tried before by Asian filmmakers, or theorized millennia ago for that matter. Indeed, calligraphy is everywhere in the media cultures of Japan, Taiwan, Hong Kong, North and South Korea, and mainland China, and starting from the birth of cinema. Actually, many of the informants for this project were themselves surprised when they became self-conscious of 


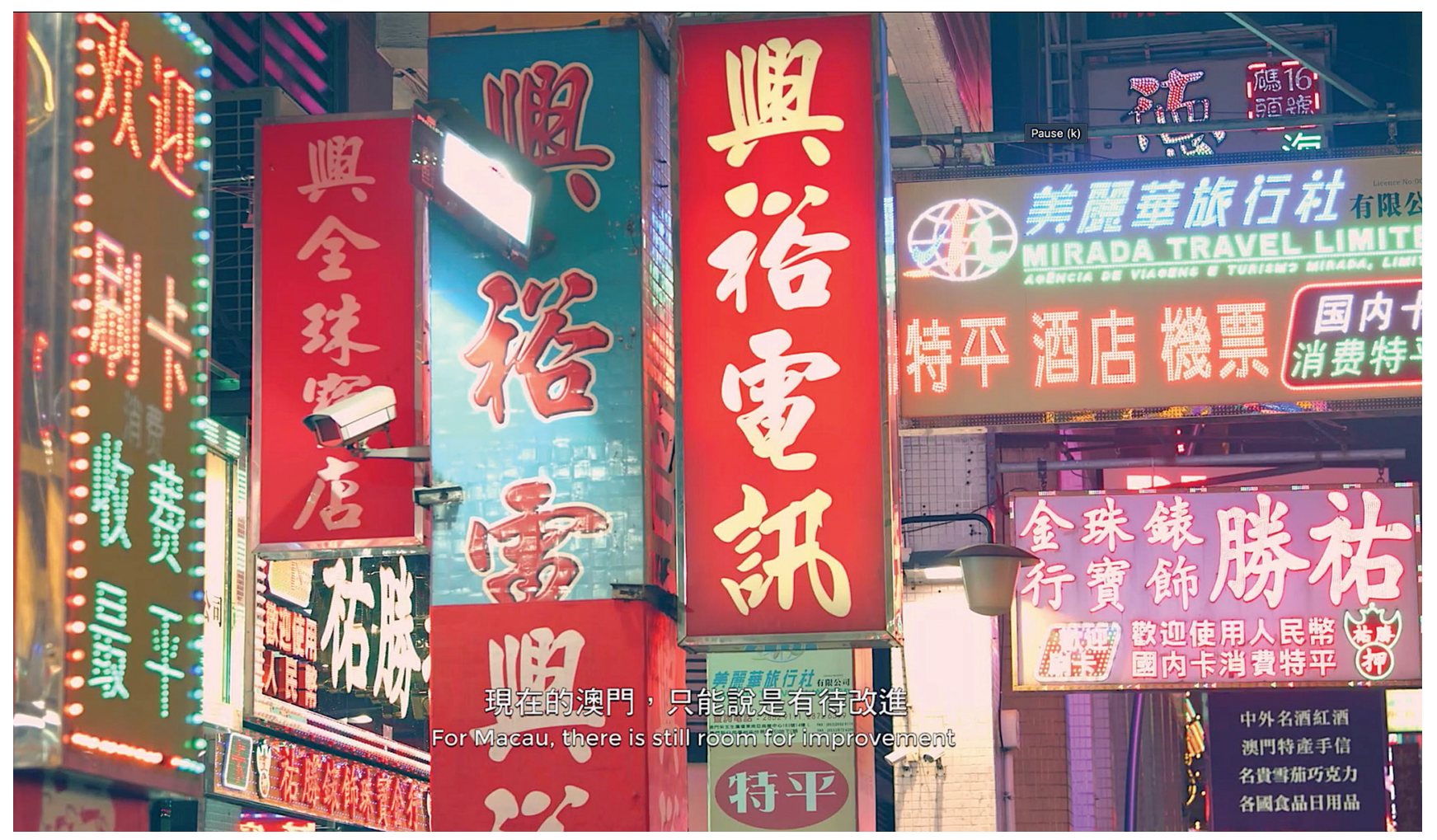

Figure 0.1. Calligraphic writing is ubiquitous in the daily life and built spaces of East Asia and has been for millennia. In contemporary cities, most of this carved calligraphy was replaced by photographic enlargements, neon, and lettering mimicking the calligraphic. Wallace Chan's Fonting the City (Zi li chengjian, 2015) is a lovely documentary about the gradual displacement of handbrushed signs by digital fonts in Macao.

calligraphy's pervasiveness in cinema-except for the art designers and props men, who knew very well and have been waiting for some recognition of their deep contributions to the art of cinema. Now that I have pointed this out, you, too, will see it everywhere.

Back in graduate school, I was scared off from the topic. My initial foray into the world of calligraphy was quite intimidating. I quickly ran up against the thou- sands of years of commentary written in three languages. Approaches changed over time and were parsed into a multiplicity of styles, and the difficulty of reading those on the cursive end of the spectrum was daunting. To make matters worse, I spoke to prominent art historians at various American universities and each greeted my project with the same response: "There is no calligraphy in Asian cinema." Films may have brushed text, but it is amateur- 
Figure 0.2. The famous grave of Ozu Yasujiro has only the single calligraphic character 無, or "nothing." It is surrounded by calligraphy one encounters in daily life, as in films, from the prayers on wooden strips to the labels on the offerings of sake.

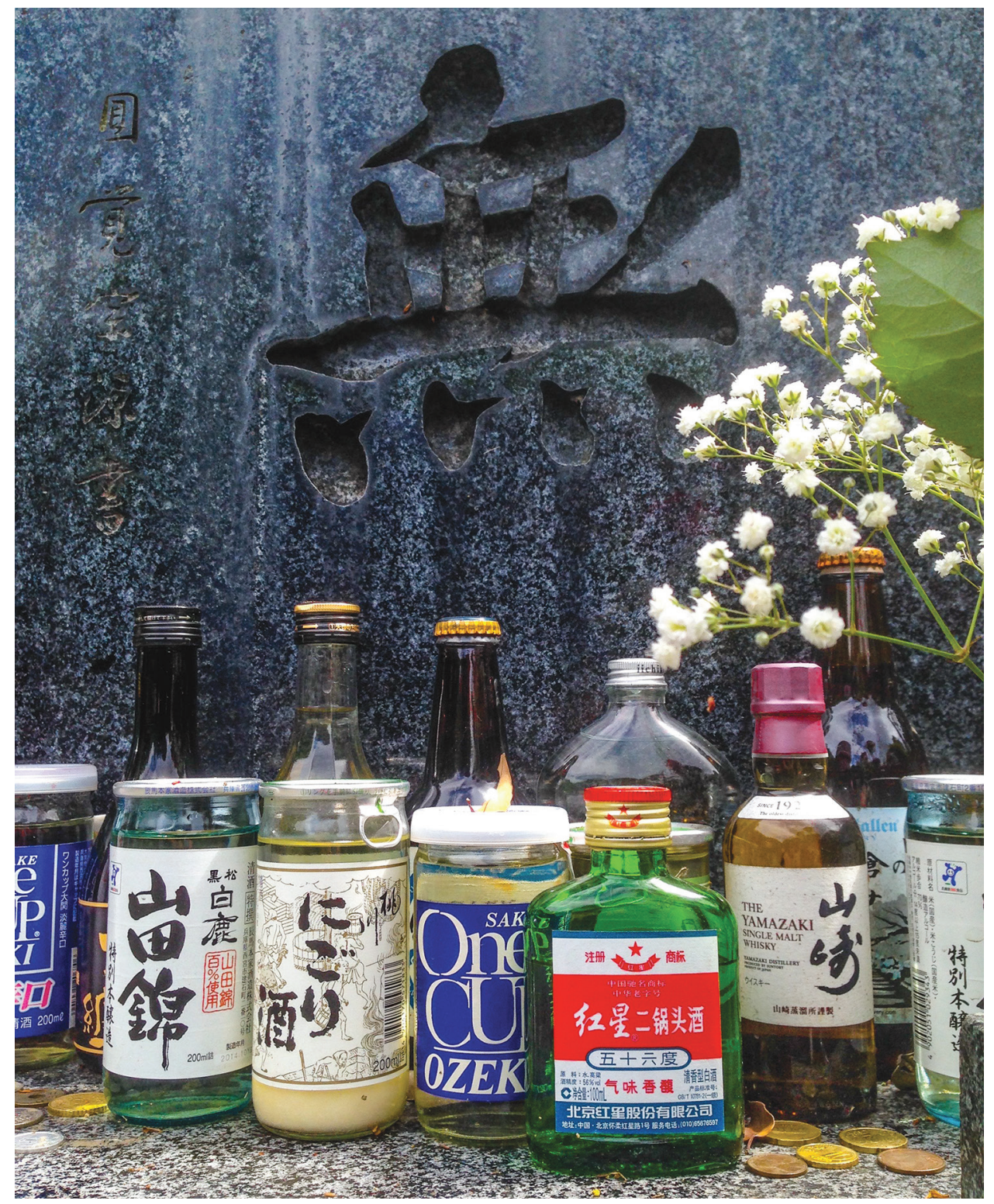




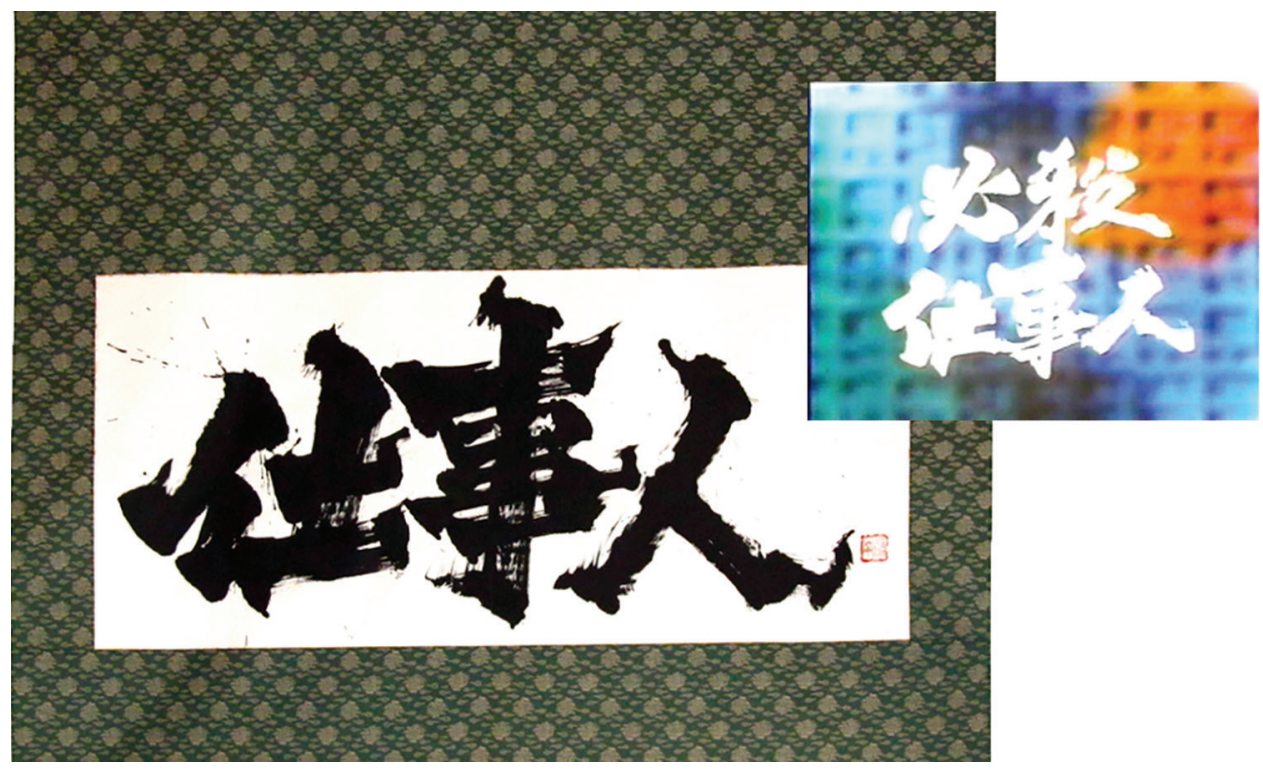

Figure 0.3. Itomi Keinan's famous calligraphy for People Whose Work Is Necessary Murder (Hissatsu shigotonin, 1972) and the scroll painting a friend gave me, evidencing the iterability built into calligraphy. A wedding present, Itomi left out the characters for "necessary murder"; however, the vigorous movement of Itomi's body during the act of inscription is viscerally palpable and points to the show's violence.

ish and never historically accurate, they said. And, in any case, calligraphy affixed to something other than paper is merely photochemical duplication. In the face of all of this, I gave up.

But I never forgot about the project. Just as I was mulling the possibility of writing a dissertation about the topic, I guided a visitor from Japan around Los Angeles. She was amazed that I was writing a graduate school essay about the popular TV series People Whose Work Is Necessary Murder (Hissatsu shigotonin, 1979-1981). I was interested in its representation of violence, but she revealed that her calligraphy teacher was none other than Itomi Keinan, who wrote the show's title calligraphy (Fig o.3, right). Everyone in Japan is familiar with this, as it brands not only the TV series but also its endless sequels, movie adaptations, video games, novels, manga, and even pachinko machines. She asked Itomi to make a massive scroll painting with the logo as a wedding present, quite appropriately keeping only the "people who work" (仕事人) part of the title (Fig o.3, left). I looked at Itomi's striking calligraphy every day, endlessly impressed by the slashing strokes and spitting drops of ink that clearly pointed to the missing characters for “necessary murder” (必殺). This living room decoration kept this project simmering on a back burner over the years. I collected examples of striking calligraphy in film but was never sure what to do with them.

Finally, a couple decades later, I found myself liberated from my fear and hesitation. Director Hara Kazuo introduced me to Akamatsu Hikozo, who is among the most important title designers in Japan. ${ }^{4}$ Akamatsu originally intended to become a cameraman but ended up in title design only because he inherited the family business when his father suddenly died in 1969. As Kimata Kimihiko points out, the timing was as propitious as it was tragic. ${ }^{5}$ The major studios were in steep decline and shutting down their design shops, so title work was migrating to outside design companies. The same industrial conditions were nurturing a lively independent sector. Arriving to the profession with no baggage and little regard for rules or conventions, Akamatsu's creative genius was unfettered. 


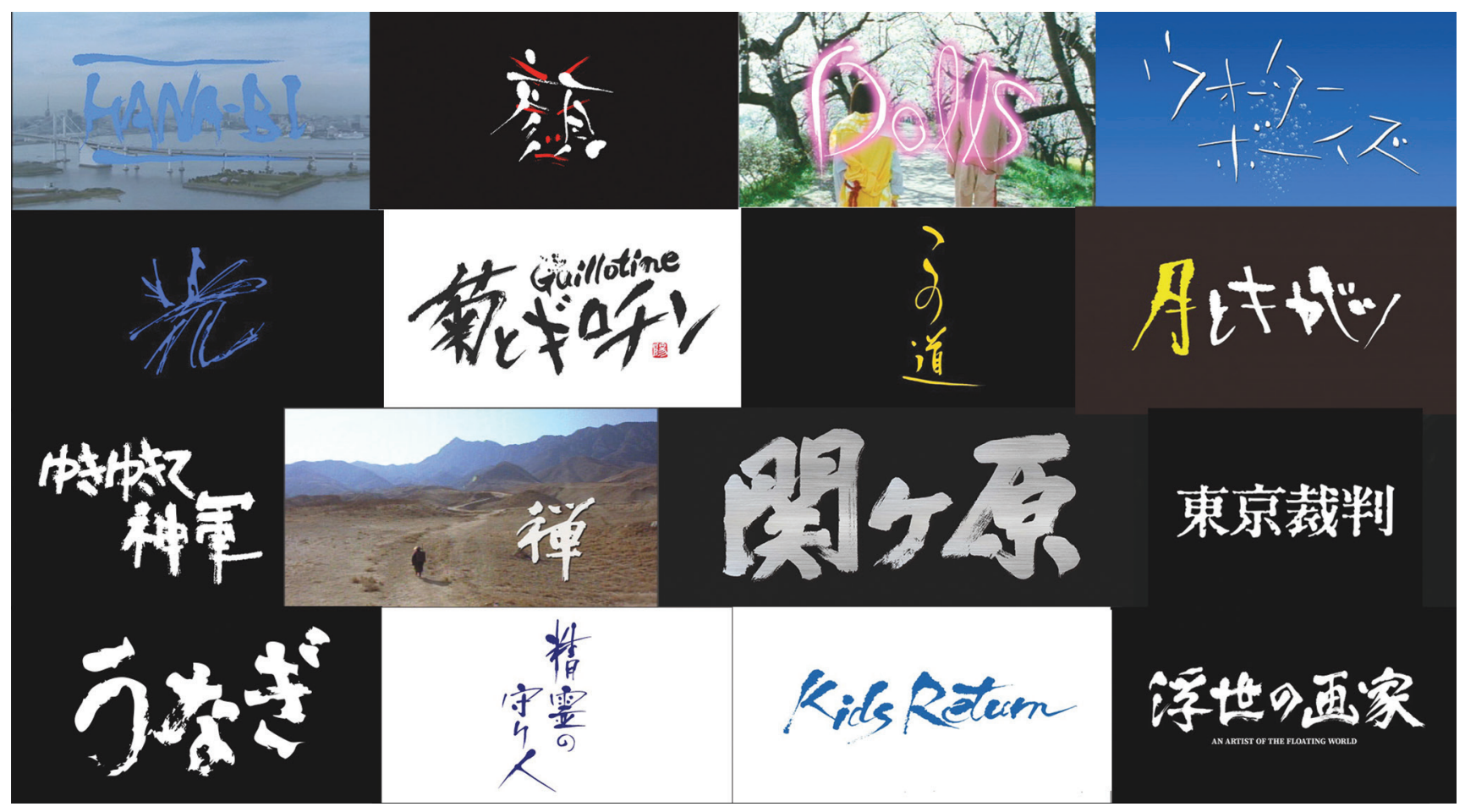

Figure 0.4. Titles by Akamatsu Hikozo include (starting from upper left): Fireworks (Hanabi, 1997), Face (Kao, 2000), Dolls (2002), Water Boys (Wata boizu, 2001), Hikari (2017), The Chrysanthemum and the Guillotine (Kiku to girochin, 2018), This Road (Kono michi, 2018), One More Time, One More Chance (Tsuki to kabetsu, 1996), The Emperor's Naked Army Marches On (Yuki yukite shingun, 1986), Zen (2009), Sekigahara (2017), International Military Tribunal for the Far East (Tokyo saiban, 1983), The Eel (Unagi, 1997), Moribito: Guardian of the Spirit (Seiei o mamoribito, 2016), and Kids Return (1996), and An Artist of the Floating World (Ukiyo no gaka, 2019).

What's more, the first jobs he took on were in the ultra-low budget, soft-core porn sector called pink films. ${ }^{6}$ Producers like Wakamatsu Koji were fine with anything as long as it was fast and cheap, so Akamatsu did things like titles brushed on freely available street pavement. Over the years, he came to be the go-to designer for independent

filmmakers, such as Wakamatsu, Hara, Kuroki Kazuo, Suo Masayuki, Kurosawa Kiyoshi, and Kitano Takeshi (Fig 0.4).

When I asked about the history of calligraphy styles and told him about how intimidating I found it all, he surprised me by revealing he could care less. He brushes calligraphy, but he also proudly displayed the tool he used for 


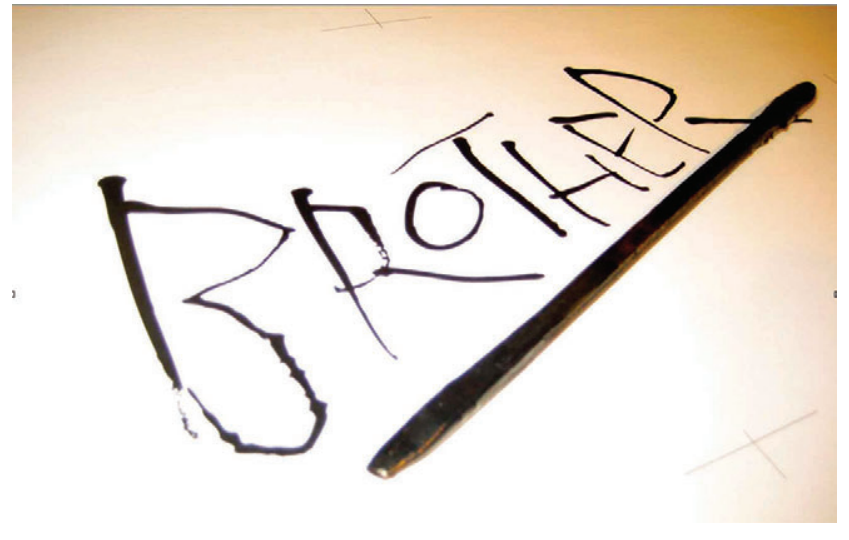

Kitano's Brother (2000): a then 20-year-old waribashi chopstick whose tip was now bulbous with layer upon layer of dried ink (Fig 0.5). Many years later, Akamatsu's relationship to tradition was summed up very nicely for me by $\mathrm{Li}$ Xianting, a Chinese art critic and calligrapher famous for his promotion and protection of modernist artists in the People's Republic of China (and also a noted calligrapher who will play an important role in the following chapters): “Tradition doesn't matter much in the end. It's all the same because it all comes down to the expression of the individual within a tension between convention and innovation."

$\mathrm{Li}$ and Akamatsu allowed me to put the blanket condemnations of those art historians into both perspective and brackets. The conventions and rules undergirding their narrow definitions of calligraphy are, first and foremost, constructions of the present. They are informed by the accretions of millennia of practice but often serve present-day needs and desires. ${ }^{8}$ Too often these contemporary motivations protect conservative power structures, such as artistic schools, clans, and associations. I will have a thing or two to say about this in a moment. Needless to

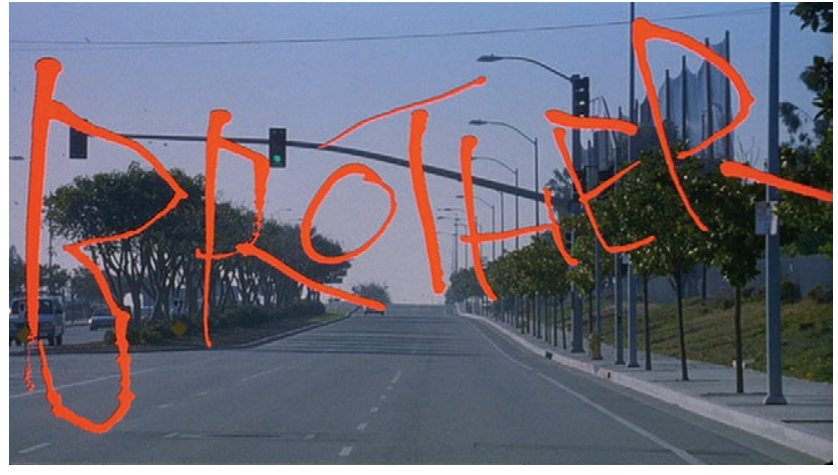

Figure 0.5. A disposable chopstick, one of Akamatsu Hikozo's beloved writing instruments, sits on the original calligraphy for Brother (2000). Its tips are bulbous from layer upon layer of dried ink.

say, transformations over time usually have to do with new factors in the field of writing: new instruments or media, the appearance of a powerful artist, top-down initiatives to change character styles or even invent new writing systems, schools, and factions. Calligraphic styles coalesce around these new elements, then harden into convention and the prickly defense thereof.

It should be no surprise that the very different attitudes of Akamatsu and Li are connected to modernism. As $\mathrm{Gu}$ Gan wrote in an influential essay concerning the "three steps" of modern calligraphy, "The ultimate aim of modernist calligraphy is to provide aesthetic pleasure linked to an idea, rather than following the path of traditional calligraphy, where often lengthy textual content is an essential element of the overall effect." Filmmakers shared this modernist impulse. More important than towing to traditional style was the contribution a given work made to the "idea" - the atmosphere of a set, a twist in plotting, or the instant and lasting impression made by a title card.

Film, the newest modern art form and one that gathered and integrated all other art forms, was a new factor in 
the history of calligraphic writing. A major thrust of this book is this: rather than protecting and preserving some invented tradition, cinema expanded calligraphy's possibilities. It provided a new platform for a proliferation of approaches to calligraphic writing. Calligraphy and cinema were made for each other.

My conversations with Akamatsu and Li were liberating. They came during a year at Harvard, which also provided an opportunity to revisit the work of film theorists Stanley Cavell and David Rodowick. These encounters pointed me and my newly unfettered thinking about calligraphy in unexpected directions. Upon returning to Michigan, I collaborated with several students to assemble an image corpus of frame grabs from our DVD collection. Working off of this corpus of nearly 3,000 images-which the University of Michigan Press has put online in conjunction with this book-I began talking to filmmakers, props men, and calligraphers in China, South Korea, Japan, Taiwan, and Hong Kong. This book is the result of all these wonderful travels and encounters.

\section{Theorizing the Calligraph}

Western avant-garde film theorists and practitioners have famously connected cinema with the art of handwriting. Their thought has roots in the Western enchantment with the hieroglyph. Before the Rosetta Stone enabled their translation, hieroglyphs could only be seen as encrypted with meaning. Long after their decryption, an air of mystery accompanied them, attracting people as disparate as the transcendentalists and modernist poets like Ezra Pound. One of the first theories of film, Vachel Lindsay's Art of the Moving Picture (1915), ${ }^{10}$ inherits Walt Whitman's love of hieroglyphs. Meaning is "mystic" in hieroglyphs, a "new Universal alphabet" or "Esperanto."11 Lindsay thought the silent cinema returned humanity to "primitive," visual writing systems like the glyphs of Egypt and
China, which in his imagination was nothing other than a union of (visual) style and meaning. ${ }^{12}$

The moment of this writing was important. Lindsay was advocating an approach to cinematic narrative that was newly taking shape in America, thanks to the innovations of directors like D. W. Griffith. Thus, it may come as some surprise that a film theorist and practitioner like the modernist Sergei Eisenstein struck a remarkably similar position fourteen years later. His most famous use of hieroglyphs appeared in the 1929 essay "The Dramaturgy of Film Form.." ${ }^{13}$ Eisenstein had encountered Japanese writing in 1920 in Minsk, where he was making propaganda posters after the revolution. ${ }^{14}$ He met a Japanese language instructor and became fascinated by Japanese. He studied hundreds of characters and decided to become a professor of Japanese. Back in Moscow, the university had yet to reopen, and he got sidetracked into theater and cinema. However, his encounter with Japanese writing was the springboard for his theorization of montage.

While Lindsay saw meaning encrypted behind the glyph-literally on the backside of hieroglyphic cards in his imaginary scenario writing method-Eisenstein emphasized the copula-like mechanics of (some) Chinese characters. Naturally, he focused in on the pictograph. For example, the character for mountain is 山. As the intertitle in Fig o.6 (right) demonstrates, pictographic characters look like their signified. Here the word "mountains" mimics a mountain range; the calligrapher emphasizes the pictographic qualities by making the three vertical strokes with broad bases and pointy tops, adding a wisp of clouds for good measure. In a more modernist spirit, Taiwanese calligrapher Tong Yang-tze used calligraphic techniques to simultaneously obscure and emphasize the pictographic aspect of the character "face," or 臉 (Fig o.6, left) for Tsai Ming-liang's eponymous film. A similar example is Akamatsu Hikozo's title for Sakamoto Junji's Face (2000; Fig o.4, top row, second from left); this uses the more copulative, less pictographic, Japanese character 顔, suggesting 

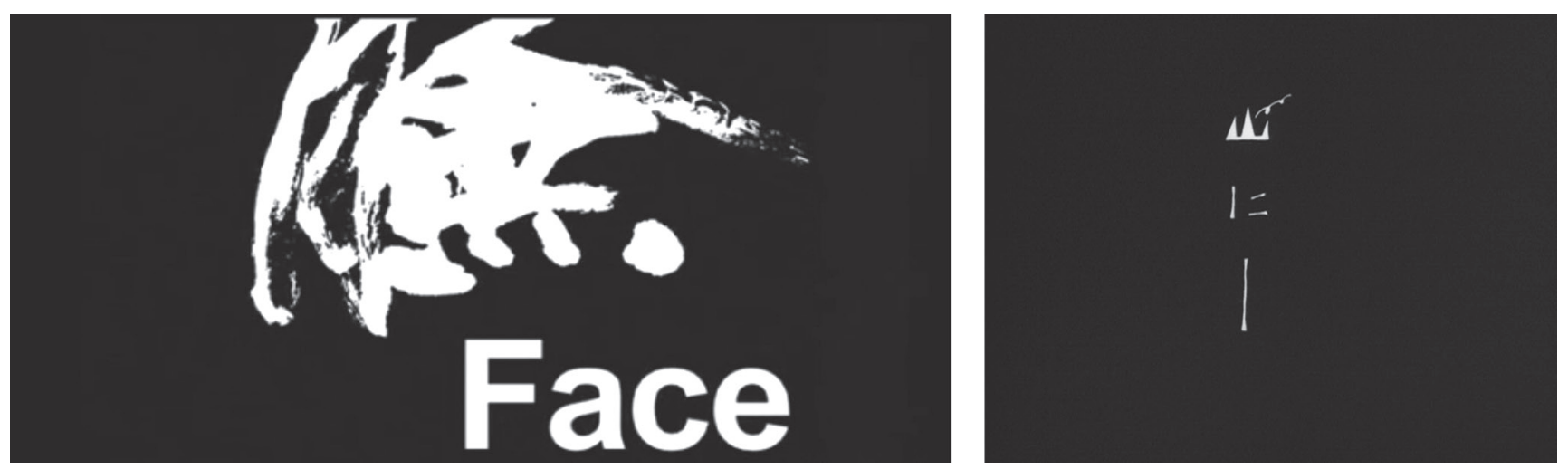

Figure 0.6. These examples capitalize on the pictographic qualities of the Chinese character. The intertitle writer for Japanese Girls at the Harbor (Minato no Nihon musume, 1933) uses lettering to turn the character for mountain (山) into a pictograph of three peaks. On the left, calligrapher Tong Yang-tze uses calligraphic techniques to bring out the pictographic character for "face" 臉 for Tsai Mingliang's 2009 film.

how readers of the Chinese character do have an inclination to look toward the pictographic.

This figural dimension quite naturally opens itself up to such play, and play is what Eisenstein was very good at. He pointed out how pictographs attach to each other to create a transcendental result that is then combined with other copulating characters in a heady proliferation of meaning. These can be as disconcerting as they are fascinating. For example, the character 坋 (C: niao, J: naburu) means "tease," "mock," or "torment." This is written by surrounding the character for woman (女) with two men (男). Perhaps this could be taken in various ways. Is it a woman teasing two men on either side of her, or two men harassing a woman ${ }^{15}$ The etymology suggests the latter, which indicates how the copulative power of characters can be as ideologically charged as it is imaginative. As we will see below, it is precisely this multivalent nature of the character that allows calligraphers, especially in the film world, to play with characters and creatively exploit them as resources for enhancing their narratives.

For Eisenstein, this copulative nature was itself essential to cinematic image making. Shots, like Asian ideograms, were depictive, figural, and intellectual or conceptual. However, what Lindsay and Eisenstein share is what David Lurie has called a fascination for the a-phonic nature of pictographic glyphs motivated by the visual world; like cinema, they seem to promise a dreamlike communication without the foreignizing and alienating bother of language itself. $^{16}$

There are good reasons to drop Lindsay and Eisenstein at this early moment in Brushed in Light. First, this kind of position is extreme and ignorant of the nature of East Asian writing systems. As William Hannas points out, beginning students of these languages love pictographic characters, but it is not long before they realize there are literally thousands of characters that are simply abstract 
and phonetic. ${ }^{17}$ Characters started out pictographic in the years after the invention of writing, but attempts to model characters on material objects quickly gave way to an orientation toward the alphabetic. While Hannas privileges speech over writing that would handily lend itself to a Derridian deconstruction, it is true that the origin of most ideographic characters is far from obvious. ${ }^{18}$ Show the character 畫—or its simplified version, 画一to people from other parts of the world and few could guess it is a pictograph for "picture." Furthermore, while there are plenty of figurative Chinese characters, the pictographic aspect is a diminutive factor in actual reading. Indeed, in all the images collected in this book, few are pictographic. So let us move on. Obviously, my interests lie elsewhere.

The more interesting writing models for cinema equate the camera to writing instruments. A little known instance is from Shen Fu, a mainland director best known for Myriad of Lights (Wanjia denghuo, 1948) and Crows and Sparrows (Wuya yu maque, 1949). ${ }^{19}$ Shen compares the camera to a pen. If the camera simply records movement, the result is not cinematic. There must be an effort to focus on human beings and draw up characters. At this point, Shen rather messily mixes metaphors and adds music to the equation because of the centrality of rhythm and editing. It is not simply like music, but about writing music, so for Shen the camera is ultimately akin to the pen. The lines drawn by Shen's camera-pen require assemblage through cinema's unique properties to make meaning, just as random lines do not make meaningful Chinese characters.

A more famous metaphor comes from Alexandre Astruc's "The Birth of a New Avant-Garde: La CaméraStylo." This was the same year as Shen Fu's essay, suggesting that one may have known about the other. Astruc was interested in the cinema as a means of personal expression. This would de-emphasize the mechanical automatisms of photochemical reproduction-what he called the "tyranny of what is visual"-in order to express human thought, and in this, he harks back to Eisenstein's cinema of copulation. Astruc wrote, "The filmmaker/author writes with his camera as a writer writes with his pen," calling for an essayistic cinema that turns its back to conventional cinema that simply records and shows the world. ${ }^{20}$ In an essay from later that year, he writes,

So this is where we are, what we await, and what we believe: a camera in the right trouser pocket, recording on an image sound track the wanderings, the slow or frenetic unfolding of our imaginary universe, confession cinema, essay, revelation, message, psychoanalysis, obsession, the machine that can read the words and images of our inner landscape, the totality of things, objects, creatures, stones, cities, gestures, and cries of the universe brought to the status of material, the art where we paint with agitated faces and write with the guttural sounds of butchered seals; the pen which pumps out directly, as part of the same universe, the most formidable vocabulary that any artist has ever had at his fingertips, the human reality which stages the ballets of our imagination on the stage of the universe, the crushed rocks reconfigured according to another order, making us like God since we are remaking, in our own image, the entirety of creation; the caméra-stylo or camera-pen, this art in which the entire universe is our material. ${ }^{21}$

Astruc's thrilling essay hardly hints at how this works beyond asserting it has something to do with technique. In spirit, however, it does point to the direction our inquiry into East Asian calligraphy will ultimately take us. Both cinema and calligraphy are filled with automatisms that are specific to their respective media and beyond the control of the humans behind the work of representation. At the same time, they register states of mind, human thought, and all manner of conditions at the "scene of writing." Unfortunately, Astruc never elaborates this beyond the caméra-stylo metaphor, and his later works (and those fol- 
lowing in his footsteps) focus in on a relatively straightforward conception of mise-en-scène and cinematic authorship. $^{22}$

Another interesting example is David Bordwell's work on silent Japanese cinema. Noting the period films, "where swordsmen hurl themselves into combat at hyperaccelerated speed, popping in and out of the frame unexpectedly, glimpsed in swift, often bumpy panning and tracking movements," Bordwell identifies what he calls a "calligraphic style" in silent era Japanese film. ${ }^{23}$ While modest in comparison to the silent era theorists' ambitions, Bordwell is ultimately like the others. Their work has remained as suggestive as it is isolated: it has not prompted systematic studies of calligraphy in film history in the same way that calligraphy has influenced other scholarly endeavors, including the history of the letter and book writing, philology, literary biography, typography, and the artistic avant-garde, not to mention graffiti and popular culture. To my knowledge, no one has written on the subject of calligraphy and cinema in any concerted or interesting way.

The same could be said of the printed word in cinema. A provocative early attempt is Tom Conley's Film Hieroglyphs: Ruptures in Classical Cinema from 2006. ${ }^{24}$ His set of close textual analyses are as playful as they are frustrating. The subtitle indicates the central problem with his book. Conley deploys a resistance model that sees onscreen text as rupture enabling against-the-ideological-grain readings. These are, in the end, more radically idiosyncratic than radical, more about an écriture that levels all cinematic representation with the actual written word, and this is rather uninteresting for our purposes.

There is also Michel Chion's fascinating Words on Screen. ${ }^{25}$ However, in the end, his considerable efforts amount to little more than an exhaustive taxonomy. My book has a bit of this as well, but I hope it is not exhausting. There are decisive differences between the two writing cultures-historical, linguistic, aesthetic, and ontological — that naturally invite a more considered approach.

My own fascinations, admittedly informed by my work and interest in Asian cinema, are anchored in the actual practice of cinema's calligraphers, the properties of language, and the specificities of East Asian brushed writing. The chapters following will introduce you to the basics of East Asian calligraphy, starting with the history of writing and its spread from China to Japan and Korea, where it was articulated in linguistically and culturally specific ways. I will chart how calligraphy appeared in cinema from the silent through to the digital eras. The middle chapters examine the legacies and powers of convention, both calligraphic and cinematic, wrapping things up with a case study of Taiwanese filmmaker Hou Hsiao-hsien and his City of Sadness (Beiqing chengshi, 1989). Finally, the book culminates with a contemplation of the complex semiotics and ontology of the cinematic calligraph that enable one to energize the other. The very new art of cinema has democratized and freed the very ancient art of calligraphy.

\section{The End}

Let us wrap up this introduction by looking at a term familiar to everyone: “The End” (zhong 終, owari 終わり, kkeut 끝). It is the typical way in which films in all three languages announce the finish of a film. There are variations. Japanese films sometimes deploy the alphabetic hiragana おわり owari. Chinese films often add the character for theater/drama/opera: 劇終 ju zhong. The Korean 页 kkeut (fig. o.7) never appears as a Chinese character because it is a purely Korean word. "The End" of East Asian cinema hints at many of the avenues of inquiry we will follow in the chapters that follow.

First, "The End" is written in an astounding variety of styles. Sometimes titles reference historical period. Consider the lovely end title for Mizoguchi Kenji's The Water 
Figure 0.7. Many Korean films use the hangul for "end"

(끝) rather than the Chinese character. This is from Genealogy (Jokbo, 1979) by Im Kwon-taek, one of the directors in Asia that deeply cared about the calligraphy in his films.

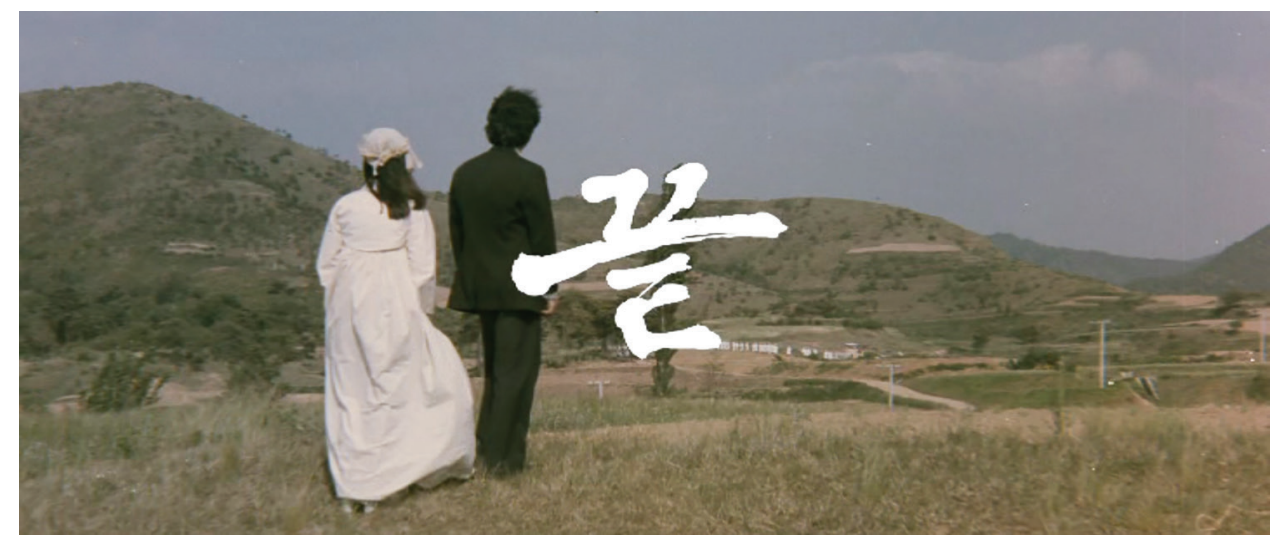

Magician (Taki no shiraito, 1933; fig. o.8). The characters on either side are cursive in the manner someone would write in the Meiji era (1868-1912), the film's setting. Squiggly lines ornament the vertical text on either side of "The End"; these are ioriten (庵点), marks that go back to the Noh theater but by Meiji indicate lines that are supposed to be sung. Indeed, the film was invariably shown with benshi narration so it is possible a song was actually sung in the theater. At the very least, they indicate the Meiji period, as does the style of the calligraphy.

The calligraphy of end titles frequently registers genre. Water Magician is a touching melodrama, and the delicate hand of the end title is perfect for this kind of woman's film. In contrast, the bold red strokes of the "end" of Blind Woman's Curse (Kaidan nobori ryu, 1970) were accomplished with a brush loaded heavily with ink, visually echoing the thick splash of human blood from the film's climax, the red being a typical convention of genre films from the era. This prickly style with its spikes and slashes is typical of the yakuza or horror films. Similarly, the vanquished bad guy from Afraid to Die (Karakkaze yaro, 196o; fig. o.9), dead as the fish next to him, stares vacantly at "The End" with delicious irony.

These examples amply attest to how beautiful calligraphy is in and of itself, as well as to its semiotic productivity.

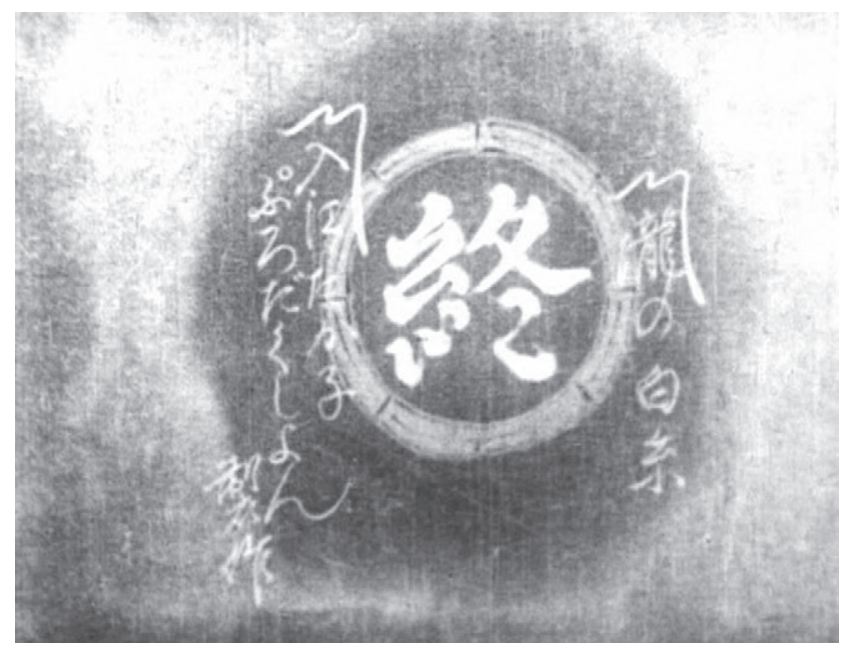

Figure 0.8. The end title for Mizoguchi Kenji's The Water Magician (Taki no shiraito, 1933) uses cursive calligraphy and is ornamented with ioriten, the squiggly lines framing text which indicate period and invoke the narratives of traditional theater and song. 


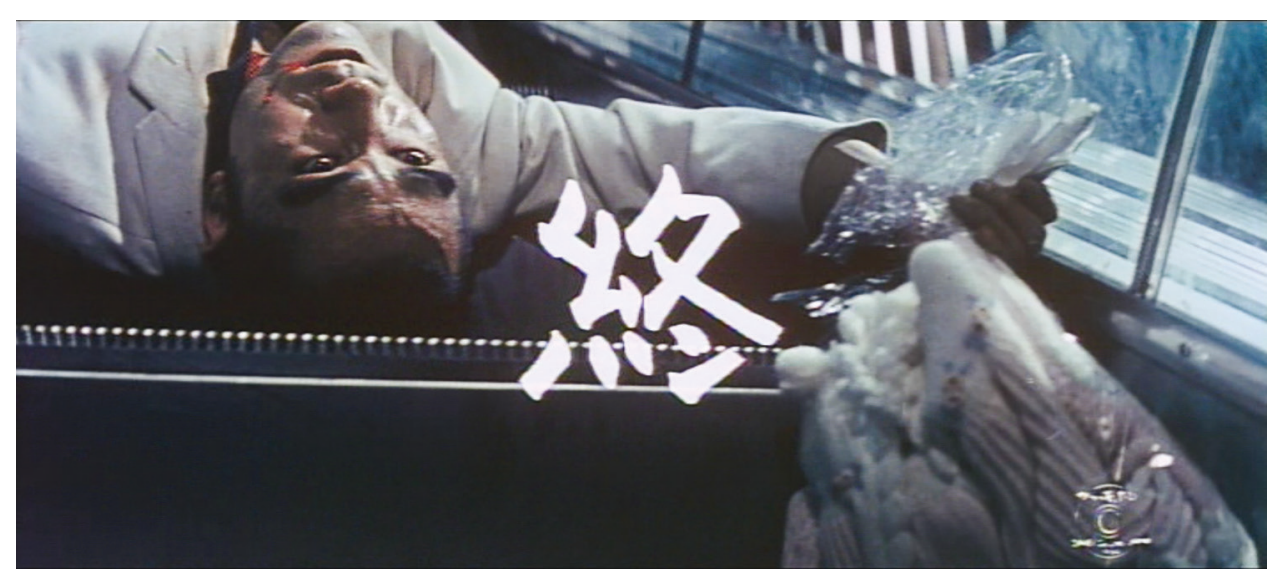

Figure 0.9. With delicious irony, the vanquished character in the yakuza film Afraid to Die (Karakkaze yaro, 1960) played by Mishima Yukio stares at "the end" title.

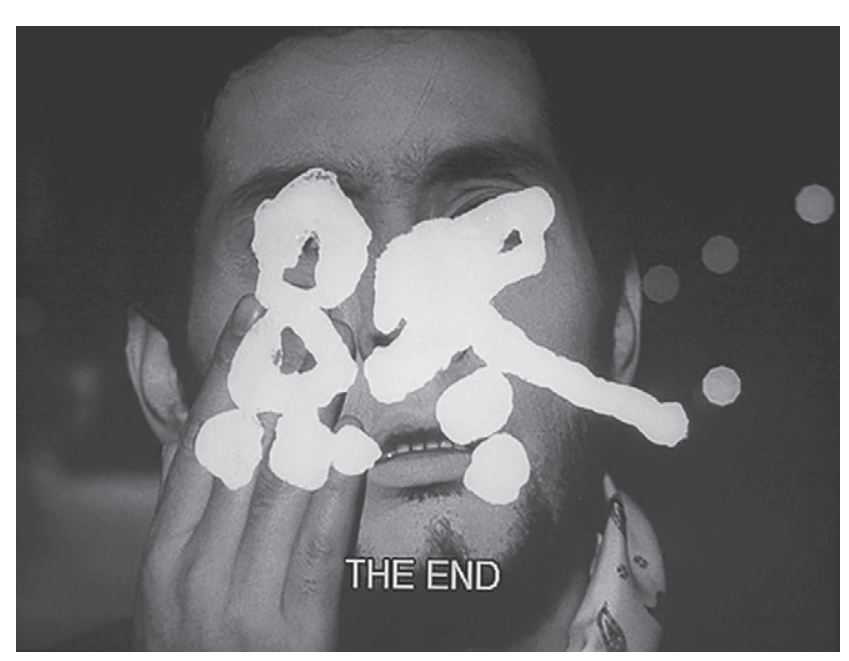

Figure 0.10. The main character in Face of Another (Tanin no kao, 1966) spent much of the film with bandages wrapping his face. At the end, his face is still covered, this time by calligraphy-his eyes peeping out of two holes in the character.
As such, they are important compositional elements. They call for careful placement. Teshigawara Hiroshi used modernist calligraphy for the ending of Face of Another (Tanin no kao, 1966; fig. 0.10). The main character spends a good portion of the film with his face wrapped in white bandages. At the end, the renown art designer Awazu Kiyoshi playfully superimposed the calligraphy over the main character's face, precisely framing the face so his eyes peep out between the gaps between strokes. This calligraphy itself is stunning, and written by the director's father, Teshigawara Sofu, the founder of the Sogetsu Ikebana school. His painting responds to cinematic composition; as we will see in chapter 4, calligraphy also can exert a novel pressure on the art of cinematographers.

Typography does this on only the rarest of occasions. Sometimes Asian filmmakers add an English "The End" to their titles, affording us a chance to compare the two approaches to writing. Consider the end title for Sammo Hung's Warriors 2 (Zan xiansheng yu zhaoqian hua, 1978; fig. o.11). The English is relegated to the edge of the frame and centered. The typeface is non-serifed, that is, utterly nondescript and boring (see also figs. o.6, 1.5, 2.14, 2.19, 2.21, 2.22, 3.3, and 4.8). Only the italicized all-caps resist the communicative aridness of the English. It sits at the edge signaling nothing but a curt and simple message. 
Figure 0.11. The contrast between the calligraphy and the English typeface is striking at the end of Sammo Hung's Warriors 2 (Zan xian sheng yu zhao qian hua, 1978).

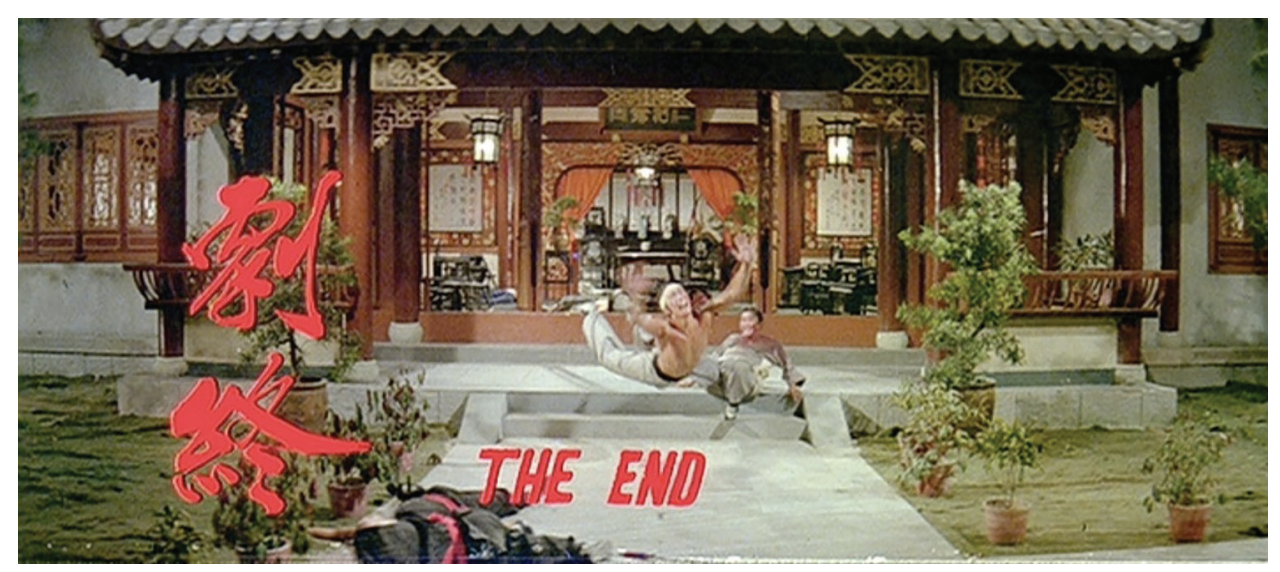

Film's over. Time to go home. In contrast, a simply beautiful 劇終 is placed carefully to the left of the frame. From its shorthand abbreviations of various radicals to the dynamic interplay between thick and thin lines, we palpably recognize the swiftness with which the brush danced over the paper. The calligraphy seized this act of inscription and preserved it out of time-like the photographic freeze-frame that lies behind the word. What's more, the dramatic strokes of the calligraphy mimic the human actors. The second character means "ending" and sits on squat, foreshortened lines from which the upper strokes explode. They mirror the flying bodies behind the letters.

This points us to an intimate connection between calligraphy, cinematography, and the human body, a preoccupation of this book. And, in the end, the complex relationship between time and space sends us back to the legendary origin of calligraphy in the misty recesses of history.

It is said that Chinese characters were created by the monstrous historian Cang Jie (倉頡) four and half millennia ago. ${ }^{26}$ It is likely his name signifies a collective of men tasked by the Yellow Emperor (2711-2598 BCE) to collect and collate all the characters circulating across the land. They were to create a writing system (Cang Jie is the name of one of the first input methods for Chinese computing as well). In the legend, Cang Jie studiously viewed the visual patterns that surrounded him in both the natural and built environments, using them to model characters.

It helped that he had four eyes (Fig. 0.12). This unique and grotesque feature is first mentioned in the $80 \mathrm{CE}$ Lunheng (論衡). Subsequent tellings elaborate Cang Jie's unique visage, becoming increasingly colorful. For example, here is the Chun Qiu Yuan Ming Bao (春秋元命苍):

Cang Jie had a large dragon's face, with four bright eyes. He was clever and virtuous, and could write upon birth. Because of the endless changes of the universe, he looked up at how the stars turned about in the heavens, and looked down upon the cracks in the tortoise's shell and the birds' feathers in the mountains and valleys, made a fist and created characters for writing. And then the heavens made grain rain from the sky, and the ghosts cried in the night, and the dragons hid away out of sight. ${ }^{27}$

Cang Jie's monstrous appearance was meant to symbolize intelligence, if not omniscience. But it also emphasizes the unique visuality of the Chinese character-its wondrous multidimensionality. Calligraphic characters 


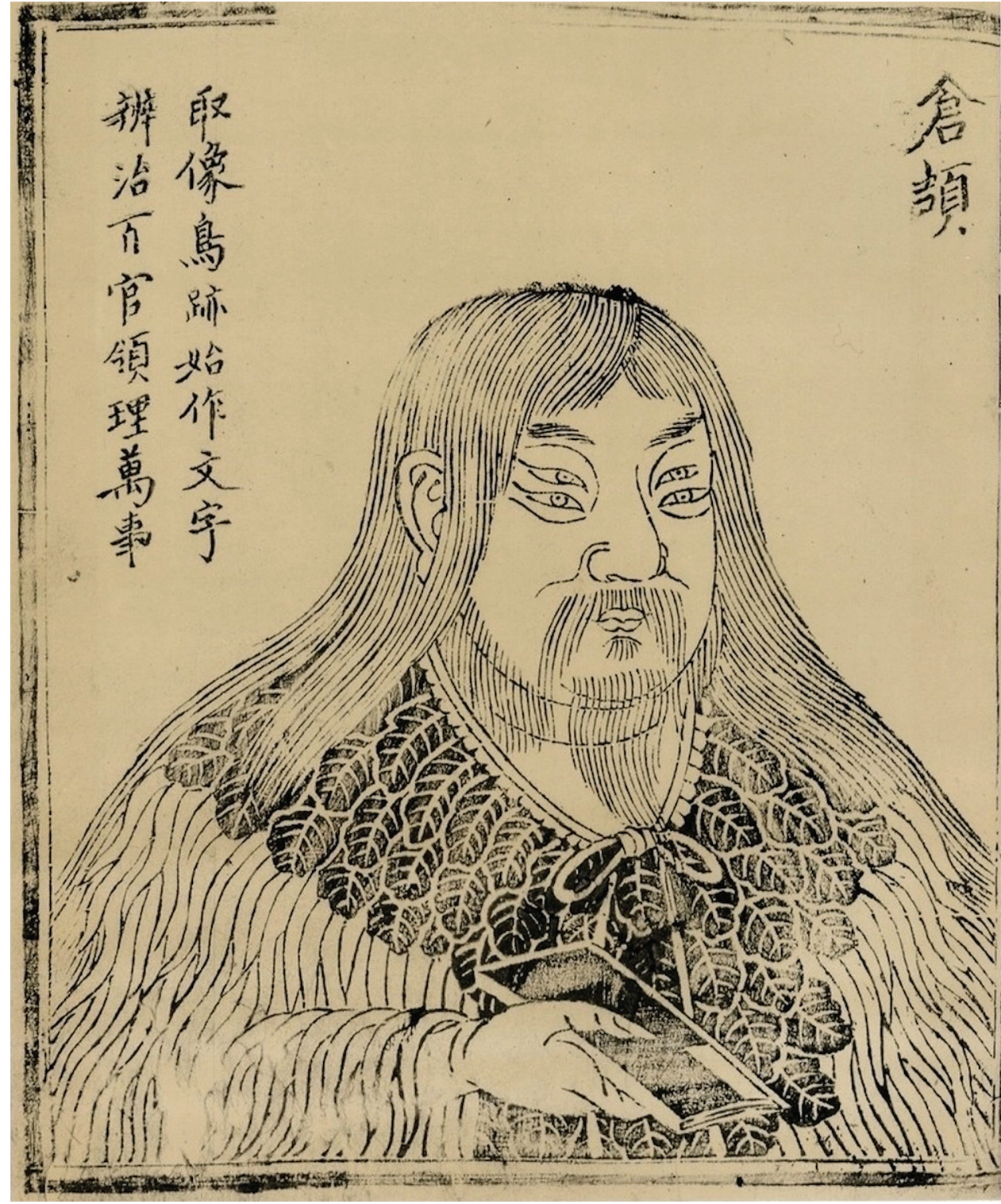

Figure 0.12. Cang Jie is the mythical creator of Chinese characters. His monstrous appearance hints at the unique visuality of the Chinese character-its wonderful multidimensionality. The first input method for Chinese computing was named for him. have a spellbinding magic about them. It is a force available to filmmakers, a trembling or shimmering one does not feel in typography and only rarely in Western calligraphy. It is the pulse of the human. At the end of his career, Eisenstein moved beyond copulative montage to consider the somatic dimensions of cinema. Had he returned to the Chinese character, especially in its calligraphic manifestation, he would have arrived at the place from which I write this book. 


\section{Notes}

1. In Brass, The Art of Calligraphy in Modern China, 11.

2. Chang, "Power of the Word," 6.

3. Nornes, Cinema Babel.

4. Akamatsu's half-century of work was feted with an exhibition at the National Film Center of Japan and received a special lifetime achievement award from the Academy Film Prize Association in 2017.

5. Kimata, Ino no Nihon Eigashi, 260-61.

6. These are called "pink films"; for more information, see my The Pink Book.

7. Throughout this book, quotations without footnoted citations were from personal conversation and interviews.

8. Yen's Calligraphy and Power in Contemporary Chinese Society is an extended meditation on this issue. She uses the term "social calligraphy" to expand the terrain for her analysis from the most strict, pure art historical definitions of calligraphy.

9. From Gu Gan, "The Three Steps of Modern Calligraphy (1990)," quoted in Barrass, 184.

10. Lindsay, Art of the Moving Picture (1915).

11. Ibid., 175 and 177, respectively.

12. Ibid., 182.

13. Eisenstein, "The Dramaturgy of Film Form," 161-80. Also known as "The Cinematographic Principle and the Ideogram."

14. Seton, 37-38.

15. Takeda, Kanji-Power, 7. Takeda overemphasizes the seductive side of "tease" in his analysis, but this is clearly buried deeply in the word's history and overwhelmed by the stronger, malevolent meanings.
16. Lurie, "Language, Writing, and Disciplinarity in the Critique of the "Ideographic Myth."

17. Hannas, Asia's Orthographic Dilemma, 102.

18. David Lurie has launched a convincing critique of Hannas and others in relation to the disciplinary formations within and without Asian studies; for example, see Lurie, "Language, Writing, and Disciplinarity in the Critique of the "Ideographic Myth."”

19. Shen Fu, "Kaimaila Shiyi Zhibi," originally published in Yingju Congkan 2 (5 May 1948).

20. Astruc, "The Birth of a New Avant-Garde: La CaméraStylo," 35 .

21. Astruc, "The Future of Cinema."

22. Martin, "Introduction to 'The Future of Cinema' by Alexandre Astruc," drawing on the work of French film theorist Raymond Bellour.

23. Bordwell, Figures Traced in Light, 85-86.

24. Conley, Film Hieroglyphs.

25. Chion, Words on Screen.

26. The first written record of his life appeared in the third century BCE. I am zeroing in on one particular telling of the story. Françoise Bottéro offers the authoritative historiography of the Cang Jie literature in "Cang Jie and the Invention of Writing."

27. Chun Qiu Yuan Ming Bao, trans. Christine Welch, in Ancient Chinese Mythology (26 August 2013): http://ancientchinesemythology.blogspot.jp/2013/08/cangjie-chinese-god-of-writing. html 


\section{CH A P T E R 1}

\section{Shufa/Seoye/Shodo}

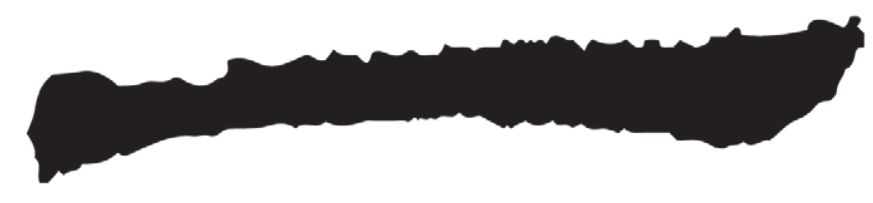

\section{Calligraphy in the West}

There is no neat word in English corresponding to the Chinese shufa, Korean seoye, or Japanese shodo. The term "calligraphy" finds its origins in the Greek word "kalligraphia," which means "beautiful writing." It was coined in the second century $\mathrm{CE}$ by Plutarch, and began as an analog to chiseling text into stone. Although the tools for inscription have changed over time-chisel, quill, reed, lead, metal bit-the original geometric grid of the ancients generally lies behind today's Western-language calligraphy.

The course of calligraphy in the West is, naturally, quite complex. However, it enters the cinema primarily in two styles. The first is blackletter, more popularly known as "gothic." Variations of this appeared in much of Europe, but were mainly obsolete by the age of cinema. The notable exception were Germanic areas, so blackletter was not unusual in German language films of the silent era and through World War II. Two particularly beautiful examples are in figure 1.1: Die Nibelungen: Siegfried (1924) and Faust (1926), with their vertical, dense strokes that favor straight, angular lines rather than curves. Most strokes are decorated by fancy serifs, the last two letters in Faust fusing "s" and "f." In the course of time, blackletter became highly conventionalized by genre. Films set in Germany, such as Hitler's Children (1943) and The Hindenberg (1975), are often rendered in this style. However, it also came to be used as 
Figure 1.1. Blackletter calligraphy in the silent films Die Nibelungen: Siegfried (1924) and Faust (1926).
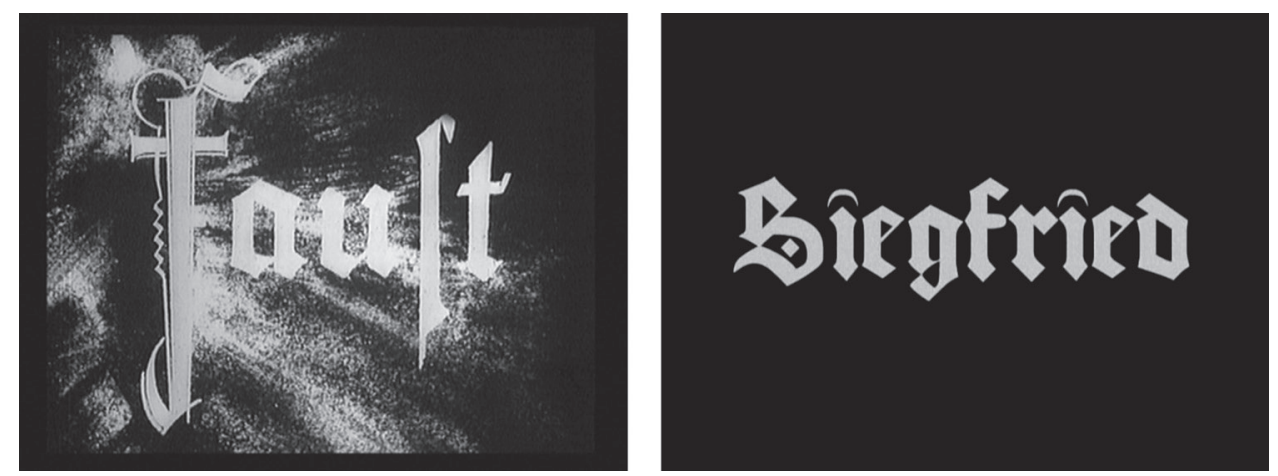

Figure 1.2. Intolerance (1916) and Christopher Columbus (1949) use variations of a humanistic hand, the latter with illuminated letters and the appearance of vellum.
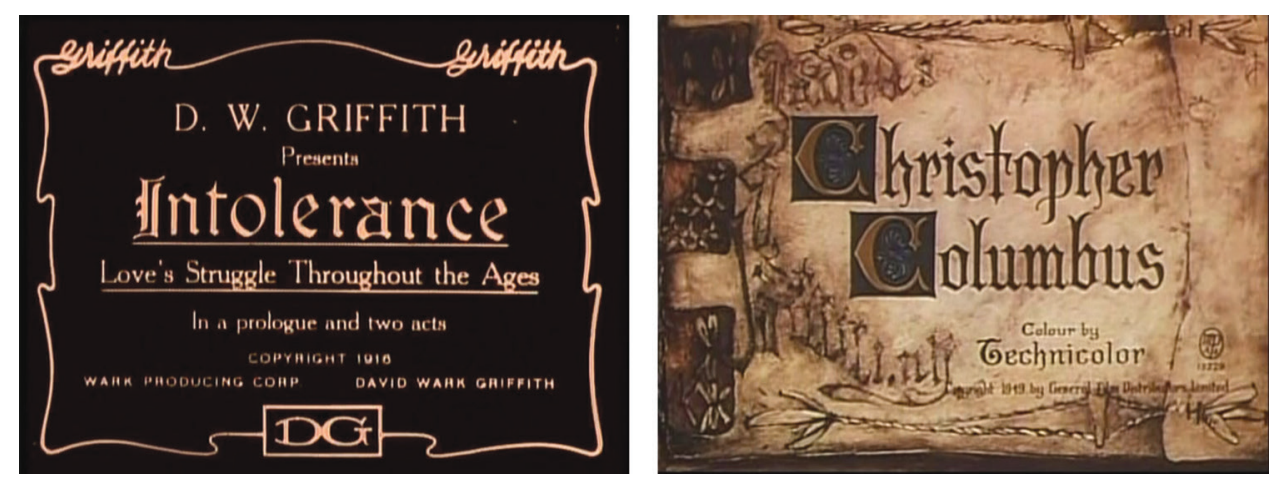

shorthand for medieval England; examples include Treasure Island (1975), Tower of London (1962), She-Wolf of London (1946), Robinson Crusoe (1954) and many others.

Other forms of calligraphy come from the so-called "humanistic hand" that initially emerged in the Renaissance as an alternative to blackletter that was swifter and easier on the eyes, more open and less severe. This is far cleaner and amendable to fancy curlicues and other ornamentation, subtle or ostentatious. It almost always indicates period when it appears in cinema. For example, Christopher Columbus (1949) appears to be written on vellum or parchment and the initial "C"s are even illuminated (fig. 1.2). Most calligraphic titles in the West are elaborations of the humanistic hand, such as Intolerance (1916). After this, cursive styles slanted the vertical lines. The invention of the printing press inaugurated a dialogue between calligraphers and engravers, and strokes lightened, connected, and flowed across the lines with the florid loops and curves of copperplate and then the late sixteenth-century appearance of cursive Chauncery. ${ }^{1}$

What is significant here is that Western calligraphyeven in its modern arty forms-is stylized yet regular. The arrangement of text implies an underlying mathematical grid. Lines are simple and straightforward. Flourishes are ornamental but do not necessarily register the selfexpression of the artist. And Western calligraphy and its scribes seldom appear in the worlds of stories. Indeed, when the handwritten letter appears in non-diegetic credit sequences, it is almost invariably for film titles using proper names: Munchhausen (1943), Chaplin (1992), Jeffer- 
son in Paris (1995), and The World According to Garp (1982). In contrast, calligraphy in East Asian film is pervasive, from titles to the scene of writing to the fabric of daily life at film studios and theaters across the region.

Regrettably, faux Asian calligraphy is more common in Western films using Asian settings. Designers drew on conventions set by fonts that first appeared in the 1860 s. Connected to the Arts and Crafts movement and Art Nouveau, they spread into popular culture after the success of Gilbert and Sullivan's The Mikado (1885). Interestingly enough, silent era filmmakers seem to have preferred deco lettering for Asian themes. ${ }^{2}$ Where Chinese characters appeared in Sessue Hayakawa's major films, such as The Wrath of the Gods (1914; fig. 1.3), they were clearly written by native speakers. This could be because there was a large Japanese cast on hand, and perhaps Hayakawa was famous enough not to put up with faux calligraphy. However, from the silent era on, faux calligraphy was the norm for indicating Asian otherness.

During World War II, faux calligraphy filled the screens, troubling domestic sensibility in films bristling with vicious racism. In the famous propaganda documentary Prelude to War (1942), Frank Capra staged a linguistic battle through calligraphic styles. Designed to introduce American civilians and soldiers to the circumstances leading to world war, cultural differences are marked calligraphically. Asian text is rendered in a clumsy faux calligraphy. Subtitles for Nazi speakers are in blackletter ("For Hitler, we live." fig. 1.4). And the most prominent American text, the Declaration of Independence, is in Copperplate or English Roundhand. Faux calligraphy remained a standard for Hollywood films of the 1950s, from Charlie Chan films (but only those set in Asia, for some reason) to Teahouse of the August Moon (1956); however, they fell out of favor in the wake of the civil rights movement and a heightened awareness of their contribution to stereotyping.

Every literate culture has some form of "beautiful writing." Aside from that of Western writing traditions, I want to highlight the stunning calligraphy of Arabic cultures. This is generally composed of thin, graceful lines, not unlike that of European languages. However, visual values center on geometric patterning restrained by an underlying grid system. Strokes themselves are determined by a mathematical calculation. More significantly, with Islam's injunctions against figural representations, calligraphy came to be a central media for religious expression. Most Arabic calligraphy quotes the Koran, and it is a relatively untapped resource in Arab cinema. Western calligraphy is humanized for easy communication and swift inscription, while Arabic calligraphy rather emphasizes design to make the word of God palpable.

This brings me to an important point of contrast. It would be a misnomer to translate the various East Asian words for calligraphy into "beautiful writing." An episode from Italian cinema is revealing in this regard. After World War II, a prominent group of films from the late fascist period were disparaged under the label "cinema calligrafico." These films were often adaptations of or referencing nineteenth-century literature and were marked by pictorialism, highly mannered mise-en-scène, and an artifice that proponents of neorealism condemned as precious, apolitical, and running away from social realities. Pierre Leprohon described calligraphismo as "brilliant arabesques in the void." In other words, in their promotion of a gritty, politically engaged cinema, the neorealists turned calligraphy into a pejorative term for "beautiful filmmaking" that did not address the realities of messy human reality (war, fascism, and the like). This is not a critical move that would occur to East Asian filmmakers because their brushed calligraphy is so much more than "beautiful writing."

East Asian calligraphy is a somatic form of art pointing us back to, and facilitating a communion with, the individual human artist, brush in hand, and the moment of inscription. It is thus a powerful tool for expressing the whole gamut of humanity's emotional life, from its delicate beauties to its grimmest nether regions. If, in their 
Figure 1.3. Native speakers clearly wrote the calligraphy for The Wrath of the Gods (1914). The medallion on the right says "Ince" in katakana, and the left has the characters for "company." In contrast, most Western films use faux calligraphy for East Asian writing.
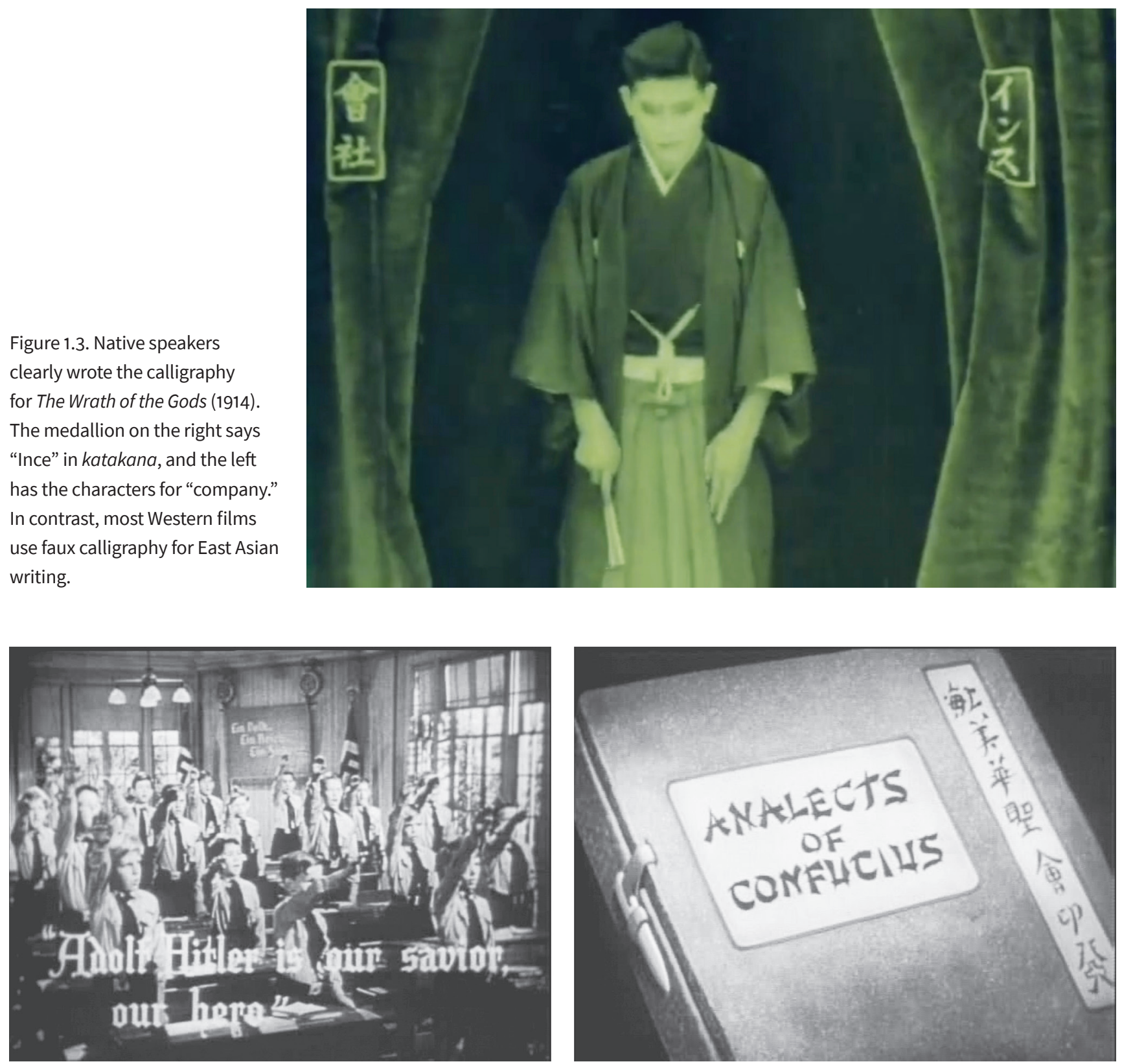

Figure 1.4. America's two enemies are othered through a calligraphic strategy in the propaganda classic Why We Fight: Prelude to War (1942), using blackletter for the Nazis and faux calligraphy for the Japanese. 
most conventional forms, Western calligraphy emphasizes (aestheticized) communication and Arabic calligraphy is about transcendence, East Asian calligraphy is about embodiment.

\section{Shufa: In the Beginning Was the Law}

The idea of "East Asia" is an imminently modern construct and, considering the region's incredible cultural and linguistic diversity over the millennia, it arguably borders on meaninglessness. At the same time, the Chinese character lends "East Asia" some material coherence. As it spread from China to its near neighbors, the character system enabled communication both within and between empires. Of course, the Chinese, Korean, and Japanese used characters in quite distinct ways, and this is signaled by the different domestic words for "calligraphy." For artists and scholars in the region, the terms are hardly equivalences, and they point out the fact that each language attaches different characters to 書 (write): shufa (書法) for Chinese, shodo (書道) for Japanese, and seoye (書藝) for Korean. The differing attitudes, aesthetic values, and practices implied by these three combinations are important to artists throughout the entire region and are central rubrics through which they define themselves against the work of their neighboring colleagues. I hesitate to make too much of these terms, but by sorting them out, we can tease out some of the peculiarities of each linguistic and cultural context. Along the way, we can raise some basic issues that will be explored in more depth in the chapters that follow.

The word for calligraphy in Chinese is shufa (書法). The first character appears in all three languages. It means "writing" or "to write." The second character in Chinese, fa (法), has a more complicated and multifold meaning: method, law, rule, principle, model, system. Perhaps it should not be surprising that their word includes this character, since China is after all the progenitor of writing in East Asia. It is probably the oldest writing system still in use in the world.

It is generally thought that Chinese writing dates back 3,00o years. The first medium used for inscription was bone, followed by bronze in the Shang Dynasty (160o$1046 \mathrm{BCE})$; the former were carved and the latter cast. Paper, brush and ink came into use around the turn of the millennium, and characters increased in numbers and complexity thanks to the delicacy and sensitivity of these new tools. What follows this is a remarkably complicated history involving a panoply of characters and stylistic innovations. It is too convoluted and overwhelming to go into great detail, although I will supply a bare bones chronology when we unpack the traditional styles in chapter 3. At this point, I briefly want to highlight a couple early and fateful moments.

In the Eastern Qin dynasty around the fourth century, an orthodoxy developed around the work of Wang Xizhi (王羲之, 303-361 CE) and his son Wang Xianzhi (王獻之, 344-386 CE). Examples of their writings were compiled in books that could be imitated. Indeed, their calligraphy is deeply admired-and modeled-across Asia to this very day. There are even references to it in cinema titles, for example, the character san (散) in Goodbye Dragon Inn (Busan, 2003; fig. 1.5). ${ }^{4}$ This is one way present-day artists can elevate their title by borrowing the power and prestige of the ancients.

A break occurred in the middle to late Tang Dynasty (618-906 CE). This was one of the high points in Chinese history, when a consolidation of political power and territory led to a vivacious political, economic, and artistic scene. In the course of the Tang, the political system stratified and began to decentralize, and local artistic practices began to tamper with received orthodoxies. People began to value individual styles and departures from the constraints of traditional models. The most famous calligrapher of the era, Zhang Xu (張旭, ca. 658-748 CE), was one of the socalled Eight Drunken Immortals. He was known for getting 

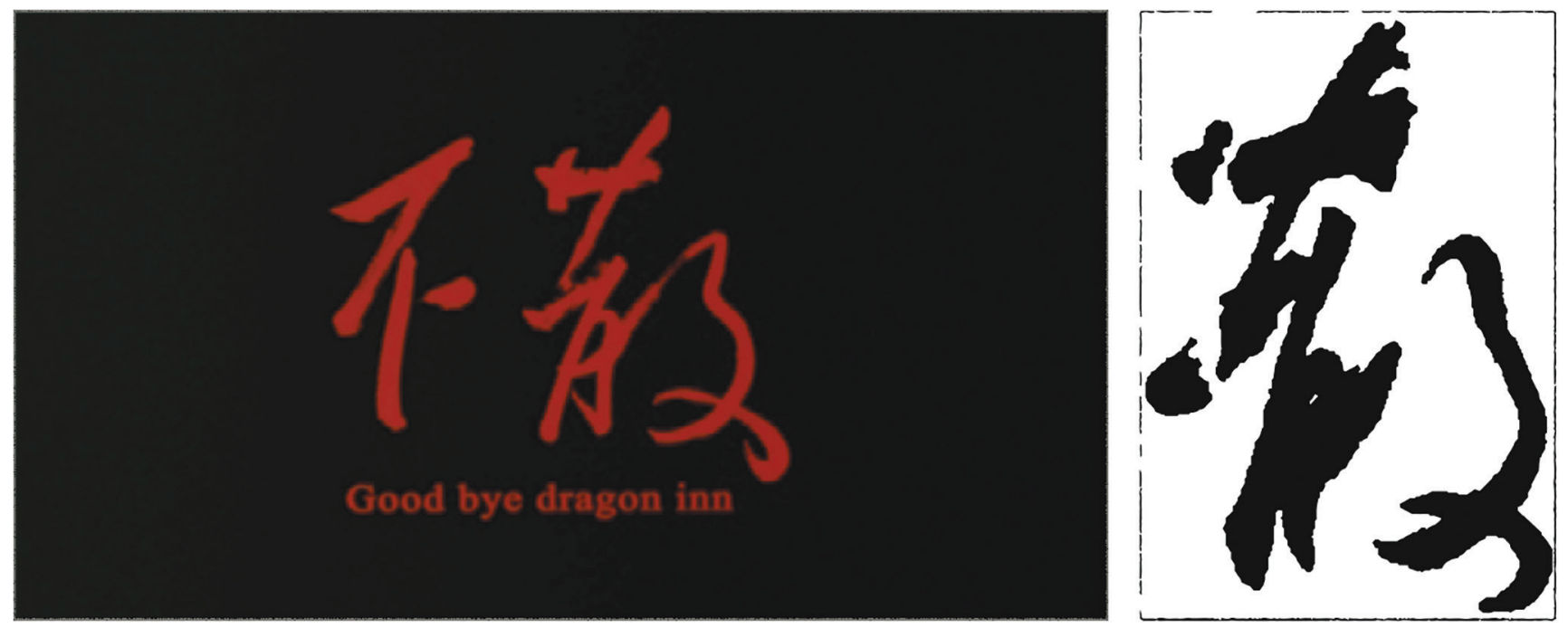

Figure 1.5. Tong Yang-tze, one of the great calligraphers in Taiwan, included a tribute to the fourth-century master Wang Xizhi (right) in her title for Tsai Ming-liang's Goodbye Dragon Inn (Busan, 2003).

wasted on wine, dipping his long hair in ink, and using it as a brush. Like the four-eyed Cang Jie, this is another provocative myth connecting writing directly to the body. The intoxicating deformations resulted in a wild cursive style that Zhang was at pains to replicate while sober.

Thus begins over a thousand year-long tug of war between received conventions of calligraphic writing and individual innovations. Over the years, the styles settled into five broad categories: seal script (管書), clerical or official script (隸書), cursive grass script (草書), running or semi-cursive walking script (行書), and standard script (楷書). All of East Asia, plus Vietnam, shares these broad categories. In fact, there are far more than this. ${ }^{5}$ What is important, however, is the way history looms over the writing practice of calligraphy. As Chang Tsong-zung explains,

Generally speaking, no matter which style dominated at a particular time, paradigms of calligraphy were always picked from the past, from the golden eras of each style. Models played an important role in the machinery of Chinese culture, establishing the pantheon of the classics and signifying the authority of lineage. The authority of paradigms gave order to history, and the role of the literati had always been to safeguard the classics and to lay the groundwork for new paradigms in interpreting current events. ${ }^{6}$

The "law" in the Chinese word for calligraphy ultimately derives from this accumulation of prestige over time and is designed to bolster and protect its public, magical, and political functions. Mastery is difficult, and so calligraphy often marks class. Just the presence of a set of brushes on a desk indicates the owner is monied and well-educated. Awkward calligraphy can signify the opposite. Tsang Tsou-choi (1921-2007), otherwise known as the King of Kowloon, is an instructive example who 
appeared in a number of documentaries. ${ }^{7}$ Poor and near illiterate, he protested the seizure of his ancestral lands in Guangdong by writing calligraphic graffiti all over Hong Kong. He absorbed the power-laden calligraphy of Chinese city space, reprocessing it in his own unique style. So he transformed, for example, an electric box into a stele, undermining the power dynamics of the historical stone monuments and breaking both civic and art historical laws along the way.

But most calligraphers in China are persnickety about the laws of brushed writing. In addition to the pressures of that glorious historical tradition, they have devoted their life to mastering all these rules and regulations. These have to do with everything from stroke order and directionality to brush pressure and ink loads. If there is one commonality among all calligraphers it is that the best artists master these orthodoxies before bringing their own individuality to their writing; at the same time, there is a vast spectrum of opinion regarding how far the individual can depart from the model before it ceases to be "calligraphy." As I met artists across the region, it was the cohort of mainland Chinese calligraphers that seem most attached to their models and simultaneously suspicious of individual innovation.

To this dynamic we must add an additional pressure specific to the modern era. In his study of premodern Japanese calligraphy, Thomas Lamarre draws a distinction between two tendencies. On the one hand, there is inscription as cultural expression (a value that becomes overriding in the modern era). On the other, there is a "capacity for practical and rational transcription," an instrumental approach driven by rationalization and centralization. ${ }^{8}$

This latter tendency is epitomized by waves of successive, top-down simplification projects starting from the eighth and ninth centuries to the present day, where an ancient character like 藝—yi for “art”—could be turned into 垒 in 1935 and finally 艺 in 1956 during the Communist era. ${ }^{9}$ Taiwan, Korea, and Hong Kong still use older forms (and Hong Kong has many characters specific to the local Cantonese language), but People's Republic of China (PRC) movie titles often use them as well. That doesn't mean cinema was exempt from this pressure from the state in the People's Republic. According to art designers in Beijing, censors interfere when calligraphic style hinders legibility. $\mathrm{Zu}$ Xiaobing, a legendary title designer with nearly a hundred credits to his name, explained, "You have to write for the masses, not the self." On the one hand, this attitude clearly exhibits a political context. Indeed, authorities in China shut down one of the first modernist exhibitions of calligraphy - by Gu Wenda in 1985-when they suspected his illegible characters harbored anti-government messages. ${ }^{10}$ At the same time, these values around legibility and writing are thoroughly modern. Paul Saenger writes,

Stated summarily, the ancient world did not possess the desire, characteristic of the modern age, to make reading easier or swifter because the advantages that modern readers perceive from ease of reading were seldom viewed as advantages by the ancients. These include the effective retrieval of information in reference consultation, the ability to read with minimum difficulty a great many technical and scientific texts, and the greater diffusion of literacy throughout all the social strata of the population. ${ }^{11}$

As a modern art form, cinematic calligraphy was subject to these values revolving around transparency and swift communication of semantic meaning. While Taiwan and Hong Kong maintained old-style characters with their high stroke counts, their title calligraphy still avoided excessive stylization that could interfere with easy legibility.

Of course, modernist filmmakers feel free to abandon any given rule. After the 1980 os modernist break in the fine arts scene, many calligraphers in Asia looked to Japan for inspiration. There they found an attractive avant-garde 
with roots in premodern practice. Works with one or just a few large characters are a self-conscious borrowing from Japan and probably influenced the approach to title design to some degree. ${ }^{12}$

Most Chinese calligraphers I encountered lived up to the rule-bound stance implied by shufa; however, it is worth noting that attitudes regarding calligraphy in Taiwan were far more amenable to experimentation and individual expression. Indeed, the most famous artist on the island is Tong Yang-tze. ${ }^{13}$ She was born in Shanghai during World War II but grew up in Taiwan. She studied calligraphy in her childhood, modeling the masters like Wang Xizhi. However, she matured as an artist in the United States, where she became a painter and designer. Upon returning to Taiwan, she brought this sensibility back to calligraphy. The mainland calligraphers I showed her work to met it with derision. But a measure of the flexibility of Taiwanese is the fact that her paintings hang in the halls of government, the calligraphic dances of Cloud Gate Dance Theatre, and many of Taiwan's greatest films, including The Wayward Cloud (Tianbian yi duo yun, 2005), and Face (Visage, 2009; fig. 0.6). It is her homage to Wang Xizhi that graces the beginning of Goodbye Dragon Inn (fig. 1.5). This kind of departure from convention is relatively rare in Hong Kong film and virtually unheard of in mainstream mainland cinema.

\section{Shodo: The Way of Japanese Calligraphers}

The term for calligraphy in Japanese is shodo (書道). Here the character for "writing" is combined with do, making it literally the "way of writing." The character is actually a bit more complex, with meanings as diverse as street, journey, way, method, and teachings. Obviously, shodo leans on these latter meanings. Calligraphers across Asia note that this locates Japanese calligraphy in close proximity to many other arts that also use the character, such as tea ceremony (sado), wrestling (judo), swordsmanship (kendo), and others. They argue that this built a flexibility into calligraphic practice distinct from the mainland. The less slavish devotion to "The Law" is certainly true, but its reasons are undoubtedly complex and the result of over a thousand years of practice with a significantly different writing system.

Chinese characters made the jump across the Sea of Japan with emissaries in the first century BCE. ${ }^{14}$ Chinese was adopted over the course of six centuries by the elite, who gradually developed a variant of Chinese called kanbun. Calligraphy also spread among this community and adapted to the local language. The Japanese developed a set of phonetic characters in the seventh and eighth centuries, which came to be called manyogana. This in turn was the progenitor of two other sets of purely phonetic script. Hiragana is a cursivization of Chinese characters for Japanese sounds (for example, 安 becomes あ); similarly, katakana is an abbreviation of phonetic characters used for foreign loan words (加 becomes 力).$^{15}$ Today, a given Japanese sentence combines these phonograms with slightly simplified Chinese characters. See fig. 0.4 for a variety of combinations: The Eel (Unagi, 1997) is in hiragana, while Water Boys (Wata boizu, 2001) and The Chrysanthemum and the Guillotine (Kiku to girochin, 2018) have katakana. The others mix hiragana and Chinese characters.

Some speculate that Japanese calligraphy's amenability to experimentation and flexibility vis-à-vis rules has origins in bokuseki (墨跡, lit. “ink traces”), a Chan/Zen (禅) Buddhist practice that directly links calligraphy to the do in shodo. As in the scroll that decorates a tokonoma in Kobayashi Masaki's Harakiri (Seppuku, 1962; fig. 1.6), bokuseki were usually bold renditions of single characters. This particular character一喝—refers the exclamation a master makes when he strikes a pupil who is starting to sleep during meditation: $k a$ ! It is cleverly pictographic as well, since the shape evokes dolls of the Bodhidharma (Daruma in Japanese), the original fifth-century transmit- 


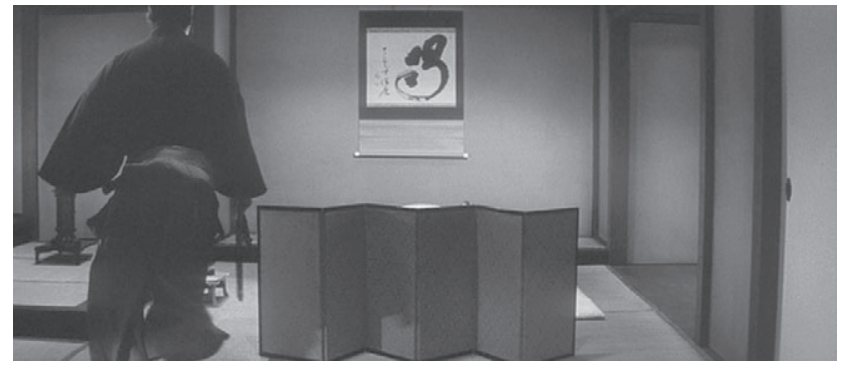

Figure 1.6. The tokonoma in Harakiri (Seppuku, 1962) displays a stunning bokuseki, probably written by Teshigawara Sofu. It is the character 喝, or katsu; this is the word Zen masters say- “Ka!"when they strike a disciple caught sleeping during meditation. Note that in this modernist work, the calligraphy is perfectly centered.

ter of Chan/Zen to China; he is purported to have lost his limbs to atrophy after a nine-year meditation.

Bokuseki was a "way" to enlightenment. Monks would execute a work of art without thinking. For the practitioners of bokuseki, the model and the laws of convention are irrelevant. That is because the whole point is to record being at the instant of inscription. It is this tradition that emphasized the large, wild characters-works that inspired the modernists on the mainland centuries later.

For Japanese calligraphy, that modernist break is marked by the 1952 formation of Bokujinkai (or "Group of People of Ink") by Morita Shiryu and Inoue Yuichi. In the pages of their journal Bokubi (墨美, lit. "Beauty of Ink"), the group tried to align their practice with the modernist painters of Europe, both for inspiration and cultural capital. But at the same time, they theorized differences between the two spheres. European modernists had long been fascinated by Japanese art, and the likes of van Gogh even integrated clunky imitations of calligraphy into their paintings.

When Bokujinkai was in full force, Belgian painter Pierre Alechinsky even travelled to Japan to make a docu- mentary film about the calligraphy scene in 1956. Calligraphie Japonaise featured the work of Eguchi Sogen, Shinoda Toko, Morita Shiryu, modernist calligraphers who were just gaining fame. ${ }^{16}$ He shows them at work, his narration precisely revealing what fascinated the artists of abstract expressionism and Tachisme. Alechinsky's narration explains,

Sogen Eguchi (sic, shown painting with a handful of brushes; fig. 1.7), for instance, belongs to a generation which was uprooted by war. He is split between the wish to maintain tradition and the will to escape from it. It took a certain amount of courage to get rid of the training he received and rebel against an order that seemed immutable. He discovered loneliness.

It was this nexus between the immutability of linguistic inscription and received style on the one hand and artistic departure on the other that constituted the space the modernist calligraphers navigated; however, unlike abstract expressionist painters like Alechinksy, modernist calligraphers were unable to completely abandon language and tradition.

This made them particularly appealing to filmmakers, who wanted striking writing for their titles and props. For example, the most influential modern school of ikebana is Sogetsu. It was founded by Teshigawara Sofu, who sometimes performed calligraphy for his filmmaker son, Hiroshi. He was one of the great art filmmakers of postwar Japan, and he took the reins of Sogetsu after Sofu's death. Excellent examples of Sofu's work are the title cards for Harakiri (fig. 1.8) and his son's Face of Another (figs. 0.10 and 1.9). The latter film begins with a strange montage of dismembered body parts floating in water and then cuts to four shots of the characters that make up the title, ending on "face." ${ }^{17}$ These are direct photographic images of Sofu's actual painting, and the last shot even shows a collection of seals that are traditionally used to affix authorship and 

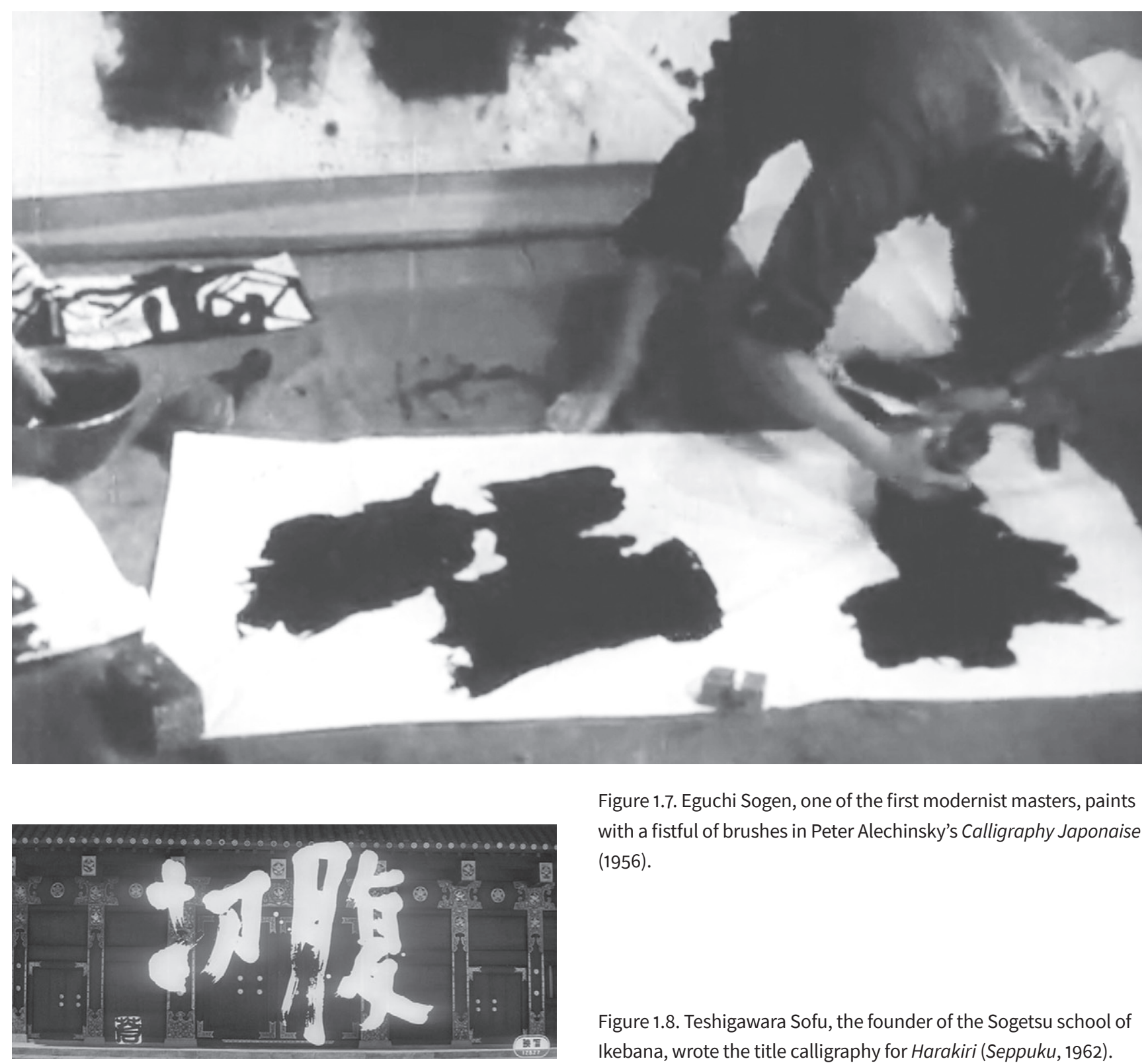

Figure 1.7. Eguchi Sogen, one of the first modernist masters, paints with a fistful of brushes in Peter Alechinsky's Calligraphy Japonaise (1956).

Figure 1.8. Teshigawara Sofu, the founder of the Sogetsu school of Ikebana, wrote the title calligraphy for Harakiri (Seppuku, 1962).

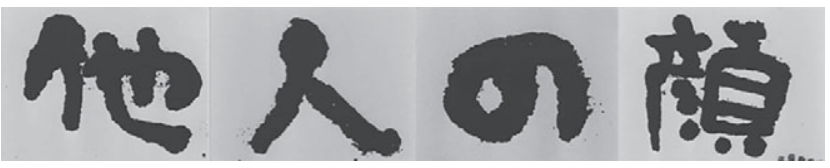

Figure 1.9. Teshigawara Sofu's title calligraphy for Face of Another (Tanin no kao, 1966) is a stunning riff on clerical style. 


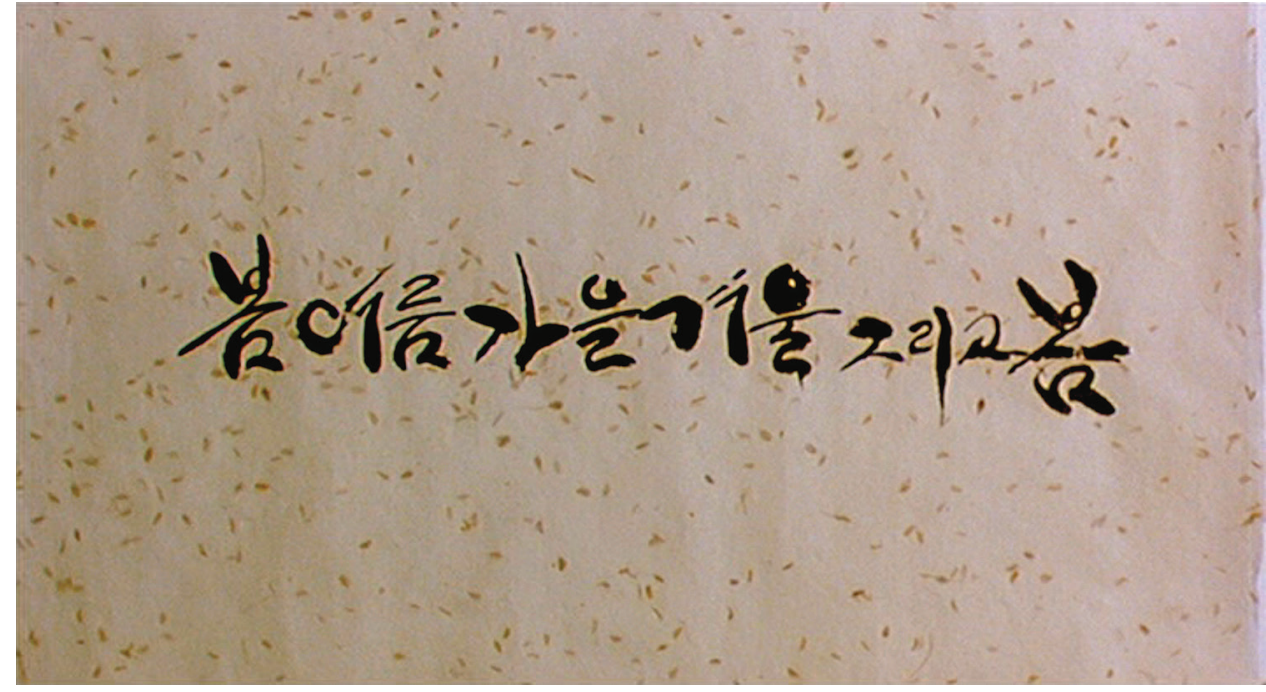

Figure 1.10. Hangul calligraphy on a lovely paperscape, from the title of Spring, Summer, Fall, Winter... and Spring (Bom yeoreum gaeul gyeoul geurigo bom, 2003). ownership and provenance. Sofu's writing style here is a striking variation of the ancient clerical style, and the treatment it receives from his son-direct, unmanipulated photographic replication-indicates a respect for the original work, media, and tradition. At the same time, this is Teshigawara staking out territory. This is not commercial cinema; it is art cinema. Hiroshi signals as much by boldly chopping up the unity of the original work of art with montage. Both father and son bring longstanding traditions, impulses, and the desires for and pleasures of individual expression to their respective art forms.

Make no mistake, "The Law" does matter in Japan, as it does in China and Korea. But the relationship to the model is complex. The practice of copying the historical model is called rinsho (臨書) in Japanese, but it's parsed into three categories: keirin (形臨) is copying calligraphy from a model; irin (意臨) means copying freely, with little regard for the model; and hairin (背臨) refers to the writing that is possible once one has absorbed the model through rigorous imitation. This is what serious calligraphers are shooting for. As in China, the Japanese calligraphy world is divided into tribal schools that replicate themselves through imitation of the respective masters and compete against themselves. ${ }^{18}$ At the same time, Japan enjoys a measure of flexibility and innovation starting with the invention of hiragana, running through medieval bokuseki, to the spectacular modernist break (especially marked by the 1930 s work of Ueda Sokyu).

Finally, there is one other term that is important here: shosha (書写). We could translate this as "handwriting" or "transcription." However, the literal meaning is "writing + copying/photographing/describing." It is what students are doing when they are learning to write. Shosha is about the beauty of uniformity and evenness (kinto no bi 均等の 美) and arranging words in perfect order. Shodo, by contrast, is about the beauty of equilibrium (kinko no bi 均 衡の美). The difference is interesting for us. Equilibrium involves the very human process of bringing various and dynamic factors into a perceived balance. Because weight and power are uneven, that balance is anything but forced and stolid. Rather, it is delicate and dynamic. In calligraphy, this dynamism comes from the entry of emotion and the human-from subjectivity, which is registered by the pace of inscription and the thickness or thinness of the 
line and the particular qualities of the ink. This is what transforms mere handwriting into calligraphy. As calligrapher Iida Reigiku suggests, "It is how a flat piece of paper archives three dimensional qualities - or even four dimensions if one factors in 'speed."'19

This humanization and subjectification of inscription will be a central concern of this book. However, as the example of Akamatsu Hikozo suggests, cinematographic calligraphy calls into question that status of the model and begs for a definition that straddles, and at times obliterates, terms like shosha and shodo, irin, and hairin.

\section{Seoye: The Geopolitical Character}

The term for calligraphy in Korean is seoye (書藝). The most immediately distinct aspect of Korean calligraphy is the writing system, hangul. This is a visually distinct mode of writing, deploying blocks filled with circles and strokes representing vowels and consonants (fig. 1.10). Incredibly enough, hangul was invented by a team of scholars working with King Sejong (1397-1450), who was something of a linguist. He promulgated the new script in 1446. Sejong wanted a writing system that was tailored to the Korean language and easier to learn and use than Chinese, which had been used by elite men for a millennium. Chinese continued to be used in the bureaucracy and was called "true writing" (sinseo 真書). This revealing name, combined with the sheer difficulty of mastering Chinese writing, helped these elite men maintain power and cultural prestige. The veneration of Chinese actually intensified during the Qing Dynasty when the court saw itself as the true successor of the Han. However, hangul quickly spread across the Korean peninsula in the fifteenth and sixteenth centuries, notably among women and commoners.

Hangul is a uniquely designed script created centuries before the emergence of the modern designer. Other languages started inscription with chirography, or hand- writing, and eventually integrated the hand into typeface. Hangul reversed this order. This was why it is distinctly built out of clean lines ending with circles. These are shapes modeled after the shape of the human mouth and tongue-the human body parts responsible for articulating linguistic sounds-rather than marks created by and tailored for the manipulation of writing tools by the hand (yet another connection to the somatics of writing). ${ }^{20}$ Unlike the figurative richness of Chinese, the pictographic qualities of hangul end with the figure cheonjiin, a circle (sky) over a horizontal line (the earth) where the vertical line (human) stands - a favorite subject for hangul calligraphers. By assembling all these elements in a square space, one can represent all the sounds that constitute the Korean language.

It was extremely rare to mix Korean and Chinese until the late nineteenth century, when Emperor Gojong (18521919) proclaimed Korean the national language, a year before the birth of cinema in 1895. In the first decades, one does see Chinese characters alone (fig. 3.18) or combined with hangul. However, the former became increasingly uncommon in the postwar era, especially since the 1990 . People still learn characters, which makes possible a clever title like the one for Kim Ki-duk's The Bow (Hwal, 2005; fig. 1.11). It features calligraphic hangul, but the calligrapher used two colors and extended the final strokes. By unconventionally extending the final strokes and painting them in black ink, they form the Chinese pictographic character for "bow."

Among "serious" calligraphers (i.e., those that would never stoop to working in a low, popular art like cinema), hangul is depreciated in favor of brushing traditional Chinese characters. This is why one calligrapher I spoke to insisted there was no calligraphy in Korean films-because they almost exclusively use hangul. His own artistic practice departs from traditional modes by mixing various ancient styles in a single work, a bravura approach indelibly linked to a conservative vision and definition of callig- 
Figure 1.11. The title for Kim Ki-duk's The Bow (Hwal, 2005) uses calligraphic hangul (활). By unconventionally extending the final strokes and painting them in black, they transform into the Chinese character for “bow” (弓). raphy. At the same time, there are other reasons why he denied the status of "calligraphy" to the brushed word in cinema. Interestingly enough, it had to do with the terminology for "beautiful writing."

As I mentioned above, the Korean word for calligraphy is seoye, which combines the Chinese characters for "writing” (書) with “art” (藝). This is, in fact, a quite contemporary neologism. Until modern times, calligraphy has been referred to by the Chinese word shufa (seobeop, in Korean). Not surprisingly, in the course of the 35-year colonial period (1910-1945), this came to be displaced by the Japanese term shodo. Assimilationist policies during the China and Pacific wars (1937-1945) included language provisions that called for the use of Japanese for books and newspapers, education, and even personal names; hangul itself was banned outright in $1933 .{ }^{21}$

Around the time of the Korean War, an influential art critic started a debate in an art journal. The question was what to call calligraphy. From our vantage point today, the terms of the discussion appear geopolitical. For quite understandable reasons, they wanted to purge shodo from the artistic vocabulary. However, at the same time, at this hot moment in the Cold War, they rejected a return to the shufa used in communist China. Interestingly, they also avoided a loan word derived from the English "calligra- phy." The Cold War era was a moment when U.S. power was eminently palpable. One could look at this as anti-United States, but it is likely a very complicated situation. These elite artists would never go so far as to reject Western high culture. The relationship to the West is complicated in this way, and it is a dynamic one finds across East Asia.

In the end, they made the fascinating choice to combine writing (書) with “art” (藝). Calligraphy has had a sketchy status in the modern art world of East Asia. Historically, it could be mere writing or aesthetically beautiful or both. However, when modernity hit and art became institutionalized by academies and museums in the early modern era, calligraphy was, incredibly, excluded. This was true in all of East Asia.22 Premodern Chinese intellectuals may have included calligraphy among the "three perfections" (san jue 三絕), along with poetry and painting, but modernity positioned brushed writing as a utilitarian, quotidian skill.

The Korean emphasis on the artfulness of writing by hand came after many decades of modernization. Capitalism brought the conception of highly manipulated and legible lettering that enabled both scientific description and a culture of commodification. This was a highly functional approach to language deeply connected to the West. The term seoye distanced calligraphy from design and asserted a nonpractical artfulness disconnected from the market- 
place. So they adopted seoye-a novel term that implied a complex opposition to Japan, China, and the United States. It is truly a postcolonial, Cold War, anti-capitalist term of art.

\section{The Stench and Fragrance of Cinematic Calligraphy}

Calligraphy ties the artistic cultures of the region together in a foundational way. But the proliferation of styles and schools came to be convention-bound and resistant to change- this despite an ultimately mind-boggling assortment of styles recognized as "calligraphy." However, all of them are exceedingly difficult to learn, let alone master. Combined with the conservatism of those who have achieved the highest level of accomplishment, it is natural that issues of value rush in at every opportunity.

Aesthetic judgments require difference and, regrettably, these differences are often coopted by national passion. Too many of the calligraphers I met were quick to make severe judgements of their peers' work. In conducting interviews, I always brought the same set of frame grabs to break the ice and get the conversation going. These were, for the most part, title cards from Japanese, Korean, Chinese, Taiwanese, and Hong Kong films, and they were mostly written by famous calligraphers at the top of their game. When talking to professional calligraphers, they would often disparage the work from foreign films and gravitate toward the domestic.

For example, one image was the title card from Toyoda Shiro's adaptation of Kawabata Yasunari's Snow Country (Yukiguni, 1957; fig. 1.12). When this one came up with a small group of professional calligraphers in the PRC, they quickly piled on: it was painted in the incorrect stroke order, the lower horizontal stroke in the initial character "snow" (雪) was too long, the L-shaped stroke on the lower left of "country" (国) was simply strange-clearly,

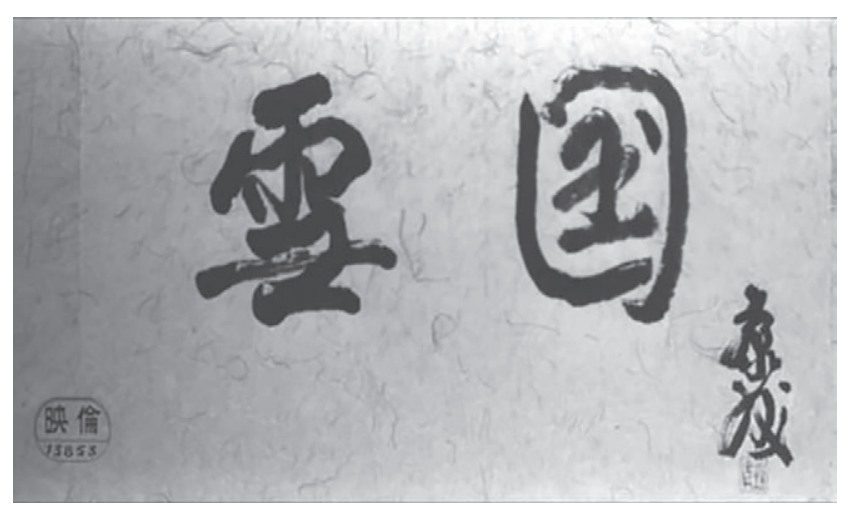

Figure 1.12. Nobel Prize-winning novelist Kawabata Yasunari gifted his own calligraphy for the adaptation of Snow Country (Yukiguni, 1957). The two broad strokes framing character for "country" turn it into a closed, bounded space.

everyone concluded, this person was poorly educated and had no idea what he was doing. Actually, this film was produced right when Toho and other studios were using famous calligraphers for titles to give films the gloss of high art. This one was written for director Toyoda Shiro by the Nobel Prize-winning novelist himself, who was noted for both his calligraphy and his calligraphy collection. ${ }^{23} \mathrm{He}$ even added his signature and seal to the lower right corner. By way of contrast, calligraphers in Japan found the same calligraphy fascinating; riffing in admiration, they suggest the first character for "snow" has snowflakes, and that the unusual strokes of "country" turn it into a bounded area like the setting of the film. They felt the idiosyncratic abbreviations in stroke order suggested it was written by someone accustomed to writing swiftly, like a novelist, not some uneducated amateur or persnickety professional calligrapher.

Today is a particularly nationalistic moment in the People's Republic of China, so calligraphers seem predisposed to despise the calligraphy of their neighbors. One prominent calligrapher and scholar from China set out the following comparison: 
Chinese calligraphy is the idea, because its artists have historically been the most studious, skilled, and possessing of a deep appreciation of nature. Japanese calligraphers have a talent for capturing mood or selfreflection, although their achievements are pale imitations of the Chinese. As for Koreans, they have no calligraphy because they have no national spirit.

This was explained to me by a respected artist at a national art institution. In the same group interview with calligraphers and art history scholars, a philosopher (wearing a Hegel t-shirt, no less) leaned over, pointed around the table, and said, "You know, all of us hate the Japanese." No one disagreed. A Korean artist once related similar sentiments as well, but flipped the nationalities around: the Chinese were lacking in national spirit and the Japanese produced "writing" but not "calligraphy." Curiously enough, the calligraphers of Taiwan and Japan were far more gracious and less nationalistic than their counterparts on the continent. This might have been nothing more than the luck of the draw, and I simply met a preponderance of nationalists and xenophobes in the other countries. Needless to say, this all got very old, very fast.

Thankfully, not all Chinese calligraphers were so blindly nationalistic. For example, Qiu Zhenzhong is the author of a major calligraphy textbook and the artist behind the calligraphic designs of Zhang Yimou's Olympics opening ceremony. ${ }^{24}$ After studying Umehara Seizan's calligraphy for Kurosawa Akira's Kagemusha (1980; fig. 1.13), he said,

This is really good. In ancient times, the Japanese learned from Chinese calligraphers, but in the learning process they developed their own styles and own history. Chinese calligraphers love their own tradition, and don't respect the Japanese difference. But great Japanese works like this one have Chinese traces. You can tell this calligrapher learned something from China, but it's also quite different. Look at the begin-

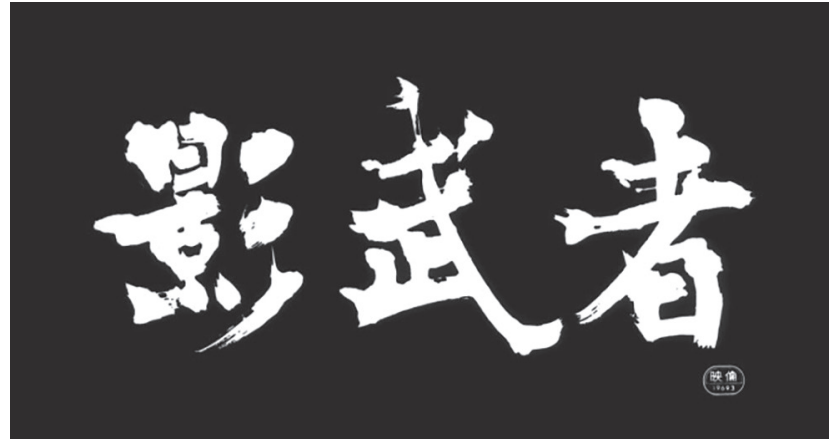

Figure 1.13. Umehara Seizan's calligraphy for Kagemusha (1980); along with Im Kwon-taek and King Hu, Kurosawa Akira was one of the directors who cared deeply about the calligraphy in his films.

ning of the strokes. He clearly thinks the important thing is inner strength. Chinese calligraphers will think it's not accurate so it looks casual or sloppy to them.

But inside this includes something serious and precise.

It is with Qiu's appreciative openness and flexibility that I approach the calligraphy of East Asian cinema. I will be looking at how a "traditional" art inhabits the modern art of cinema. An accumulation of millennia of conventional practices and cultural sentiments rushed into the cinema from its very invention. Over more than a century, filmmakers have drawn on the resources of the traditional while tampering with the rules, as artists will. And while a handful of directors cared enough to use famous calligraphers, most were more interested in the beauty of the brushed word and played with all the semantic and aesthetic possibilities at hand. For Asian spectators of the East Asian cinema, this immediately engages domestic sensibilities in a local cinema. And when the same audience views foreign films, calligraphy marks a work as familiarly regional. Finally, for viewers outside the region, myself included, calligraphy contributes to the foreign fragrance of East Asian cinema. ${ }^{25}$ 


\section{Notes}

1. Wong, The Complete Calligrapher, 16.

2. Kim and Kim, "Typecast: Meaning, Culture, and Identity in the Alphabet Omelet (¿Which Came First?)."

3. Quoted in Landy, The Folklore of Consensus, 207. The key text in Italian is Martini, La bella forma.

4. Wang's original calligraphy may be seen at http://chinesecalligraphy-dictionary.wikichina.com/show.asp?id=27459\&biao=1

5. In "A Discussion on Calligraphy" (Lun Shu), sixth-century artist Yu Yuanwei claimed to know 120 script styles; this, along with an exhaustive historical categorization of major styles, can be found in Tseng's A History of Chinese Calligraphy.

6. Chang, "Power of the Word," 12

7. The best is probably King of Kowloon (1998). It can been seen online: https://youtu.be/E8oe3goTnQw. For more on Tsang, see Soon, "Reading Tsang Tsou Choi."

8. Lamarre, Uncovering Heian Japan, 78.

9. For an analysis of this history, see Yen, Calligraphy and Power in Contemporary Chinese Society, chapter 6.

10. The artwork in question was his "Mythos of Lost Dynasties Series-Tranquility Comes from Meditation (Primitive World, Composition of Words, and Synthesized Words)," from 1985 .

11. Saenger, 11; cited in Lamarre, op. cit., 101.

12. This was related to me by Qui Zhenzhong.

13. Also known as Grace Yang Tse Tong.

14. As evidenced by the earliest artifacts decorated with Chinese characters, according to Lurie, "The Development of Writing in Japan"; Miyake (Old Japanese, 8) puts the date slightly later.

15. The most compact and useful description of the develop- ment of the Japanese writing system is Lurie, op. cit. His longer version would be Realms of Literacy. Also see Seeley, A History of Writing in Japan and Kornicki, The Book in Japan.

16. It may be seen online at https://archive.org/details/japanesecalligraphy

17. Note the character is different and simplified in comparison to the title of the Tsai Ming-liang film (fig. o.6).

18. Needless to say, this lends itself to corruption. In 2009, the Japanese calligraphy world was rocked by scandal when a disgruntled student of one school revealed that the annual calligraphy contest run by Nitten was rigged. The main teachers for seal engraving were taking turns at getting awards for their students, a problem that had infected calligraphy and other sections. This kind of corruption naturally flows from the tribal protections installed around style, and the institutionalization of the student-teacher relationship. For a history of the scandal, see A, "Nitten: The Shame of Our Nation Nippon."

19. The information in this paragraph is general knowledge but deeply inflected by my conversations with calligraphers Iida Reigiku and Takeda Soun.

20. Park Sun-young interview.

21. Hannas, Asia's Orthographic Dilemma, 64.

22. I am grateful to Yasuko Tsuchikane for pointing this out to me.

23. See Kawabata Yasunari to sho.

24. Andrea Bachner performs a wonderful analysis of this ceremony in Beyond Sinology.

25. I borrow this connection of odor to nationalism and the global circulation of cultural products from Iwabuchi, Recentering Globalization, 2002. 


\section{CHAPTER 2}
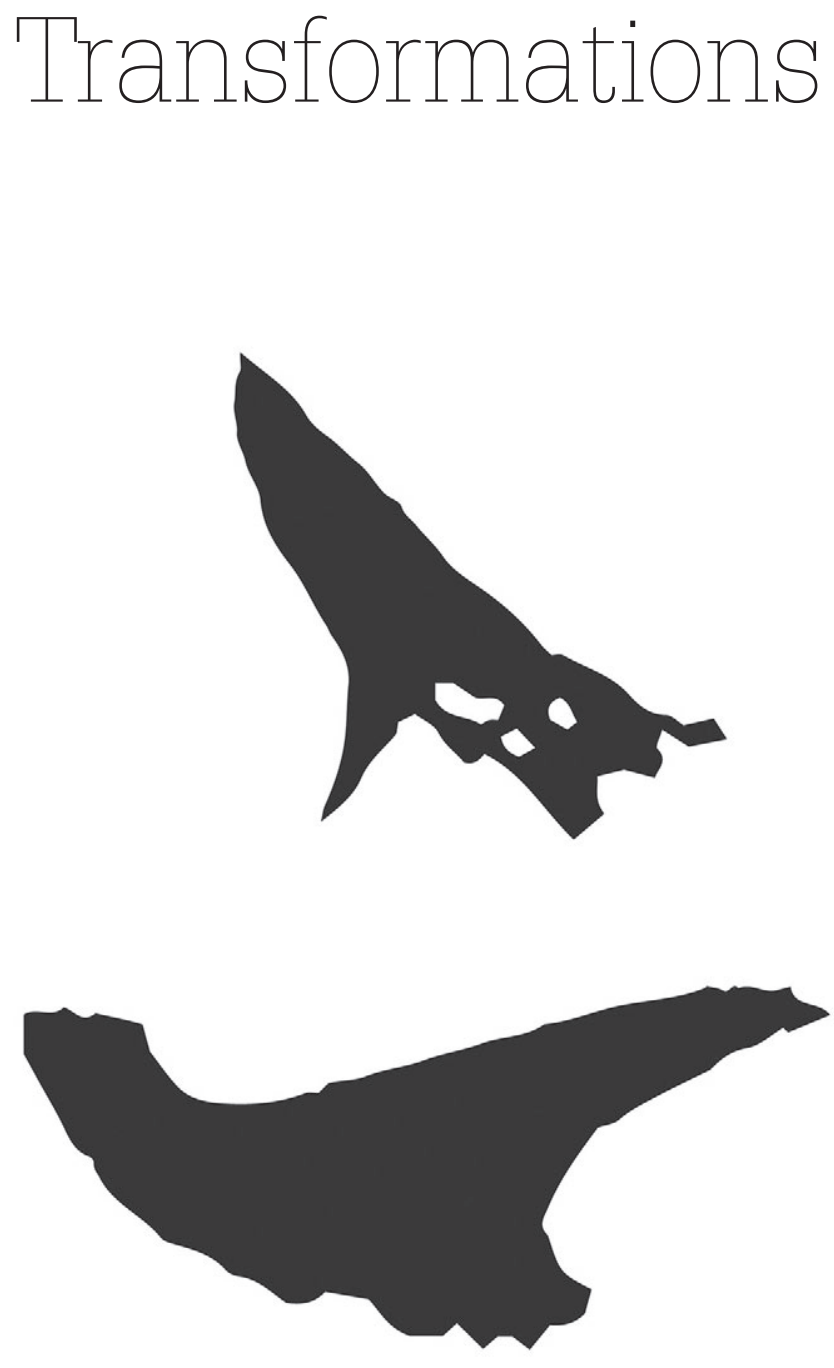

\section{The "Silent" Calligraph}

We begin, well, at the beginning. The motion picture was invented in 1895 and, within a handful of years, had spread globally. The first films were one-shot records of the world. They were often beautifully composed, yet were fairly raw. The complexity of cinema increased exponentially when filmmakers began stringing shots together. It was at this very early moment that calligraphy found a home in the movie theater; we can immediately recognize that calligraphy's visual excessiveness lent itself to the cinema.

From the very start of cinema's commercialization, advertisements used calligraphy along with lettering and the printed word. Film theaters popped up in the pleasure districts as one amusement among others. Before any spectators saw a movie, they often walked down a street lined with calligraphic banners, posters, and lanterns beckoning them to cross the transom to view the novel spectacles inside (fig. 2.1). Theaters adorned their entrances with calligraphy (fig. 2.2), and audience members were given programs that often used calligraphic design elements (fig. 2.3).

When the lights dimmed, a major visual feature of the films being projected was calligraphy. Beginning and end titles were a matter of course, but the intertitle was hardly automatic. Intertitles in early cinema introduced the scenes that followed. As narratives became increasingly 


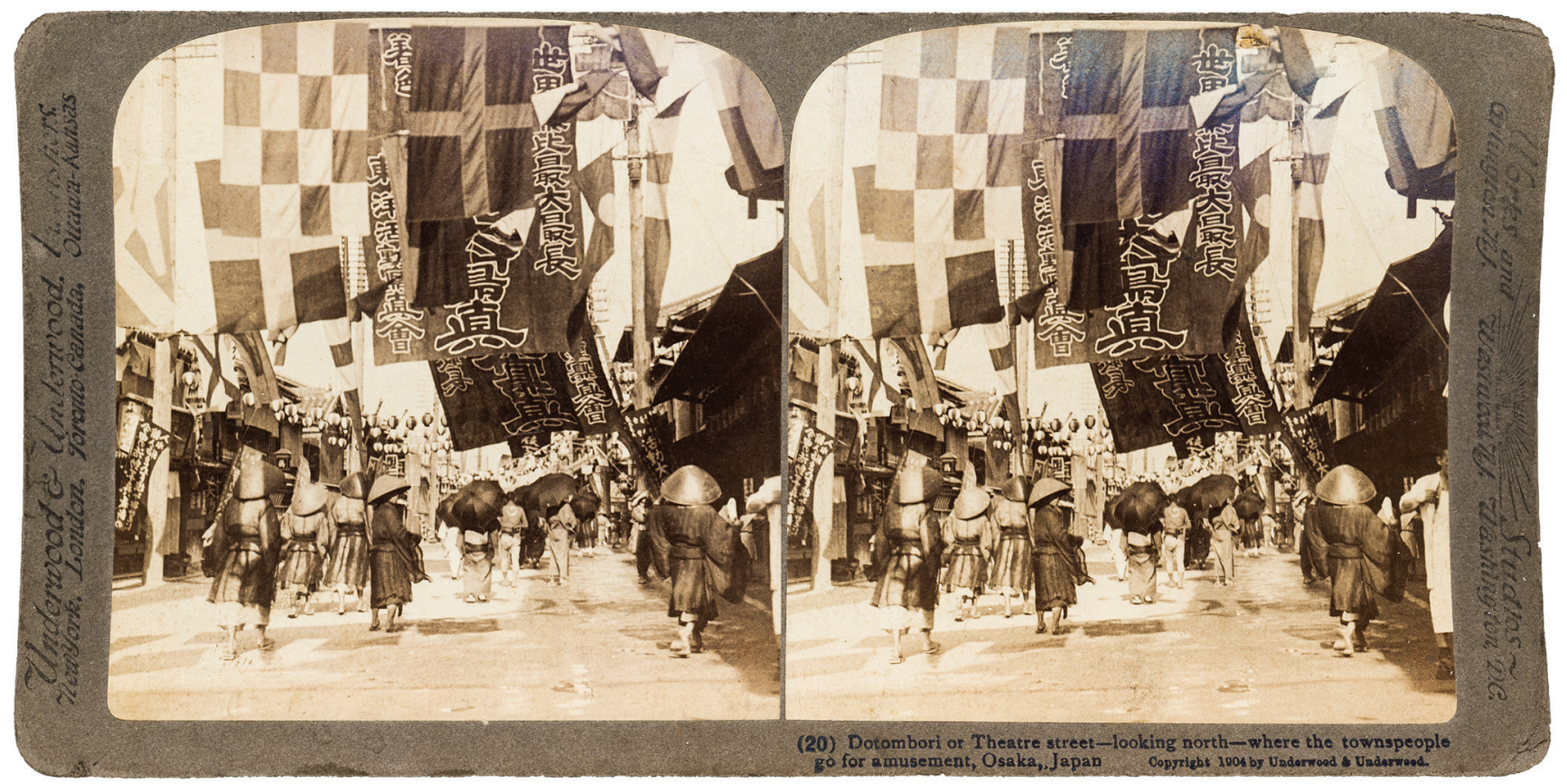

Figure 2.1. At its invention, cinema was seen in relation to popular amusements from traditional storytelling to new technologies of vision like the stereopticon. This stereopticon card shows Osaka's Dotenburi entertainment district in 1904. The large banners advertise "the world's longest color film."

complex, so did the intertitles. It wasn't long before they put words in the mouths of characters, or helped define setting or narrative twists and turns.

Intertitles enjoyed everything from high design to no design. In much of the world, they were accomplished with small printing presses; and where decorative, artists used lettering, drawing the outline of letters and then filling them in. Lettering was often used in East Asia as well, although calligraphy of one type or another was the favored mode of preparation. Figure 2.5 shows the original materials for prewar intertitles in Japan. The designer began with a sheet of thick, white paper and covered it with layers of black ink. Then calligraphers brushed the intertitles using gofun (胡粉), bright white ink in use since the eighth century and made out of pulverized scallops or oyster shells. Once painted, these were photographed and then thrown away while the intertitle was edited into the finished film. The only reason these examples exist is serendipity. One survived because a production company turned a few of the cards into covers for their scenarios; the other was slipped into a scrapbook created by a famous actor.

As movies became more elaborate, so did intertitles. They registered larger currents in design as modernity transformed the arts. Intertitles shifted from vertical inscription to a mix of vertical and horizontal lines. Word 


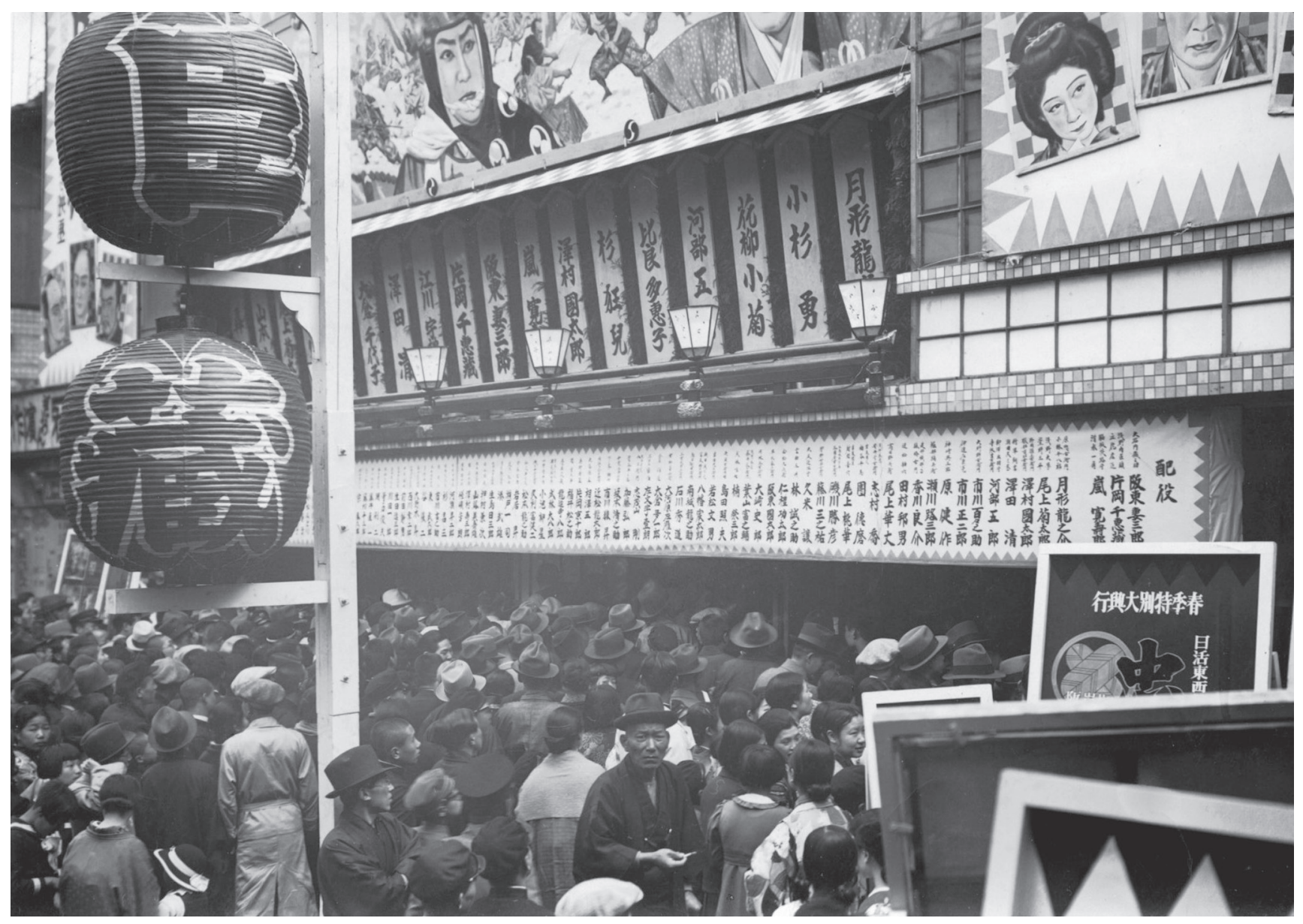

Figure 2.2. The Teikokukan in Kyoto, when it was showing Makino Masahiro's Chushingura: Heaven and Earth Episodes (Chushingura: ten no maki, chi no maki, 1938). The theater is covered with calligraphy, from the title on the lanterns to the all-star cast above the entrance. Courtesy of the National Film Archive of Japan. 
Figure 2.3. Spectators at Kyoto's Teikokukan received programs like this one, which combines calligraphy and lettering. Courtesy of the National Film Archive of Japan.

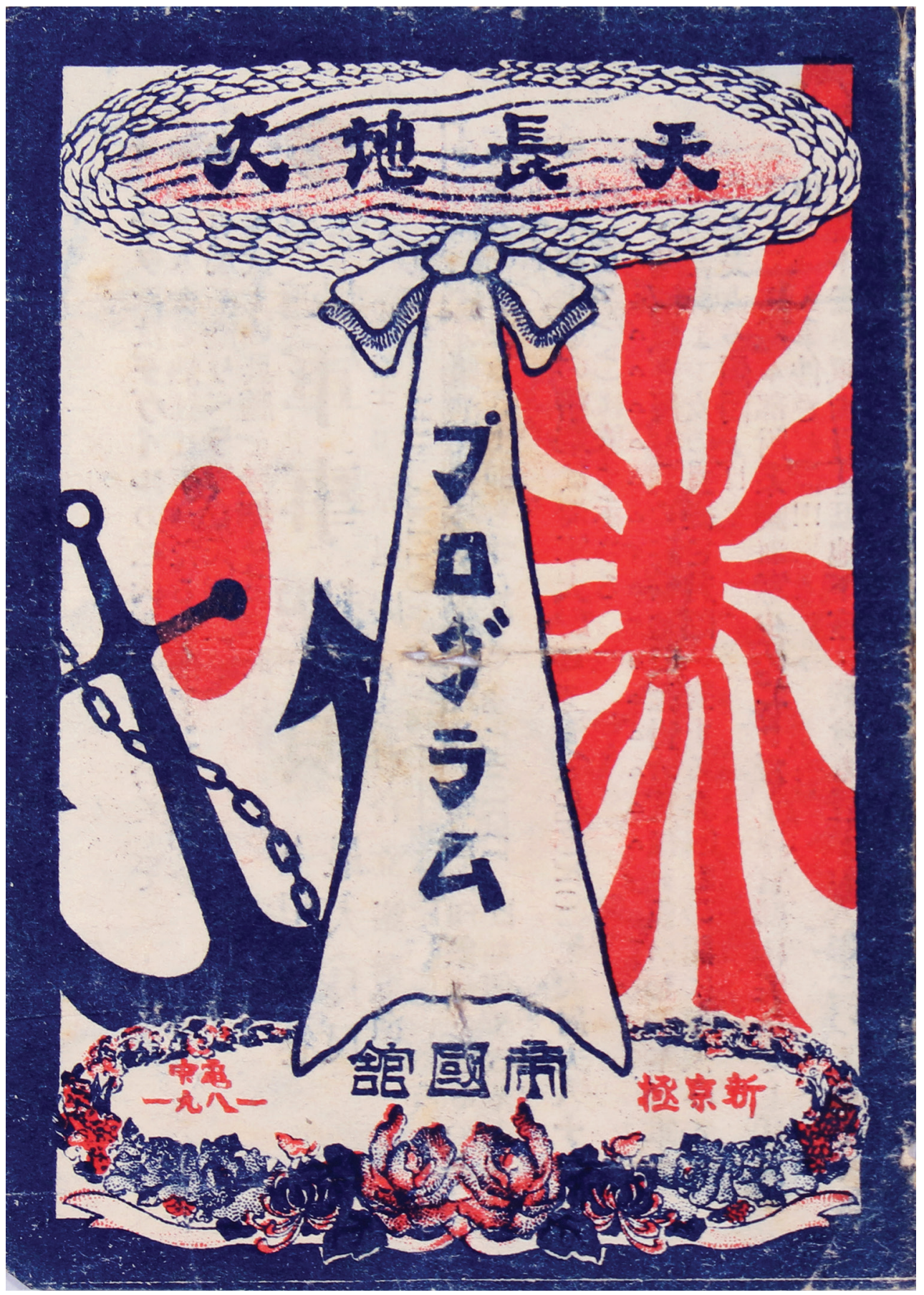



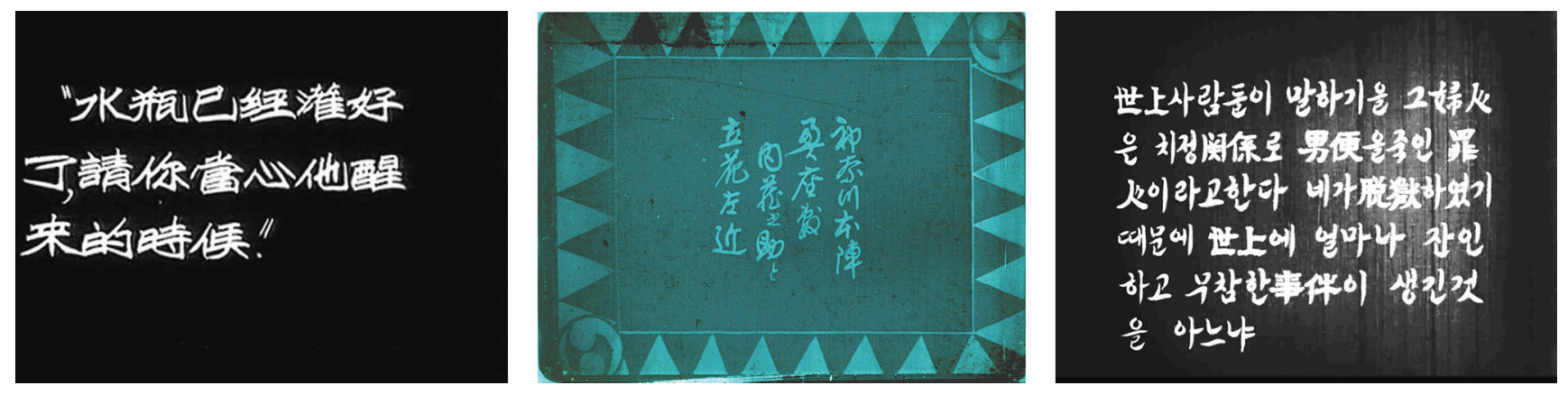

Figure 2.4. Typical calligraphic intertitles for the silent films The Goddess (Shennu, 1934), Chushingura (1903), and A Public Prosecutor and a Female Teacher (Geomsa-wa yeoseonsaeng, 1948). Chushingura courtesy of the National Film Archive of Japan.
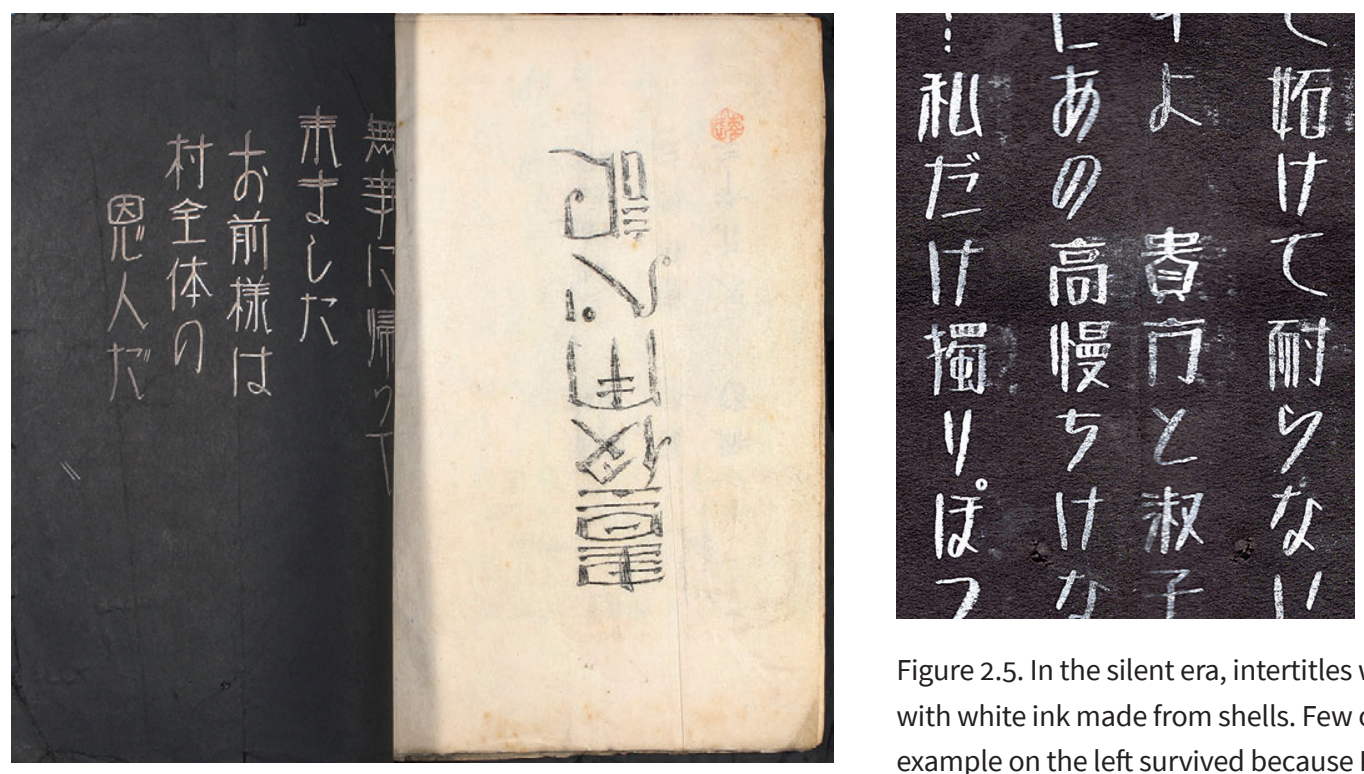

Figure 2.5. In the silent era, intertitles were brushed on black cards with white ink made from shells. Few of these cards are extant. The example on the left survived because Kawai Productions in Kyoto used it as a script cover. The detail above comes from an unknown film and was preserved in an album owned by actor Onoe Monya. An art deco variation of clerical style, it shows the care with which these brush styles were conceived and executed. Courtesy of the National Film Archive of Japan (left) and benshi Kataoka Ichiro (right). 

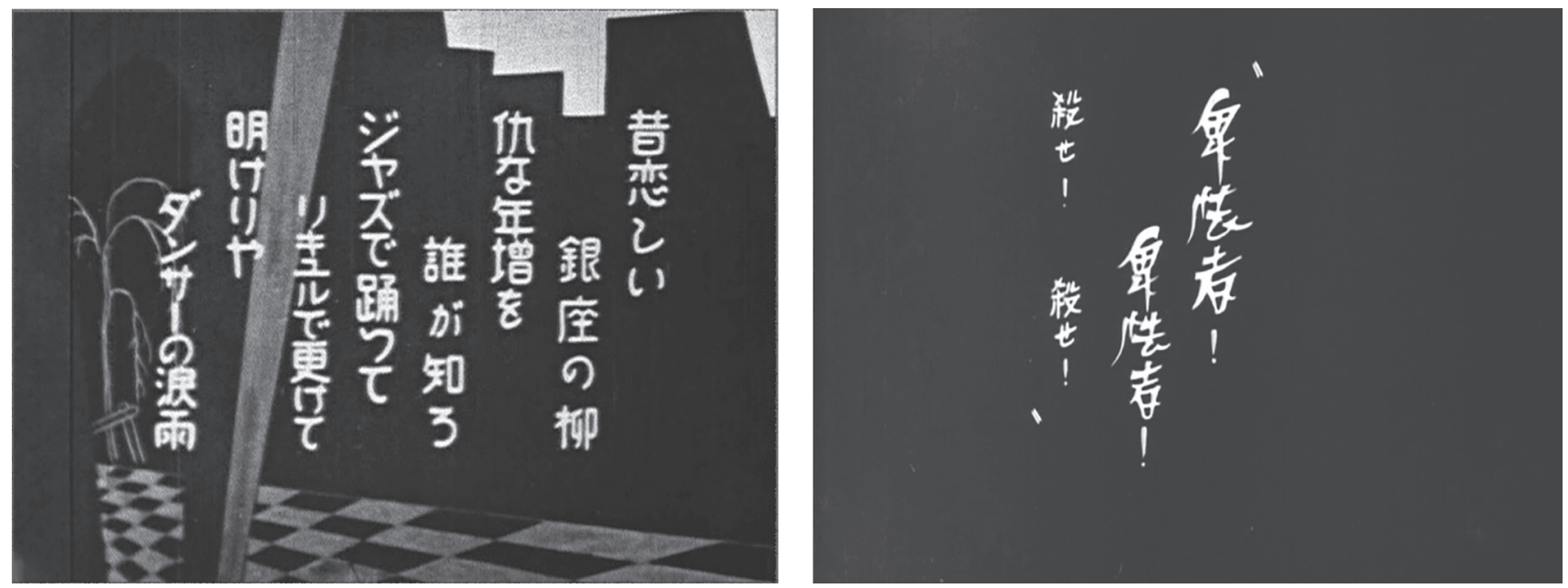

Figure 2.6. Some titles echoed modernist art movements like art deco and expressionism. Here are Mizoguchi Kenji's Tokyo March (Tokyo koshinkyoku, 1929) and Futagawa Buntaro's Orochi (1925).

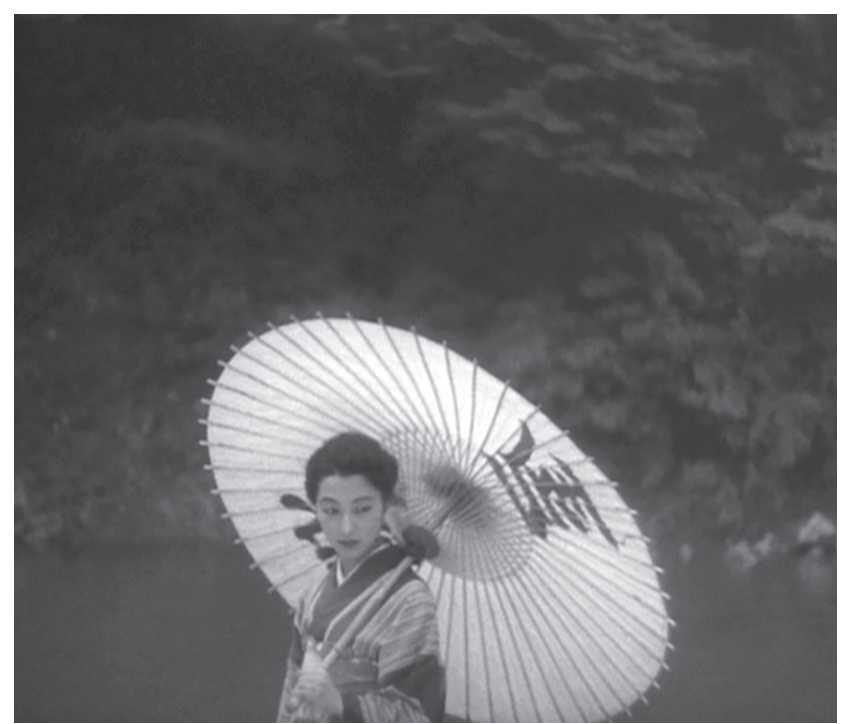

Figure 2.7. The calligraphic parasol in Shimizu Hiroshi's The Masseurs and a Woman (Anma to onna, 1938) indicates the hot springs setting and class. 

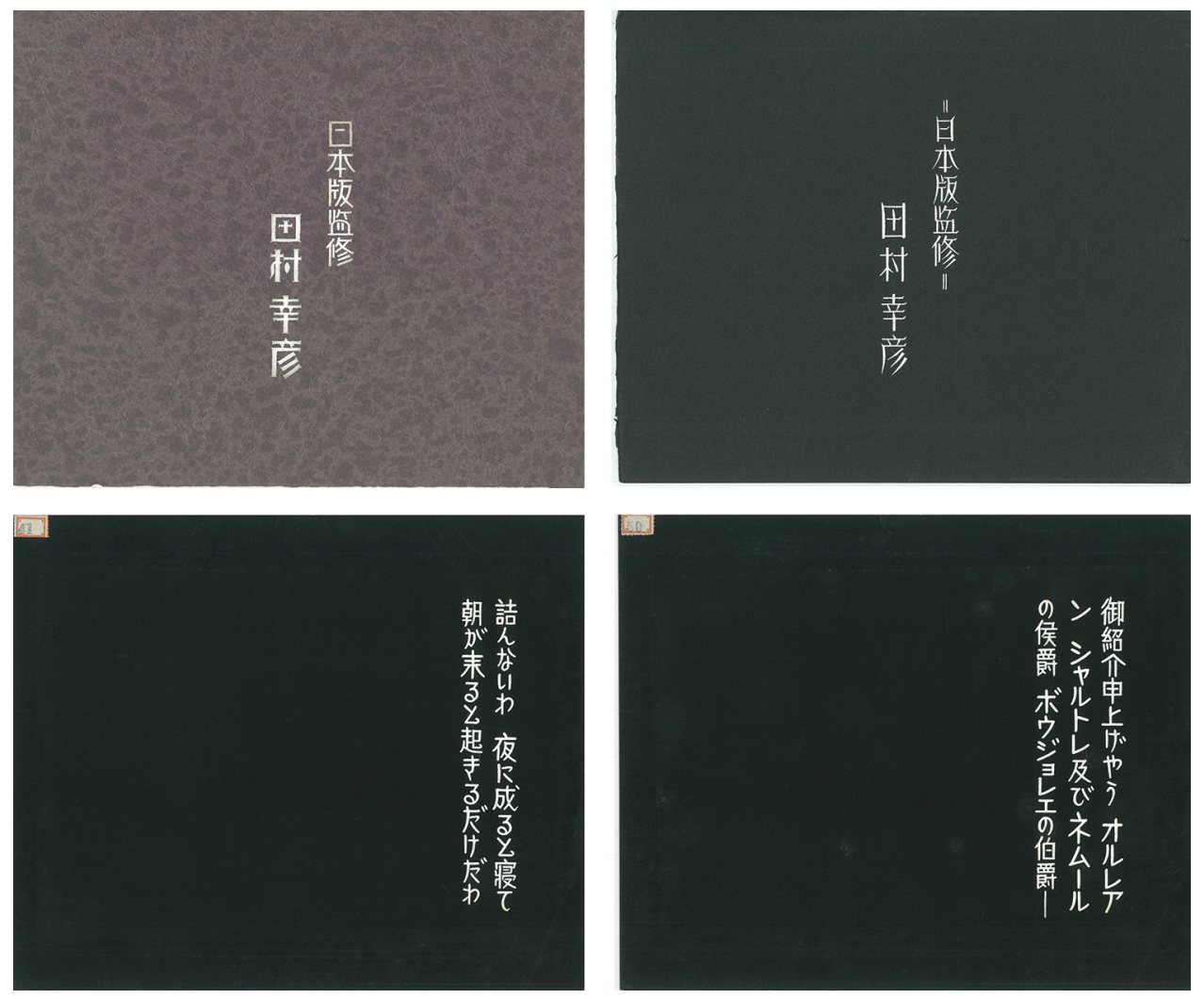

Figure 2.8. In the talkies era, subtitles were brushed on black cards for optical printing. These cards are by Tamura Yukihiko, Japan's first subtitler. Courtesy of the Toyota City Museum of Local History.

was one among many in the history of East Asian cinema (see figs. 4.13 and 4.14).

For this reason, art designers adopted idiosyncratic styles of writing that were marginally accurate in the historical sense, yet easily legible, especially when photographed and projected. While the use of calligraphic props became ever more complex as the medium transformed, these intertitles came to an abrupt end in the 1930 .

\section{Marginalizing Calligraphy}

The silent era practices described above set conventions that have continued to us in the present day, particularly for set design, props, and advertising. However, that cacophony of the written word in silent film culture radically transformed with the coming of sound. At that moment, intertitles disappeared, leaving the non-diegetic written word gracing the beginnings and endings of films. Virtually the only calligraphy left in between was written on props or the walls of sets.

The exception is the foreign film, where the calligraphy of the silent era intertitle was literally marginalized in the form of subtitles. Until the digital age, subtitles were actually brushed (fig. 2.8). An artist would receive the subtitle list. As with the intertitles of the silent era, he or she used kofun to write each subtitle on a black card. These cards were photographed, and upon development resulted in black letters on a transparent film strip. When sandwiched with the film's negative and printed, the black 
words blocked light and, reversed once again, turned into white calligraphy on top of the photochemical image. In the postwar era, they switched to black ink on white cards for acid-etching processes.

In the early subtitling operations of Asia, speed and efficiency were paramount; thus, writing the subtitles was often a collective effort, essentially subjecting the translation process to assembly line-like group work. The ten-minute reels of $35 \mathrm{~mm}$ film were divided among calligraphers to speed the process. If one looks carefully at old prints, the subtitle differences between each calligrapher's hand are sometimes discernible at reel changes. However, they strove mightily for a clean, Helvetica-like uniformity (fig. 2.9). They ignored the aesthetic and ontological contexts of the films, starting from the assumption that the original source meanings may be transported discreetly and non-problematically to the target language.

This was calligraphy that denied it was brushed by hand. Few people realize that these subtitles were calligraphic because their style is so nondescript. It was also remarkably uniform across the region's industries-this despite the language differences.

We may attribute this first to colonialism and also to a globalizing capitalism (the first Asian films to be translated were subtitled in New York). However, a more fundamental reason for their similarity is a common set of values vis-à-vis translation across the East Asian film industries. Just as visual text was being eliminated from the screen in favor of realistic, synched speech, the translator was to remain marginalized-ideally "invisible." ${ }^{1}$ While the beautiful writing of calligraphy loudly announces its presence, the translator's subtitles were discreet by design. They quickly adopted a self-effacing style akin to the nonserifed Helvetica typeface. At the same time, the surface of the foreign film became striated by an invisible grid. This guided the positioning of the subtitle as it was shoved to the edge of the frame. A rare exception were subtitles for songs. Street Angel (Malu tianshi, 1937; fig. 2.10) even used

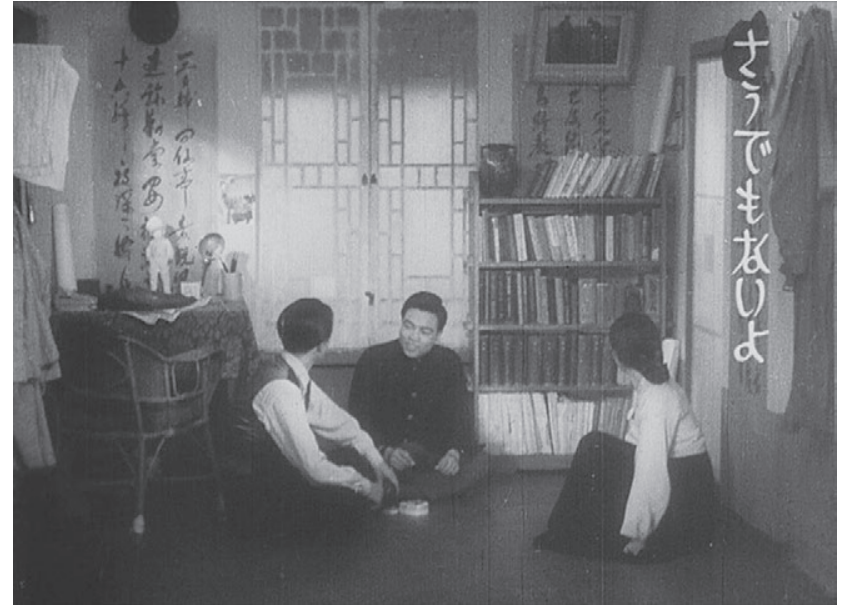

Figure 2.9. Spring of Korean Peninsula (Bando-ui bom, Korea, 1941): Both the scroll (left) and subtitle (right) are brushed, but one is so cursive it is virtually illegible while the other is designed for easy reading. The scroll is in Chinese, suggesting an upper class family, but the subtitle for this Korean film is in Japanese, the language of the colonizer.

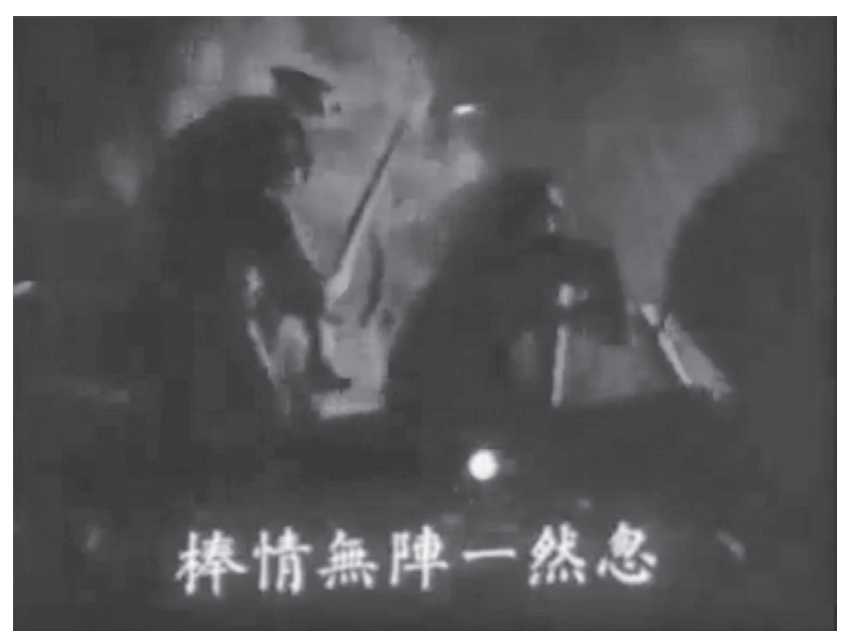

Figure 2.10. Street Angel (Malu tianshi, 1937) includes subtitled songs with a bouncing ball cueing audience participation. 
a bouncing ball, the animation hinting at the role subtitles play in building audience comprehension, their participation in the construction of meaning.

The excess at the heart of the calligraphic was brought under control in the nondescript subtitles locked to the edge. It is hidden in plain sight through nondescript styles that reduce the brushed letter to mere writing. Real calligraphy retreated to the domains of set ornamentation, title and end cards, and paratexts like posters and trailers. But in between the title and end title, calligraphic text virtually disappears.

Put another way, the human inextricably linked to the hand was excised.

\section{The Analog Glyph of the Sound Era}

Within a few years of the appearance of the talkie, the technology and conventions of the sound film took hold. Lettering and typeface became more common for film titles, and calligraphy increasingly became the domain of period films and gangster films. For example, samurai or kung fu films usually used striking calligraphy. When color film became widespread, these titles were almost always a bright bloodred.
In other words, calligraphy was both informed and restricted by generic codes. Genre films are highly conventionalized for various reasons. As studio product, they are manufactured in assembly-line fashion. Film workersincluding calligraphers-operate in lockstep under the guidance of convention. They produce their films faster and for less money. At the same time, the conventions come to determine the expectations of spectators, offering opportunities for creative calligraphy. For example, the generic, bloody spikes of Battles without Valor or Humanity (Jingi naki tatakai, 1973; fig. 2.11) peg this as a yakuza film. The strokes look as if they were drawn by a slashing sword, the ツ radical over the character "battle" 戦 looking like spattering drops of blood. Superimposed over an image of the atomic mushroom cloud, the title promises to offer a violent tale set in what remains of Hiroshima. The calligraphy thus meets generic expectations while viscerally provoking recent memories of total war.

With the rationalization of production in genre cinema, calligraphy becomes an important part of the art department. Over the years, the studios of East Asia accumulated considerable collections of calligraphy. Figure 2.12 reveals an inside view on the props departments at the major studios of East Asia. All of the studios I visited kept bookshelves or cabinets filled with scrolls. Nearby would

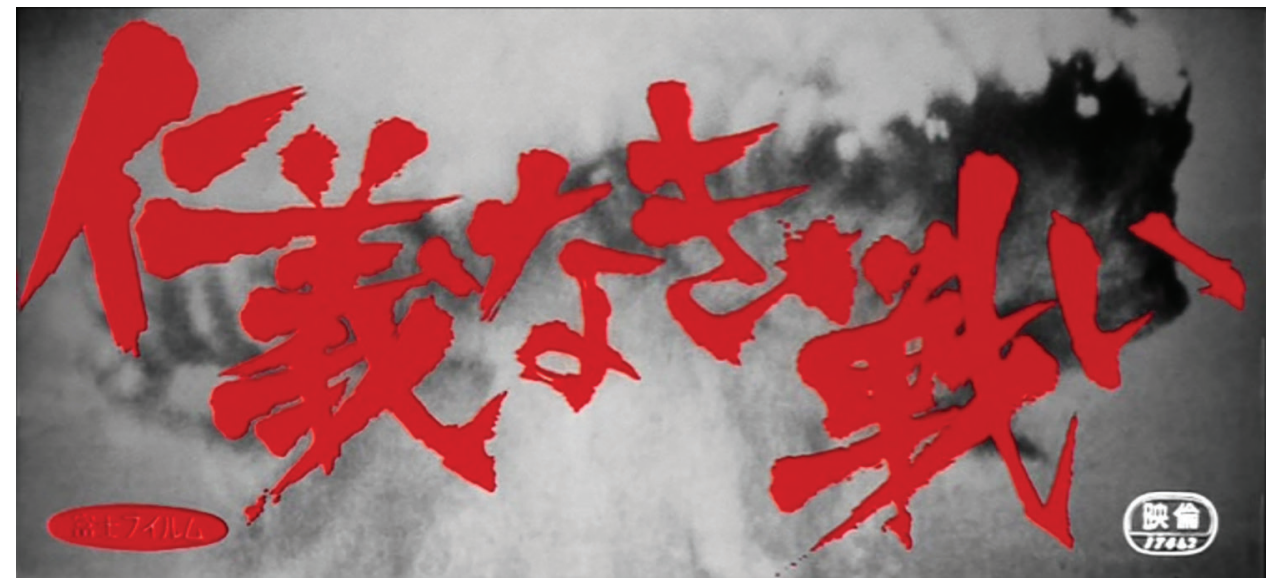

Figure 2.11. Conventionalized calligraphy for the yakuza film evokes slashing blades and drops of blood: Battles without Honor or Humanity (Jingi naki tatakai, 1973). 

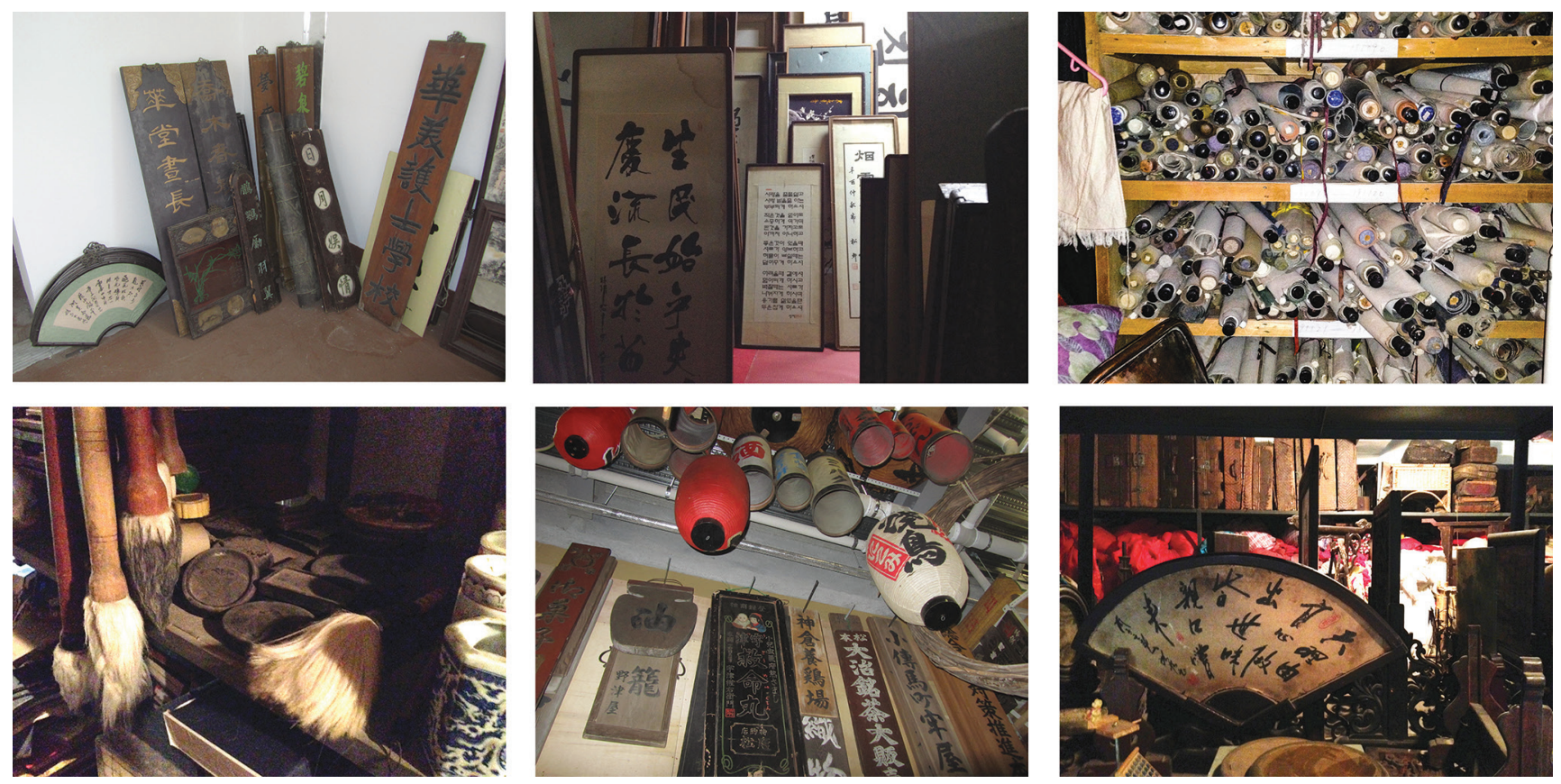

Figure 2.12. Props departments of East Asian cinema; clockwise from upper left: Shanghai, Seoul, Beijing, Seoul, Tokyo, and Beijing.

be a collection of ornamental screens or sliding doors. And there were always a considerable assortment of brushes, brush racks, inkstones, and other paraphernalia associated with the ateliers of calligraphers and the studies of scholars.

Props men and set designers had to become art historians, particularly in the postwar period when calligraphy receded from daily life. They typically had a stable of calligraphers at hand, choosing a certain artist for a particular job. They needed specialized knowledge for dives into the maze-like prop departments, picking period-appropriate props to dress their sets. Most art departments had staff members known for their calligraphy. If the scene called for particularly excellent calligraphy, they would venture off studio grounds and hire a professional. There were actually shops near some studios where talented calligraphers offered their skills, usually for painting signs before the digital era.

By the 1950s, these props departments were well-oiled machines, pumping out props for films at an amazing rate. This was also the stage for a new development in the life of the cinematographic calligraph. Asian cinema was largely restricted to domestic or regional distribution until the 1950s. The exceptions were generally diasporic communities in North and South America.

Then came Rashomon (1950). After Kurosawa's film won the Golden Lion at the Venice International Film Festival, the Japanese studios rushed to produce new films for the Western market. In this situation, the film's success gave the director more and more power over his studio produc- 


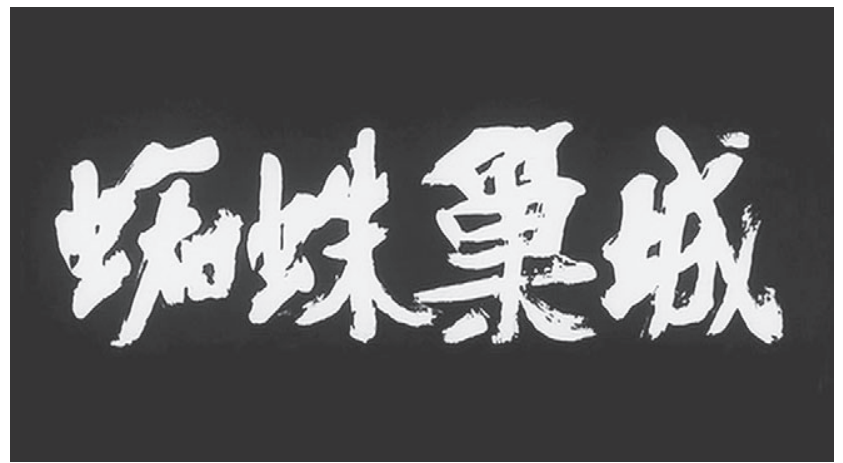

Figure 2.13. Starting with Throne of Blood (Kumo no sujo, lit. Cobweb Castle, Japan, 1957), Kurosawa Akira used famous calligraphers for his films' titles. For this one, calligrapher Kaneko Otei chose a brush with fraying hairs that created stray lines like cobwebs. It announces the film as an eerie ghost story.

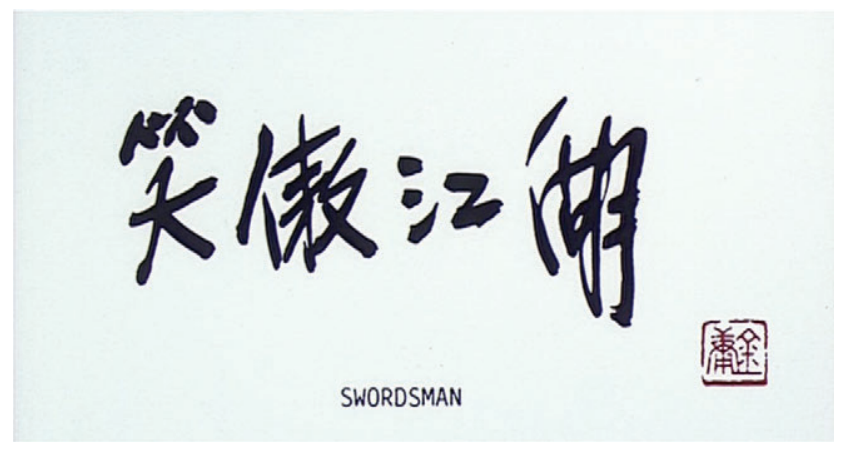

Figure 2.14. King Hu was one of Asia's directors who deeply cared about calligraphy, usually writing his own for his films; for The Swordsman (Xiao ao jiang hu, 1990), he even affixed his seal at the lower right.

tions. Kurosawa was a connoisseur of Japanese traditional arts and, starting with his adaptation of Macbeth, Throne of Blood (Kumo no sujo, 1957; fig. 2.13), he began using famous calligraphers for his titles. Kaneko Otei painted Throne of Blood, whose title literally means "cobweb castle." The stray hairs on Kaneko's brush left delicate strands of ink, evoking spider silk; it is strange, eerie calligraphy that announces itself as a break from the generic samurai flick and a giant step toward the fine arts world, both for cinema and for the letter brushed in light. Kurosawa's other film titles were produced by the most celebrated calligraphers in modern Japan, including Nishikawa Yasushi (High and Low [Tenkoku to jigoku, 1963]), and Imai Ryosetsu (Ran [1985] through Maadadayo [1993]). Ryosetsu also contributed calligraphy for Kurosawa's autobiography, Toad Oil (Gama no Abura, 1984) and the complete collection of his scenarios. ${ }^{2}$

Korean and Chinese cinemas had their counterparts to Kurosawa. Two other names invariably pop up in conversations about film calligraphy: King $\mathrm{Hu}$ (who did his best films in Taiwan) and Korea's Im Kwon-taek. All three directors forged an art film mode within industries dominated by assembly line-like convention. They understood and valued artfulness and empowered their art directors, imposing the highest of standards upon them. King Hu himself was an accomplished calligrapher. Most of the calligraphy in his films was from his own hand (fig. 2.14). His actress Sylvia Chang relates the story of Hu unsuccessfully searching for the perfect prop during the production of Legend of the Mountain (Shanzhong chuanqi, 1979). ${ }^{3}$ The story centers on a monk copying a mysterious sutra that various ghosts and humans covet. Hu wanted purple paper, but simply couldn't find the hue he needed. Soon the cast was searching paper stores all over Asia, and Chang finally found the perfect purple paper in Korea, which is strikingly used in the final film.

A few years after the break represented by Throne of Blood, wave after wave of new cinemas hit world cinema. This phenomenon affected East Asian cinema unevenly. The freedoms of art cinema were most deeply felt in Japan, where the departure from early sound film codes governing the use of calligraphy were keenly felt. I have already described the striking calligraphy of Teshigawara's titles, but this alliance with the fine arts made itself spectacularly visible with Shinoda Masahiro's Double Suicide (Shinju ten 
Figure 2.15. Double Suicide (Shinju ten no Amijima, 1969): the woodblock print-inspired production design of Awazu Kiyoshi envelops characters in a calligraphic space.

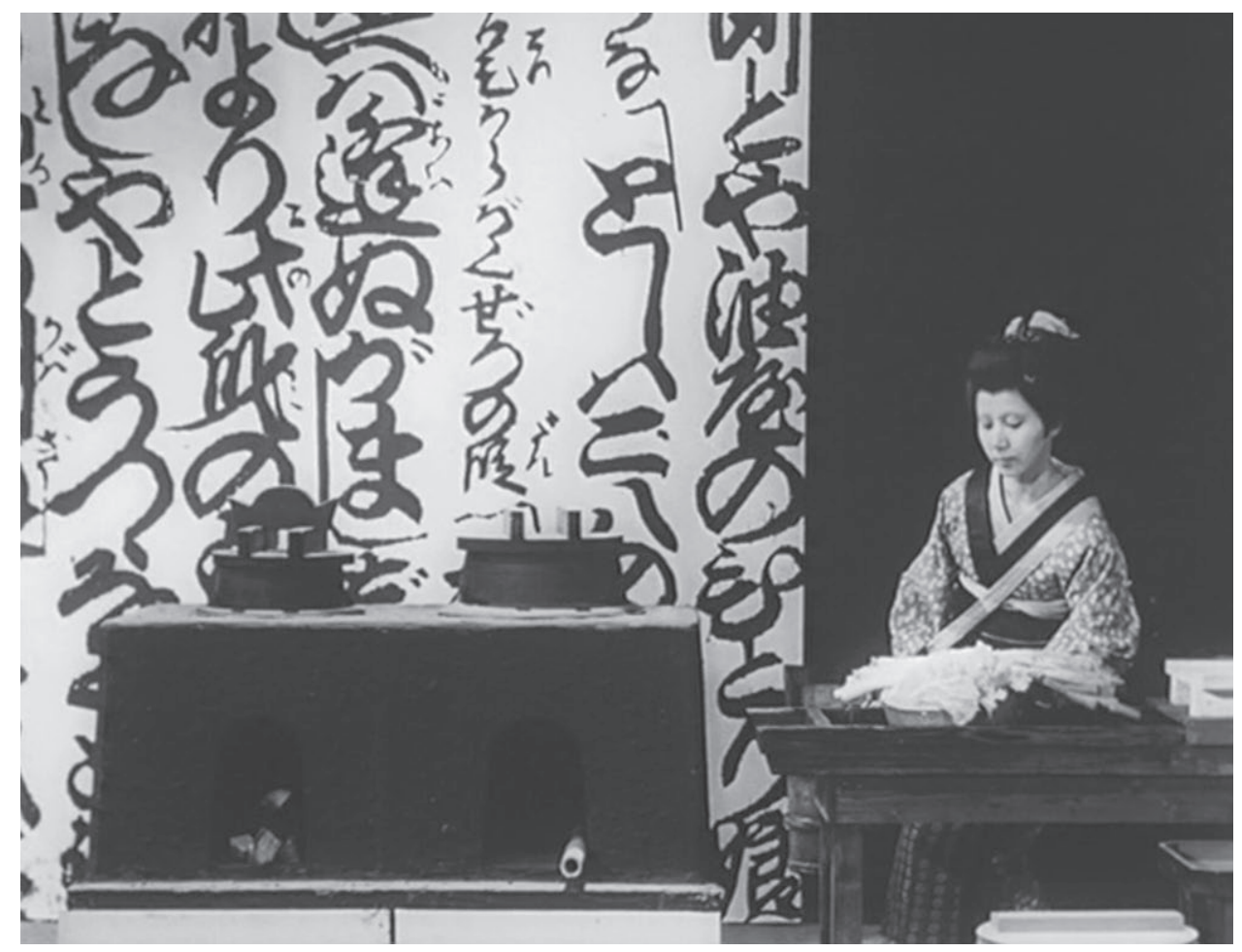

no amijima, 1969; fig. 2.15). Shinoda's film is an adaptation of the bunraku play of the same title. It represents one of the most spectacular uses of calligraphy in film history. Taking a hint from the strong formalism of the puppet theater upon which it was based, Shinoda places his characters in a stylized space that is wall-to-wall calligraphy. These are pages from a book, presumably the scripts being performed within the calligraphic walls. They are duplicated and enlarged from xylographic woodblock prints, script brushed on paper, then pasted onto a board and finally carved out and printed-and then enlarged into wall paper by Awazu Kiyoshi and the film's art department.

The style of the characters marks the setting as the late Tokugawa period (1603-1868) and suggests a merchantclass environment. As we saw, the main styles of calligraphy were created in the centuries before and after the turn of the millennium, and were transmitted through history by closed communities of elites. As literacy spread in medieval Japan, and then particularly among the merchant class of the early modern Tokugawa period, alternative calligraphy styles proliferated. The most widely disseminated of the bunch was the shoren'in style (青蓮院流), which was renamed oie-ryu (御家流) style in the early modern era. ${ }^{4}$ It is a powerful-looking handwriting with minimal difference between thin and thick strokes, and it strove for legibility. Japanese viewers immediately know this is an early modern narrative space.

This independent sector was where filmmakers could forcefully and globally play with calligraphic aesthetics and philosophical possibilities. This was especially true in the realm of the experimental film. One famous film is Jonouchi Motoharu's Gewaltopia Trailer (Gebarutopia yokokuhen, 


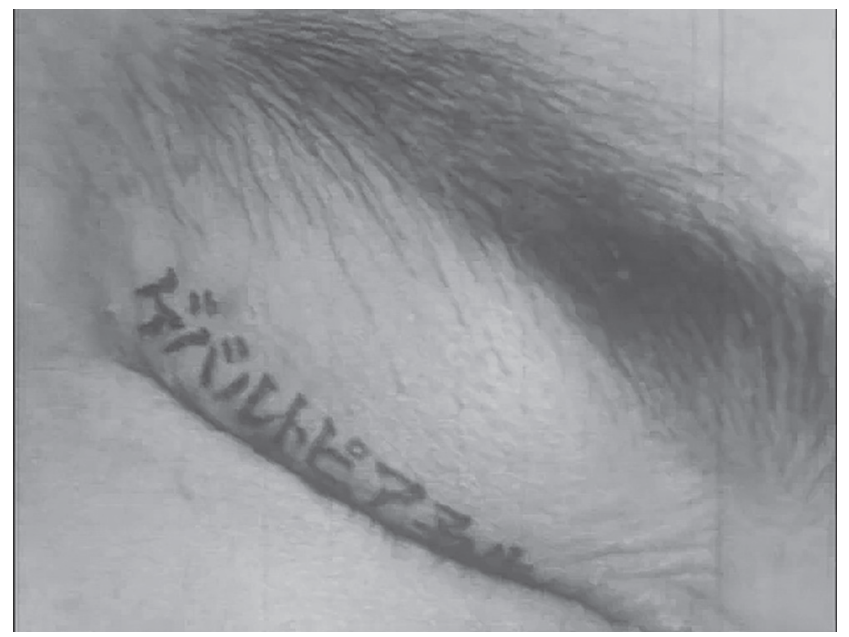

Figure 2.16. The title of Gewaltopia Trailer (Gebarutopia yokokuhen, 1968).

1968). The title is a neologism that could be translated "An Announcement of a Paradise of Violence," so it could be a movie trailer for the end of the world. The film is a heady collage, mixing documentary footage of street protests and teach-ins with violent feature film clips from King Kong (1933), The Golum (1915), and Nosferatu (1922). Interspersed throughout are extreme close-ups of body parts, each of which is decorated with a calligraphic phrase. The film opens with a shot of a closed eye: the title of the film is painted across the lid (fig. 2.16). The eye opens and is replaced by an enormous mushroom cloud. After this, disjointed calligraphic phrases painted on various body parts cut into the montage of images, in the manner of silent film intertitles: "One Day Spring Came to the Earth"; "Toward the Labyrinth of Violence"; and "Aaah, Cruelty." The embodied hand of brush writing was ideal for such an inscription on these fragile body parts embedded in violent imagery.

In contrast, Matsumoto Toshio used writing in a more analytical manner in his Everything Visible Is Empty (Shiki soku ze $k u$, 1975), the other prominent calligraphy film of the Japanese avant-garde. In the early 1970s, Matsumoto was already a major figure in the experimental, documentary, and feature film scenes. Although he was a committed modernist, he wanted to break free of the Western grip on values and progressive history that inevitably positions the European avant-garde and philosophy as the measuring stick for quality. He read many books on Eastern art and philosophy and religion, and found himself entranced with the Heart Sutra (般若心経, circa seventh century). This is one of the most famous Buddhist scriptures, as well as one of the shortest at 266 characters.

The film repeats these characters five times, holding each character 12 frames, or two characters per second. The first time around, Matsumoto uses the scriptural text verbatim, with each character filling the screen and each in one of twelve colors. He managed this with a stunning color chart that essentially served as a script (fig. 2.17). The second time he repeats the sutra, he intercuts icons of body parts associated with the five senses-ear, mouth, eyes, skin - between each character while tinting them with bright primary colors. The third repetition adds iconography having to do with the phenomena (shiki 色) that constitute the objects of the five senses. Blank frames add flicker and a new rhythm to the regular beat of the sutra. He emphasizes images that have to do with human instinct and desire, particularly hunger and sexual desire. In the fourth repetition, the world of phenomena is comprehended and the cosmic imagery indicates a world of meditation grappling with the principles of the cosmos. At the same time, the remaining characters expressed the essence of the Heart Sutra. And in the final repetition, the images drop away, leaving only flashing colors, and the only remaining characters: emptiness/void (空; fig. 2.17) and nothingness (無). Along with the minimalist music by John Cage pupil Ichiyanagi Toshi, the film arrives at a climax designed to make the body tremble as it, even for an instant, comes into contact with the world of shiki soku ze ku. 
One of the things that makes an important contribution to this sense of escalation and climax is the calligraphy. The first two repetitions use photographed woodblock text. As with Double Suicide, these are produced by calligraphers' work on paper being glued backwards to a slab of wood. The sides are carved out, leaving a printing block. The style here is an unadorned standard script. In fact, Matsumoto took them from a pamphlet typically used in temples for chanting the sutra. However, with the turn to sensuality and the iconography of shiki, or the phenomenal world, Matsumoto switches to his own beautiful brushed calligraphy. At one level, it is merely bringing the Buddhist tradition of sutra copying into the cinema. But more importantly, it indicates the intimate connection of calligraphy to the sensual world of the human body, inspiring a kind of synesthesia.

Thus, when the fifth repetition leaves nothing but color and "nothing"/無, the remaining characters revert to the multiply mediated letter of the woodblock.

\section{Bytes and Pieces-Calligraphy and Collage}

The invention of the graphic user interface and the digitization of moving image media offered both new aesthetic possibilities and challenges to artists in the film world. Some effects were invisible to viewers. For example, in the 1990s, hand-brushed subtitles were displaced by laserdriven, digital fonts that mimicked the calligraphic style invented in the 1930s. In fact, one of the early computer subtitling fonts was modeled directly on the script of Sato Hideo, who hand-wrote the subtitles for over 2,500 films, from Dr. Zhivago (1965) to Titanic (1997). ${ }^{5}$ His son, a computer engineer, initially developed the font for The Hurricane (1999) and went on to create versions that mimic both acid-etched and photographic subtitles (fig. 2.18). This is just one of many examples of what came to be called retrosubtitle fonts. The designs are so close no one noticed the

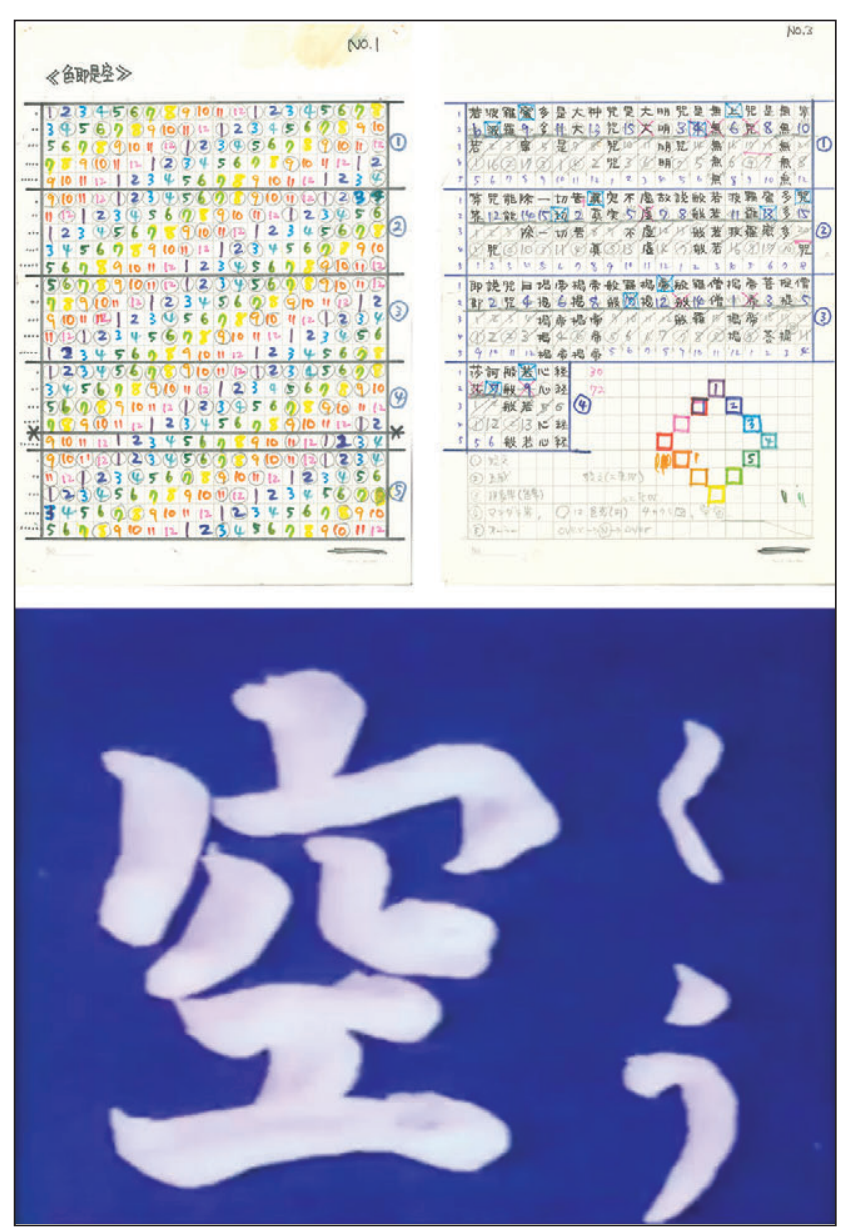

Figure 2.17. Everything Visible Is Empty (Shiki soku zeku, 1975) is an experimental film copying and performing the Heart Sutra. The calligraphy is by director Matsumoto Toshio himself. Matsumoto organized each shot placement using the color-coded score above the image. Courtesy of Matsumoto Toshio.

digitization of foreign subtitles-except the calligraphers who lost their jobs. It took decades for digital technologies to make their mediation in the film world felt by audiences. However, the impact on their relationship to writing was immediate. 


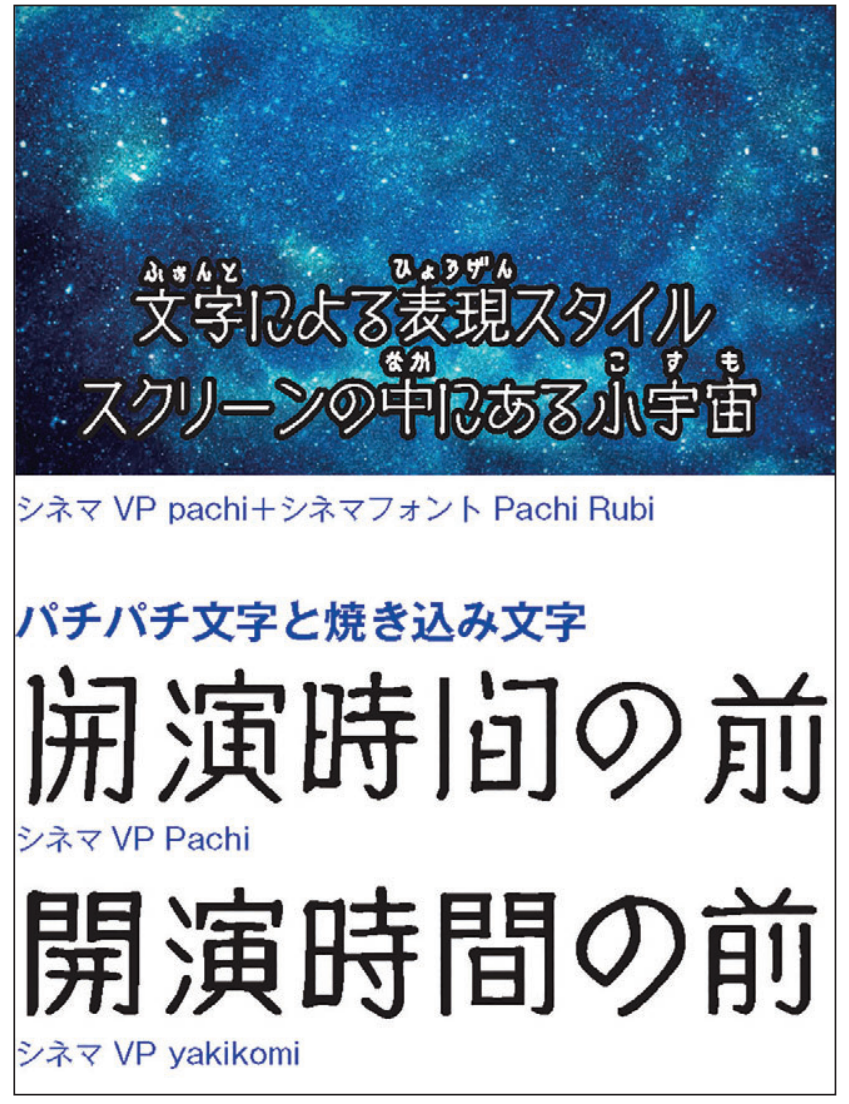

Figure 2.18. When computers displaced brushed subtitling in the 1990s, font designers imitated the calligraphic styles that were established sixty years before (see fig. 2.3). This font is based on the hand of veteran subtitle writer Sato Hideo, who created two versions. VP Pachi imitates the gaps and shortcuts of acid-etched subs; VP Yakikomi models photo-chemical, printed subs. Courtesy of Sato Hideo and Font Alliance Network.

Before the computer revolution, being literate in East Asia meant being able to produce Chinese characters on paper. One of the most profound transformations of the digitization of writing has involved people's relationship to the character. First and foremost, graphic interfaces produce a range of synonymous characters from phonetic input, taking off enormous pressure to remember thousands of characters; writers can input the sound and select the proper character. However, the impact has been far more profound. Lee Dong Kook has pointed to the less obvious changes:

The era of Koreans writing Chinese characters with a pen has past; we are now living in the era of typed hangul. Characters, together with images, are transmitted everywhere at all times. However, these digital characters are disposable and consumed without limits and so are not spiritual or sacred anymore; digital characters are devoid of handwriting's individual self-awareness, personal taste, and smell. The whole paradigm-not only the characters like Chinese and hangul, but also the entire ecosystem of characters that embrace writing tools such as paper, pens, and ink, as well as typing systems-has shifted completely. This phenomenon suggests that, unlike in the past, calligraphy cannot be the dominant genre anymore in the field of character art. $^{6}$

Ironically, it was in Korean cinema, of all places, that calligraphy thrived when digital hit the design world, a moment coinciding with a weakening of the studio system, the rise of independent production, and the simultaneous shift of art design from the studios to independent design shops. These designers were quick to adopt the Macintosh personal computer, like their colleagues around the world. However, the Koreans faced a unique problem.

Unlike Chinese characters and Japanese kana, hangul is an assemblage of lines and circles in a box. They appear simple enough to the untrained eye, but a given vertical or horizontal line, 1-shape or circle possesses a unique size and position, depending on the consonant and vowel elements they are combined with. There is a bewildering array of variations. A decent, well-balanced hangul font requires nearly 12,000 different strokes/positionings. This is no 
problem for calligraphy or handwriting but is a serious challenge to font designers.

Because of this very practical input problem, early computer fonts were proprietary. Only massive corporations like Samsung could afford to create a new font. The design crowd, all early adopters, were frustrated at this paucity of styles, which interfered with their desire to use text powerfully and with individualized flair.

So they all turned to calligraphy. Few designers had formal training, but they discovered that ink and brush enabled astounding possibilities for text design. These thoroughly analog glyphs could easily be scanned and manipulated further. The computer could add color, change size, and even dismantle and reassemble the characters. They called this new form "kaelligeurapi" yet another term to add to shufa, shodo, and seoye. Basically, the digitized, aestheticized and commodified application of seoye, various writers translate it not as "calligraphy" but as "handwriting derived from calligraphy," "brushed fonts," or "typography + illustration." I simply call it and claim it for "calligraphy."

The turning point for kaelligeurapi was the 2000 film Die Bad (Jukgeona hogeun nappeugeona, directed by Ryoo Seung-wan, Korea, 200o). Korean film was swiftly transforming after the blockbusters The Contact (Jeopsok, 1997) and Shiri (Swiri, 1999). Film marketing was decisively shifting to television and the internet, and this called for new talent. At the same time, the personal computer (PC) was affecting the design industry in profound ways. Designers, especially young ones, were now opening up their own shops, so they went from merely working for a paycheck at the film studio to running their own offices and chasing after new clients. ${ }^{8}$ The PC made this possible while giving them a new measure of autonomy. No longer would they so deeply depend on photoengravers and print shops. $^{9}$

Before this, filmmakers never went to designers when they wanted calligraphy. As Kim Zhong-kun explains, "At that time nobody thought they needed to pay for calligraphy. Everyone just bought a drink or a meal for the artists, or at worst went to Chungmuro and got it done at a daepilso," 10 shops where someone good at calligraphy and literature in Chinese characters wrote letters, signboards, or envelopes.

All this changed with the poster for Die Bad in 2000 (fig. 2.19). It features three young men in dynamic poses against a blue-green sky. The figure in the foreground bends over as if hit in the gut. A thin stream of ink-like blood flies from his mouth, a stray stroke from the daggerlike title calligraphy above. The designer was Kim Hye-jin of Kkotsbam. She recalls,

I didn't intend to use calligraphy, but rather bold typography. However, they shot this still photograph for the poster with the concept of dancing. They had the main actors jump at the same time, and it was hard to get them all in the same shot. So it really didn't look good with typography. I tried to express a dancing, acting atmosphere by using disposable chopsticks to preserve that boldness. So the dripping was reflecting the bleeding. But the client didn't like it. Said it was illegible. This was purposeful. People had to stop and try to figure out what it says. They still didn't like it. But after a week, they finally said OK. The public reaction was good, and the director really hated it; but he had to change his mind when the poster became so popular.

The success of the Die Bad poster caught the attention of other designers, who quickly picked up the brush. A prominent early adopter specializing in the practice was Kim Zhong-kun, who called his company Philmuk-phil for "brush" and muk for "ink stick." He established his reputation with Sympathy for Mr. Vengeance (directed by Park 


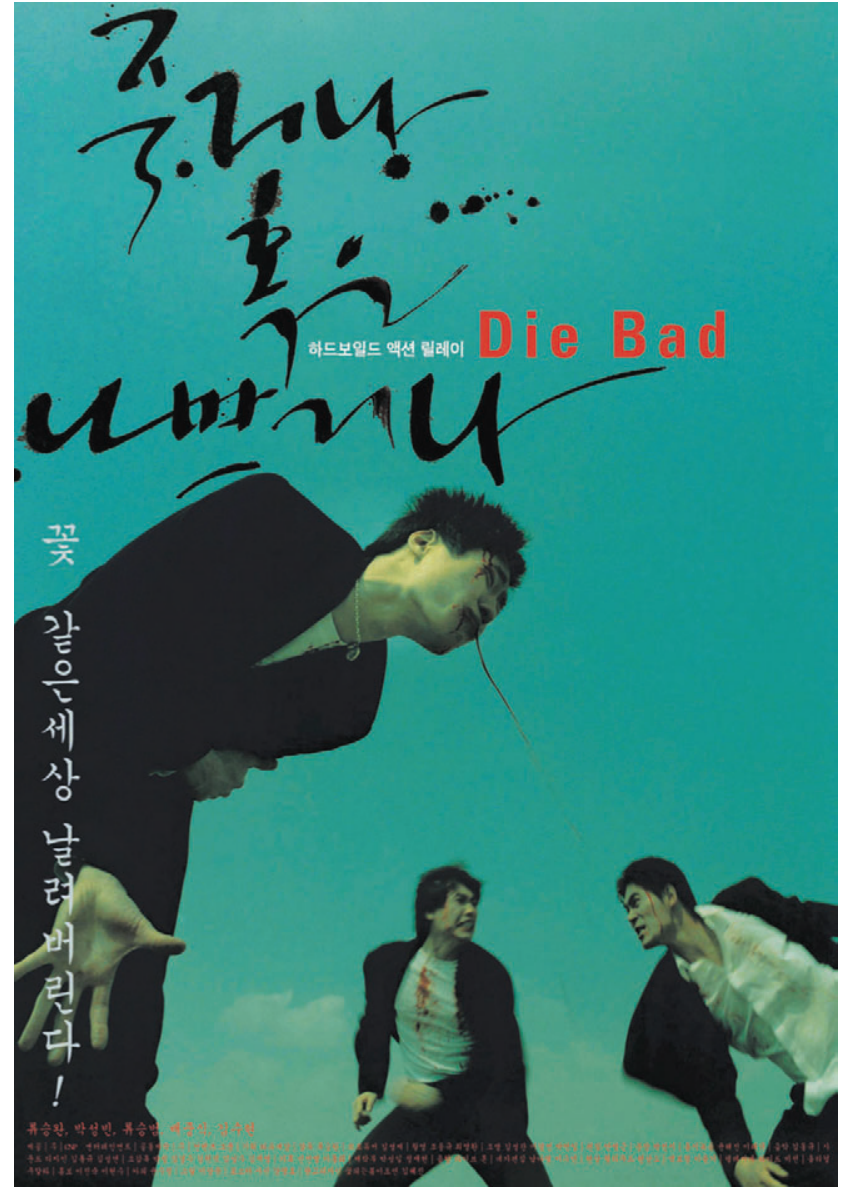

Figure 2.19. Die Bad (Jukgeona hokeun nabbeugeona, 2000); this poster design, with flourishes mimicking the spitting blood, marks a turning point in Korean title design.

Chan-Wook, Boksu neun na ui geot, 2002; fig. 2.20). The poster's image is from the film's ending, where the main character drags a bound man into a pond, dagger in hand. The bold, white title calligraphy ends at the knife's edge with two slashing strokes. As Ban Hyeonjeong wrote at the time, the film helped establish a new prominence for calligraphy in Korean film culture.

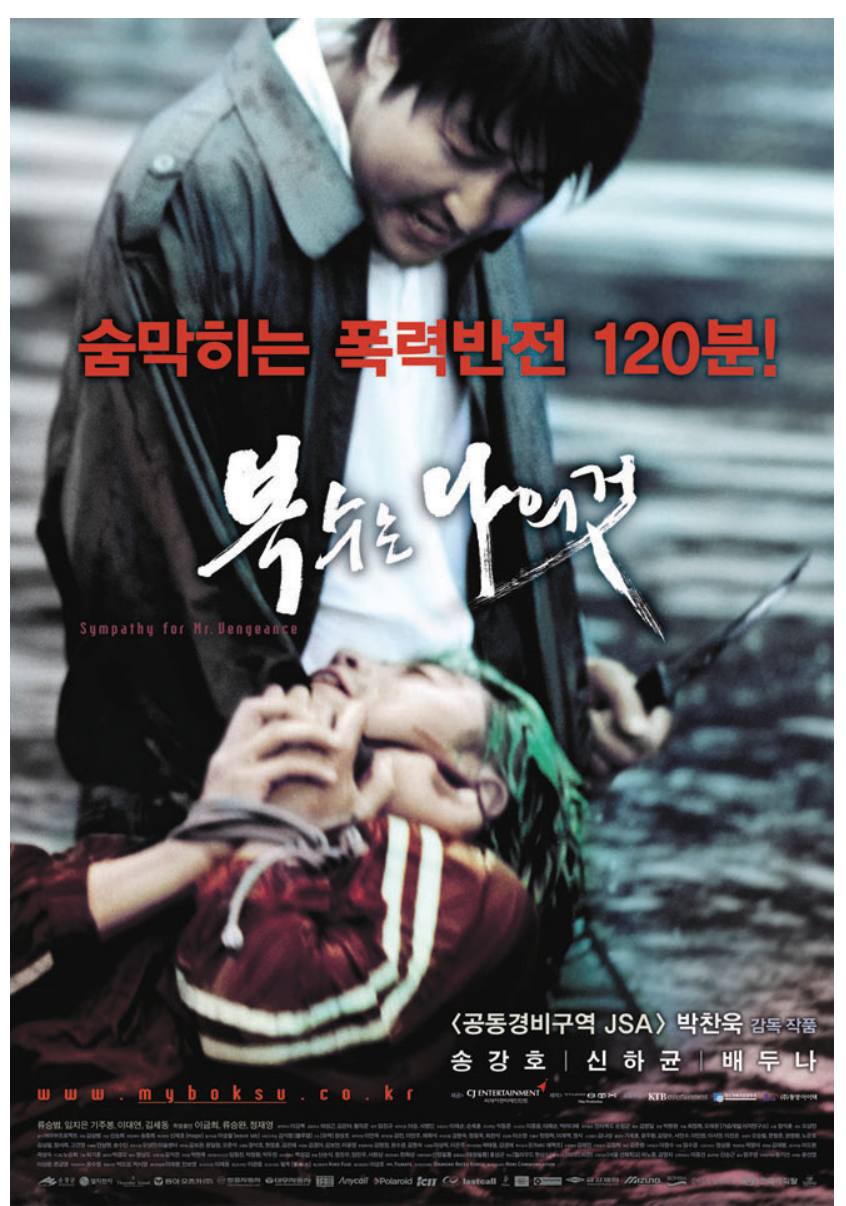

Figure 2.20. Sympathy for Mr. Vengeance (Boksuneun nauigeot, 2002) - the final character's spike was designed to work against the knife in the film's poster. Courtesy of CJ.

An unnamed font is hovering around Chungmuro. It was transferred from No Blood No Tears (Pi do nunmul do eopsi, dir. Ryoo Seung-Wan, 2002) to Sympathy for $M r$. Vengeance and then dominated the homepage of Painted Fire (Chwihwaseon, dir. Im Kwon-Taek, 2002) to surprise the world. The so-called new styled title-logo of brushwriting that is based on the harmony of brush 
Figure 2.21. Choi Ji-Woong modeled his calligraphy for Kim Ki-Duk's Pieta (2012) on a logo for Jane Eyre (1943), which he found on a flyer from his personal collection. Courtesy of Propaganda and Kim Ki-Duk.
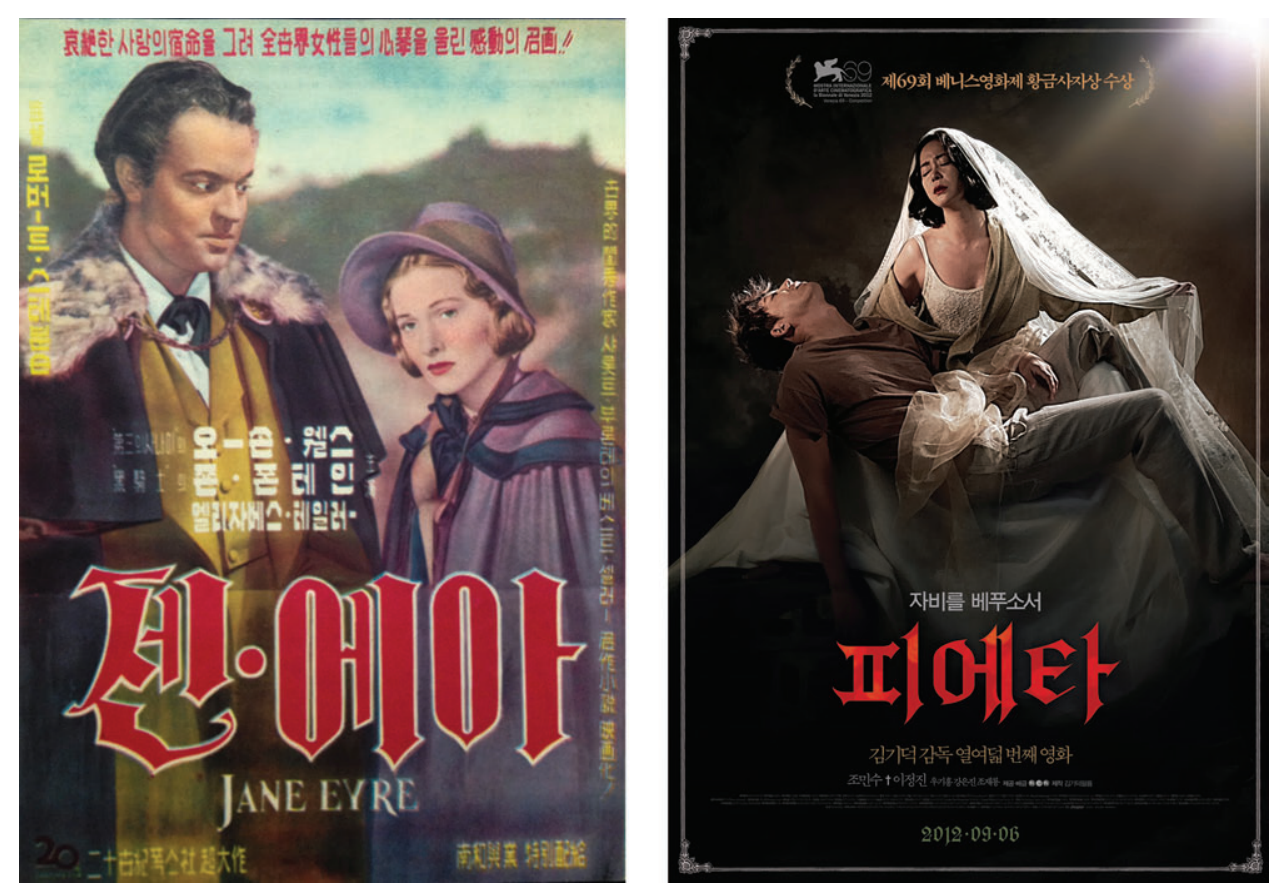

and ink. Chungmuro is now kneeling under this undescribable font. Here lies the world of the new concept of title-logo called kaelligeurapi. ${ }^{11}$

Designers also began using more calligraphy for all manner of publication and product. Depending on the job, they deployed a wide variety of writing tools, from brush to tissue paper to disposable chopsticks. They could adopt radically different protocols for writing. For example, the Korean poster for Kitano Takeshi's Zatoichi (2003) was constructed in Illustrator, piece by piece, each stroke painted separately and then scanned and assembled digitally. Kaelligeurapi can even encompass something like Propaganda's poster for Kim Ki-Duk's Pieta (2012). The French and English advertising used Western calligraphy, but Choi Ji-Woong's original poster rendered hangul in Western cal- ligraphic style. A self-styled historian of film design, Choi modeled his work on a logo for Jane Eyre (1943) on a flyer from his personal collection (fig. 2.21).

Not surprisingly, traditional calligraphers despise kaelligeurapi for the way it prioritizes affect over convention. For their part, designers criticize the inflexibility of the old school and associate their practice with a conservative defense of school and clan prestige. However, Bitnaneum's Park Si-Young insists that "kaelligeurapi is not against traditional seoye, but rather adjacent to Helvetica-like fonts."

To this day, there are relatively few computer fonts for the Korean language. Most are a close variation of the Helvetica-like style Park disdains. This has led to a new practice in the life history of Korean calligraphy. Designers for the film world have forged a new practice: kaelligeurapi fonts. These are Illustrator sheets with all the pos- 
sible strokes necessary for "writing” calligraphy in hangul. Called "callipackages," even designers enjoying no talent for brushwork can piece together works of calligraphy by cutting and pasting strokes from the callipackagecalligraphy as collage.

\section{Collage and Time Travel in Chinese Cinema}

Computing brought a similar, but somewhat hollow and disenchanting development to Chinese language cinema. In Taiwan, I visited the studio of $\mathrm{Chao} \mathrm{Yu}-\mathrm{H}$ siu, a professor of fine arts at Taipei National University of the Arts and a calligrapher of some repute. We sat down at a computer, and he called up the title calligraphy for The Banquet (Ye yan, 2006). He explained the title on the film itself deploys seal script, a variation of cursive grass script with tiny hangul annotations for the Korean poster. I often encountered this kind of command over past styles among professional calligraphers, and it was endlessly impressive; however, nothing prepared for me for his next move. Chao then showed me the poster from the People's Republic of China release and pointed out that it had completely different calligraphy . . . by Song Dynasty poet Su Dongpo (蘇東坡, 1037-1101)!

Assuming that the poster designer merely modeled her calligraphy on the Song master's style, I clearly didn't look adequately impressed. Chao continued, "No, really, this is actually calligraphy by Su Dongpo." He pulled a large folio-sized book from his shelf, a collection of Su Dongpo's work. With little effort, he found the pages he was looking for. Each contained a long text with the very same glyphs as the film title. Chao turned to his computer and called up The Message (Feng sheng, 2009): "These two characters? One is also by Su Dongpo, but the other is from Wang Duo" (王鐸, a Ming Dynasty master calligrapher, 1592-1652). He followed with The Warlords (Touming zhuang, 2007), which features the work of three different calligraphers. By this time, I was confused and amazed, which clearly pleased him. He then showed me the designers' trick.

Consider the title calligraphy for John Wu's Red Cliff 2 (Chi bi Part II: Juezhan tianxia, 2009, fig. 2.22). It uses work by calligraphers such as Jing Shijiang (敬世江, contemporary), Li Liufang (李流芳, 1575-1629), and Yan Zhenqing (顔真卿, 709-785). The latter was an influential Tang Dynasty calligrapher with an unparalleled reputation. He also "contributed" the character 戦 "war," which was preserved and transmitted to us via a stone stele of Yan Zhenqing's "A Poem for General Pei" (Pei jiangjun shi 裴将軍詩, fig. 2.23). One of the most admired calligraphers in history, his work is often used as model for practice (curiously enough, the poem the Red Cliff 2 designer stole from Yan combined a variety of different styles, as one can see in the figure). Another example is the credit sequence for Johnnie To's Drug War (Du zhan, 2012; fig. 2.24), where an animated tour inside the human brain pauses on a blood vessel that turns white, crumbles into pure cocaine, and cascades onto a dark surface to spell the title. The designer has combined the very same Yan Zhenqing character with the calligraphy for "poison" from Yuan Dynasty scholar Zhao Mengfu (趙孟煩, 1254$1322 \mathrm{CE})$.

This practice is possible thanks to the fundamental tool of the digital age, the database. There are presently several calligraphy databases on the internet. Steer your browser to www.9610.com/zidian. Plug in a given character and a selection of samples from the masters of many dynasties appear on the screen.

This tool, combined with Illustrator, makes it possible for designers with no ability to "write" beautifully by constructing montages of masterful calligraphy, and on the cheap. They simply plug each character of a title into the database and select the iterations that strike their fancy. Mixing styles, artists, and eras doesn't matter when design is at stake. 


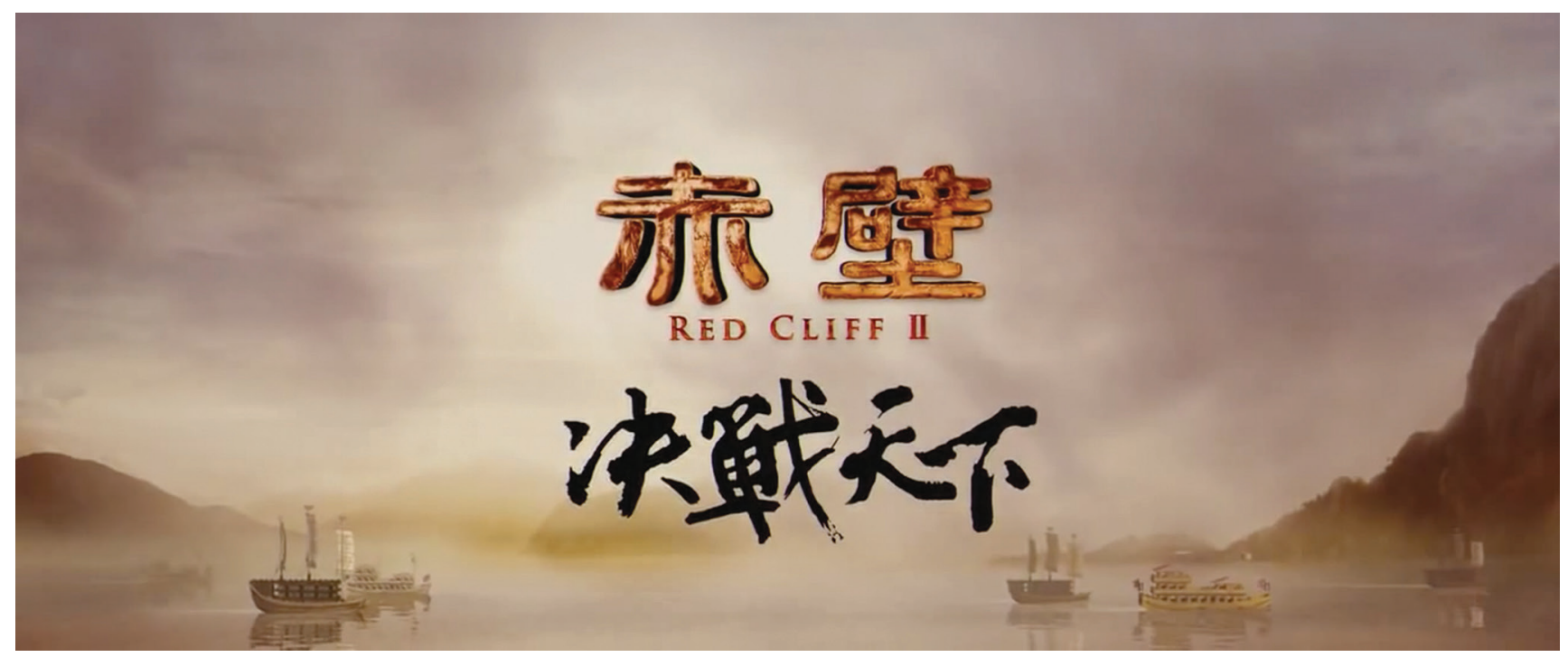

Figure 2.22. Red Cliff 2 (Chi bi Part II: Jue han tian xia, 2009) uses a collage of characters from ancient masters.

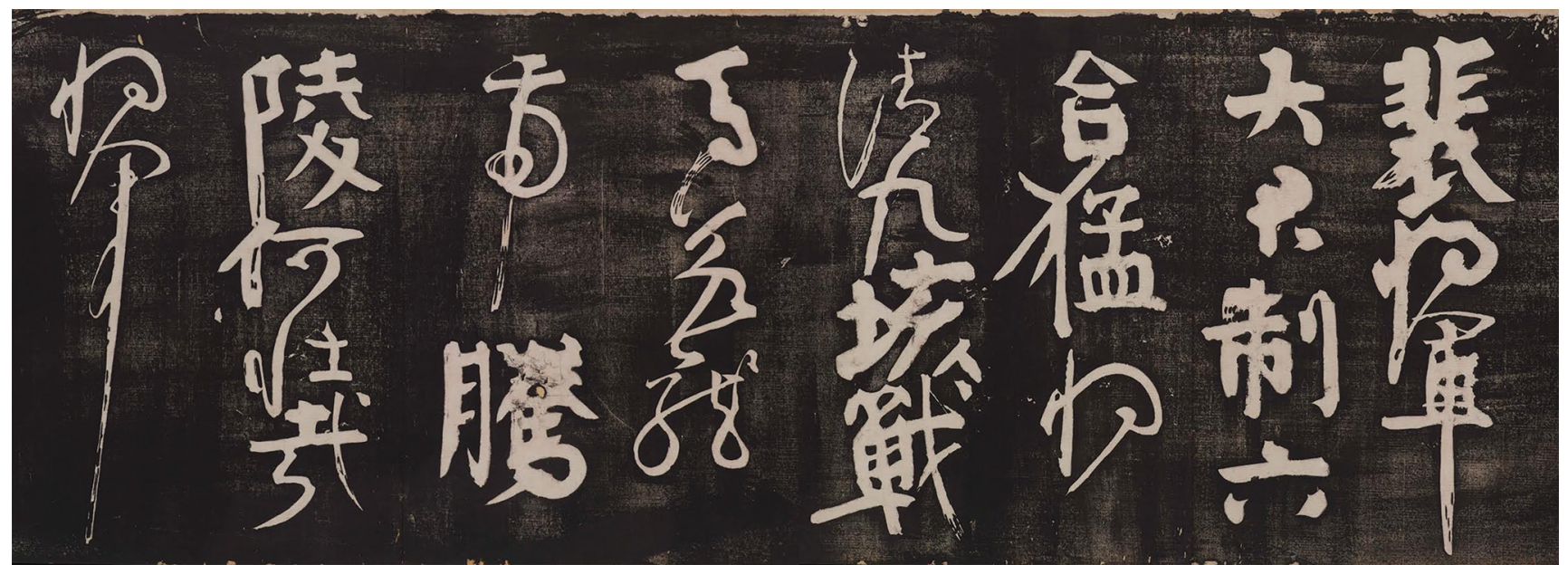

Figure 2.23. Rubbing of a stele with calligraphy for "A Poem for General Pei" by Yan Zenqing's (709-785), one of the most famous calligraphers in history. A designer borrowed the character for "war" (戦; bottom middle) for the logo of Red Cliff 2 (Chi bi Part II: Jue han tian xia, 2009; fig. 2.22). Courtesy of the Taito City Calligraphy Museum. 

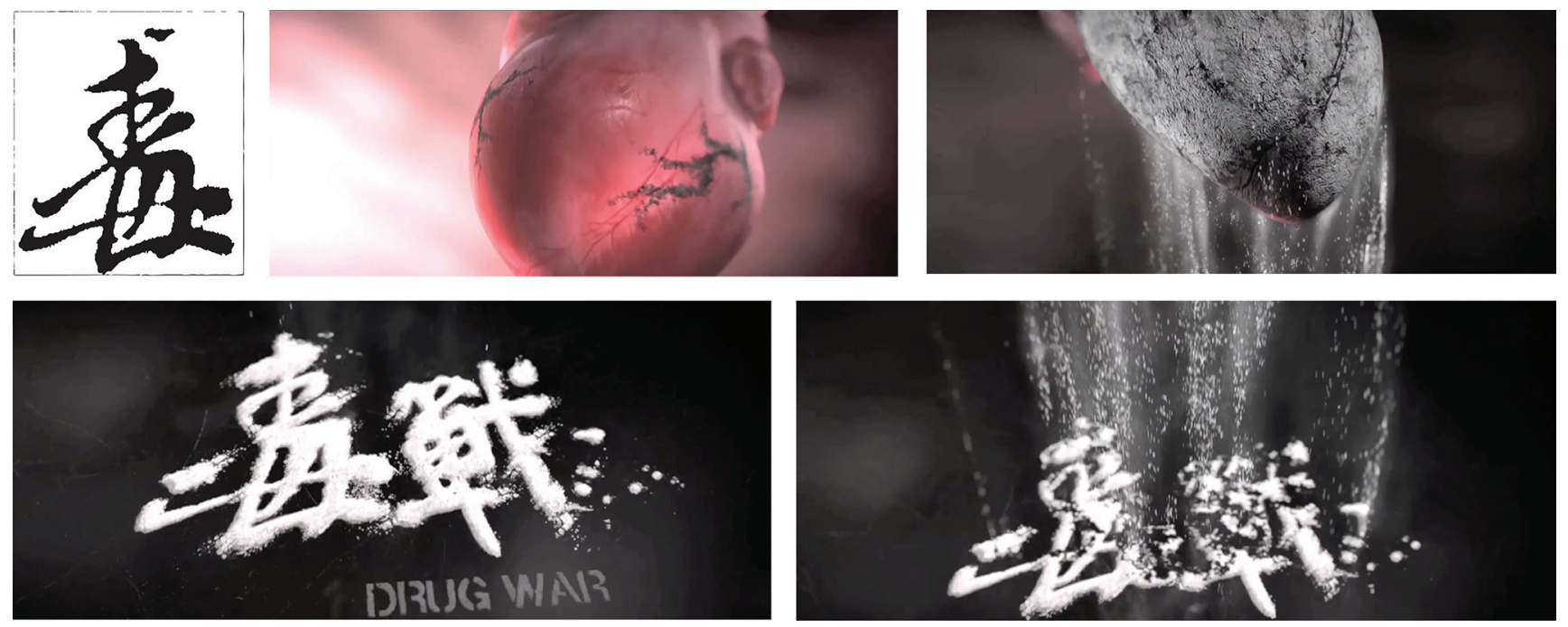

Figure 2.24. Johnny To's Drug War (Du zhan, 2012) combines the same Yan Zenqing character for war with the character for "poison" brushed by Yuan Dynasty scholar and calligrapher Zhao Mengfu (1254-1322; upper left). The animated sequence (clockwise from upper left) shows a blood vessel crystalizing into cocaine and sprinkling into the shape of the film's title.

\section{The Life of Calligraphy}

In the examples above, the influence of the digital is subtle, or even covert. Sometimes it is more obvious. For example, designers will add textures to the character or play with the edges of the strokes. However, Drug War demonstrates one way that digitization is overt and spectacular. That is the animation of the letter. Usually, this means animating the process of inscription-appearing, stroke by stroke, as if by magic. This is mostly the domain of television commercials. My favorite digital experiments, however, are by the Japanese calligrapher Sisyu. She is a young artist that is in strong demand for logos in corporate Japan and major government buildings; she even painted the official calligraphy for the reconstruction of the imperial shrine in Ise in 2013.

Starting in the 2010s, Sisyu has collaborated with the design group teamLab. ${ }^{12} \mathrm{~A}$ typical example is the extremely popular exhibit in 2015 at Tokyo's National Museum of Emerging Science and Innovation, which meant that the vast majority of viewers were children. The exhibits did not disappoint, and for people of any age. In one room, Sisyu's calligraphs drifted down a massive screen showing a natural area. The set of characters are painted in the ancient pictographic forms (a nearby handout translated them into contemporary Japanese style). When the characters dropped into reach, viewers could slap them and they would instantly transform into animated images of the signified meanings. For example, the character for 馬 morphed into a horse that galloped across the screen.

Sisyu and teamLab's most successful collaboration has 

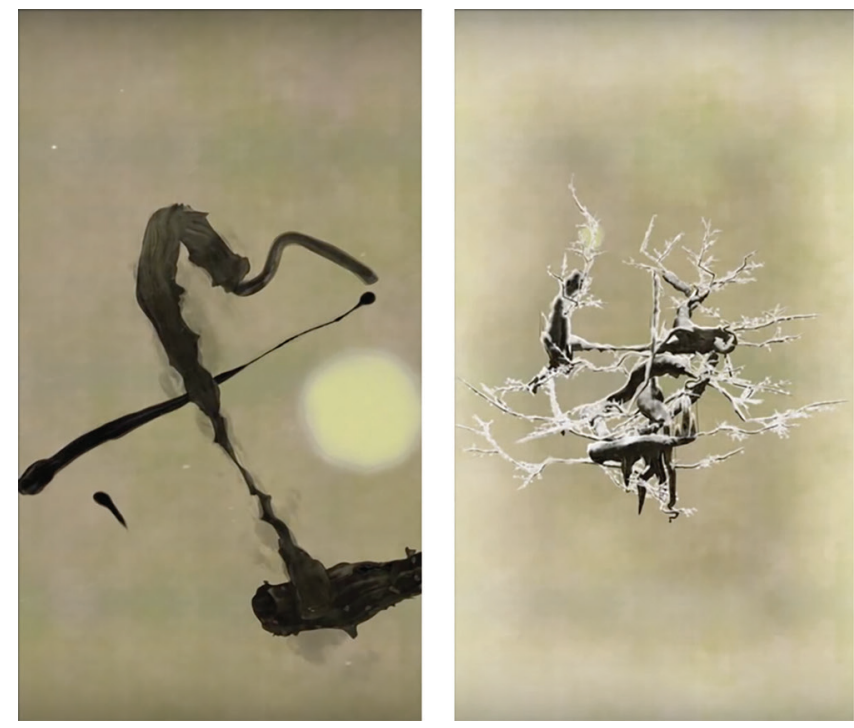

been a 7-minute, looped triptych of three vertical highdefinition television (HDTV) displays called Cold Life (Tsumetai seimei, 2014). Each screen features a digitized and animated character for "life" (生). Each plays a version of the same writing event from Sisyu's hand, each a variation on "life." The beginning of the loop is absolutely stunning. An invisible brush lays luminous ink across a blank screen. The borders of the strokes are permeable and wispy streams of ink float into virtual space (fig. 2.25). Each stroke displays a wire frame, giving them three-dimensionality. Then the calligraphy slowly rotates on a central, vertical axis.

As the invisible hand continues writing in a $3 \mathrm{D}$ space, birds fly into the frame and land-turning the strokes into branches as the character is completed. The rotation slows, and snow falls on these branches of "生”; when the snow melts, a profusion of leaves and flowers appears, growing so thick that the character becomes illegible. The other two
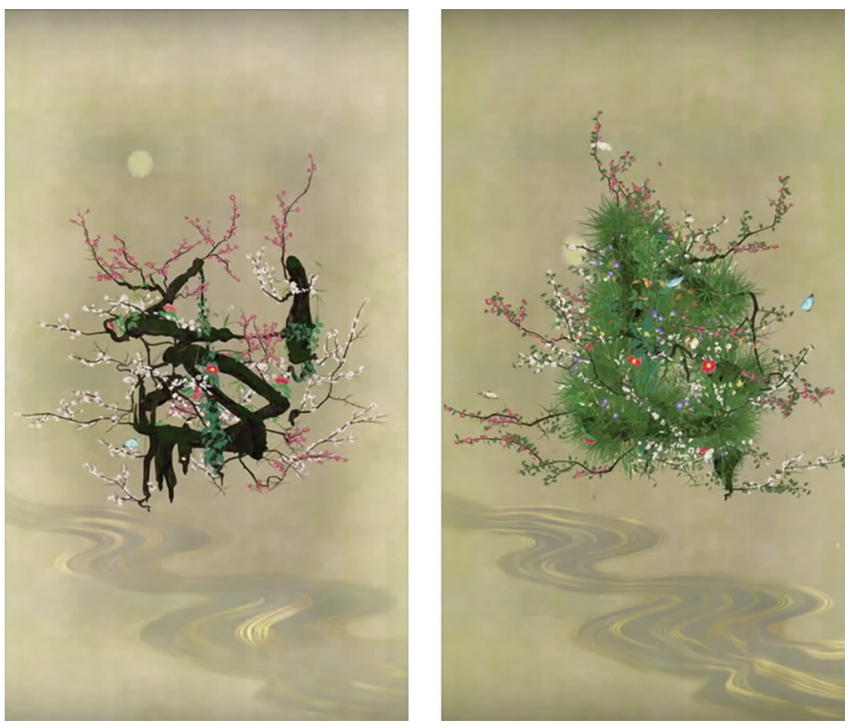

Figure 2.25. An animated calligraph (生) by calligrapher Sisyu and Team Labo appears out of the ether, then slowly spins from winter, through spring to summer.

screens featured different aesthetics, one revealing the wireframe underlying each stroke.

These experiments are breathtaking, but most highly trained, traditional calligraphers would assert they constitute a break in the long history of the art form. Indeed, despite the fact that they shared that same rigorous training, it is likely that traditional calligraphers would look at the fine and innovative work of Sisyu, Kang Byun-in, or Qiu Zhenzhong's televisual Olympics Opening Ceremony, and curtly say, "It's not calligraphy." Indeed, I regularly heard this refrain across Asia. I've also heard the flipside: Takeda Soun, one of the most popular young calligraphers in Japan and a prolific writer on the subject, told me with a mischievous smile, "I've been told that I might be good when I reach 70 years old."

Thus, the digital is only the latest in a series of turning points in the lifestory of East Asian calligraphy. We could 
say this began with the simplification programs across the region, the shock of modernist aesthetics and the vicissitudes of capitalism. The result is a multifold alienation from both millennia of aesthetic rules and regulations and the conception of calligraphy as the capture of intellect and inner emotion. Li Gangtian, formerly head of China's national calligraphy association and a famous seal carver, bitterly complained to me that contemporary practice focuses exclusively on form, especially in fine arts applications (although the forms of digitization above take this to an extreme). He said,

It can be seen as progress in terms of seeing calligraphy as art, but I think it's lost its inner spirit. We are all wondering how to popularize calligraphy while bringing it back to its origins, so the association has created a slogan, “Chinese Calligraphy to the World” (中國書 法走向世界). In film you have genres like the tragedy, and calligraphy for a title could express that genre; the question is whether the calligraphy in film can express the tragedy of the writer.

This is certainly true of Sisyu's moving image experiments with teamLab. Their fascinating studies are fairly simple in the end. Indeed, as the rotation in the three screens slowed and the completed characters began their gentle transformations, many viewers lost interest and moved on to the next spectacle.

However, what I loved about the work was the way it literalized something I heard from many calligraphers in East Asia. They assert that Asian calligraphy is threedimensional. In contrast, the fixed typefaces of printing, along with other forms of handwriting, are strictly limited to two-dimensionality. Brushed Chinese characters, kana and hangul are vivacious. Restlessly vibrating, shimmering on the page, they are animated by the act of writing in all its complexity. Where the callipackage of Korea and the database collages of China are as arid as Helvetica font faces, Sisyu and teamLab are hinting at something I will explore in great detail in the course of this book. That is, the powerful ways in which East Asian calligraphers invest in their characters a certain kind of life一生.

\section{Notes}

1. See Venuti, The Translator's Invisibility: A History of Translation and Nornes, Cinema Babel.

2. Kurosawa Akira, Gama no Abura and Zenshu Kurosawa Akira.

3. She told the story during a $Q$ and A after the film at the 2017 Filmex festival in Tokyo.

4. Koga, Sho no Himitsu, 88; Tsujimoto, "Formation and Growth of an Education-Based Society," 8.

5. "Mojimoji Kafe: Eiga Jimakushi”; Shibuya, "Ningen to Geijutsu."

6. Lee, "Language, Code, and the Future," 22.

7. Choe, "Hanguk yeonghwa poseuteo taiteul rogo ui pyohyeon bangsig e gwanhan yeongu." Since the mid-20oos, there is also a tendency to prefer the Korean word "son geulssi," or handwriting (Kim, "Dijiteol gwa anallogeu ui mannam son geulssi”). Calligrapher Kim Zhong-kun is particularly enthusiastic about this term, along with munja design (文字 design), as the form is a kind of "Dijirogeu" (digital + analog) — a neologism coined by Yi Eoryeong and cited by Kim (see Kim, op. cit.).

8. Bak, Calligraphy ui pyohyeon bangbeop e gwanhan yeongu, 20.

9. Gang, Kaelligeurapi ui seoyejeok dijainseong yeongu: yeonghwa taiteul eul jungsim euro, 20.

10. 代筆所: Jang, "Yeonghwa poseuteo buteo uisang paeteon kkaji, kaelligeurapi ui segye."

11. Ban, "But taiteul logo jeonseong sidae: 'neohui ga kaelligeurapi reul aneunya."

12. Many YouTube examples are on their website: www.teamlab.com 


\section{CH A P T E R 3}

\section{Defining Calligraphy}

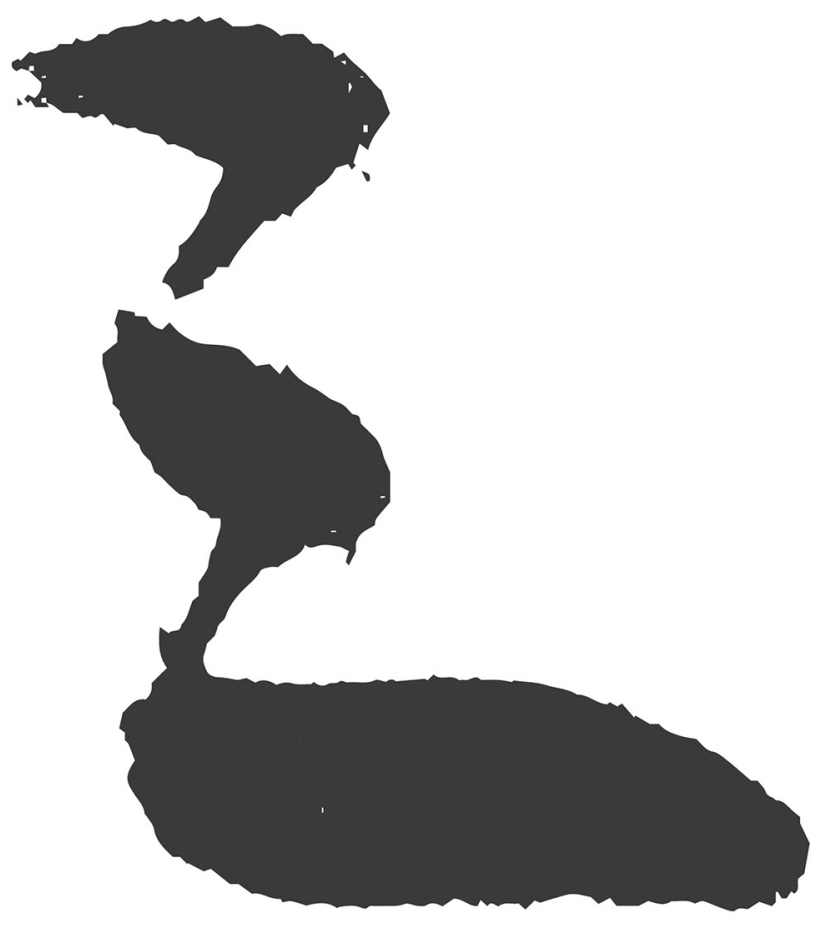

\section{Cool Type}

I have noted that more than one calligrapher or art historian has dismissed this project with a variation of the phrase, "There is no calligraphy in cinema." Obviously, I disagree. However, rather than simply dismiss them in turn, I should explain why they think this way and why I do not. In other words, some attempt at definition is in order. This will require an entire chapter, as it is more complicated than the simple disambiguation "beautiful writing."

Let us begin by looking at what calligraphy is not: typography. Although the typography of cinema is generally rather dull and nondescript, it hardly need be. ${ }^{1}$ Creative typography is truly magical, and, frankly speaking, writings on typography are often more provocative and interesting than those on calligraphy.

Consider the example of director Yoshida Kiju, one of the giants of the Japanese New Wave in the 196os and 1970s. He makes quite fascinating use of calligraphy in a number of his films, so he will pop up in several places in the chapters to come. Interestingly enough, Yoshida takes an unexpected position to talk about typography in cinema. He approaches the topic from a theoretical position he staked out back in the 1960s, especially in essays like "My Theory of Film: A Logic of Self-Negation." It is a stance vis-à-vis artistic practice that values complexity for 
Figure 3.1. Yoshida Kiju prefers the "coolness" of type, which activates spectators and resists their desire for a hint about the movie to come. Clockwise from upper left: Flame and Women (Hono to onna, 1967), Eros Plus Massacre (Erosu purasu gyakusatsu, 1969), The Affair (Joen, 1967), and Good for Nothing (Rokudenashi, 1960).

the ambiguities that force spectators to be creative participants in the making of meaning.

It is for this reason that Yoshida prefers typography for his titles. He values its "coolness," which leaves the spectator open to all possibilities at this opening moment of the film. Indeed, while a number of his films have quite striking calligraphy for their title cards, most feature "cool type" (fig. 3.1). Heroic Purgatory (Rengoku eroika, 1970), A Story Written on Water (Mizu de kakareta monogatari, 1965), Farewell to the Summer Light (Saraba natsu no hikari, 1968), and Eros Plus Massacre (Erosu purasu gyakusatsu, 1969) all have white, non-serifed typeface on black backgrounds. Good for Nothing (Rokudenashi, 1960), Bitter End of a Sweet Night (Amai yoru no hate, 1961), The Affair (Joen, 1967), and Flame and Women (Hono to onna, 1967) have black type on white or grey backgrounds. His adaption of Wuthering Heights (Arashi no oka, 1988) uses bold, serifed typeface with fuzzy edges, as if it were printed on porous paper. However, in this and all the other examples, the restraint of the written word is in utter contrast to the extravagantly obtuse compositions of the cinematography and the challenging complexity of the narratives.

Thanks to the cool type of these titles, they signal nothing about their films' content. This puts the specta- 
tors on an uneven footing, forcing them to engage the narrative with minimal handholding and maximal creativity. In other words, even nondescript typography can be an aesthetic, even highly theorized, choice. (However, it is likely that few of the films using typeface for their titles are backed by such thoughtfulness.)

For Yoshida, the "danger of calligraphy" is that it positions spectators. There is an excess of expression. As Tom Lamarre writes, the discipline of calligraphy can "elicit participation, shape subjects, and induct perception," so it is about "interpellation, subjectification, and embodiment." Actually, this is ultimately what makes calligraphy so powerfully fascinating.

Of course, this contrasting of typeface and calligraphy need not be so stark. Steve Jobs, for one, linked the two. He attributed the Macintosh computer's emphasis on powerful font tools to a calligraphy class he took shortly before producing the first Mac prototypes: "I decided to take a calligraphy class to learn how to do this. I learned about serif and sanserif typefaces, about varying the amount of space between various letter combinations, about what makes great typography great. It was beautiful, historical, artistically subtle in a way science can't capture, and I found it fascinating." ${ }^{4}$

We should also note hybrids that trouble the difference between the typed and brushed word. One is "lettering." This is writing that appears calligraphic at first glance. It is typically used for titles and posters or other forms of public relations (PR) (for example, the covers in figs. 2.3 and 6.1). Decorative and large in scale, it is usually connected to specific genres (like the epic or gangster film) or aesthetics (like art deco). Designers produce it by initially drawing an outline, then filling it in. This began back in the silent era, particularly for art-deco titles. However, its most prominent use was for the hand-painted billboards decorating theaters across Asia, which continued well into the late-twentieth century. This was often an analogue method for reproducing a brushed, calligraphic original (and the photographic screenscape) on a grand scale. These ranged from billboards several stories high adorning the movie places of the urban centers to settings at the smallest of scales; for example, according to experimental documentary filmmaker and film poster designer Wang Wo, his career began in a factory where his assignment was to paint large posters for the workers' film screenings. ${ }^{5}$ Not surprisingly, hand-drawn lettering was all but displaced by the computer, for both logos and for billboards. At the time of this writing, there are only a few theaters left that actually use painters; they have all been replaced by digital printers.

Lettering and typography are useful foils for foregrounding the complex aesthetics and ontology of East Asian calligraphy. The rest of this chapter will start with the rules and standards of conventional approaches that set calligraphy apart from other forms of writing, then account for the ways in which cinematic calligraphy, the shimmering letter, breaks those rules in ways that are unforgivable for many calligraphers who have devoted their lives to learning the rule-bound conventions.

\section{Four Treasures}

Conventional definitions of calligraphy invariably begin with the "Four Treasures" (文房四寶), which date back to ancient China and are shared to the present day with Japan and Korea. They are ink, brush, paper, and inkstone. The centrality of the accoutrements of writing is also felt in other parts of the world. Michel Chion writes, "The bottle of ink, so important in Victor Hugo's imaginary, is 'this black sun whence night gleans forth,' which seem already to contain the work, the book to be written. The inkwell ennobled and ritualized the act of writing." The "treasures" of calligraphy are more than suggestive of wonders of the written word, because the strict definition of East Asian calligraphy is predicated on the deployment of these 
tools. From this material level, the artist brings to bear a set of writing conventions that determine the movement of his or her body. The replication of, or departure from, those stylistic conventions is judged by a connoisseurship inflected by the accumulated wisdom of the ages and a lifetime of training-as well as less lofty factors like nationalism and politics. None of this is straightforward in the world of the cinematic calligraph.

For those immersed in this tradition, it is likely they associate calligraphy exclusively with ink and brush. Ink is essentially carbon soot in stick form. It is liquified by scraping the hard stick in a small puddle of water. The properties of both the water and the ink stick affect the final calligraphy, although to be frank the effects of one choice over another are hard to detect. Brushes, on the other hand, make a dramatic difference. Shafts are made of bamboo or other woods but sometimes precious materials like ivory or gold as well. The hairs of the brush are from any number of animals and come in a wide variety of shapes, sizes, tip lengths, and percentages of different animal hairs. All of this affects the work of the artist.

Most cinema calligraphy uses the traditional ink and brush, which is then photographed or scanned. However, diegetic calligraphy offers up some unusual alternatives. One occasional substitute for ink is human blood. The most famous examples are the movie versions of the Abe Sada story. In movie adaptations, as in real life, Sada kills her lover during sex, castrates him and paints love notes on his body in his blood with her finger: "Sada, Kichi, Just the two of us." The most famous films are Oshima Nagisa's In the Realm of the Senses (Ai no koriida, 1976) and the Nikkatsu Roman Porno version A Woman Named Abe Sada (Jitsuroku Abe Sada, 1975). In the latter, she also carves her name into his skin (fig. 3.2). These messages to and from the dead link people through discourse and bodily movements and fluids. This may be the most provocative and intimate of the connections between calligraphic writing to the human body - and to past times, places, and events.

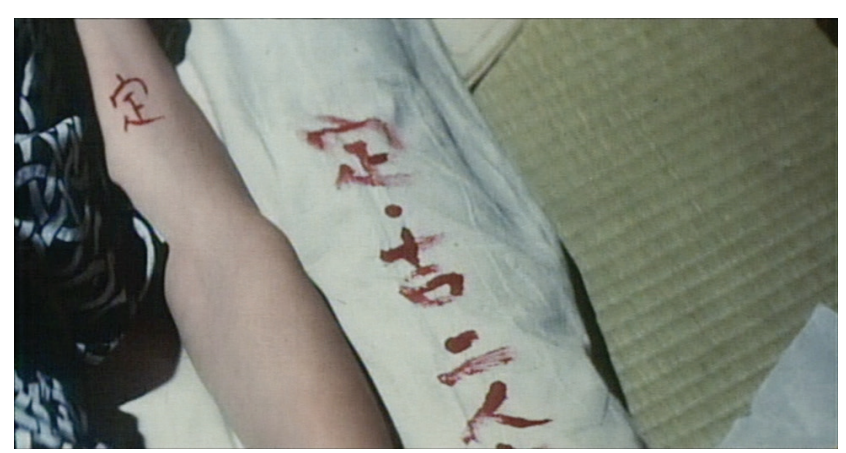

Figure 3.2. Based on an actual incident, the main character of $A$ Woman Named Abe Sada (Jitsuroku Abe Sada, 1975) castrates her lover, paints their names on their futon with a finger dipped in his blood ("Sada, Kichi Alone"), then carves her name into his arm.

For titles and poster art, there are film world substitutes for the brush that I am fully prepared to claim for the cinematic calligraph. We have already seen Brother (fig. o.5) and Die Bad (fig. 2.19) make effective use of disposable chopsticks for their titles. A favorite example for an alternative to the traditional brush is Kim Hye-jin's calligraphy for Failan (2001; fig. 3.3). This Korean melodrama is an adaptation of the Japanese short story Love Letter (1996), and the title is the main character's name. Each stroke has a wispy, soft quality enhanced by the ink's absorption by the paper. Designer Kim accomplished the effect by using Kleenex instead of a brush. As Ban writes, the tissue paper created "the lingering imagery of both firmness and softness of the female name Failan." At the same time, this could only be accomplished with highly absorbent paperthe third treasure.

Most calligraphy sits, restlessly as it were, on a sheet of rice paper. The quality and structure of the paper affects the absorption of ink, so serious calligraphers choose their paper with care. At the atelier of Itomi Keinan, the artist responsible for the famous title calligraphy of the Hissatsu 


\section{offoriter}

Figure 3.3. The wispy characters of Failan (2001) were achieved by using tissue paper rather than brush, matching the melodrama of the weepie.

shigotonin franchise (fig. o.3), I was led into a room filled to the rafters with paper. Itomi had paper acquired over the course of his entire career. Much of it was from China, which he preferred over paper from other parts of Asia. It had different shades of white, different textures, different thicknesses. Interestingly, much of it was old; the older the better, he explained, and proudly pointed to a shelf with blank Japanese paper from the Tokugawa Era (1603-1868).

The properties of paper determine the character of the border between stroke and background, whether it is a soft or hard edge. The strokes of, for example, yakuza gangster films in Japan tend to use hard edges (fig. 2.11). By way of contrast, the title of Byun Young-joo's melodramatic Ardor
(Mirae, 2002; fig. 3.4) is quite different. The poster features a medium shot of two lovers, their sweaty bodies thoroughly entwined. The calligraphy of the title mimics the luscious curves of the bodies and the backdrop of grass. The artist, Oh Seunguk, used extremely absorbent paper. He explained, "The blotting expresses the erotic code of the film. I focused on the fact that the film is not just a vulgar eros but a sentimental eros. I expressed this in the manner of an oriental ink painting."

There are also alternatives to the third treasure, paper. One that has already come up is skin. Aside from the Abe Sada films, the most famous example of this comes from the Kobayashi Masaki film Kwaidan (1964), a famous ghost 


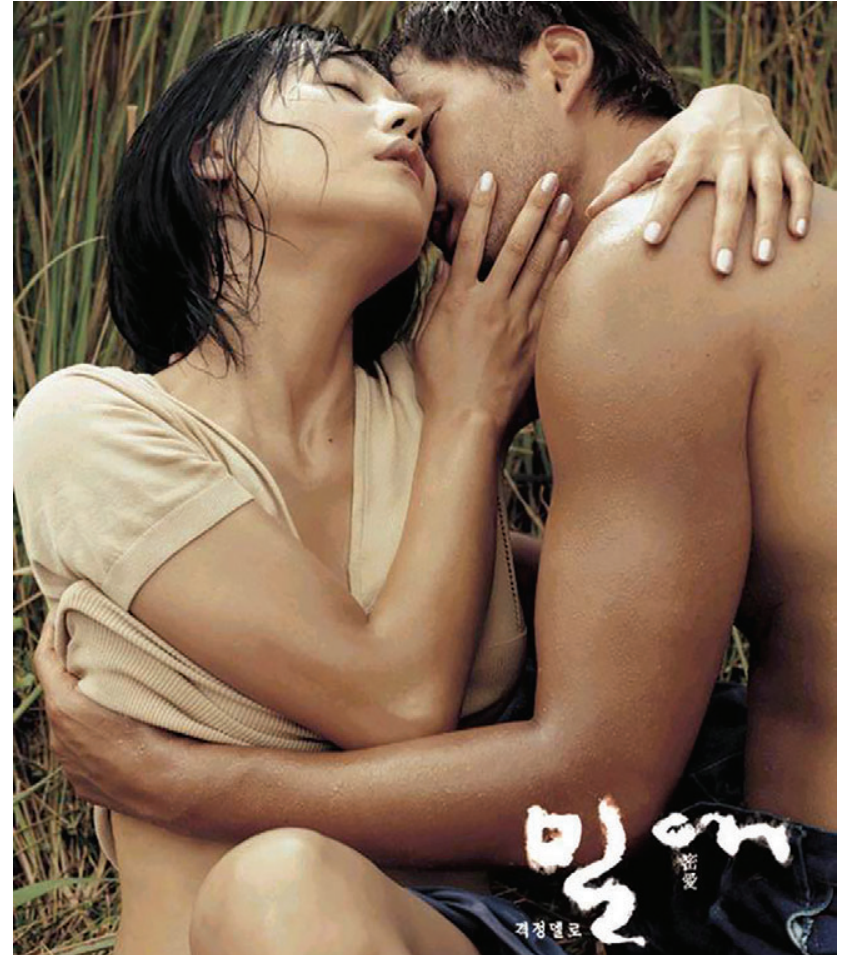

Figure 3.4. For Byun Young-ju's Ardor (Mil-ae, 2002), Oh Seungwook's calligraphy mimics the sensuous curves of the lover's bodies. story in which a monk protects himself by covering his body with the Heart Sutra (fig. 3.5). There are other famous instances of such apotropaic spells, notably Mizoguchi Kenji's Ugetsu (Ugetsu monogatari, 1953) and Hanging Tree (Janyeomok, 1985), and Brave Archer (She diao yingxiong zhuan, 1977). In the latter, the character is actually flayed to steal the writing, and the skin as paper metaphor is grotesquely literalized.

If a surface accepts ink or paint, it has hosted calligraphs recorded on film. Oftentimes it is a traditional object, such as silk, lanterns, scroll paintings, sliding doors, fans, or couplets decorating door frames. However, consider the clever variation presented by Jia Zhangke's Platform (Zhantai, 200o, fig. 3.6). Brushed characters on panes of glass in a hospital doorway exhort visitors not to fight or cause trouble. Strictly speaking, this is not calligraphy because the words were brushed with red paint applied to glass. However, these are not only calligraphic but are thoroughly cinematized by Jia. He puts one actor behind one of the windows, giving the frame within a frame the appearance of a poster. And the composition is symmetrical, perfectly placing the vertical calligraphy on

Figure 3.5. Painting on skin, rather than paper, is usually connected to magic spells (clockwise from upper left): Kwaidan (1964), Ugetsu Monogatari (1953), Brave Archer (She diao yingxiong chuan, 1977), and Hanging Tree (Janyeomog, 1985).
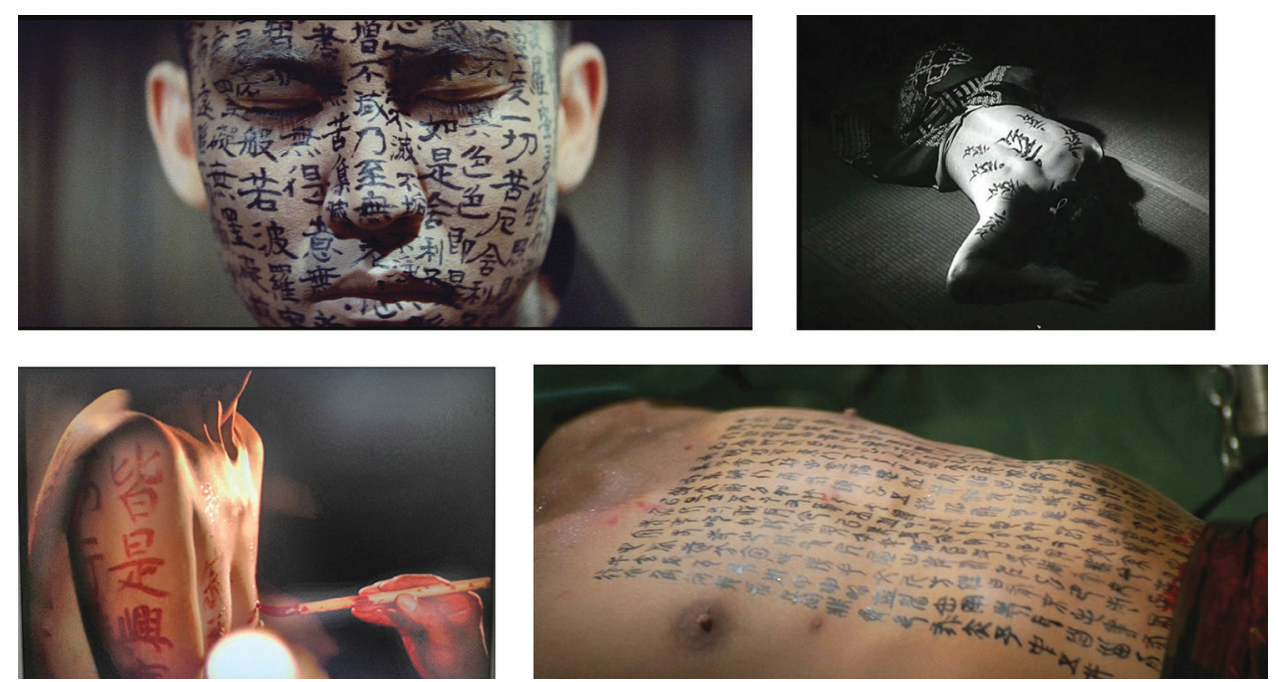


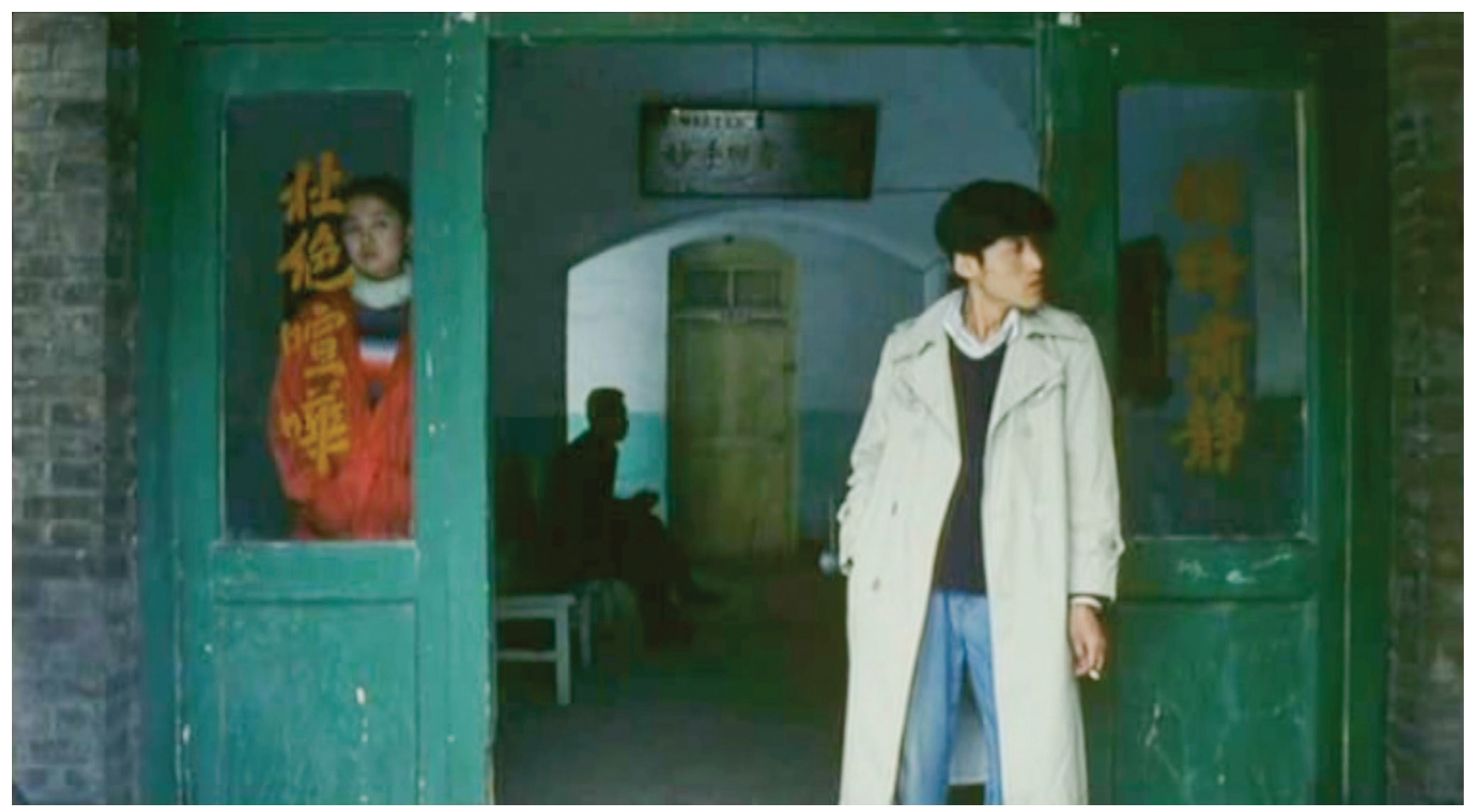

Figure 3.6. Substituting glass for paper, Jia Zhangke exploits the special qualities of cinema to turn glass frames within the film frame into traditional couplets in Platform (Zhantai, 2000).

either side of the frame and ironically turning them into an amusing cinematic parody of the traditional couplet. Those are effects made possible by cinema.

This is all to confirm Tom Lamarre's assertion that "the surface for inscription is not neutral." The effects it engenders invariably engage established convention and also enable creative innovation. Nowhere is this clearer than when calligraphs appear against what Lamarre calls a "paperscape." This is a practice that goes back to ancient times, when the paper features a background-often abstractions evoking clouds or mountains or sometimes flecks of gold or silver and the like. Filmmakers sometimes use paperscapes to indicate period, as Mizoguchi did for his wartime Chushingura (1941, fig. 3.7). Other times, it is merely abstract or colorful (see figs. 0.8, 2.4, 3.23, and the final image of the book).

Occasionally, it is simply the textured surface of handmade paper the original artist used, such as that in Yoshida Kiju's Akitsu Onsen (1962; fig. 3.8, see also figs. 1.9, 1.10, 1.12, 2.14, 3.19, 3.22, 7.4, and 7.5). According to Okada Mariko, the film's producer and star, the title card was designed to be gendered, to signify femininity, as the film is a powerful melodrama. So Okada chose a particular female calligrapher, the great Shinoda Toko, for her gently sweeping strokes. Shinoda used a pastel paper filled with wispy fibers that complemented her style. Yoshida and 


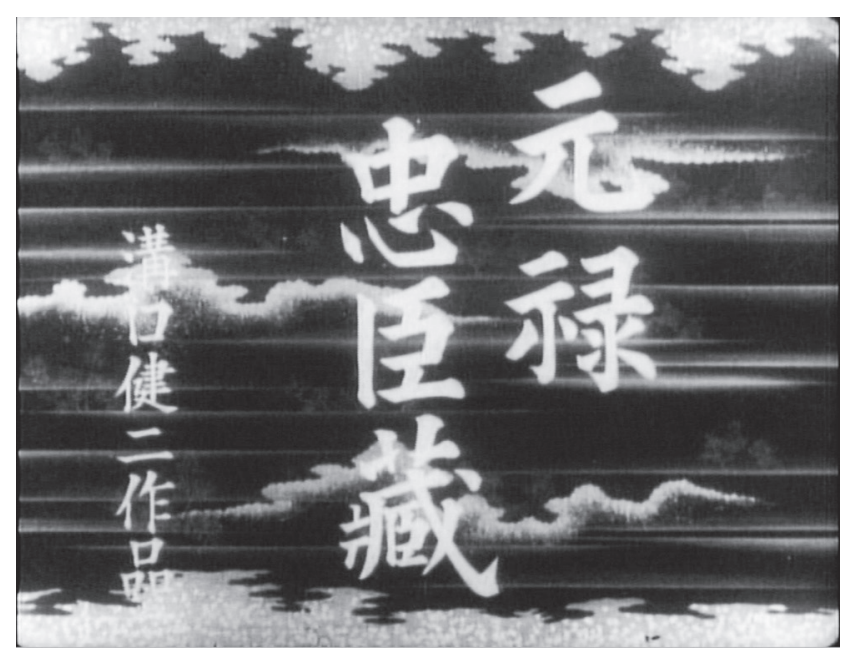

Figure 3.7. Chushingura (1941) uses an ornamented background, which Thomas Lamarre calls a "paperscape."

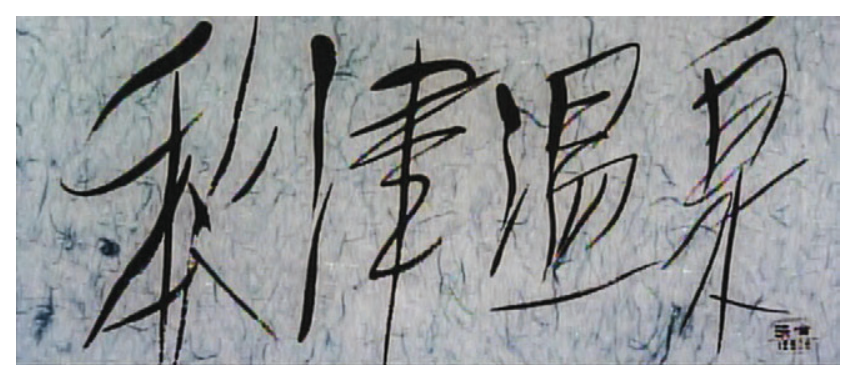

Figure 3.8. The paperscape from Yoshida Kiju's Akitsu Onsen (1962) is textural, not pictorial; the calligraphy is by Shinoda Toko, one of the most important modern artists of Japan.

Okada simply photographed the work of calligraphy to preserve the aura of the original on film.

In contrast, most calligraphy in film does not get such loving and respectful treatment. It is written by anonymous artists or staff art designers and uses inexpensive paper because it is fleetingly viewed and is multiply mediated by celluloid capture, replication, and projection (making it relatively disposable). Curiously, one paperscape spe- cific to cinema is the antiqued background for calligraphic props. When scroll paintings are meant to look old and venerable, the art department sprays the paper with a fine coating of dots (fig. 3.9). Filmed, then projected, they appear as ancient paper.

Most calligraphy, however, resides on a rectangular sheet of white rice paper. In the case of the non-diegetic calligraphy of title cards, this gives the profilmic, precinematic object a special spatial quality. Because the paper itself is long gone, there are a number of aesthetic and ontological consequences.

First, the calligraphy simultaneously ignores and exceeds the borders of the paper. The profilmic calligraph is indifferent to the edge of the paper it sits on. Unlike the view of paintings-including, I would argue, the action paintings of Jackson Pollack, Franz Kline, Willem de Koonig, and others - the characters feel less framed than floating, or emplaced in cinematic space, which always implies the offscreen world. Second, it follows that the paper no longer bears the calligraphy, and it becomes a uniquely cinematic object. This is certainly why calligraphs allow themselves to be so easily lifted off the paper and transferred to what we might call, taking a hint from Lamarre, the "screenscapes" of cinema, as in figs. 0.3, 0.4, 0.5, 0.7, 0.9, $0.10,0.11,1.8,2.11,2.22,2.24,3.20,4.6,4.8,6.7$, and 6.9. Screenscapes are the live action backgrounds over which calligraphy is superimposed.

The last of the Four Treasures is the inkstone. These are highly decorative slabs of stone that feature a sloped well. Water is added to the well, and the artist methodically grinds the ink stick against the slope. Rock from certain parts of China has been particularly prized over the centuries. Calligraphers feel the surface of the inkstone affects the character of the ground ink. As far as my untrained eye can tell, all this has little bearing on the cinematographic calligraph. However, the inkstone is an indispensable feature of an intellectual's study. Thus, the props departments in East Asian studios are filled with inkstones for set design- 

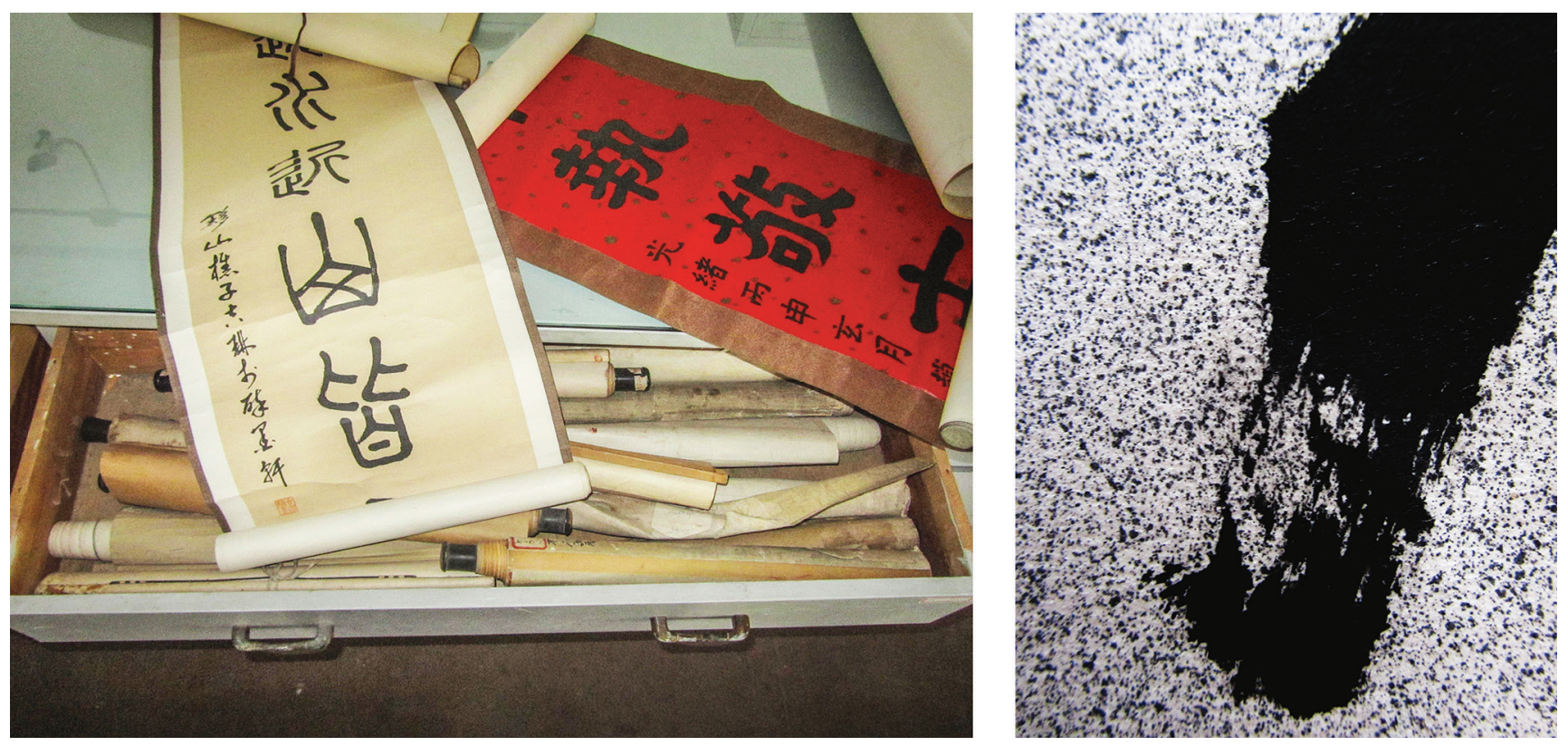

Figure 3.9. A thirty-foot long, double-sided cabinet in the props department of the Shanghai Film Studio is chock-full of scroll paintings. The scroll on the left features seal script; the one on the right uses a red paperscape with flecks of gold. On the right is a close-up of another work painted on a paperscape specific to cinema: the brand-new paper has been lightly sprayed with ink to give it an antiqued appearance onscreen.

ers to choose from (fig. 3.10). And for the most part, they are rather mute, peripheral objects in films. Perhaps it is because of the difficulty of representing their special qualities. In her lovely book on inkstones, Dorothy Ko laments,

Even high-resolution photographs fail to capture the qualities most important to the Chinese craftsman or connoisseur: not just the form or design of the stone but the softness of touch akin to a baby's skin, the minute veins and other mineral features, and the wooden instead of metallic echo when tapped with the forefinger..$^{10}$
The Chinese film Inkstone (Yantai, 1996; fig. 3.11) is perhaps the only film to give the inkstone a prominent place in its narrative. It brings out the organic erotics of the inkstone's curves. The story centers on an old woman living alone at the end of her life. Her living room is dominated by a massive inkstone of ancient origins. Her niece wants to sell it to buy aspirational electric appliances, but the old woman obstinately refuses. Her stubbornness is a mystery-after all, who wouldn't want a new refrigerator or color TV in place of a useless boulder? Flashbacks gradually reveal the reason. Frustrated by an impotent husband, the couple opens their marriage and she takes up with the 
Figure 3.10. Well-used inkstones and brush cups from the props department of Namyangju Film Studio, near Seoul.
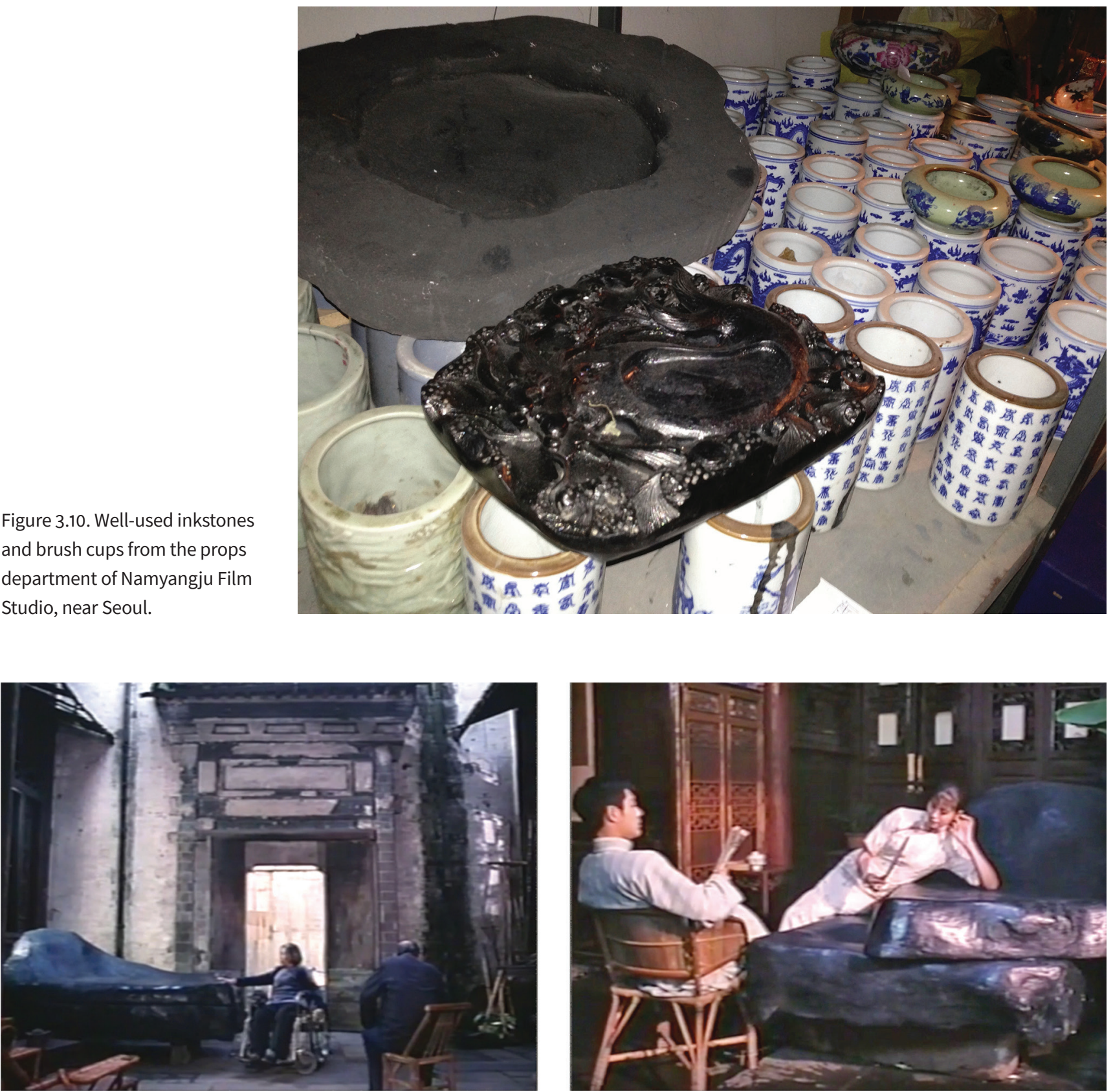

Figure 3.11. Inkstone (Yantai, 1996) centers on an old Chinese woman who owns a bed-sized inkstone. Flashbacks to her youth (right) bring out the erotics of the fourth treasure. 


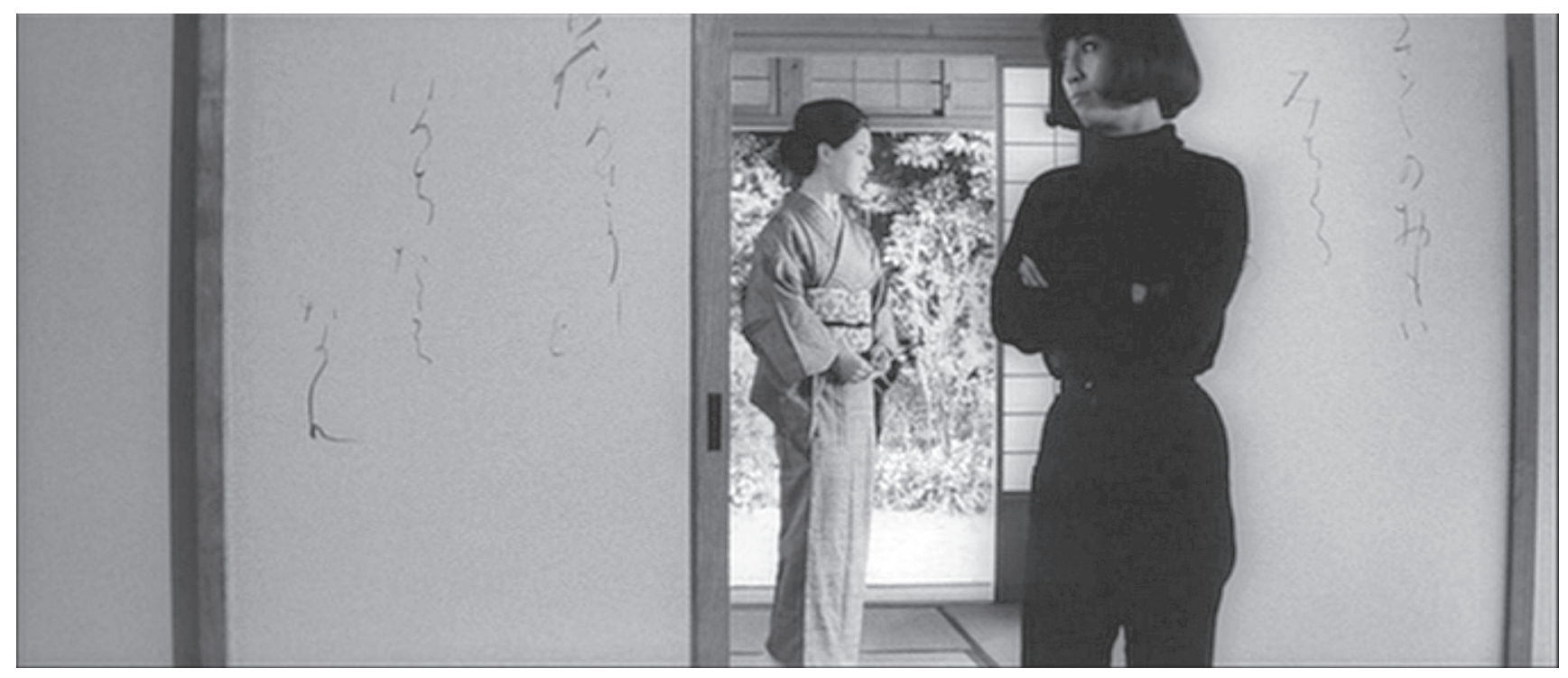

Figure 3.12. In The Affair (Joen, 1967), director Yoshida Kiju has his actor read this poem as she writes it on the fusama, otherwise most viewers could not read the cursive grass-style calligraphy.

handsome servant. The inkstone, as you might have surmised, is conveniently the same size as a bed. When they make love, the camera's close-ups intercut the soft curves of the entwined bodies and the inkstone. Thus identified with life and love, the old woman clings to the inkstone as a memento. When she herself dies, the niece calls in an antique dealer. As his crew lifts the stone, it splits in two. The top half slides off, revealing the interned body of the servant. This is the most elaborate treatment of the inkstone I have found. Usually, it is merely a mute prop on the desk of an intellectual.

So these are the Four Treasures-ink, brush, paper, and inkstone. They are the objects through which calligraphy theory has traditionally premised its definition of the art. Cinema demands we tweak these objects to accommodate the meeting of media made possible by the moving image, and not only because of the myriad substitutes we find in film culture. What's more, for cinema, we must also add three more treasures.

First, as suggested by Korean designer Kim Zhongkun, the computer is a fifth treasure, which he popularized with the phrase mun-bang-o-u (文房五友). ${ }^{11}$ Although Kim is thinking about the Korean phenomenon of kaelligeurapi, the computer has made a global impact on film calligraphy across East Asia. At the most basic level, calligraphy is no longer photographed but rather scanned. It can then be colorized, texturized, distorted, and even animated.

The sixth treasure is sound. If writing makes thought visual, the cinematographic calligraph also makes it aural. There are many kinds of sound that accompany calligraphs. For titles, it is usually non-diegetic music. But there are also times when characters read calligraphy aloud. For example, Yoshida had a character read the poem she just wrote in The Affair (Joen, 1967; fig. 3.12). The reason was 
Figure 3.13. Set in $227 \mathrm{BC}$ and centered on an assassination attempt on the First Emperor of Qin, Zhang Yimou's Hero (Yingxiong, 2002) is filled with scenes of writing. This major prop uses seal style, which achieved a relatively unified form by this moment in history.

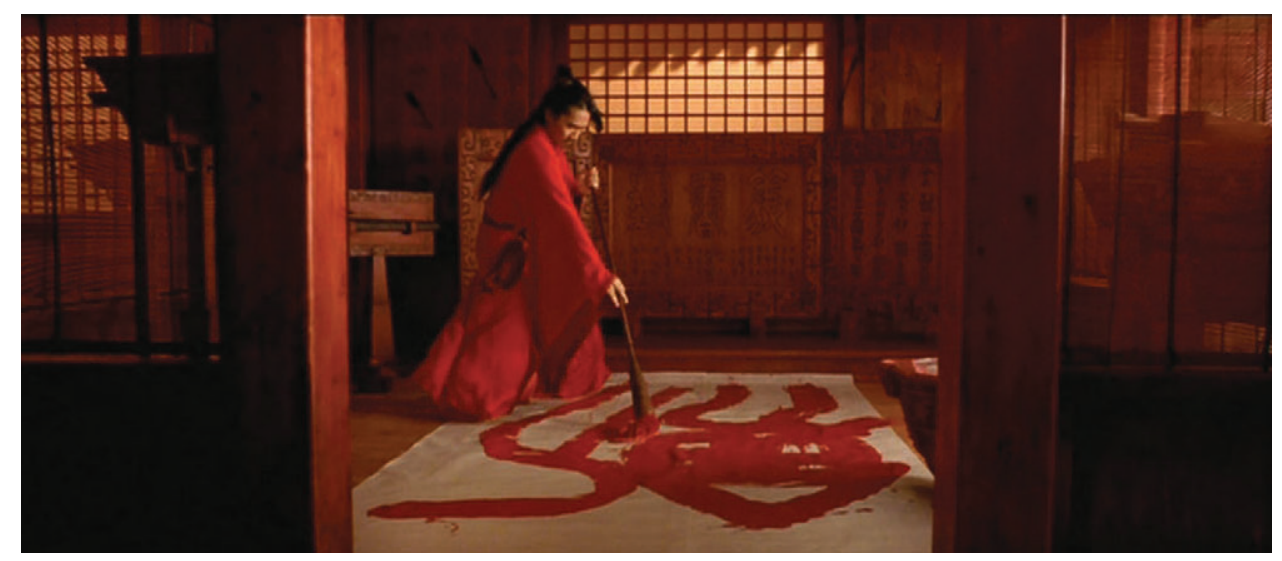

practical: the writing was so cursive it is illegible to all but a handful of spectators. Other films show characters reading letters or messages for the same reason, or simply to facilitate plot movement. Still others accompany the act of writing with its natural sounds of hair gliding over paper and the rustling of clothing.

Finally, the seventh treasure is movement, specifically the movement made spectacle by the cinematic apparatus. In contrast to writing by pen, the act of inscription by brush is ready-made visual spectacle. It should be no surprise that many films play with the profound similarities between calligraphy and the martial arts. Zhang Yimou's Hero (Yingxiong, 2002) is an extended comparison, or in Andrea Bachner's term, conjugation, of calligraphy and swordsmanship. Its most spectacular set piece features an enormous army converging on a calligraphy school. Outside, two of the main characters spin and flip in the air as they cut down thousands of arrows with their swords. Inside, a calligrapher stands over a huge sheet of paper, writing (fig. 3.13). Zhang crosscuts between the frenetic sword play and the slow-motion brushwork inside. In her wonderful analysis of the film's national allegory, Bachner argues, "The obsessive conjugation of calligraphy and swordsmanship . . . in the movie emphasizes the fact that both sword and brush are instruments of conquest, reiterating the bind between military and discursive power." ${ }^{2}$ Our concerns here, however, are somatic rather than ideological. Few films have represented the act of calligraphic inscription with such sensuousness. The calligrapher's body flows every which way as he wields the broomsized brush. When he stops, he stands over the character "sword," which is as tall as his own body and rendered in bloodred ink.

Undoubtedly, the most famous and fabulous comparison of calligraphy and martial arts is Magnificent Butcher (Lam Sai-wing, 1979; fig. 3.14). ${ }^{13}$ This is one of countless Wong Fei-hong films, here starring Kwan Takhing (reprising the role for the sixtieth-some time) and directed by Yuen Woo-ping, who choreographed the kungfu-like fights in The Matrix trilogy (1999-2003). The scene begins with Wong warming up in his study, whose walls are adorned with bold calligraphy. A pan reveals a servant grinding ink in an inkstone. Just as Wong prepares to stab the paper with his brush, the film's antagonist, Master Kwok, shows up with two goons. Kwok picks up a brush and, wielding it like a weapon, makes a series of kung-fu moves in the air - complete with an audible "swoosh" for each gesture. Suddenly, he stabs at Wong Fei-hong, but the 

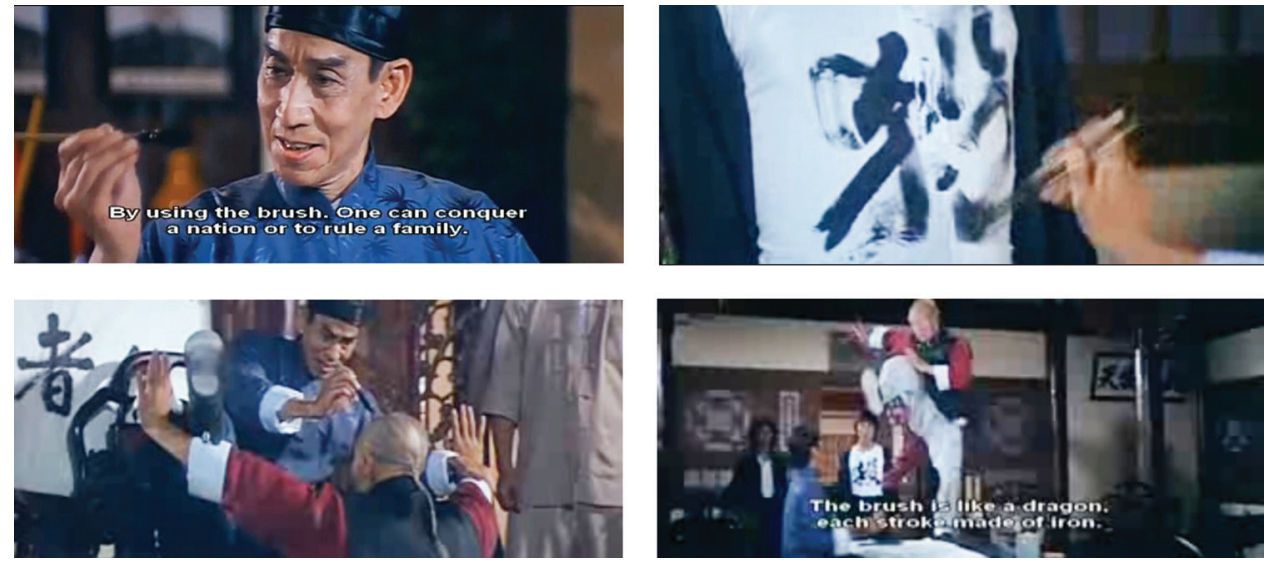

Figure 3.14. Kwan Tak-ming, as the kung fu master Wong Fei-hung, turns the brush into a weapon in a spectacular fight scene from Yuen Woo-ping's Magnificent Butcher (Lin Shirong, 1979). He paints the character 殺 ("kill/murder/slaughter") on his enemy's chest, humiliating him rather than killing him. master locks brushes with Kwok and forces him to paint the character 仁 (benevolence, humaneness) on the prepared paper. In anger, Kwok paints a big 殺 (kill, slaughter) on the henchman's chest and then attacks Wong again. A spectacular battle ensues, brush on brush, until Wong seizes his opponent's writing instrument and paints 者 (person), incredibly alternating brushes with each stroke. Kwok dips his finger in the inkstone, and they resume their battle, now brush on finger. Wong uses Kwok's finger to paint 無 ("nothing”). Kwok dares Wong to finish the last character, 敵 ("enemy"), which he accomplishes amidst an all-out martial arts battle. After displaying the final work of calligraphy - "the honorable man has no enemies"Wong writes a character, backwards, on Kwok's forehead. The vanquished Kwok slaps his head, effectively printing the reversed character on his palm: 服 “submit and obey."

The three treasures that cinema adds to the original four capture the sounds and movement of the writing scene, rendering them as cinematic spectacle while integrating them into narrative. The moving images and sounds bring new dimensions to this most ancient art form. They breathe life into the onscreen calligraphy, a dynamic phenomenon we will return to at the end of this book.

\section{Five Styles}

Another way calligraphers go about defining their artistic practice is through a set of standardized styles. Depending on the source, the list usually features five possibilities, although there are actually far, far more:

- Seal Style (管書, C = Zhuanshu, J = Tensho, $\mathrm{K}=$ Jeonseo)

- Clerical/Official Style (隸書, Lishu, Reisho, Yeseo)

- Cursive Grass Style (草書, Caoshu, Sosho, Choseo)

- Semi-Cursive Walking/Running Style (行書, Xingshu, Gyosho, Haengseo)

- Standard Style (楷書, Kaishu, Kaisho, Haeseo)

This is basically a chronological list. Seal style was the first writing system in China, starting roughly 3,500 years ago. The characters were pictographic and carved on tortoise shells, followed by strips of bamboo starting in the eighth century BCE. In this era, the heart of China was home to many peoples and different rulers. Despite these differences, writing in seal style spread across the region, so that by the time the First Emperor of Qin (259-210 BCE) unified the land in a single empire, the writing system 
Figure 3.15. The many personal seals owned by Kurosawa Akira (黒澤明) always used ancient seal style. The one on the right also has his English initials, AK. Courtesy of the Kurosawa Digital Archive.

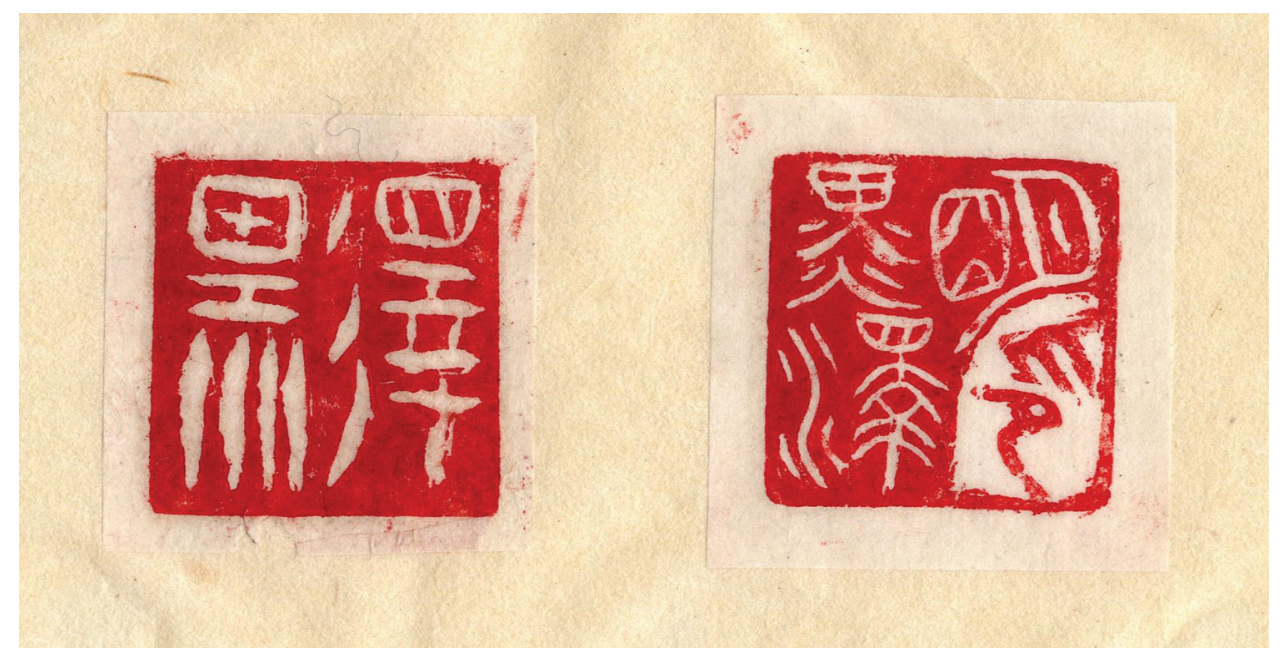

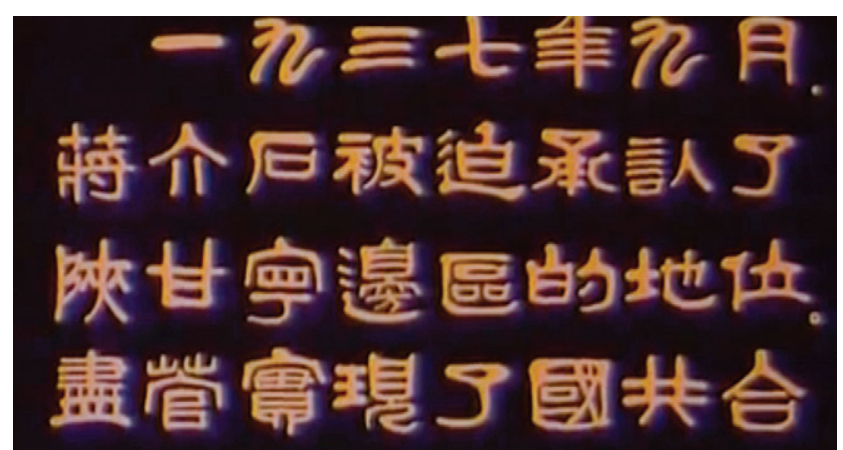

Figure 3.16. Yellow Earth (Huang tudi, 1984) uses clerical style to infuse a sense of enduring history into the opening of the film, which is set during the Japanese invasion of China. In the first line, the effect of seeing a modern date (一九三七年九月) in ancient script is striking.

proved a convenient way to communicate across linguistic differences. Films set in this distant era, such as Hero (fig. 3.13), usually use seal style on their props to signal this early historical period. However, it is most typically seen as carved seals. These occassionally appear in filmsparticularly for title cards (figs. 1.8, 1.9 1.12, 2.14, 6.8, and
7.2) - in every period. And, of course, this was a form of writing woven into daily life, as Kurosawa Akira's personal seals suggest (fig. 3.15). ${ }^{14}$

The relative unification of seal script kicked off a cyclical process of conventionalization and innovation that resulted in the subsequent styles. Seal style involved many strokes, requiring time and effort to write. As part of the unification of writing in the third century BCE, the characters also underwent a process of simplification. This led to the formation of the clerical, or official, style. The characters became squarer, with fewer strokes. Like seal style, clerical style almost generally indicates settings between the third century BCE and the first few centuries of the new millennium.

However, creative filmmakers also deploy it as a productive archaism. For example, Chen Kaige's Yellow Earth (Huang tudi, 1984) is set in 1939, but its title calligraphy and opening intertitles are written in a variation of clerical style (fig. 3.16). This setting was an unusual moment in the modern history of China; despite the deep political fracture between the Communist Party and the Kuomintang, these competing groups paused their own conflict 
to beat back the invading Japanese military. The film follows a young communist soldier who travels to far-away Shaanxi in order to collect folk songs. In addition to this story about local traditions, the stunning cinematography by Zhang Yimou focuses on massive landscapes and renders them in ways that evoke Chinese landscape painting. The intertitle introducing the film explains the historical moment of unification in opposition to the Japanese, using the archaic clerical style to suggest the long history of the land and people-and perhaps the unified rule under Qin as well.

In the first century $\mathrm{BCE}$, paper was invented. Combined with the brush, new expressive possibilities emerged for calligraphy. It became possible to inscribe characters with greater speed, so writers naturally took short cuts. This led to the creation of the grass style. This is a cursive script that is increasingly illegible to readers across Asia as they migrate from brush to pen to computer. Unfortunately, virtually no East Asian films from the early period (roughly 1899-1917) have survived. Those that have suggest that regular intertitles for fiction films were written in the cursive grass style, for example in the oldest surviving Chushingura (1910-1915) directed by Makino Shozo (fig. 2.4). However, in the silent era, handwritten letters were often rendered on props and only sometimes used in intertitles (and then usually accompanied by intralingual subtitles). A typical silent-era example is the intertitle from Futagawa Buntaro's Backward Flow (Gyakuryu, 1924). Figure 3.17 is a famous quotation from the Noh play Crane and Turtle (Tsurukame): (「千代のためしの かずかずに 何 を引かまし 姫小松」“Chiyo no tameshi no/kazugazu ni/nani o hikamashi/himekomatsu"). ${ }^{15}$ Other intertitles in this film use a very legible modernist style, hinting at the influence of art deco. This title switches to grass style because it is quoting the ancient play.

The next style to appear was the semi-cursive walking style. Essentially a variant of the earlier clerical script, it emerged roughly the same time as grass style. It retains a degree of cursive ornamentation, but avoids the cursive crushing of grass script and was in common use by the end of the Han Era in China, 200 years into the new millennium. Consider figure 3.18, the title card for Lady Jang (張 禧嬪 Jang huibin, 1961). Note how the characters are perfectly formed. There are no strokes skimming from character to character. Each is discreet and sitting in its own imaginary, square box. At the same time, the writer has taken a few shortcuts, particularly in the last character; they enabled a quicker inscription while producing some aesthetic flourishes, yet none of these cursive gestures interferes with reading. They are perfectly legible characters. Thanks to this combination of pleasing ornamentation and readability, the semi-cursive style gained popular traction, becoming the most typical style used in daily life.

The last of the conventional styles is the standard style, which coalesced in the third century CE. Admired for its stately beauty, standard style became "standard" by the Song Dynasty in the seventh century as a default script for official documents. To this day, standard style is used for formal and bureaucratic purposes across East Asia. A particularly pretty example is the title card for Ozu Yasujiro's An Autumn Afternoon (Sanma no aji, 1962; fig. 3.19). This was deliberatively written at a slow pace, laid with care stroke-by-stroke. Indeed, this style exemplifies a key principle of calligraphy called the "threefold rule" (三折 法 misseppo, in Japanese). Each stroke is accomplished through a three-stage process: brush starts $\rightarrow$ brush sends $\rightarrow$ brush ends. The Chinese characters for this are 起筆 $\rightarrow$ 送筆 $\rightarrow$ 終筆, the Japanese using the evocative onomatopoeic "ton $\rightarrow$ so $\rightarrow$ ton." Excellent examples in An Autumn Afternoon are in the strong vertical strokes in the first and last characters. The writer began with a ton, pressing the brush into the paper, followed by a downward movement-so-and then stopping abruptly to finish the line with a second ton, creating a slight upward hook as the tip of the brush departed the page. Each character was drawn with such deliberation, requiring skillful control of 
Figure 3.17. An intertitle from Backward Flow (Gyakuryu, Japan, 1924) renders a quote from a famous Noh play in grass style. Now such cursive writing requires special training to read: 千代の ためしのかずかずに何を引かま し姫小松.

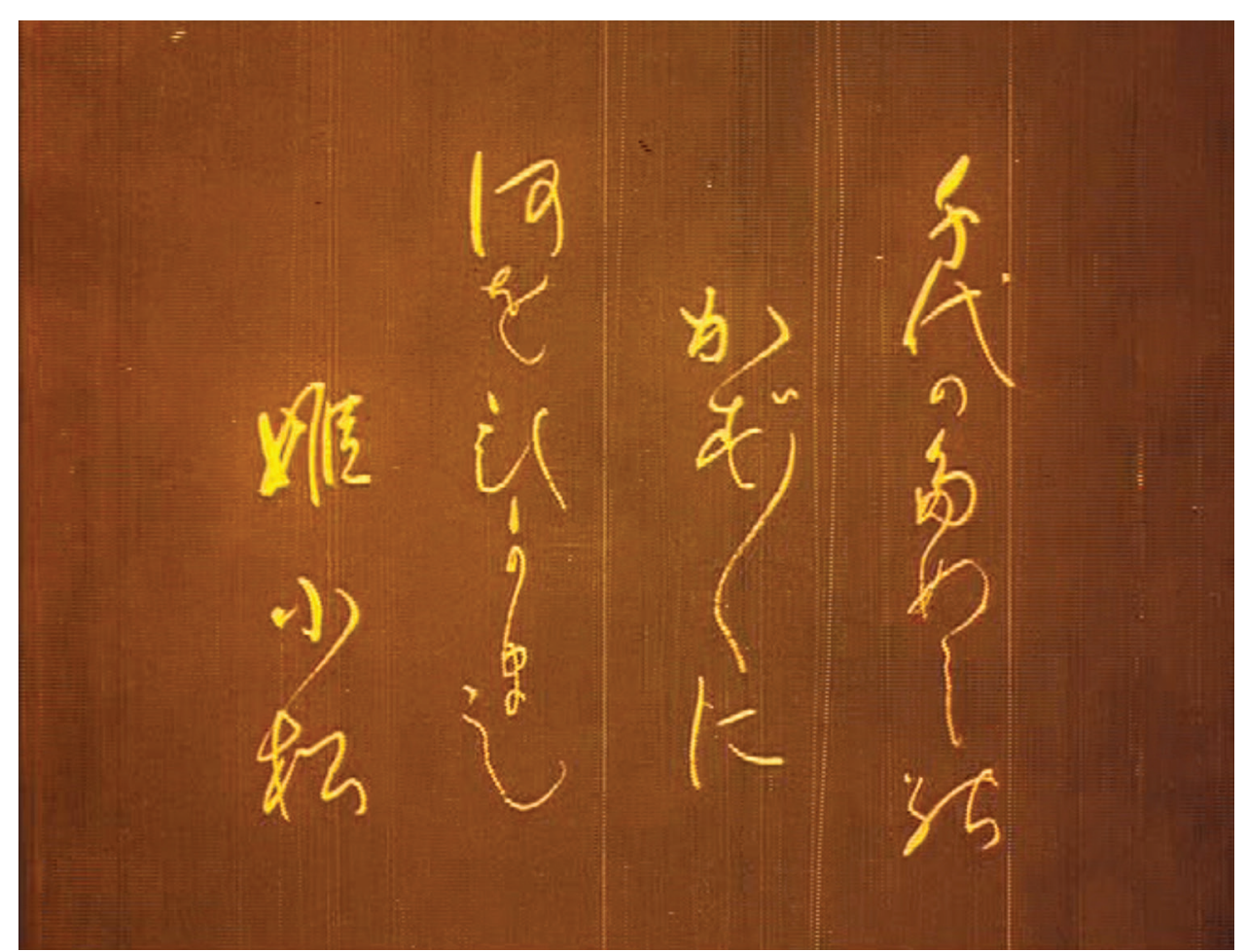

ink load, starting and ending points, brush speed, pressure on the page, curving movement, and the like. As the most legible of the styles, standard presents itself as far simpler than it in fact is.

A student of calligraphy often starts studying calligraphy by imitating model paintings (臨書) in each style. These can be either the works of ancient masters, their own teachers, or merely a store-bought book. Only after years of imitation are students allowed to depart from the models. It is thought that only by mastering and internalizing each standard style that meaningful art is possible. Individual style is valued but only in relation to the model.

It takes rather rarified connoisseurship to make such judgement calls. After speaking to highly respected art historians and calligraphers about specific works by renown
Figure 3.18. The title card for Lady Jang (Janghuibin, 1961) uses semi-cursive walking style for the characters 張禧嬪. 


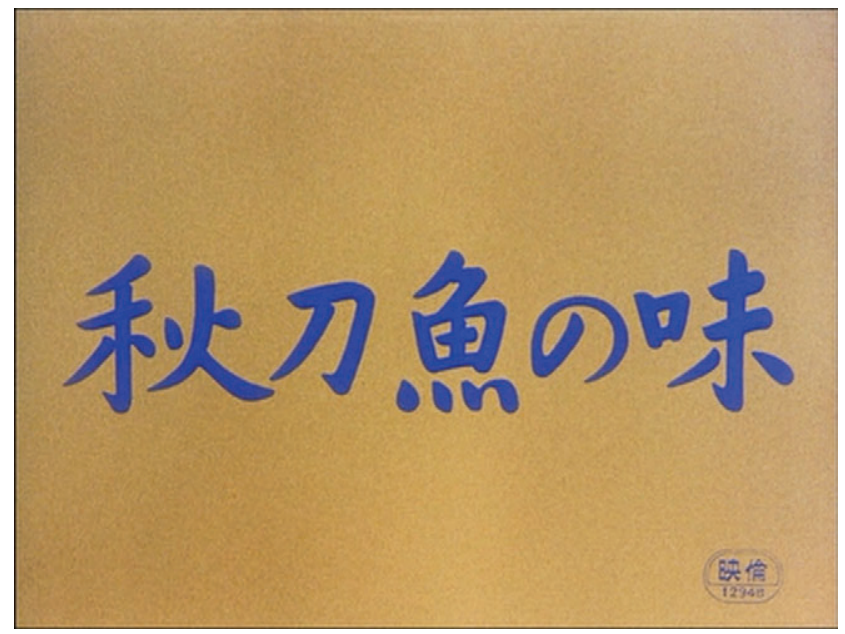

Figure 3.19. Ozu Yasujiro's An Autumn Afternoon (Sanma no aji, 1962) uses standard-style calligraphy, which was deliberately written at a slow pace, laid with care, stroke by stroke.

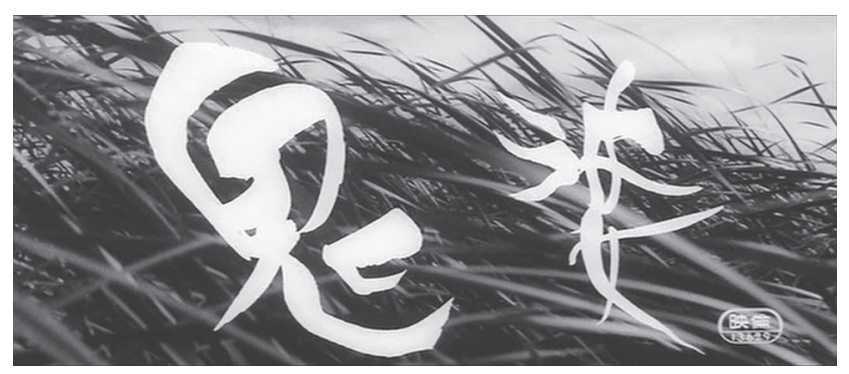

Figure 3.20. Onibaba (1984) deploys an eclectic style with wispy strokes to echo the grass of the screenscape while simultaneously setting the stage for the film's ghost story.

calligraphers, I am convinced there is a level of arbitrariness in this connoisseurship. The relationship to the model is important, but evacuating individualized departures from the norm involves a good amount of personal predilection.

The situation for cinematographic calligraphy is essentially the same, just more extreme and featuring a broader spectrum of relationships to the model. One can find excellent examples of the standard forms. However, much to the consternation of tribal calligraphers and some historians, calligraphy closely toeing to the normative styles is relatively rare in cinema. Two reasons stand out. First, many calligraphers in the film world - whether they are in props departments or design shops-often have little to no classical training. More importantly, film calligraphers feel a stronger tug of debt from the film than from the tradition or personal relationships to masters or schools. This is also why few of them are deeply compelled to strive for historical accuracy. ${ }^{16}$ Genre, conventions, emotional tone, and cinematic aesthetics trump millennia of tradition. Likewise, when title calligraphy appears on a screenscape, the calligrapher often throws the model manual out the window in order to interact with the image onscreen. The calligraphy of Onibaba (lit. "old witch," 1965; fig. 3.20), for example, may not be an identifiable style, but the sinewy brush strokes beautifully echo the grass of the screenscape while simultaneously hinting at the artful horror story about to unfold.

\section{Three Irreplaceables}

With the cinematographic calligraph, there are so many exceptions to all the rules, models, and treasures that I found an attractive alternative in what Li Xianting calls the "Three Irreplaceables."17 They are brush, rhythm, and arrangement. Li is a powerful art critic in Beijing and a calligrapher of some repute (he did the title artwork for Zhao Liang's Petition (Shang fang, 2009, fig. 3.21; other examples of his calligraphy are in fig. 6.10 and the author's profile picture). Li is historically important for the cover and support his criticism provided to the modernist artists emerging after the Cultural Revolution. Thus, his Three Irreplaceables distill essential ingredients, readily dispensing with conventional rules and three of the treasures when called 
Figure 3.21. Director Zhao Liang asked the famous art critic and patron of Chinese modern art Li Xianting to write the title for Petition (Shang fang, 2009). After the production, Zhao had the original mounted and proudly displays it in his studio.

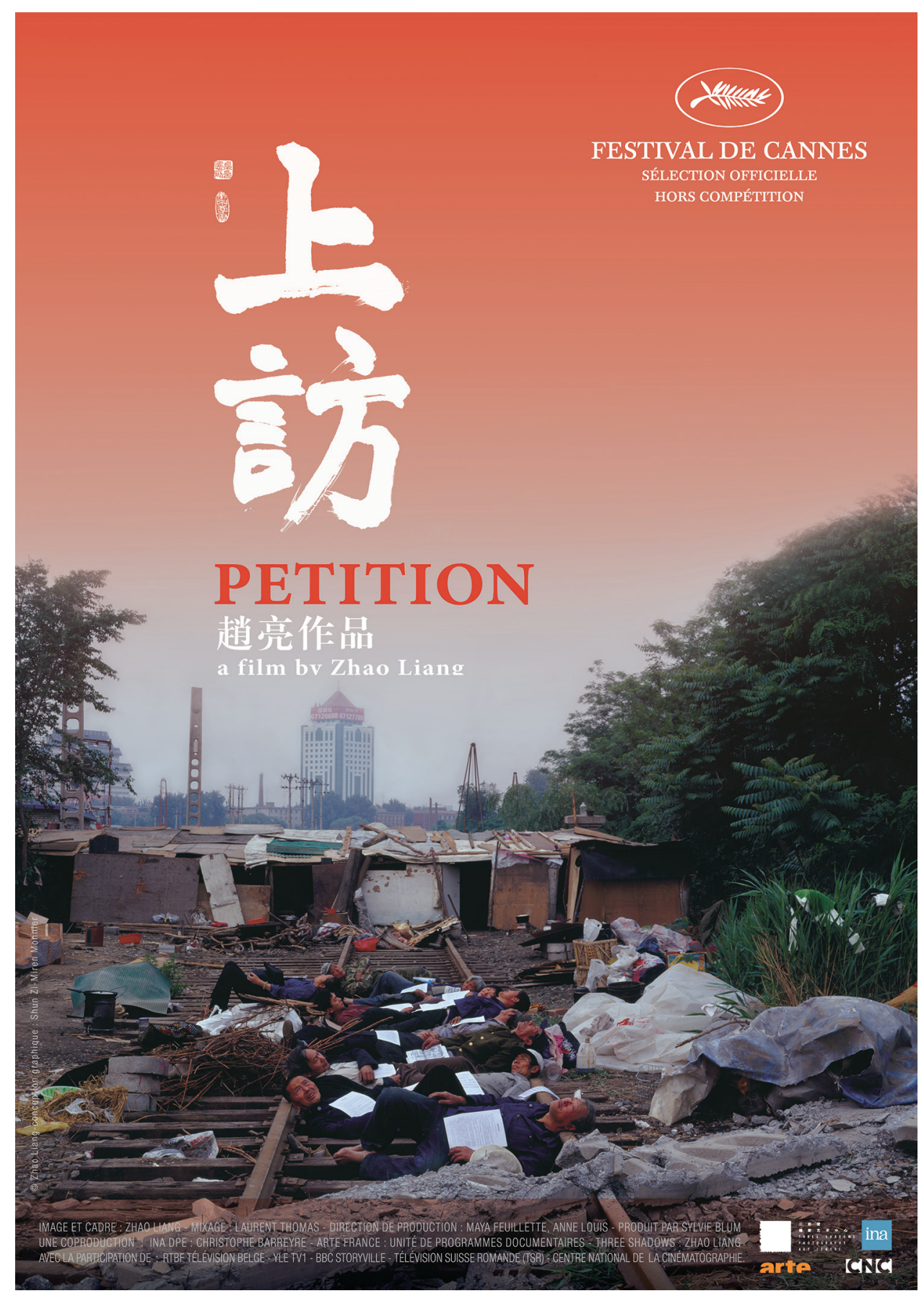

Abé Markus Nornes. Brushed In Light: Calligraphy In East Asian Cinema. 
for. Only this kind of flexibility can accommodate the modernist calligraphy he champions. For the same reason, his schema lends itself to film calligraphy as well.

The brush, as opposed to the quill or pen, is a first condition for East Asian calligraphy. At the same time, I am inclined to put "brush" in quotation marks at certain points in this book-and Li might as well, depending on the artist. To the degree I am interested in comparative or theoretical issues, I want to allow for a mimicry of the brush in handwriting, finger painting, animated, or digitized calligraphy and lettering. All strive to mimic the brush to tap its aesthetic power.

Rhythm, for Li, refers to both the effect of lines interacting on the page, as well as the registration of the artist's gestures in the act of writing. As an embodied art form, this is, indeed, irreplaceable. Treasures may be substituted, but whatever liquid or tool one uses for inscription it has to obey the rules governing the movement of the arm and hand. In fact, that motion is conditioned by the brush in the first place, no matter the instrument or surface. This is because as characters were invented and refined, the logic of brushwork determined stroke order, starting and end points, and the moments the brush is lowered and lifted.

This leads to a peculiar articulation of space, Li's third irreplaceable. The codification of stroke order enables fine manipulation of line, often apparent to the untrained eye of spectators who have learned and absorbed the basic rules of writing. Essentially, time and space enjoy a supplemental relationship. As Richard Lord evocatively explains,

Calligraphy is not solely the writing of existing words, not just an embellishment of existing graphics. Fung Ming-chip . . has said, "When there's the first brushstroke on the paper, then there's some kind of space relationship between brush movement and space. As the second brush stroke was finished, the space between the two strokes was made. When the first word was done, the space within the word (interior space) and the surrounding of the word (exterior space) was created." This is a unique, but primal "management of space"; it is a rhythm, a captured nuance of meaning and feeling, in itself almost a new life creation. The new symbolic potentialities behind familiar words taunt the calligrapher with their epiphanic gaze. ${ }^{18}$

Taiwanese calligrapher Chao Yu-hsiu puts it more bluntly: "People tend to concentrate on the black, but I think it's all about the white. The structure of each line affects the white around it. And with film this becomes complicated." This is because cinematographic calligraphy so often interacts with animated screenscapes and backgrounds other than white.

Gauging the space between characters is an acquired skill. In Western and Arabic calligraphy, spacing is flexible, yet fairly regular and predictable. So is the grip of the hand on pen or quill; it is not unusual for one's hand to start hurting from the stress of that regular movement. In contrast, the space between characters and lines in East Asian calligraphy is radically flexible, as is the space between brushstrokes and the size of each character. There are even terms for this; for example, in Japanese, midarigaki are cramped lines and chirashigaki are open, "scattered" lines. The complexity of this spatial dimension means the hand and arm move over the paper in a remarkably intricate dance of multiple-directionality, rhythms, and angles. And when executed properly, it rarely hurts to write for long periods (it seems if anything hurts, it is the muscle under the shoulder blade).

Let us look at some examples of this play of line and space, brush, and rhythm. Ozu Yasujiro's title for An Autumn Afternoon is calligraphy by the book (fig. 3.19), at least at first glance, with careful, meticulous brushwork-a frame with five equal spaces for characters. However, many lines do not connect, so the strokes are freer. Their tips are rounded, thanks to the brushwork and its generous load of 


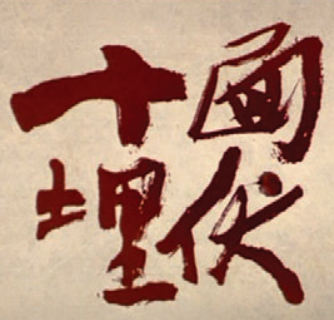

Figure 3.22. The characters for House of Flying Daggers (Shi mian mai fu, 2004) were written with great velocity, exemplifying a favorite saying of Chinese calligraphers: "Loose enough for a horse to pass; tight enough to stop the wind."

ink. The overall effect is soothing, deceptively simple, and perfect for this gentle melodrama. This actually required great control, as much as the next, more flashy example.

House of Flying Daggers (Shi mian mai fu, 2004; fig. 3.22) is directed by Zhang Yimou. He is one of the few directors in China who consistently taps the top calligraphers for his titles, in this case Wang Delong. ${ }^{19}$ Like An Autumn Afternoon, the background appears to be paper and the ink is colored other than black. While An Autumn Afternoon presents a line with five equally proportioned characters, House of Flying Daggers is constructed out of four characters in a perfect block centered in the middle of the frame (read top to bottom, left to right). The ink load and shape of the brush are obviously different from the Ozu film, and they were written not with deliberation but rather explosive velocity. What is especially interesting here is the third irreplaceable-the arrangement of the strokes. They exemplify a favorite saying of Chinese calligraphers, "Loose enough for a horse to pass; tight enough to stop the wind” (疏可跑馬密不透風 Shu ke paoma, mi bu toufeng). This typically poetic mash-up of opposites highlights the dynamic interplay of line and space. Lines of different gravities open up and close off space in unpredictable ways. The characters appear ready to fly off the page, just as the story's characters soar in their sword fights.

The two examples above exhibit a conventional brilliance; it is these same conventional understandings of brushwork, movement, and arrangement that can make masterful departures from the norms exciting. One of the very best is Taiwan's Tong Yang-tze. She is especially known for her spectacular collaborations with Cloud Gate Dance Theater on performances that explore the affinities between dance and calligraphy. In cinema, her highly distinctive style graces the titles for Wong Kar-wai's Grandmaster (Yidai zongshi, 2013; fig. 3.23), and many of Tsai
Figure 3.23: Wong Kar-wai's Grandmaster (Yidai zongshi, 2013),

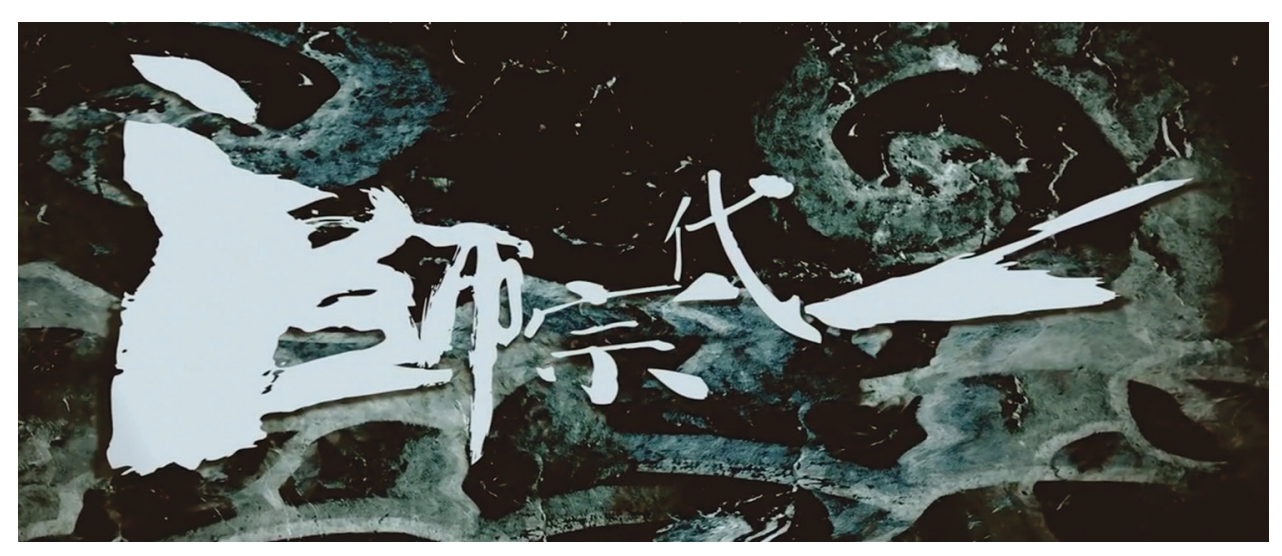




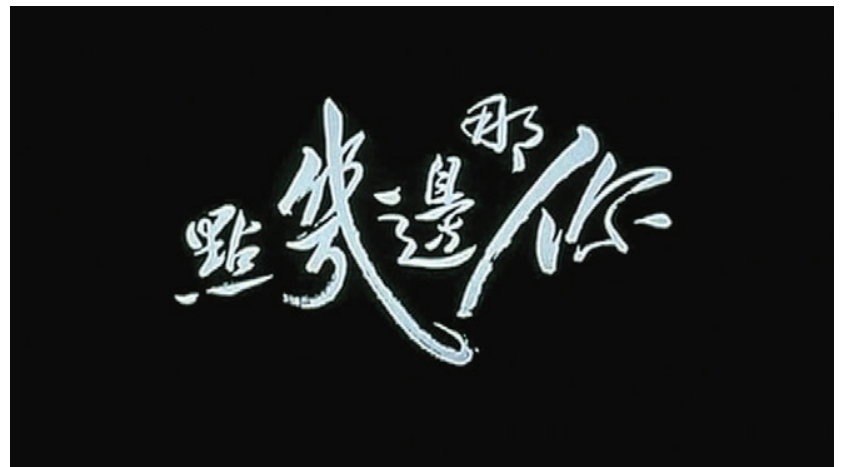

Figure 3.24. Tong Yang-tze's title for Tsai Ming-lian's What Time Is It Over There? (Ni na bian ji dian, 2001) has a strange V-shaped design, evoking the hands of a clock.

Ming-liang's films, such as River (He liu, 1997), Wayward Cloud (Tian bian yi duo yun, 2005), and Face (fig. o.6).

One of Tong's most striking works for film is the title for Tsai's What Time Is It over There? (Ni nabian jidian, 2003; fig. 3.24). This is a bizarre film about three characters in Paris and Taipei who become strangely synchronized across the vast space of the planet. Tong arranges the characters in an idiosyncratic array from right to left. She exaggerates two strokes with firm brushwork. This creates a strong V-shape, an arrangement normally forbidden in calligraphy. It creates a fascinating rhythm with the eye as it saccades across the screen. The first character openly greets the eye, then propels the gaze to the cramped middle, before another expansive character (open enough to let a horse through) releases one out of the other side. The play with temporality is literalized by the V's evocation of a clock face, and it also hints at the space of the film with its arcing lines. It is difficult to imagine Western calligraphy pulling off such a beautiful and playful title card. For our enquiry into the definition of calligraphy, it is most instructive. It fails the test of definition by traditional means; however, it most definitely embodies the modernist spirit of Li Xianting's Three Irreplaceables.

\section{One Missing Ingredient}

The Four (or five or six or seven) Treasures or Three Irreplaceables are both useful for understanding what East Asian calligraphy is as well as what sets it apart from traditions of calligraphy in other parts of the world. However, one other element deserves careful consideration: the Chinese character itself. Now, above and beyond the fact that the Chinese East Asian tradition was developed specifically through and for the Chinese writing system, there are qualities of the character that lend themselves to playful manipulation through a combination of the Treasures, Irreplaceables, and the tools of cinema.

The first thing that likely comes to mind is the pictographic aspect of Chinese writing. We already saw a couple examples in the introduction (fig. o.6). However, as I noted at the beginning of this book, pictographs are surprisingly few and far between in East Asian film titles. This is because filmmakers and spectators themselves are either oblivious to the original referent or simply don't use the pictographic aspect in making meaning. Needless to say, it remains a resource for filmmakers.

In contrast, the act of writing is far more important. More often than not, the lettering in Western writing is small so the hand operates in a narrow space above the paper, and the strokes for each letter are extremely tight and short. This is why, in contrast to Asian calligraphy, writers are susceptible to cramps in the hand. Making the act of writing legible upon the movie screen requires a closeup-and an extreme one in the case of small screen media made for TV monitors or phones. This, in addition to the relatively minor place calligraphy holds in Western culture, explains why the only substantial examples of writing calligraphy I can think of in the West are Name of the Rose (1986), which shows rows of medieval scribes hunched over parchment, and Game of Thrones (2011-2019).

In contrast, the act of writing with the brush in East Asia is spectacular in and of itself, making it quite attrac- 


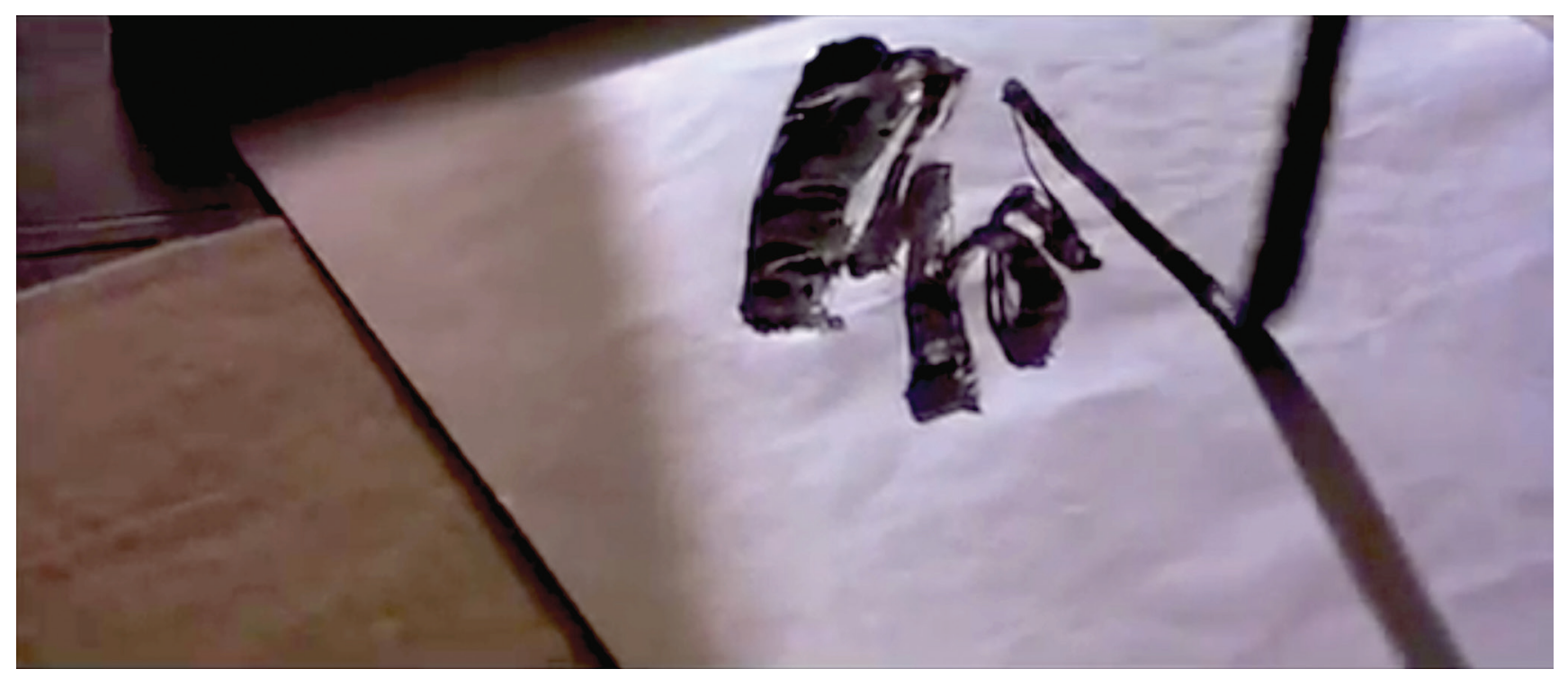

Figure 3.25. When the deceptively dangerous Zhang Ziyi writes Michelle Yeoh's name, she deforms the character 俞 through impressive cursive shorthand, giving it the distinct appearance of the character for sword-劍—and revealing her secret martial arts training.

tive to filmmakers - as we saw in the kung fu film above. While the pen is gripped close to the nub, the brush is held far back on the shaft. This opens space between the hand and writing surface, so the artist writes with the entire arm-and sometimes the entire body. A dance of writing, it is inherently cinematic.

This visual spectacle is often combined with playful manipulation of characters. For example, in Crouching Tiger, Hidden Dragon (200o), Yu Xiulian (played by veteran actor Michelle Yeoh) visits the younger Yu Jiaolong (Zhang Ziyi), who she suspects stole a renowned sword. The latter is practicing calligraphy. She offers to paint her visitor's name一俞秀蓮. Close-ups show her hand brush the name out with steady grace (fig. 3.25). Yu Xiulien remarks, "I never realized my name looks like the character for 'sword.' You write gracefully. Your calligraphy reminds me of swordplay." In fact, this physical grace deformed the character 俞 with cursive shorthand, giving it the distinct appearance of the character for sword: 劍. The semantic difference between 俞 and 劍 is produced by the cursive "crushing" of the radical 月 in the lower left corner. The shorthand for those two radicals is similar enough to allow for double reading exploited by the filmmakers.

An even more complicated example of the protean productivity of the Chinese character comes from Red Cliff 2, where a woman's calligraphy becomes a beautiful and touching vehicle for the narrative. One rainy night, a woman is bidding farewell to her husband, who is off to war. Preparing for his departure, she has been practicing the characters "safe" and "sound”一平 and 安 (ping and an). He asks her about the word choice and she almost, but not quite, reveals that it is the name she chose for the child she 

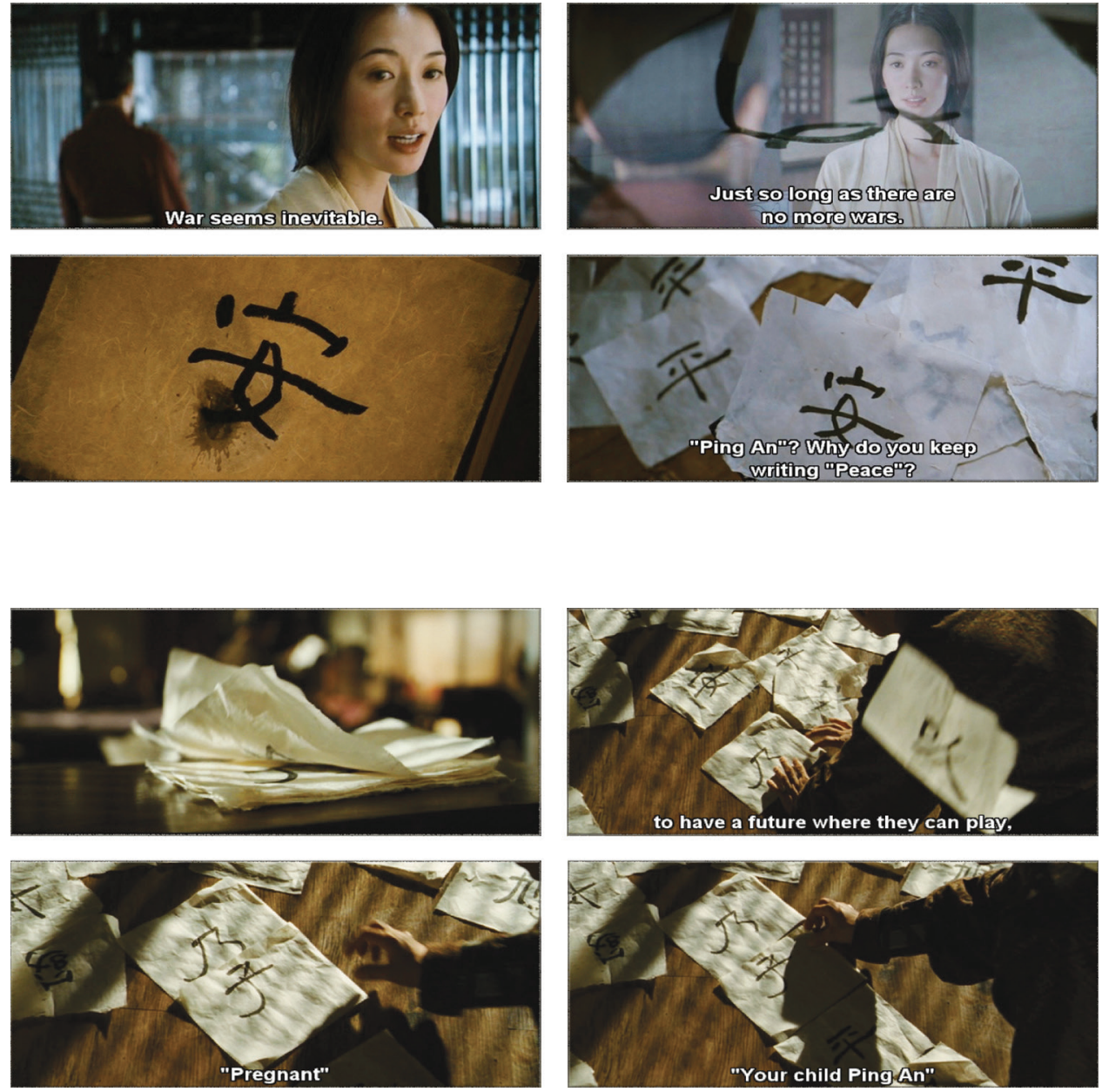

Figure 3.26. (clockwise from upper-left): In Red Cliff 2 (Chi bi, 2008), a husband bids farewell to his wife as he departs for battle. They make love in the rain, and a single raindrop falls on one of her practice sheets for "calm/quiet/ peace" 平安, landing squarely on the radical for “woman” 女.

Figure 3.27. (clockwise from upper-left): In a subsequent scene, her practice sheets are blown onto the floor. The husband shuffles the paper around. When the sheets for 乃 and 子 combine to make 孕, he realizes she is with child. is pregnant with. Instead, she makes love to him among her practice sheets. A drop of rain leaks through the roof and lands squarely on the character 安 (“calm, peace”; fig. 3.26). To be specific, it lands on the lower radical, 女 (“woman”).

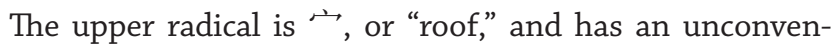
tional gap between the strokes on the left side-a leaky roof. The water leeches the ink of the character for woman, a visual echo of the tear running down her cheek; at the same time, it foreshadows her fate later in the film.

An even more complex scene follows later in the film.
This one plays with two other characters she had been practicing: 乃 (nai, "to be, thus, so, therefore, then, only, thereupon") and 子 ( $z i$, "son, child, seed, small thing"). The husband returns home only to find his wife missing. She has left a letter explaining she is pregnant and the child's name is 平安 Ping An. A breeze flows through the house, sending the practice sheets fluttering to the floor. The husband kneels down to collect them. Suddenly, four sheets shuffle into grammatical order (fig. 3.27): 平安乃子 Your child, Ping An. Stunned, the husband suddenly shifts the 
latter two sheets together, turning them into radicals, and they come to form a new word: 孕 yun, or "pregnant."

As I discussed in the introduction, the Russian film theorist Sergei Eisenstein was fascinated by both the pictographic and copulative power of the Chinese character and its radicals. The creative manipulation of characters in Crouching Tiger, Hidden Dragon and Red Cliff exemplifies what Eisenstein called intellectual montage. Actually, they are considerably more complex than his own examples. And they are possible specifically because they are calligraphic Chinese characters. These scenes simply would not be imaginable with moveable type or digital typography, let alone the Western alphabet. This is why the English subtitles for Crouching Tiger, Hidden Dragon are pretty much incomprehensible, and probably why the shortened international version of Red Cliff leaves the second scene out altogether.

\section{The Last Word: Brush}

This chapter has attempted to define what, exactly, cinematographic calligraphy is. This would seem to be obvious on the face of it all-it is simply "calligraphy in film." However, lovers of tradition, whether practitioners or scholars, are quick to complicate matters. By their definitions, calligraphy in cinema will always be imperfect-or even "not calligraphy"-by virtue of its inevitable tampering with the Four Treasures and Five Styles.

Admirable as this venerable tradition is, there is also something rather dull about it. Calligraphy, more than any other artistic practice, is based on the mimetic replication of past forms. Valuable departures from the models are possible by masters; however, they are often detectable only to other masters, or at least those immersed in the tradition. Those departures are intricate, and often remarkably minute and recognized only within the rarified domain of veteran artists and connoisseurs. Regrettably, this often leads to an exclusivity, if not elitism, which itself too readily feeds nationalistic chauvinism.

Cinema liberates and democratizes calligraphy. It serves to vernacularize and integrate the brushed word into the daily life of moviegoers, while opening its multitude of possibilities to both high modernist and populist impulses. True, it also subjects a refined art form to the whims of capitalism and plebeian taste. However, there is no denying the many beautiful, not to mention pleasurable, ways in which filmmakers integrate calligraphy into both their work and their lives behind the screens.

This is why I find myself deeply attracted to Li Xianting's Three Irreplaceables. His schema is open and flexible enough to accommodate the cinematographic calligraph. It also gives a central importance to the brush. As should be obvious by now, I am uninterested in making the brush a dogmatic precondition, a treasure not to be tampered with. We have already seen some of the creative substitutes imagined by filmmakers, such as tissue paper, chopsticks, and the human finger.

At the same time, like Li, I want to give the brush a special focus. That is because my primary concern here is the recording property of languages in the expressive and very human act of writing. In this sense, I am fundamentally concerned with “writing," or 書. And in this sense, the power and sensitivity of the brush is astonishing. In Western calligraphy, the artist requires an array of bits, quills, or pens to achieve different shapes and sizes. In contrast, a single brush can accomplish a dazzling variety of thicknesses. Its sensitivity registers the smallest tremors of the hand and the speed driven by fingers, wrist, and arm, as well as the load of ink it empties onto paper. The sensitivity of the brush enables the writer to impress one's emotion or thought or state of mind at the instant the brush moves. The theoretical considerations in the next chapters will continually draw our attention to this script of a very specific quality: handwriting that hints at the embodied act of inscription. 
Notes

1. Of course, there are exceptional, stunning examples of typography in film titles; however, they are just that: exceptional. Consider two major collections on Twitter: Title/Trailer Cards (@ titletrailer) and TitleStills (@TitleStills).

2. Yoshida, "My Theory of Film," 22.

3. Lamarre, op. cit., 84.

4. Quoted from Steve Jobs' Stanford Commencement Address (June 12, 2005): https://youtu.be/UF8uR6Z6KLc

5. Hanart TZ Gallery in Hong Kong staged a fascinating exhibition of movie posters from Ghana, where such lettering continues to the present day for rural screenings. KUNG FU IN AFRICA: Golden Age Hand-Painted Movie Posters from Ghana (19851999), Hanart TZ Gallery (March 2016): http://www.hk-aga.org/ event/kung-fu-in-africa-golden-age-hand-painted-movie-posters-from-ghana-1985-1999/

6. Hugo, "Ce que dil la bouche d'ombre" (Saying of the Shadow-Voice) in Les Contemplations (1856); quoted in Chion, Words on Screen, 97.

7. Ban, op. cit.

8. Ban, op. cit.

9. Lamarre, op. cit., 93.

10. Ko, The Social Life of Inkstones, 7.

11. Han, "But euro pyohyeon haneun dijain ui segye, Pilmuk"; An, "Kaelligeurapiseuteu Gim Jonggeon."
12. Bachner writes at length about the history of discourses that privilege the links between the Chinese character and material reality, which she calls "fantastic" and "hallucinatory." Her arguments are erudite and impressive, and I can only hope my own angle on the connections between written word and body avoids the fantasies she so convincingly critiques.

13. A YouTube clip of this scene may be found here: https:// youtu.be/pyoUduez3y4

14. The Kurosawa Digital Archive, which is authorized by the family, has other examples: http://www.afc.ryukoku.ac.jp/ Komon/kurosawa/index.html

15. http://www.geocities.jp/kikyou_kotoha/turukame.html

16. For a fairly ornery art historian demanding period accuracy from artists who could care less, Jerome Silberberg's, "Cinema and the Visual Arts of China," in Companion to Chinese Cinema, 408, analysis of Hero is particularly amusing.

17. I found Li particularly useful to my argument, but he does echo decades of discussion about calligraphy theory in the modern era. A very useful gloss may be found in Shi Xionbo's introduction to "Zhang Yinlin: A Preface to Chinese Calligraphy Criticism (1931)."

18. Lord, "Logographic Art," 53.

19. He also did the calligraphy for Zhang Yimou's Hero and Riding Alone for Thousands of Miles (Qian li zou dan qi, 2005). 


\section{CH A P T E R 4}

\section{Force and Form}

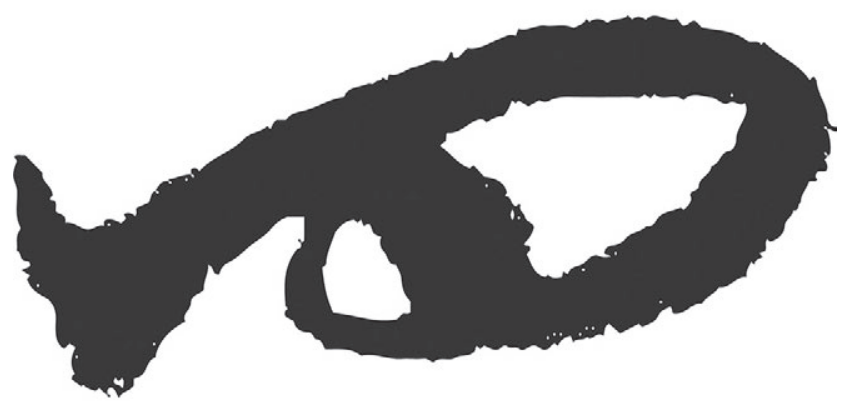

One of the most unusual and wonderful tendencies in East Asian calligraphy is the regularity with which it veers into stunningly beautiful illegibility. There is a great term for this in Japanese: "crushing." Cursive calligraphy, then, consists of what are called "crushed characters" (崩字) in Japanese. ${ }^{1}$ This is historically contingent. Before the age of typography, all writing was accomplished by the hand, and the efficiency of cursive writing made it ubiquitous. There was a vast heterogeneity of shortcuts in the pre- and early modern periods. Thus, calligraphy dictionaries often have a broad sampling of possible crushings for a given character. For example, the character for "writing"/書 might appear as any of the renditions in fig. 4.1, and this is only a small sample of the possibilities.

By the modern era, cursive styles became increasingly standardized. Literate moviegoers could both produce and read them. Thus, it is not unusual to find silent films with letters and messages in crushed characters. For example, in Mizoguchi's The Water Magician (Taki no shiraito, 1933), the dialogue intertitles are painted, white on black, in a highly legible script akin to standard style. However, when the main character sits down to read a letter written on a length of paper two meters long, Mizoguchi cuts to a close-up (fig. 4.2). The long letter scrolls across the screen, slowly enough for viewers to read. This kind of cursive all but disappeared from the cinema in the postwar era, when it stopped being a regular feature of school curricula. ${ }^{2}$ As 


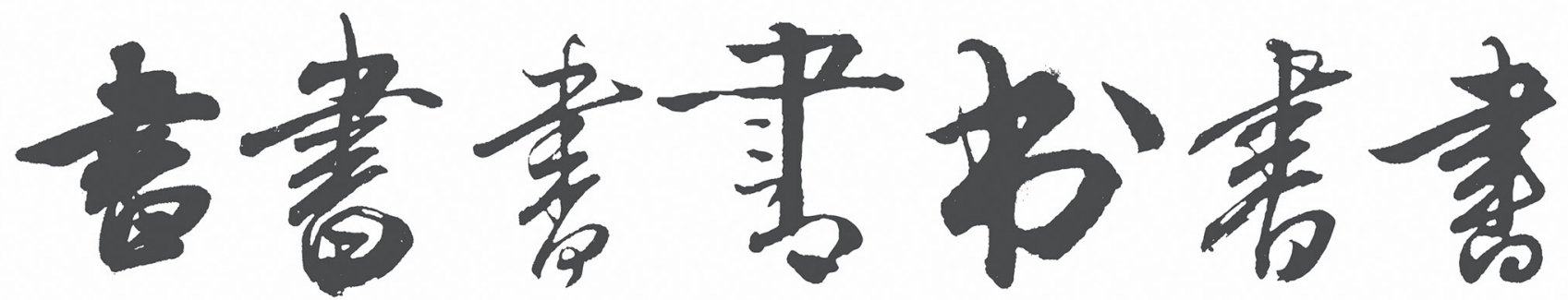

Figure 4.1. "Crushed" characters by various ancient masters for 書, "to write."

Chinese title designer Zu Xiaobing explains, "You can't make a character too cursive because there's only a limited amount of time to read before the next cut, and because young people simply cannot read them."

Some directors get around this through a narrative device. In Yoshida Kiju's The Affair (Joen, 1967), a woman paints a beautiful poem on the sliding door; the characters are illegible to the untrained eye (fig. 3.12). In fact, even students of calligraphy or historical documents would probably require a calligraphy dictionary and a good amount of time to decipher the poem. So Yoshida has the character read it aloud.

Most flamboyant cursive writing appears on props like this. Because their function is primarily ornamental, legibility is beside the point. It is unlikely many people could actually read the writing on the spells from the Hong Kong comedy Mr. Vampire (Jiangshi xiansheng, 1985; fig. 4.3); however, just as they served the narrative function to paralyze the zombie vampires, their conventional charms worked on the audience without the need to be actually read. These kinds of props are typically produced by the studio scene shop, sometimes off model books that serve as templates for art designers with minimal formal training (fig. 4.4). Or they are simply pulled off the shelves of the props department. Illegibility makes recycling props from previous productions an economical way to dress a set.

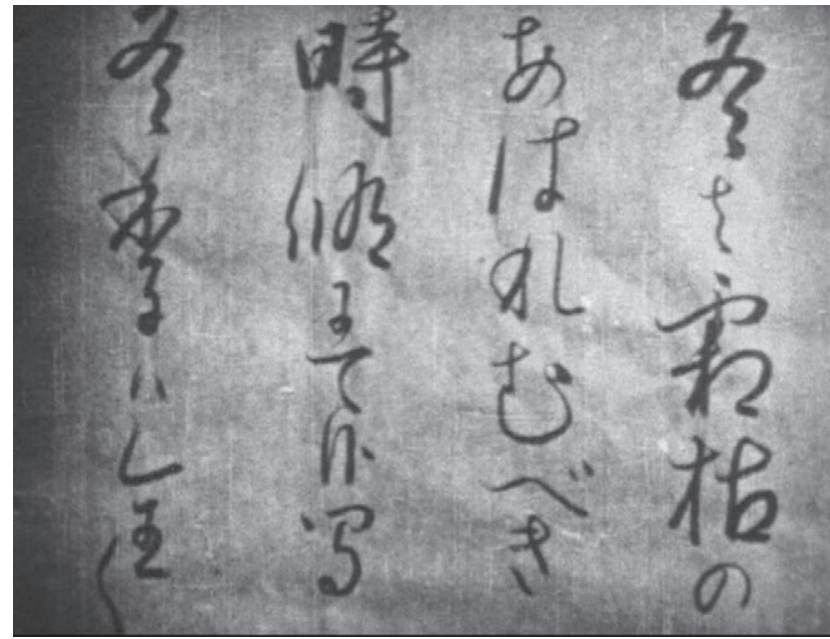

Figure 4.2. Crushed characters in a diegetic letter in The Water Magician (Taki no shiraito, 1933).

Thus, there is a wide spectrum between instant legibility and utter illegibility. Tom Lamarre demonstrates how this sets up a range of binaries that calligraphy oscillates between:

$\begin{array}{ll}\text { Pragmatics } & \text { Ethics } \\ \text { Intelligibility } & \text { Sensibility } \\ \text { Intellection } & \text { Emotion } \\ \text { Imitation } & \text { Expression }\end{array}$


And to these I would add:

$\begin{array}{ll}\text { Anonymity } & \text { Individuality } \\ \text { Helvetica-like } & \text { Cursive } \\ \text { Non-diegetic } & \text { Diegetic }\end{array}$

A given work of calligraphy can reside firmly on one side of this column or the other, like the easy-to-digest silent film intertitle on the one hand and zombie spells on the other. But many, or perhaps most, works oscillate between the two poles. Even legible writing can be expressive in its own way, but the tendencies are there. If the previous chapter concentrated on the pragmatics of the intelligible character, this chapter will focus more on the other end of the spectrum - the forces at work in form itself.

Actually, there is a long history of denigrating the semantic content of calligraphy in favor of form. Robert E. Harrist Jr. argues that this was nothing less than a "cornerstone" of early calligraphy criticism and theory, citing classical writings by Sun Guoting (孫虔禮, ca. 648-703 $\mathrm{CE})^{4}$ and Zhang Huaiguan (張懷瓘, ca. 714-760 CE). On this occasion, Harrist was actually writing about Xu Bing, a contemporary artist from the People's Republic based in New York and Beijing. Xu Bing's art brilliantly plays with intelligibility and illegibility in both his mother tongue and English. His best-known work is Book from the Sky (Tianshu, 1981-1991), a grand installation of calligraphic woodblock books. As with any written text, the pages attract viewers' attention and invite them to pause and read. The style is modeled on woodblock printing fonts from the fifteenth century Ming Dynasty and before, and from the distance it promises maximum ease of reading. ${ }^{5}$

However, Book of the Sky immediately frustrates such efforts, because the 4,000 or so characters making the book are entirely of Xu's creative construction. Each character is a novel assemblage of actual radicals but arranged in a visual montage that results in no semantic meanings. Harrist writes,

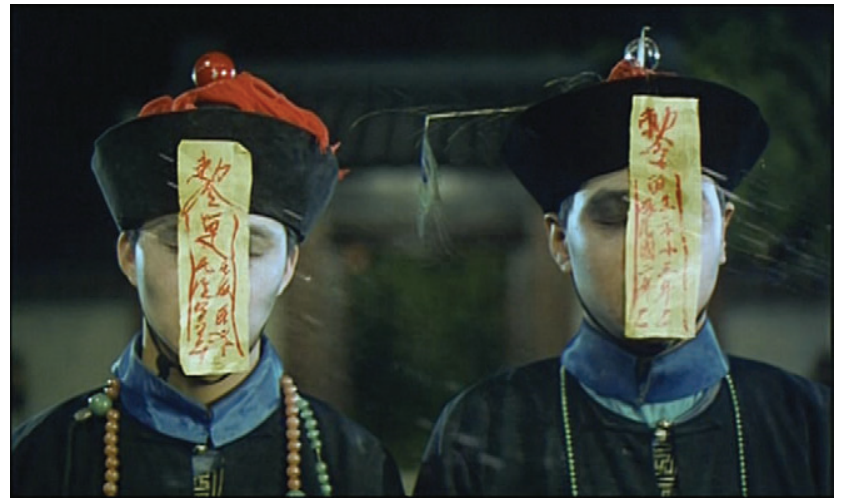

Figure 4.3. In Mr. Vampire (Jiangshi xiansheng, 1985), the illegible charms of this Hong Kong comedy don't need to be read.

Ironically, what Xu Bing's work invites is analysis of a theoretical tension embedded in the history of calligraphy, the most tradition-bound of the arts of China. This is the tension between the perception of calligraphy as a system of lexical communication bearing semantic meaning and the perception of calligraphy as a system of pure visual forms. ${ }^{6}$

Xu Bing's work, along with the similarly faux characters of $\mathrm{Gu}$ Wenda, is perplexing, producing a wide variety of explanations and interpretations. However, Harrist points to an important dynamic for our approach to the cinematographic calligraph. On the one hand, humans are driven to search for meaning, and no other form provokes this search more powerfully than the written word. Visual signs naturally draw our attention, as well as our desire to know what they signify. Xu says he is interested in playing with "habits of mind," which unconsciously draw our attention to the calligraphic word. Its materiality has a strange power.

This is precisely why Japanese director Itami Juzo hated written signs. When he and his crew arrived at a location, the first order of business was always to remove 


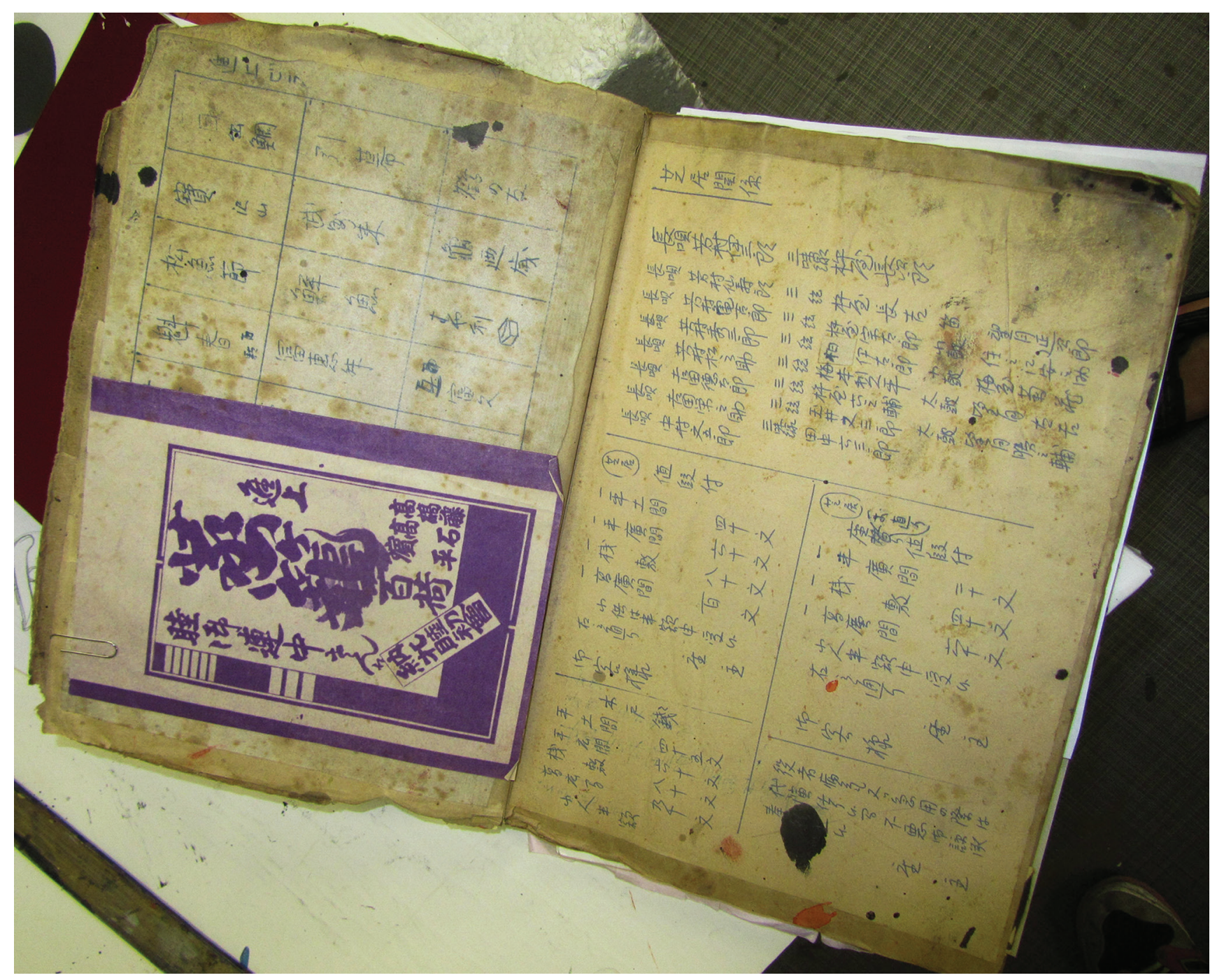

Figure 4.4. This model book from Toei Uzumasa Studio in Kyoto is a source book assembled ages ago in the prop department to guide art designers. It has models for all manner of sign, fan, menu, lantern, and other props, specifying proper content and calligraphic style depending on object and time period. 
all signs or artwork with calligraphy. For exteriors, the art department would go down streets talking to merchants about hiding their signs inside until the shoot was over. Itami's comedic cinema features a lean approach to narrative. He clearly did not want anything distracting from the carefully crafted forward motion of his stories.

Itami is an outlier. There are far more directors who find themselves deeply attracted to the calligraphic word. Whether legible or not, they are a uniquely powerful ornamentation.

This is to say that form itself-especially the brushed character-exerts a special force on human perception. And many filmmakers and art directors, like Xu Bing, exploit the human habits to greet this force with attention through narrative design, set construction, and mise-enscène. At the same time, this force itself is greeted differently in Japanese, Korean, and Chinese language cinemas, a curious phenomenon I will turn to at the end of this chapter. First, let us consider how people read calligraphy, even if they cannot understand its content; in other words, if they aren't reading for meaning, what exactly are they reading?

\section{Calligraphic Form and Time}

The artists of abstract expressionism and Tachisme were fascinated by Asian calligraphy. They learned about calligraphy through Laurence Binyon's Painting in the Far East (1908) and the work of Roger Fry, as well as from personal travel. ${ }^{7}$ Martin Powers charts this fascinating relationship in "The Cultural Politics of the Brushstroke." ${ }^{8}$ Powers' essay is a historiography of the brushstroke, before and after the modernist break, and in both China and in the West. He shows how artists like Alechinsky, Mark Tobey, Julius Bissier, Jackson Pollock, and Pierre Soulages drew inspiration from Chinese and Japanese calligraphy for conceptualiz- ing the single stroke as individual expression-very much a modernist appropriation of calligraphy.

However, from a different perspective, one could say that the abstract expressionists' art is ultimately more about layering than line. The intricate patterns on the canvases of Pollock and Tobey invite the eye to scan at will. There is a temporality built into the layering of the paints in these works; yet, the order of application is unclearbeside the point, really-as is the directionality of the brush, or even the pressure of the brush on the receiving material, or the original speed and rhythm of the artist's gestures. This is even true of Franz Kline, who denied the influence of calligraphy but is eminently calligraphic, and whose work is organized by bold rhythms thanks to his powerful, black brushstrokes. In contrast, the line calligraphy is built on has both temporality and directionality. Amidst a debate about the differences between abstract expressionism and avant-garde calligraphy in the pages of Bokubi in 1953, Arita Koho argued, "In the traditional Eastern art space, ink line is a key to everything. The particular sensibility of a line born from line's time quality has a potential to clarify and simplify the depicted object ... It is thus possible to say that an ink line with its time qualities forms a space." In contrast, the abstract expressionist line is, in the end, utterly abstract.

Were Chinese calligraphy painted by the same principles, the result would be something like Wang Wo's Zhe Teng: According to China (Zhe Teng, 2010; fig. 4.5). It was produced with so many strokes that a feel for line disappears, and this has several consequences. Stroke order becomes beside the point, which makes it difficult to sense the movement of the artist's hand and brush. What's more, the work has a decidedly non-calligraphic temporality. In calligraphy, one can feel the rhythms and velocities of the brushwork. The strokes and spots indicate pauses, sweeps, and jabs of differing speeds. Even the gradual thinning of line as ink load depletes indicates the time between trips 


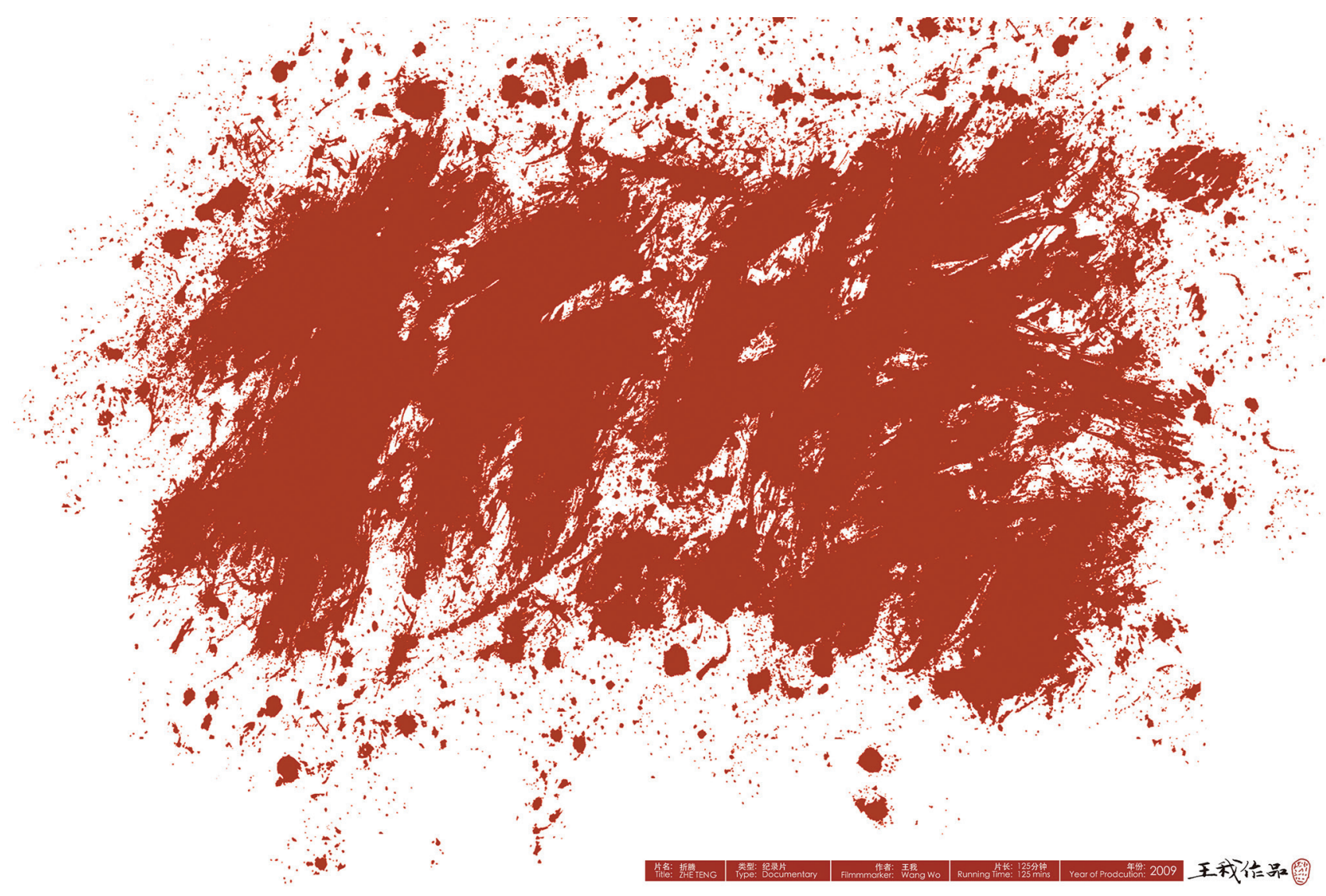

Figure 4.5. Were Chinese characters painted by the principles of abstract expressionism, the result would be akin to Wang Wo's Zhe Teng: According to China (Zhe Teng, 2010), where the individual stroke does not call for attention

to the inkstone. But Wang's Zhe Teng invites the viewer to apprehend it as an instant. It required hundreds upon hundreds of strokes to accomplish this effect, but none of the individual lines demand attention. This is an action painting of sorts, not a work of calligraphy. Additionally, the relationship between tradition and innovation loses its finely calibrated tension here. These are key protocols for the appreciation of East Asian calligraphy that link the act of writing to the act of viewing.
Put another way, in abstract expressionism there is a special disconnection between artist and viewer. The artist freely applies brushstrokes to the canvas, and the viewer enjoys an equal freedom to scan the work at will. The viewing of calligraphy is utterly different-first and foremost because it is ultimately a reading protocol and thus subject to the various rules and regulations of language itself. Xu Bing's example notwithstanding, even the most illegibly cursive calligraphy obeys certain rules about stroke order 
and the combination of characters. Furthermore, it is no exaggeration to say that all viewers of calligraphy in East Asia possess the experience of painting words by brush, memorizing stroke order, and the relative relationships between lines.

In this way, and in a fashion completely different from abstract expressionism, calligraphy synchs the brush of the artist and the eye of the spectator. ${ }^{10}$ One's body has naturalized proper stroke order to the extent that the hand is guided by motor memory. ${ }^{11}$ And having practiced calligraphy, at grade school at the very least, the viewer/reader easily tunes into the temporality of the characters in a work of calligraphy. She or he knows and feels the varying speed of the artist's strokes. The viewer's eyes do far more than capture the pages of characters, let alone smaller units like the word or the character - as if it were a picture, present before the viewer in its entirety and acquired at a glance. No, viewers scan the line of characters aware of the order of application of ink. Their eyes follow these lines in fits and starts, sweeps and pauses.

The technical term for this eye movement is "saccading," which is essentially the caress of the eye on characters. It is far more pronounced in calligraphic writing than in typography. What's more, the saccading eye is indelibly linked to the original bodily movements of the artist.

Saccading is deeply affected by style, and in cinema, this has often been codified by genre. Melodramas like those of Ozu or Yamada Yoji typically use rounded strokes that were drawn slowly and carefully. Period films, ghost stories, and gangster films almost always feature razor-like strokes that imply the slashing attack of brush on paper. There are different ways in which these styles position the viewer in relationship to the unfolding film. This dynamic goes back to premodern times. It is hinted at by the thirteenth-century treaties written by Jiang Kui (姜䝺 1155-1221 CE):

The first requirement for the bearing [of the characters] is a noble character [on the part of the calligrapher]; the second is modeling oneself on ancient masters; the third is good-quality brush and paper; the fourth is boldness and strength; the fifth is superb skill; the sixth is moist brightness; the seventh is a suitable internal balance; the eighth is occasional originality. When these requirements are met, long characters will look like near gentlemen; short characters will be like strong and unyielding persons; skinny characters will be like hermits living in mountains and marshes; fat characters will be like idle rich men; vigorous characters will be like warriors; handsome characters will be like beautiful women; slanting characters will be like intoxicated immortals; correct characters will be like gentlemen of high moral standing. ${ }^{12}$

Note how this quote shifts from concrete description of the act of writing to a string of metaphors describing the character of the characters. It is a small step to describing the characters of cinema, which is what makes calligraphy so useful to filmmakers - or unattractive to directors like Yoshida Kiju and Itami Juzo.

Furthermore, because this is dependent on tradition, filmmakers can break away to powerful effect. While the examples above involved calligraphy expressing something about the films, kaelligeurapi artist Park Si-Young notes, "If there is a romantic drama or action film, the style will be different. If you want the action film to be softer, you can soften it. If you want to harden a romance, that is just as easy. The decision usually comes from marketing. But sometimes I don't even think about the story at all."

\section{Form, Force, and Mise-en-scène}

The examples above are, like the thirteenth-century quote from Jiang Kui, tied to genre; however, the conventionalization of shape, size, stroke order, and line allow sensitive calligraphers to do so much more. The most obvious issue is 


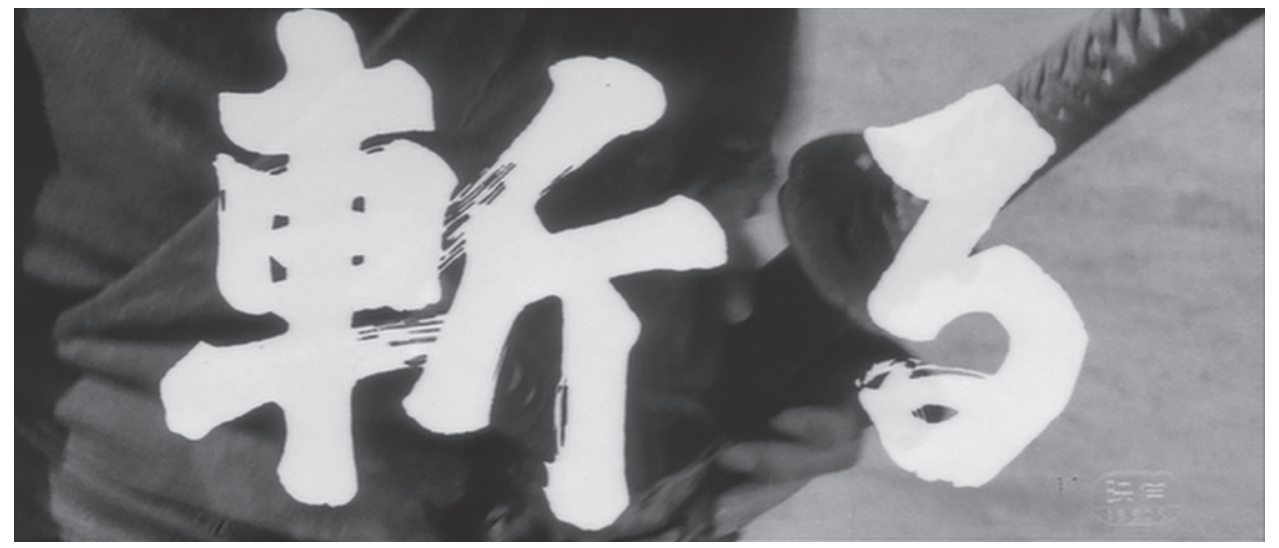

Figure 4.6. Most films with a title and subject matter like Kill! (Kiru, 1968) would use spiky, violent strokes. This calligrapher builds the swelling desire to kill into the thick strokes of his title-which literally and ironically means "killing a human with a slicing blade."

that of mise-en-scène, the arrangement of all the elements in the frame. First of all, calligraphers adjust their work to the film's thematics while playing off the semantics of words when legible. An excellent example comes from Kill! (Kiru, 1968; fig. 4.6). Most samurai films like this would use the spiky strokes which evoke the lacerating blades of swinging swords. Director Okamoto Kihachi, always rethinking genre expectations, instead builds the swelling desire to slaughter into the thick strokes of his title-which literally means killing a human with a slicing cut.

A contrasting example may be found in the title of novelist Mishima Yukio's Patriotism (Yukoku, 1966; fig. 4.7). This is a powerful experimental short about the failed fascist coup d'état in 1936. The story, such as it is, focuses on an officer and his wife who make passionate love before committing ritual suicide with Wagner's "Tristan und Isolde" playing in the background. Obviously, it was a beautiful and twisted run-through for Mishima's own death only four years later.

The title calligraphy is fascinating, starting with its semantics. There are two words for "patriotism" in Japanese. Aikoku 愛国 combines the character for "love/affection" 愛 with that for "country" 国. But Mishima chose the second option, yukoku, which swaps “愛 love” for “憂 melancholy, grieve, lament, be anxious, sad, or unhappy."

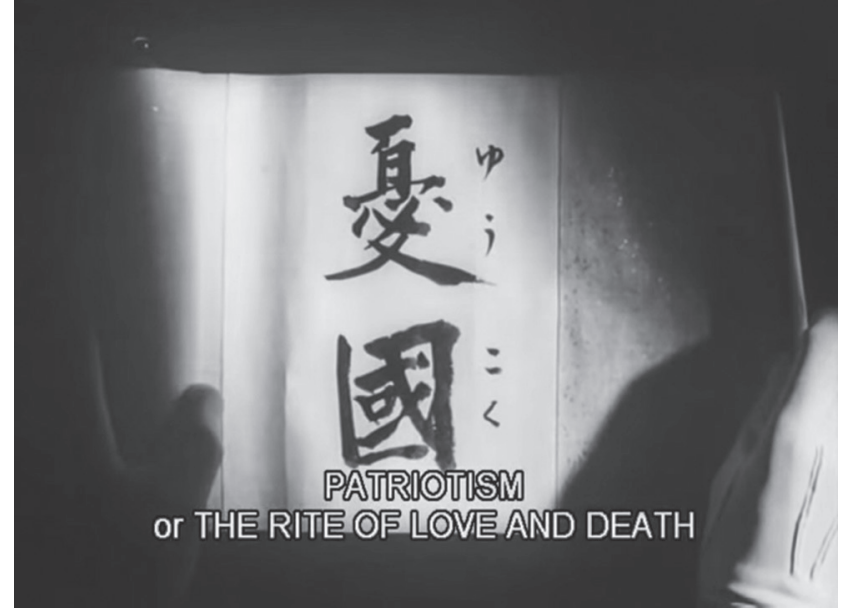

Figure 4.7. The strokes in the title of Patriotism (Yukoku, 1966) pull apart as if they could tumble in a heap, imparting anxiety and doubt, calling into question the very nature of "patriotism."

These are precisely the emotions the soldier feels in the wake of the failed coup. They similarly imbue the tone of the film up to its gruesome climax. Mishima actually signals all this in his calligraphy for the opening title.

At the opening of the film, the gloved hands of the officer open a scroll, revealing the title. The two characters are arranged vertically. The bottom character for country 
國 is beautifully written with a stolid conventionality. It was laid down very slowly and deliberately, inscribing the tempo of Mishima's breathing into the strokes. The top character, $y u$ 憂, is unnaturally elongated, pulling the title into a vaguely triangular shape and drawing the eye to the character for "country." At the same time, the brushwork is strangely loose. The strokes pull apart as if they could tumble in heap. In toto, it imparts anxiety and doubt, undercutting and calling into question the very nature of "patriotism." I showed this to many calligraphers, none of whom had ever seen the film, and all of whom were impressed. They paused to take in the first character, wondering what in the film caused the artist to tamper with the brushstrokes like this. Novelist Mishima painted the film's calligraphy himself. ${ }^{13}$ Clearly his own anxieties about Japan were expressed in his hand.

The second way that calligraphers account for mise-enscène and depart from conventional writing is to create an interplay between writing and the composition of their screenscapes. An impressive example is Sammo Hung's Warriors 2 (Zan xiansheng yu zhaoqian hua, 1978), which is clearly drawn by a serious artist-though not one with a slavish devotion to either convention or the masters (fig. 4.8). In the screenscape, two combatants are suspended in a freeze-frame as they fly in the air toward a brutal collision. The title of the film stretches across the frame from actor to actor. The line of characters displays a symmetry similar to the screenscape, but so much more. The writing becomes progressively smaller toward the middle. The second from the left character is "too small"; having a preponderance of strokes, the artist made it smaller. The swooshing shape of the title calligraphy and the saccading of the eye add a propulsive motion to the frozen image of the screenscape. This calligrapher was truly thinking carefully while planning his attack.

Third, and most unexpectedly, calligraphers' contributions to props on the set unconsciously and profoundly affect mise-en-scène. The interaction of diegetic calligra-

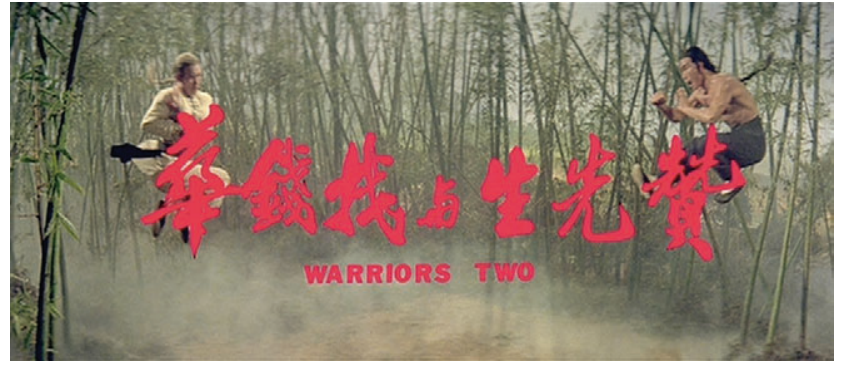

Figure 4.8. The pre-title sequence in Warriors 2 (Zan xian sheng yu zhao qian hua, 1978) ends with this freeze-frame, the line of characters displaying a symmetry echoing the screenscape. The characters also become progressively smaller toward the middle, propelling the eye across the frame.

phy on props is generally determined by conventionalized instinct rather than brilliant, self-conscious and masterful design as in the examples above. Working on my corpus of thousands of images, I came to realize that diegetic calligraphy has a very special relationship to the edge-of the screen, as opposed to the paper. This is one place where the differences between Korean, Japanese, and Chinese cinema are decisively distinct.

In Korean cinema, people are often arranged in front of large folding screens covered with characters-almost like paperscapes adorned with calligraphy (figs. 4.9 and 4.10). Called byeongpung, these screens are markers of class and were particularly important in the Joseon Dynasty (1392-1910) and the colonial era (1910-1945). Thus, in the postwar era, one finds them primarily in historical films. The props department of Namyangju Film Studio is chockfull of byeongpung from past productions (fig. 2.12, upper middle).

Byeongpung are gendered objects. Taking up a lot of space and demanding attention, they were displayed in the area of the home with heated floors-in other words, the domain of the men. I spoke to Gim Hogil, a props man for forty-five years and set designer for over sixty Im Kwon- 
Figure 4.9. In Chunhyang (Chunhyangjeon, 2000), as in other films, Im Kwon-taek typically places characters in front of screenscapes of calligraphy.

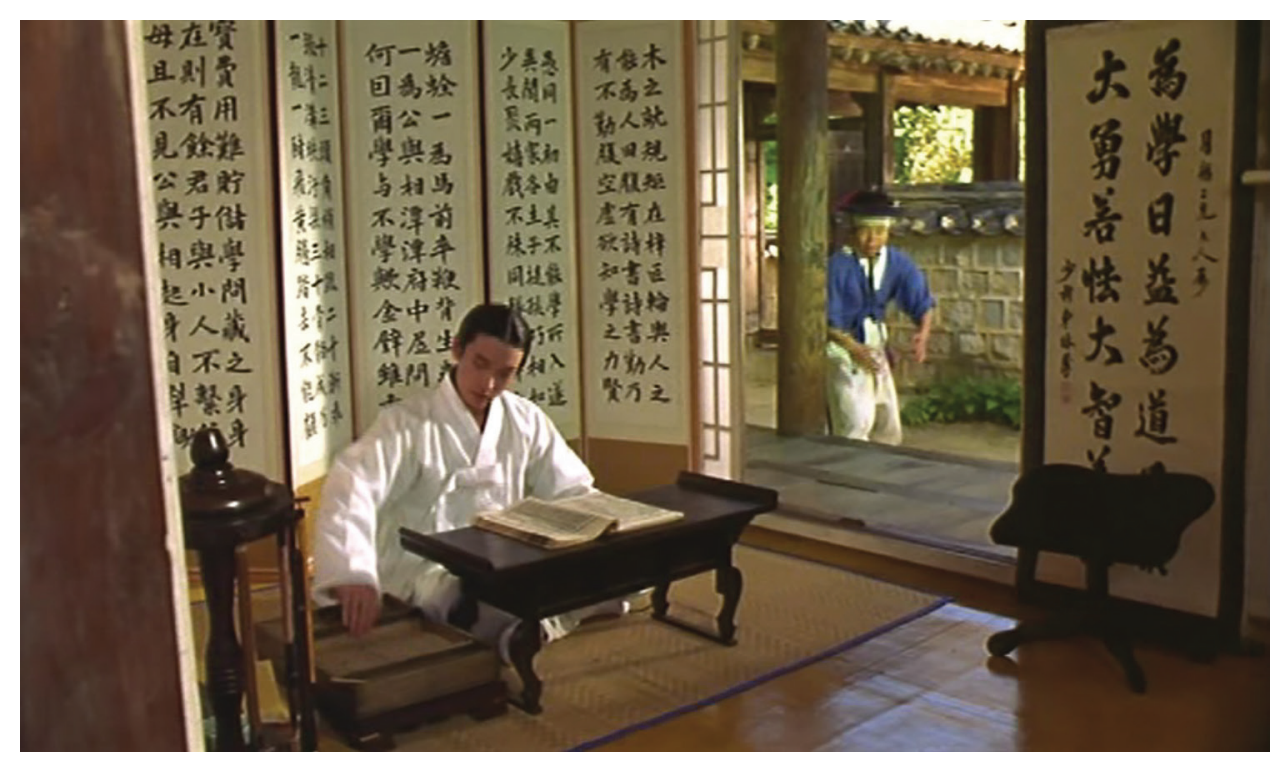

taek films. Gim explained that calligraphic screens were usually commissioned from calligraphers working outside the studio. For films set in Joseon, set designers used these calligraphic screens to mark male spaces, while they use screens with landscape paintings as backdrops for female characters and for weddings.

Japanese filmmakers rarely use these freestanding screens, although one occasionally sees calligraphy ornamenting fusuma screen doors (fig. 3.12). More typical are scroll paintings, especially those placed in tokonoma. These are the special nooks in Japanese style rooms where scroll paintings, pottery, and other decorations are put on display, as in the silent film Ginpei from Koina (Koina no Ginpei, 1933; fig. 4.11) and Kinoshita Keisuke's 24 Eyes (Nijushi no hitomi, 1954; fig. 4.12).

In Japanese cinema, calligraphy is almost always tipping the balance of the composition. When a prop with brushwork appears, it functions as an obtuse decorative element. So filmmakers shuffle them to the far edges of the frame. Orochi shows this sensibility started in the silent era. 24 Eyes may display the scroll in the middle of the frame, but note how the bold vertical line is just offcenter, and the business of the left hand side of the room sets the overall composition off-balance.

Directors in most of the world "naturally" arrange their mise-en-scène according to the so-called "rule of thirds," a globalized rule of thumb for visual composition and visual media of all kinds. This is, in turn, related to the mathematical golden mean. Today's digital cameras even sport viewfinders that place two vertical and two horizontal lines dividing the frame into thirds. The earth's horizon generally sits on one of these lines and objects are arranged at the intersections. However, since the silent era, Japanese filmmakers prefer to place prominent props closer to the edge of the frame.

Nowhere is this truer than with diegetic calligraphy. As argued above, the written word draws our attention as if it emits a force field, and we have the naturalized habit to look whenever it calls for us. So filmmakers must place calligraphic props with care. Positioning at the edges 

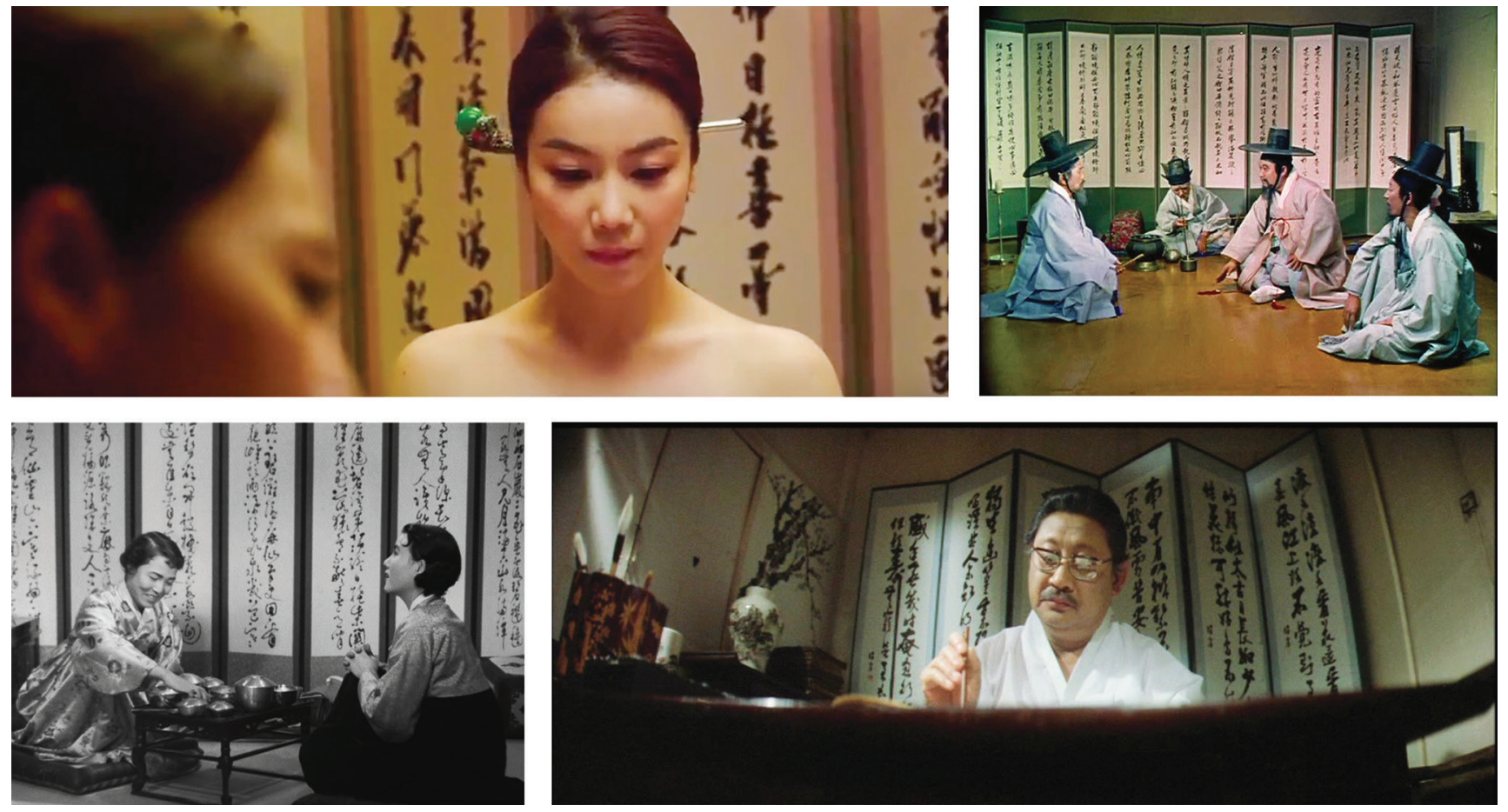

Figure 4.10. Korean period films often create analogues to the screenscape with props. Here are typical examples (clockwise from the upper left) from The Villainess (Aknyeo, 2017), The Happy Day of Maeng Jin-sa (Maeng Jin-sadaek gyeongsa, 1962), Genealogy (Jokbo, 1979), and Madame Freedom (Jayu buin, 1956).

makes for a very dynamic frame, opening up the rest of the space for the actors to accomplish their narrative business. Alternatively, when calligraphy appears on moving props, it comes to organize the staging, as opposed to anchoring the mise-en-scène. A typical prop for this is the traditional umbrella (figs. 2.7, 4.13, and 4.14).

This sensibility runs deep. Even for an otherwise symmetrical two shot in Brother, Kitano Takeshi puts a plate with the character for "morality/righteousness/honor/ justice" (義) between two gangsters (fig. 4.15). However, Kitano, playing the character on the right, pushes the cal- ligraphic prop just ever so off-center. This adds delicious irony to the otherwise stable and heroic symmetry of the image, while being thoroughly standard composition in Japanese.

At the same time, overtly modernist projects actually centered calligraphic props. For example, when the officer of the failed 228 coup in Patriotism makes love to his wife, it is in a blank white space on a centered platform below a massive scroll—painted by the novelist himself-with the word "sincerity/devotion" (shisei 至誠; fig. 4.16). Yoshida Kiju, infamous for his remarkably abstract visual composi- 


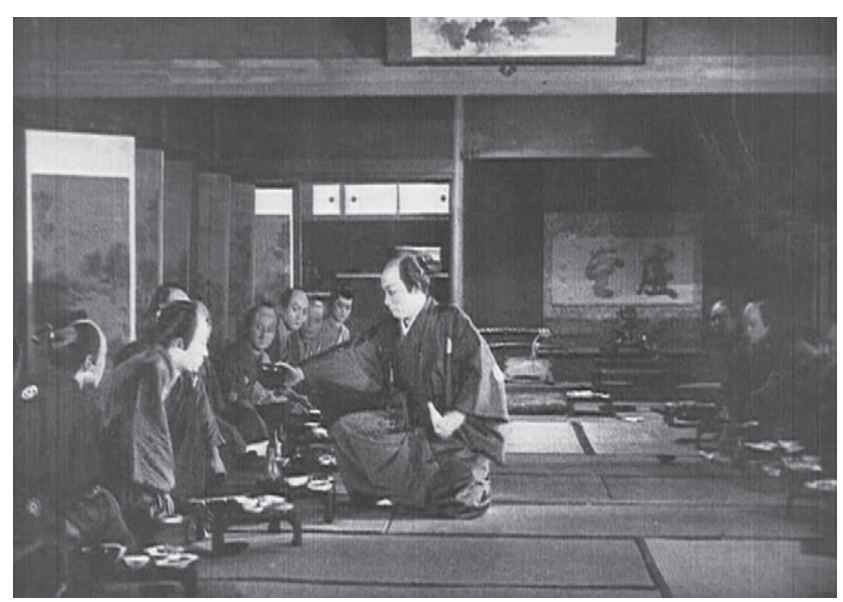

Figure 4.11. Calligraphic screens are relatively unusual in Japanese cinema. However, one scene in Ginpei from Koina (Koina no Ginpei, Yuki no Wataridori, 1934) has both, screens along the left edge and a massive scroll in the right-hand tokonoma.

tion, also made a film about the same incident called Coup d'état (Kaigenrei, 1973). In one scene, a framed painting of 真明 shinmei, lit. "true light," sits precisely in the center of the cinematic frame while the actors- their faces cut off at the nose-perform in the lower left corner.

Another modernist intent on breaking convention was Kobayashi Masaki. In contrast to both conventional Japanese mise-en-scène and the use of folding screens in Korea, consider Hara Kiri (1962). The screen in fig. 1.6 is placed in the foreground and is darkly lit, with the unadorned backside facing the camera and hiding half the cinematic space. The tokonoma - which is in the corner of the room-is centered and graced with a stunningly cursive character. Here again, the centered, symmetrical composition constitutes an artful departure from convention.

The opposite is true in Chinese language cinema. In Chinese film, the brushed letter exerts a rather strange pressure on the mise-en-scène. When there is calligraphy

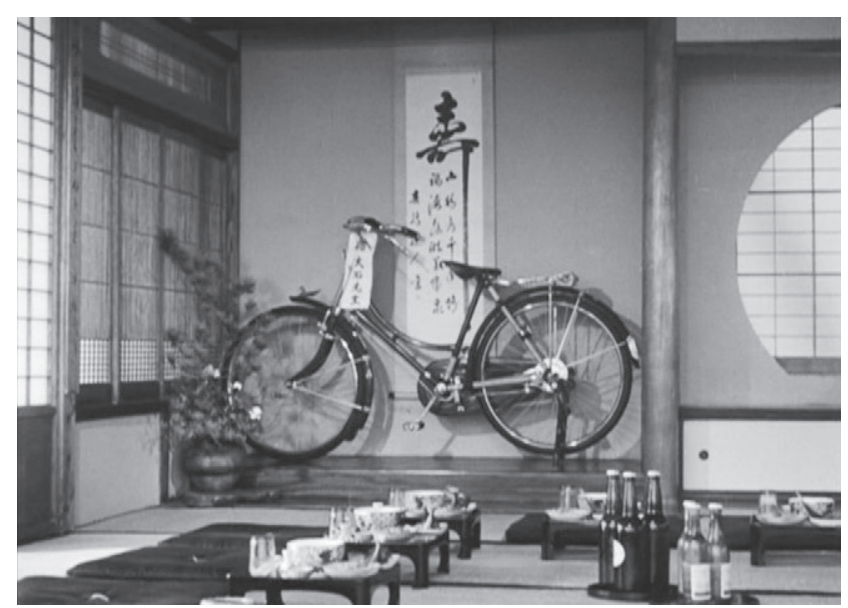

Figure 4.12. A present sits in the honored space of a tokonoma in 24 Eyes (Niju-shi no hitomi, 1954), the vertical stroke of the calligraphy carefully displaced from the very center of the frame.

on the set, the composition snaps, as if by magic, into strikingly perfect symmetry. This is a form of visual composition quite unusual in world cinema. We either associate it with formalist directors (Wes Anderson, Stanley Cooper, Xavier Dolan) or fascists (Leni Riefenstahl) or films otherwise obsessed with power (think any Star Wars film). This is precisely why Spanish surrealist Luis Buñuel has the bourgeois father of Phantom of Liberty (Le fantôme de la liberté, 1974) say, "I am sick of symmetry" as he pushes a framed tarantula from the center of his mantlepiece to the far end next to a gilt candelabra.

Chinese directors have no such revulsion for symmetry. Rather, they clearly feel compelled to produce it whenever calligraphy enters the frame. One reason, perhaps the way it all started, is surely architectural. Traditional Chinese architecture, from personal homes to the Forbidden City, made great use of symmetrically organized space. This guided the placement of both ornamentation and 

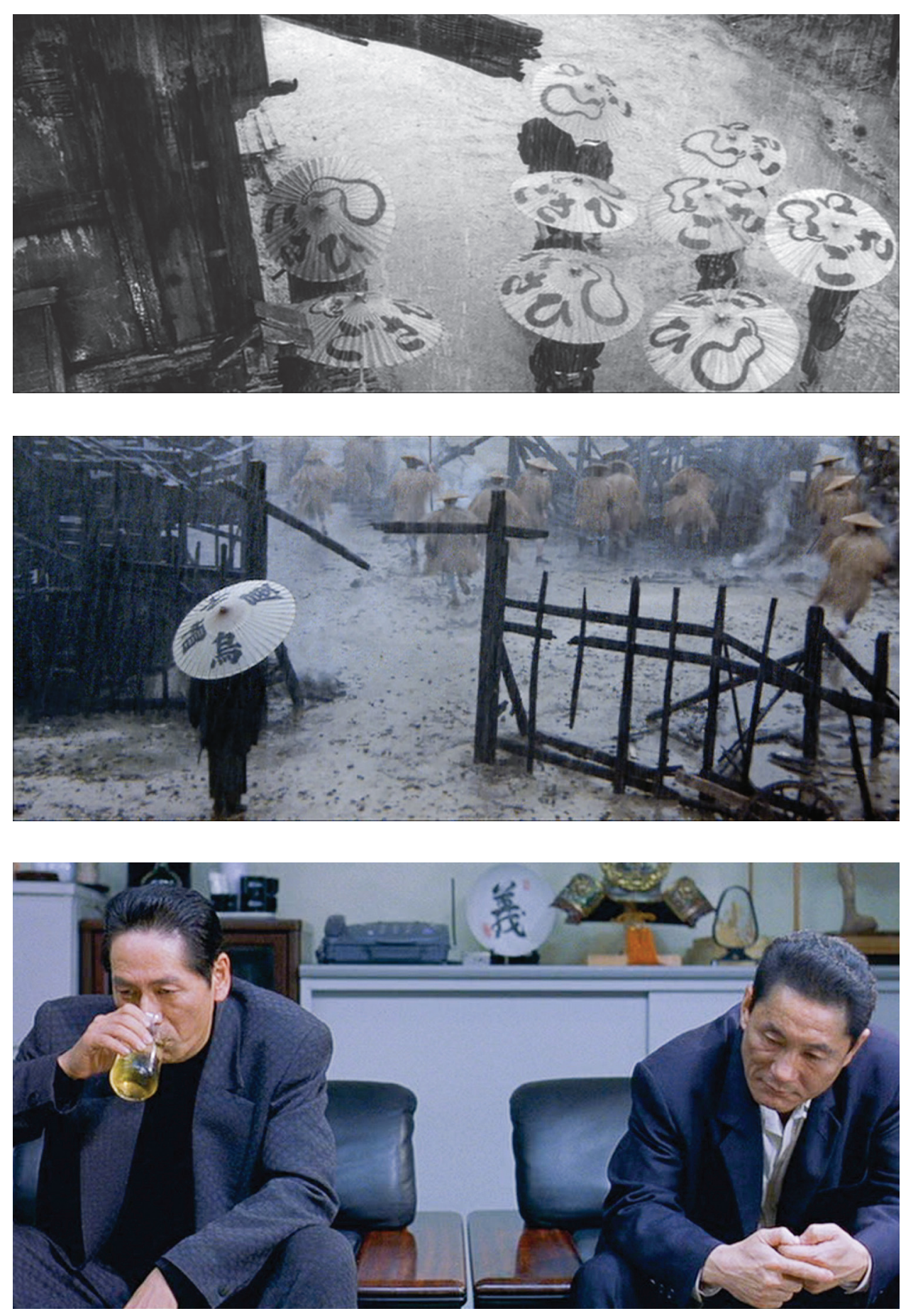

Figure 4.13. Kill! (Kiru, 1968): staging actors' movement starts with the calligraphic props.

Figure 4.14. The strong image of the calligraphic umbrella tilts the composition in Zatoichi Meets Yojimbo (Zatoichi to Yojinbo, 1970).

Figure 4.15. In Brother, the two yakuza may be arranged with perfect symmetry, but the calligraphic plate is pushed ever so slightly off-center. 


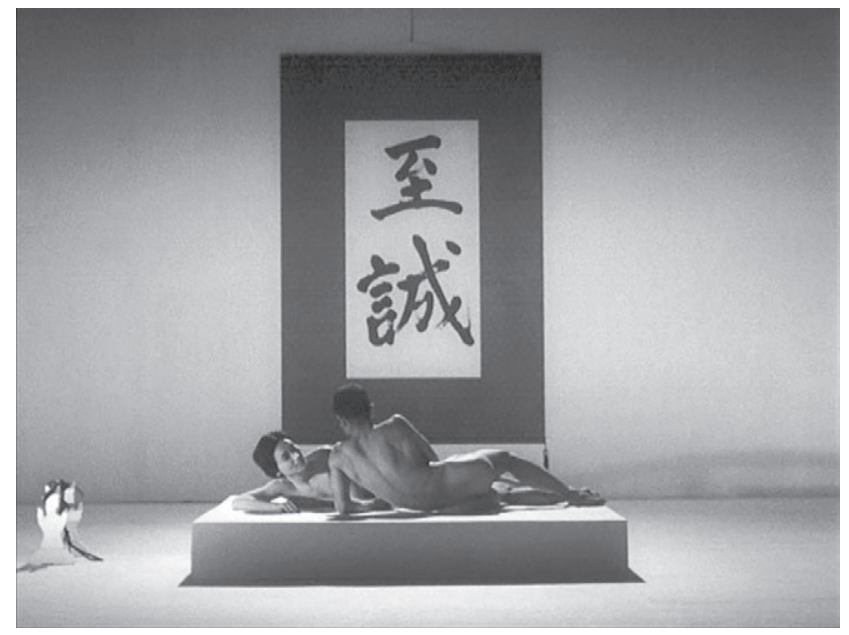

Figure 4.16. Patriotism (Yukoku, 1966)-the couple makes love one last time before suicide beneath a massive scroll painting with the word for "sincerity" and "devotion." Modernist aesthetics call for centering in Japan.

furniture. One common use of calligraphy was on large plaques often centered high above the floor, a typical prop in period films. However, by far, the most important calligraphic prop in Chinese film is the couplet. This refers to a rule-bound form of poetry often displayed on side-byside scrolls, although in cinema it usually shows up as duilian, strips of paper pasted on either side of door frames (and often with a third piece centered above the door).

Figure 6.10 shows some actual couplets greeting visitors to the Li Xianting Film Fund in Songzhuang, the artist colony outside the sixth ring road in Beijing. This was the site of the most important film festival for nonofficial, independent work-before it was repeatedly shut down by authorities. The couplets on this door to their theater say "Free Thought, Free Style" and "Independent Consciousness Independent Moving Images." These couplets, written by Li himself, are written and displayed in the face of police pressure to cut back their activities, especially the Beijing Independent Film Festival. (Another example from the front door of this hutong compound is in the author's profile at the end of this book.) However, most couplets are poetic and wishing for good luck, and they are to be found everywhere in Taiwan, Hong Kong, and the PRC. Naturally, they regularly appear in Chinese language cinema.

One often sees creative variations. A Summer at Grandpa's (Dongdong de jiaqi, 1984; fig. 4.18) has a strong example. This is probably because it features a complex combination of graphic and cultural elements that bear down on the cinematography. It is a formal wedding ceremony. There are couplets on the wall, with two candles before them. A priest stands precisely in the middle, his robe split by symmetrical red trim and with his hands splayed out to either side. Above his head is a bold circle with the symmetrical character for double happiness. It shines in red neon, no less. Moreover, not one but two couples bow before the priest, in synch. It is a scene that demands symmetry.

Chinese films made with modernist sensibilities sometimes eschew symmetry. For example, in Yellow Earth (Huang tudi, 1984) director Chen Kaige and cinematographer Zhang Yimou were working against the socialist realism - a truly monumental style - that dominated cinematic aesthetics in the PRC. An important setting is the doorway of a farmer's home. The soldier notices the home's couplet has only brushed circles (fig. 4.19). He offers to paint a proper poem, but she refuses. Being illiterate, it is the same either way for her. In his subsequent work, particularly the spectacular period films, Zhang uses symmetry as much as any other Chinese director-which is to say it like every other director (see figs. 3.13 and 4.21). On the other hand, even a director known for obtuse compositions like Tsai Ming-liang will still center rare instances of calligraphy amidst a chaos of lines shooting in every which direction (fig. 4.20). It is that deeply ingrained.

I once asked Zhang Yimou's cinematographer, Zhao Xiaoding, about the preponderance of symmetrical composition in Chinese cinema. He had just finished work on Shadow (Ying, 2018; fig. 4.21), which is stunningly filled 


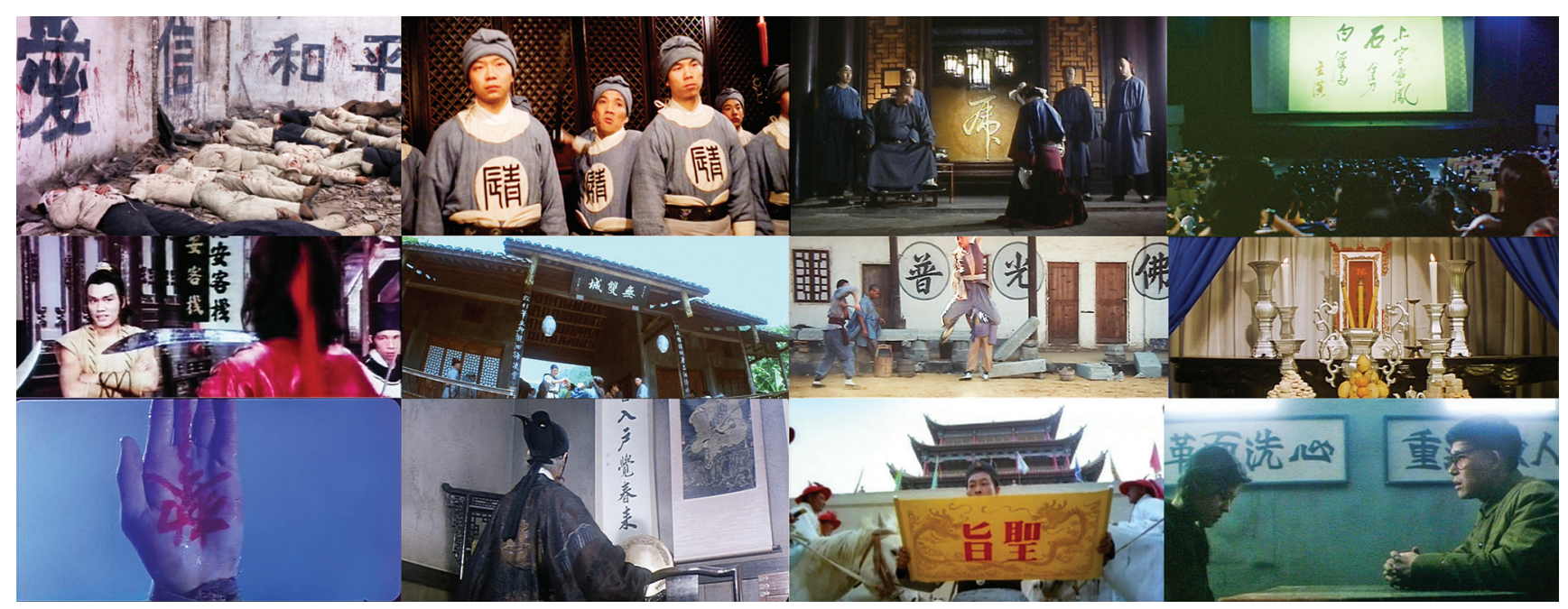

Figure 4.17. These compositions all deploy symmetry, but not to the ends of monumentality (clockwise from upper left, ending in the middle): Black Sun (Hei tai yang nan jing da ceng sha, 1995), Goodbye Dragon Inn (Busan, 2003), Fong Sai Yuk I (Fong Sai Yuk, 1993), Fight Back to School (Tao Xue Wei Lung, 1991), The Sword (Ming jian, 1980), Blue Kite (Lan fengzheng, 1993), Dragon Inn (Long men xia zhang, 1992), Swordsman (Xiao ao jiang hu, 1990), Chinese Ghost Story I (Qing nu You hun, 1987), One-Armed Swordsman (Duk bei dou, 1967), Storm Riders (Fung wan: Hung ba tin ha, 1998), and South Shaolin Master (Nan quan wang, 1984).

with both calligraphy and symmetry. His answer could have been ripped from any introduction to cinema textbook in English: symmetrical composition imparts a sense of power, stability, and monumentality. Of course, this is also how it is used in most Chinese movies. However, that does not account for the hospital doorway in Platform (Zhantai, 2000; fig. 3.6), the title of Warriors 2 (fig. 4.8), or the calligraphic talisman pasted to zombies in Mr. Vampire (fig. 4.3), and countless other examples neither monumental nor trying to express power. None of the Chinese cinematography manuals account for this broad tendency of Chinese language cinema.

Here, as in Korean and Japanese cinema, the very presence of calligraphy on the set exerts enormous pressure on mise-en-scène. Sets are built, lights are set, cameras are placed, and actors are arranged to display calligraphic props, to capture and amplify their force through culturally specific forms. As Xu Bing's work demonstrates, calligraphy engages powerful habits of mind in the human animal.

There are explanations for this in well-known ancient treatises, which are interesting for their somatic approach. One common theme in calligraphic theory from early on is the way brushwork channels qi 気, a fundamental concept in Chinese philosophy. It is often translated as "energy" or "life force." Works of calligraphy marshal, transform, and 
Figure 4.18. In A Summer at Grandpa's (Dong dong de jianqi, 1984), Hou Hsiao-hsien replaces the calligraphic double happiness over a Christian altar with a neon version bracketed by traditional calligraphic couplets.

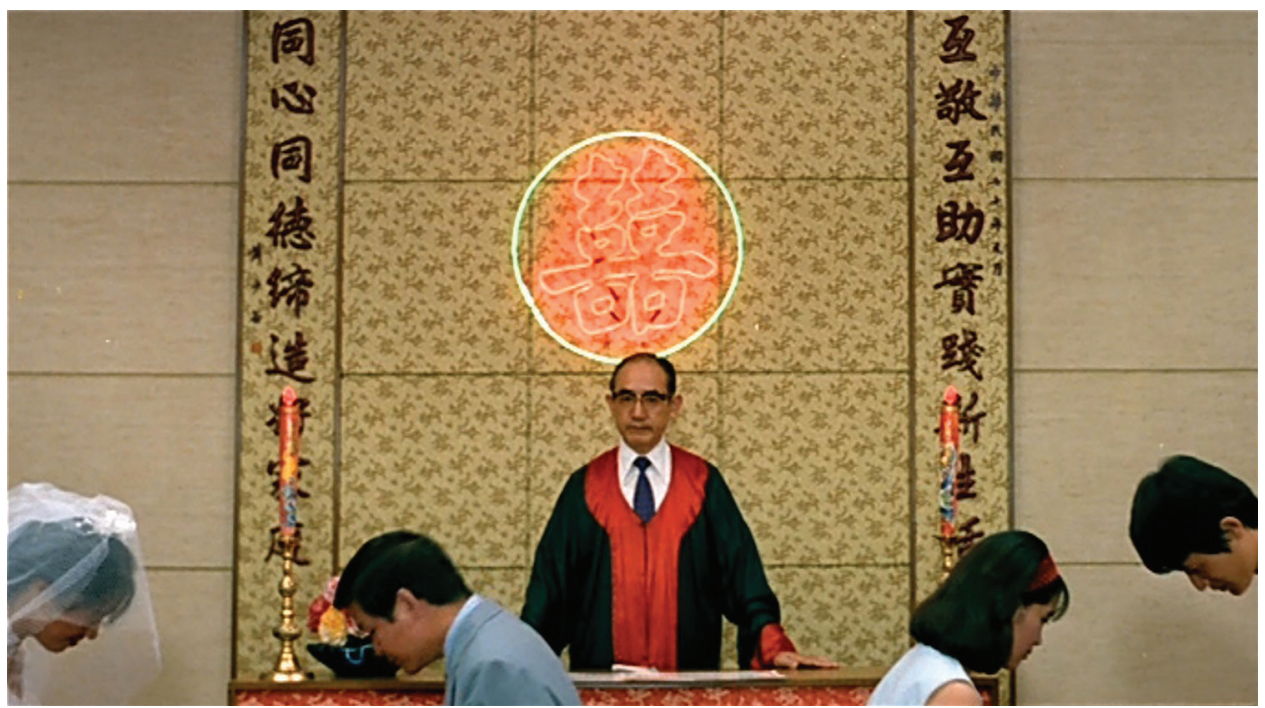

Figure 4.19. The soldier from Yellow Earth (Huang tudi, 1984), framed by couplets with circles instead of characters because the owner is an illiterate farmer.

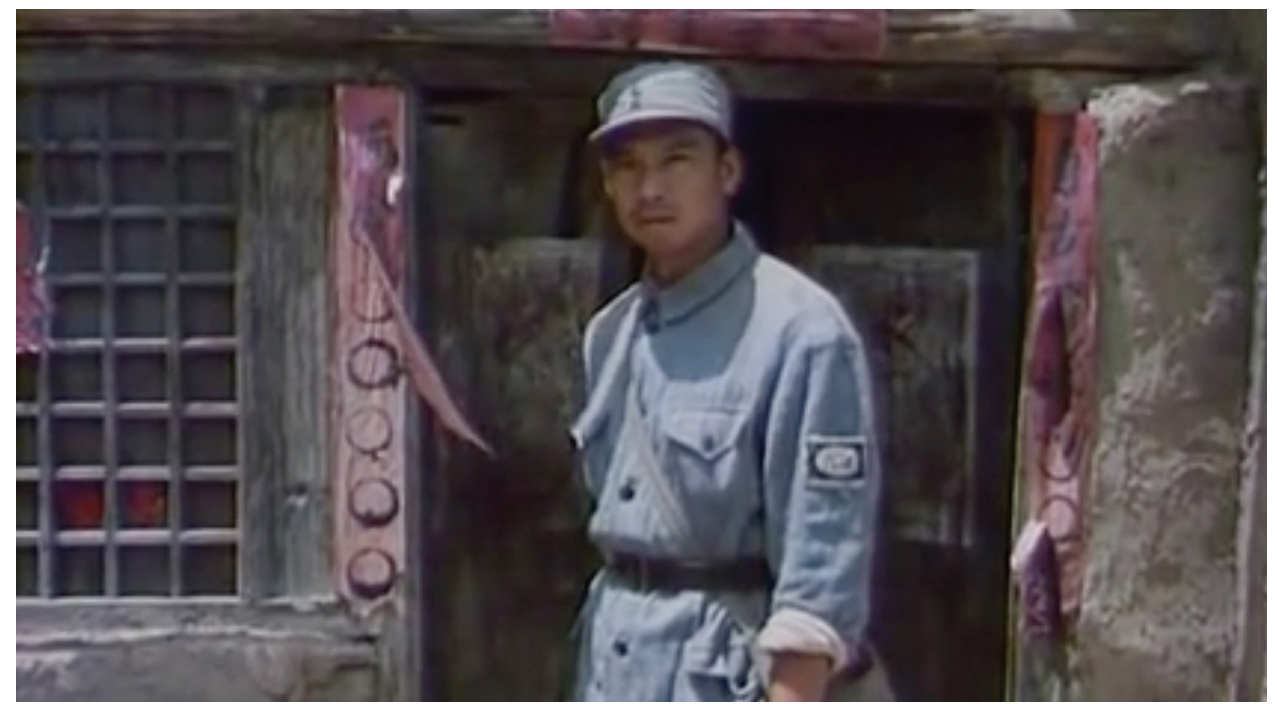

express qi. As Yen Yuehping puts it, "the Chinese traditionally understand that the macrocosmic universes and the microcosmic human body interpenetrate one another in a shifting relationship, and $q i$, the quasi-substance-cumquasi-energy, interconnects the two systems. Therefore, the calligraphic work is seen as an embodiment of the cosmic qi mediated through the calligrapher's body." ${ }^{14}$ Art historian John Hay traces this theorization to ancient Chinese medicine, the principles of which were established just prior to the invention of calligraphy. This probably 
accounts for the rich archive of physiological metaphors in calligraphy theory. At the same time, it might explain the peculiar phenomenon of non-majestic symmetry in Chinese film. Hay writes,

In connection with these patterns of energy transformation, we should note the remarkable prevalence of resonance in Chinese art. Whether it be the rhythmic repetition of basic units such as pillars and brackets in architecture, the constant echoes of parallelism in literature, or even the psychological echoing of one artist representing (fang 倣) another, in all of these we can identify resonance as a constant factor. ${ }^{15}$

I am unprepared to subscribe automatically to the ancient philosophical underpinnings of $q i$, but the aesthetic consequences of this visual resonance are palpable to any spectator. In other words, the calligraphic symmetry of Chinese cinema, the calligraphic screenscapes of Korean cinema, and the oblique compositions of Japanese cinema are not about fascistic or religious ecstasy, but rather the creation of resonance through repetition of form and its attendant visual vibrations.

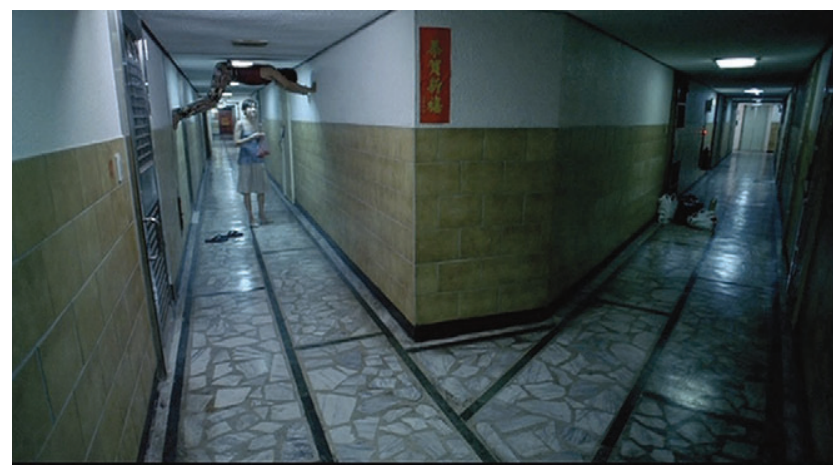

Figure 4.20. Even in a modernist work like Tsai Ming-liang's Wayward Cloud (Tianbian yi duo yun, 2005), calligraphy calls for symmetry.

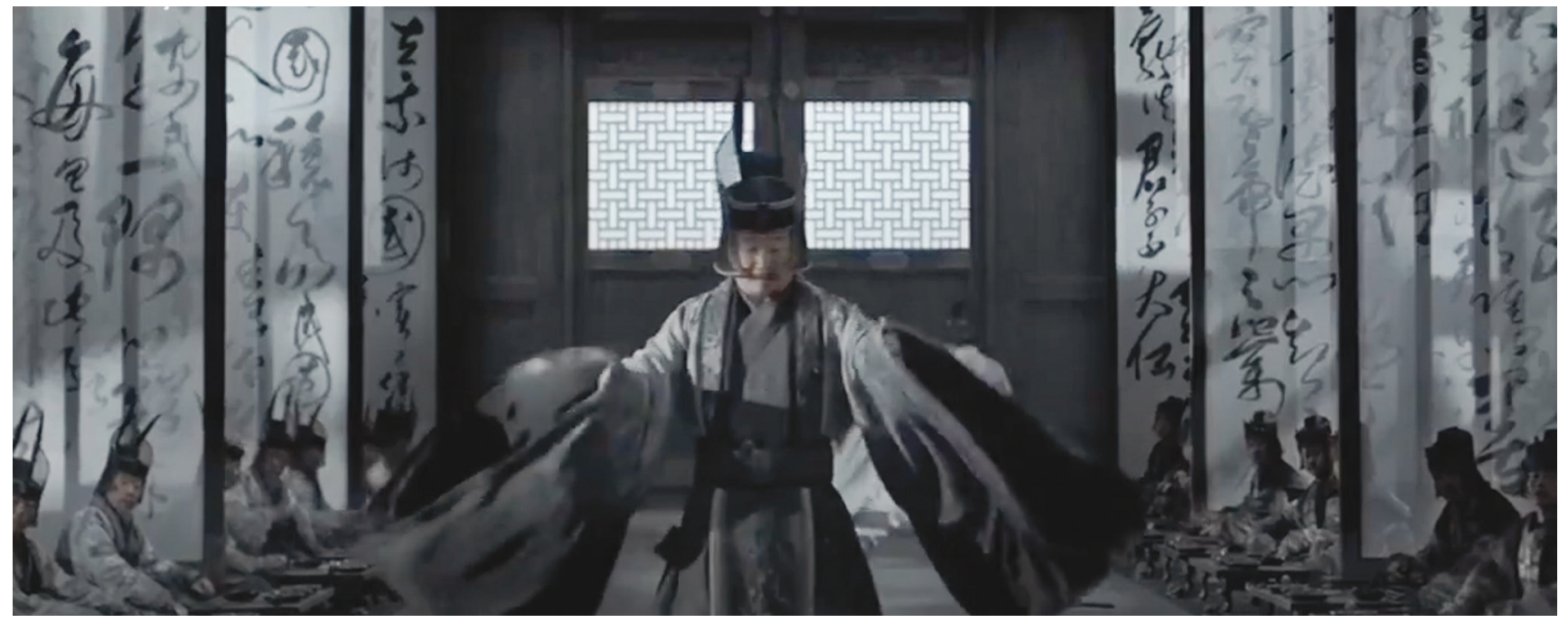

Figure 4.21. The stunning Shadow (Lan fengzheng, 1994) by Zhang Yimou snaps into symmetry whenever calligraphic props appear. 
Notes

1. The analogous terms in other languages are not as evocative. In Korea, cursive characters "flow" (heullim-che) and in Chinese, characters are “wild” (kuangcao, 狂草).

2. Adal, “Japan's Bifurcated Modernity: Writing and Calligraphy in Japanese Public Schools, 1872-1943," 243.

3. Lamarre, op. cit.

4. Sun Guoting is also known as Sun Qianli (孙虔礼).

5. Rojas, "Xu Bing's Dialogue with China's Cultural History"; Silbergeld, "Introduction," 20.

6. Harrist, "Book from the Sky at Princeton," 32-33.

7. Hammers, Socialist Concerns in the Aesthetics of Roger Fry.

8. Powers, "The Cultural Politics of the Brushstroke."

9. Bogdanova-Kummer, "The Line Between Calligraphy and Painting: A View from Post-War Japan," 124.

10. There is a similarly unfortunate disconnect through extreme abstraction in the sound experiments of Tone Yasunao. In his 1976 piece Voice and Phenomenon, he combines a performance of writing calligraphy with found images that match pictographic characters selected from premodern Chinese poetry. He riffed on this basic concept using scanned characters for Molecu- lar Music (1982) and writing on a computer pad for 495,63 (2007), deploying computers to convert the calligraphy into sound. In this way, Tone combines the extra-linguistic dream of the pictogram with an electronic translation into noise-evacuating the human along the way, and losing the most interesting aspect of the brushed word. 495,63 can be seen here: https://youtu.be/_ gQ4zOxVWJM

11. Neuroscience scholarship on mirror neurons suggests that looking at an action can fire the neural pathways laid when the action was previously performed. It follows that watching moving images of people writing calligraphy would by more powerful for East Asian spectators who were trained in writing by brush. It would be interesting to run experiments that investigate whether looking at works of calligraphy excite the brain in any similar ways.

12. Barnet and W. Burto, The Written Image, 29.

13. Interview with producer Kuzui Kinshiro, March 16, 2005.

14. Yen, Calligraphy and Power in Contemporary Chinese Society, 158.

15. Hay, "The Human Body as a Microcosmic Source of Macrocosmic Values in Calligraphy," 196. 


\section{CHAPTER 5}

\section{A Prop Unlike Any Other}

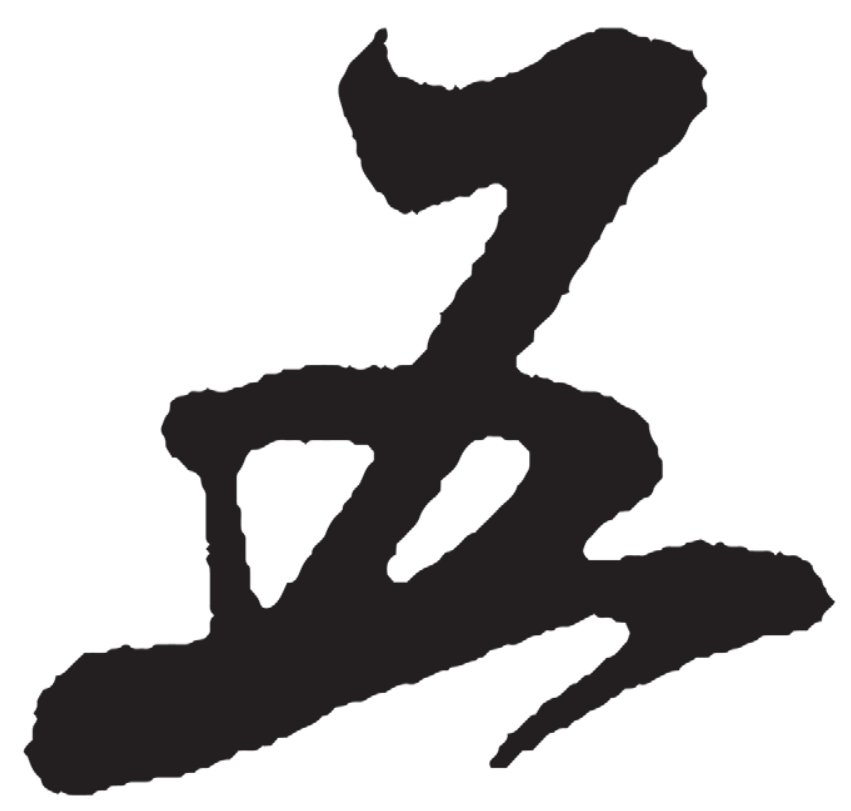

\section{Hou Hsiao-hsien and Narrative Space}

In the previous chapter, I demonstrated how works of calligraphy are props unlike any other. They simultaneously grab the viewer's attention and exert unusual pressure on cinematic composition. They demand accounting for, whether they are legible or not. It is why Korean filmmakers drape backgrounds in swathes of brushed characters, why those in Japan shuttle calligraphic props to the edges of the frame, and why Chinese default to symmetry. Alternatively, it is why Itami Juzo ordered his staff to hide anything with calligraphy on it-even when shooting on the street. We've also seen how art designers, screenwriters and directors capitalize on the brushed Chinese character's differences from typography. Millenia of imitative practice has made calligraphy a remarkable resource. Being both linguistic and visual, its conventions are readymade to evoke historical period, express aesthetic sensibility, and comment on or create narrative meaning.

The aesthetic and narrative treatment of calligraphy achieves remarkable complexity in the cinema of Taiwan's Hou Hsiao-hsien. This chapter will use Hou as a case study, particularly his City of Sadness (Beiqing chengshi, 1989), to pull together the many discoveries and problematics the book has dealt with thus far. ${ }^{1}$ We will then turn, in the final chapter, to one last revelatory connection between calligraphy and cinema. 
Let's begin here with a quote from a pivotal essay from the history of film theory. In his theorization of cinematic narrative, Stephen Heath writes,

The centre [of film] is the movement, not movements but the logic of a consequent and temporally coherent action. The vision of the image is its narrative clarity and that clarity hangs on the conversion of space into place, the constant realization of a center in function of narrative purpose, narrative movement. ${ }^{2}$

Heath is writing about the narrative structures and operations of the Hollywood classical style, the coherence and seamlessness of which he pits against the art cinema of Jean-Luc Godard and Straub-Huillet. These latter filmmakers, for Heath, represent a more complex address with a "certain freedom of contradictions." $\mathrm{He}$ is, of course, mounting an ideological attack on Hollywood to valorize the art cinema alternative. I will not rehearse the theories of suture here, but I am interested in the way Hou Hsiaohsien converts space into place in a way that Heath did not anticipate but which he would surely approve of. On the face of it, Hou would seem to affiliate with the other two filmmakers, as his films feel too oblique to think of as "centered around narrative purpose" and do seem to offer up the freedom to contemplate daily reality with all its contradictions, qualities that Heath promotes. Indeed, what is so striking about the cinema of Hou Hsiao-hsien is its odd combination of randomness - of narrative events, of mise-en-scène, of narrative space-with masterful control. That these two are brought into spectacular tension is our starting point here. It is here that calligraphy plays a role as a prop unlike any other.

Hou's approach to cinema is singular. One knows it when one sees it. This is his real connection to the Japanese filmmaker Ozu Yasujiro, to whom he is often compared. They both developed such idiosyncratic approaches to narrative cinema that no one truly mimics them, either because their styles are too specific or simply too difficult to pull off. As for Hou, he has, over the decades, steadily loosened up what appeared to be a complex set of unwritten rules. They were at their most rigid and rigorous in City of Sadness: put simply, Hou liked to find a particular view on a given location and stubbornly stick to it. He set an axis of viewing through the set, moving his camera forward and backward with only the occasional (and strategic) pan or track. Close-ups were rare and the long take standard. Shot-reverse shot figures are oddly staged, the few times he uses them. ${ }^{4}$

This makes for a unique conversion of space into place. One becomes hyperaware of off-screen space because of the lack of pans and reverse shots, a feature one finds in the work of other Taiwanese directors, most notably Edward Yang. ${ }^{5}$ Spaces remain slightly disorienting and opaqueremain space at some level-until the gradual repetition of views nurtures a familiarity with their nooks, crannies, pathways, and the objects contained therein. And one of the most interesting of objects is definitely calligraphy and its role in the construction of this peculiar narrative space.

Arguably, the construction of narrative space begins with title cards, which instantly set a context for the photographic images to follow. Hou's early films all used a standard non-serifed typeface typical of Central Motion Picture Company productions of the era. After he went independent, the director captured the freedom to design title sequences for each film. He usually used typefaces, with the most notable calligraphic title gracing Good Men, Good Women (Haonan haonu, 1995; fig. 5.1). Hou explains his choice:

I go by instinct. It ultimately depends on the content. In the case of City of Sadness, the title contains the strong word "sorrow" (beiqing 悲情). It describes an emotion and is pretty powerful. Because of this, I chose to use typography. In a way it expresses sadness better. In contrast, I chose calligraphy for Good Men, 


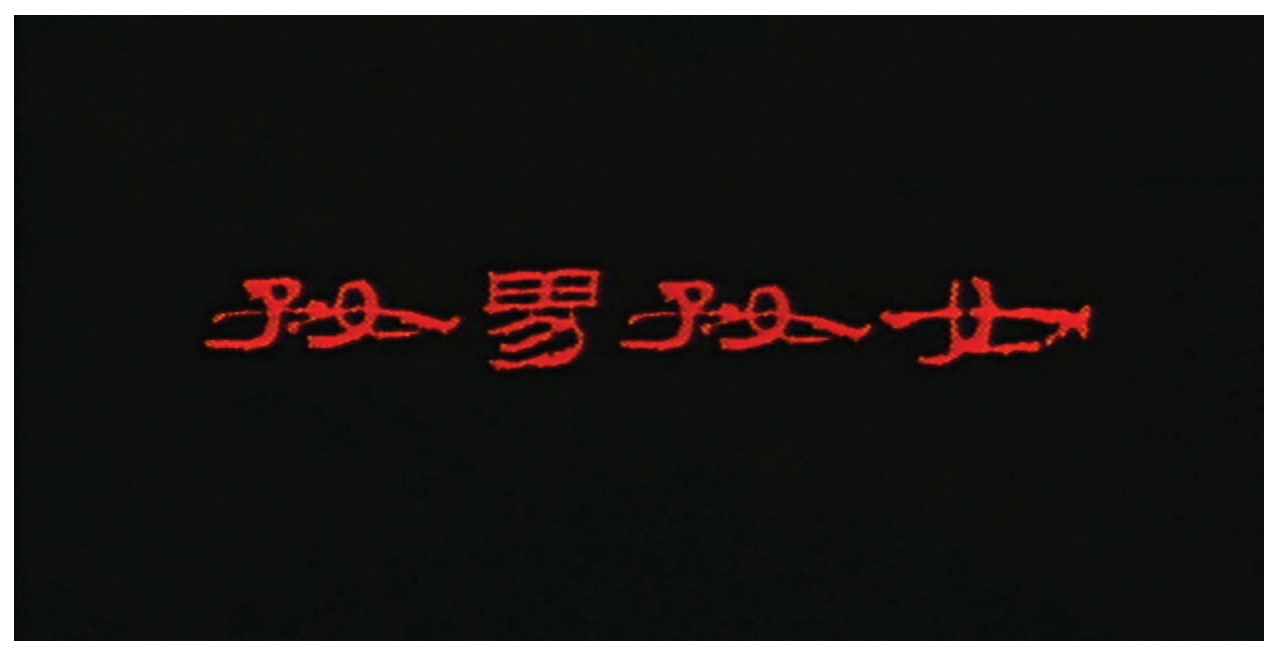

Figure 5.1. Hou Hsiao-hsien constructed the title for Good Men, Good Women (Haonan haonu, 1995) by cutting and pasting from an art book on ancient calligraphy.

Good Women because the film itself called for it. I went through an art book filled with many examples of works by famous old calligraphers. When I found one I liked, I just cut out the three characters I needed and put them together. ${ }^{6}$

We have seen how this montage of characters is not atypical in the age of the digital remix. That Hou did this back in 1995 is revealing. It belies his casual attitude about calligraphy - something rather at odds with the overarching control of his unique approach to cinema.

With few exceptions, Hou eschews symmetrical miseen-scène, even for sets decorated with couplets. The mirrored structure of the couplet, gracing either walls or portals, exerts no pressure on Hou and his cinematographers. Other values guide their composition, notably the geometric complexities and possibilities of the built environment, particularly that of Chinese and Japanese architecture with its proliferation of frames-screens, sliding doors, windows, and walls with the wooden framework exposed. This is not the off-kilter composition of Japanese cinema. At the same time, what appears to be ad hoc and random at first glance seems to have a certain tendency, if not a logic. Calligraphy, when it appears in Hou's films, gravitates toward the center, even if it is rarely centered. The axis of the camera is always nudged away, pushing the sign, painting, or couplet slightly to the side.

Considering this seemingly clever exception to the symmetrical mise-en-scène of most Chinese-language cinema, perhaps Hou's departures from the conventional framing of calligraphy are less casual than they seem. In the pages that follow, I would like to explore these many aspects of the cinematic calligraph in Hou's most complex and powerful film to date, City of Sadness.

\section{Telling Time}

What if we were to assume a rigorous placement of calligraphy, as opposed to indiscriminate or slapdash? ${ }^{7}$ After all, everything else about Hou's filmic form seems to be so calculated. While there is one scene in City of Sadness that features calligraphy quite prominently, most viewers would probably ask, "What calligraphy?" For them, the analysis 

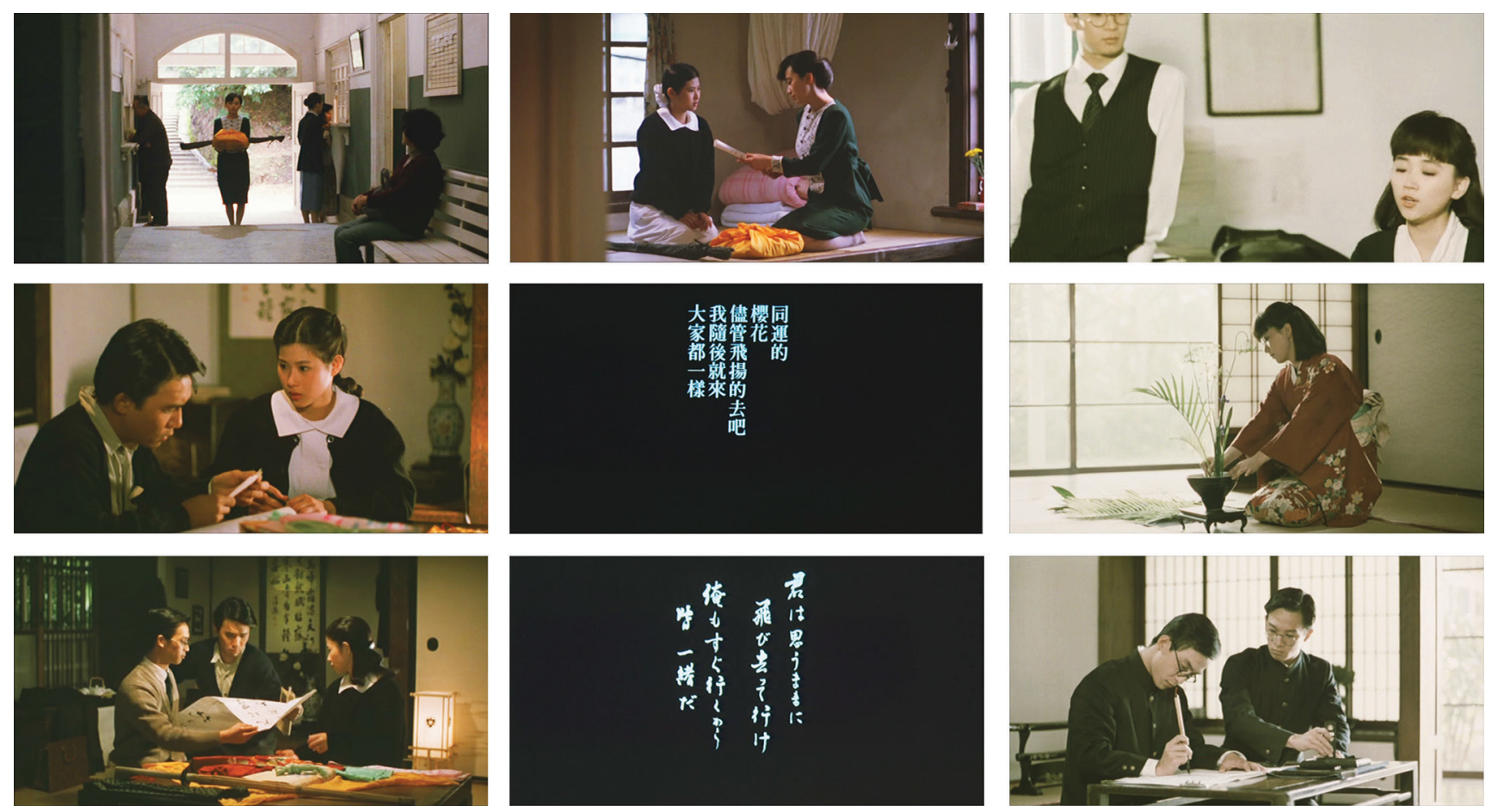

Figure 5.2. The complex temporality of the calligraph is made palpably clear in the sequence most prominently featuring calligraphy from City of Sadness (Beiqing chengshi, 1989). The sequence starts from upper-left, moving clockwise to the center image.

may come at some surprise. It will jog their memories by pointing to the ubiquity of the brushed word throughout this film, which is so full of different kinds of writing. Indeed, it is the many forms of writing that help make City of Sadness such a complex work of art. The script that inevitably attracts the most attention are the intertitles. The photographer at the putative center of the story, Wenching, is a deaf-mute. To communicate, he and his silent interlocutors scribble in notebooks. Hou gives us access to these nonverbal conversations through silent cinema-style intertitles. $^{8}$

Another major form of writing in the film-also hand- written with pen or pencil-is the diary of Wen-ching's lover Hinomi. Along with Wen-ching's intertitles, her writing establishes her as a second major enunciative source for the narrative. As Emilie Yueh-yu Yeh and I discuss in Staging Memories: Hou Hsiao-hsien's A City of Sadness, these are the wellsprings of the storytelling. Significantly, both defy the pedagogical nation building of the newly arrived Kuomintang (KMT), with its loudspeaker and radio proclamations. That these writings are by a deafmute and a woman build a rich irony into what could be a heavy-handed nationalist project in less skilled hands.

The complex temporality of the calligraph is made pal- 
pably clear in the sequence most prominently featuring calligraphy. It occurs twenty-five minutes into the film when a Japanese woman arrives at the hospital to bid farewell to Hinomi (fig. 5.2: this first shot is at the upper left corner). She bears gifts: a kimono, a bamboo kendo sword, and a calligraphic scroll. The two sit, side-by-side in formal Japanese style on tatami (fig. 5.2: top-center). Sachiko, the Japanese woman, explains that the painting is for Hinoe's brother, who was present when her own brother wrote it.

This sets the stage for a flashback which arrives unmarked-a typical strategy employed by Hou that builds layers of ambiguity and undecidable temporalities into his narrative. Here, the jump in time is indicated only by Sachiko's hairstyle and a subtle change in lighting. She plays "Red Dragonfly" (“Akatonbo"), a Japanese children's song, for Hinoe's class of students (fig. 5.2: top-right). Her diegetic song slowly dissolves into a non-diegetic solo piano rendition and another undecidable ellipsis leading to an image of Sachiko wearing the kimono to arrange flowers (fig. 5.2: center-right).

The scene of writing arrives after yet another ellipsis (fig. 5.2: bottom-right). Sachiko's brother carefully brushes a Japanese poem for the scroll while Hinoe observes, all the while grinding ink on an inkstone. The gifted painting, we learn, was created collaboratively. An intertitle displays not just the poem's Japanese-language text, but the calligraphic painting itself (see fig. 5.2: bottom-center):

\section{Fly away as you like \\ I too will soon follow \\ We all together}

A voiceover intones the poem in Japanese-the voice inflected with a Chinese accent. Upon finishing the reading, the intertitle gives way to a view of Hinoe, Hinomi, and Wen-ching, as the sister delivers the presents to her brother; another ellipsis has taken place (fig. 5.2: bottomleft). The voice now diegetic, we retrospectively realize the flashback actually ended with the calligraphic intertitlealthough the previous time's music continued-and the present of the film is flung forward to a Taiwan newly absent of Japanese. Incredibly, the complex layering of time continues. Hinoe begins telling a story about Japanese sentiments surrounding death and dying, as Wenching scrutinizes the painting in the background. Halfway through his story, Hinoe's story is interrupted, disappearing with a cut, and Hinomi finishes the story off by writing in Wen-ching's notebook (fig. 5.2: center-left). Instead of intertitles, we hear Hinomi reading her text in voice-over. The scene finally ends with a silent soundtrack, the music having slowly faded to quiet, and a typographic silentcinema-style intertitle finally delivers a Chinese translation of the calligraphic painting (fig. 5.2: center). The next scene returns us to the hospital entranceway where the phenomenally complex sequence began. Hou has woven the tangled temporality of the calligraph-that visual trace of a long absent event of the human body in action-with the equally and similarly variegated time of cinema.

\section{Anchoring Space}

Calligraphy also plays a central role in the space of the film, or to be specific, in the conversion of space into place. The more straightforward and conventional of the contributions involves the establishment of setting. City of Sadness depicts Taiwan's entry into a postcolonial world. One example comes from the powerful opening scene, when the eldest brother nervously awaits the birth of his child. The room is pitch black. In the background, two voices compete for the soundtrack. One is his wife, who screams in pain; the other is the Japanese emperor declaring an end to the Pacific War and Japan's colonization of Taiwan. The brother fidgets with a light bulb, which spills light over a calligraphic charm pasted to a column. It reads “great happiness/felicity" (hongxi 鴻禧) and is brushed on 
a vertical strip of red paper with a gold border. The word and the paper, and the pasting of calligraphic charms or exhortations onto the architecture, are all cultural practices pre-dating and enduring the colonial occupation that is ending at this very moment. The scene introduces City of Sadness as a (re-)birth of a nation that will be carrying many histories into the future.

There are some nineteen works of calligraphy in City of Sadness (not including six rolled up scrolls sitting in vases), and not all make this kind of contribution to the establishment of setting or historical moment. Some appear only to grace the walls at happy moments like the opening of the restaurant or the wedding; others are partially obscured. At the same time, nearly all of them are bound by a logic peculiar to Hou Hsiao-hsien and the unique character of his narrative space.

The conventional, classical film typically turns space into place through the deployment of a set of normalized cinematic forms. Entering a space for the first time, "common sense" leads the director to introduce the setting, and simultaneously orient the audience to spatial relationships of people and objects, with a wide "establishing shot." The camera then moves closer to the action, using two-shots, pov shots, and most especially the shot-reverse shot figure. This last strategy is the volleying back and forth of camera views from face to face. It is this complexity of formal choices and realist conventions - combined with the Quattrocento optics of the apparatus - that so deeply engages human subjectivity and, according to the screen theory of the late twentieth century, connects it to ideology.

Hou eschews this system for one of his own devices. He does not chop his scenes up with montage, favoring instead the long take. This is one reason close-ups are few and far between. He rarely uses point-of-view shots; the only example in City of Sadness displays the bloody calligraphic message from late husband to traumatized wife. Hou does use the establishing shot, in a sense. That is because most of his shots look and feel like establish- ing shots. However, whereas most filmmakers introduce viewers to a new location through a wide view mapping the coordinates between objects in an attempt to achieve a cognitive mastery of space, we could say that Hou by contrast establishes a view. Instead of moving in and around the set, he dwells on that view in a long take to allow we viewers to take it in, to settle in as it were, because every time the narrative revisits that space, we more than likely see a variant of that same view.

At this point, I cannot resist indulging in an anecdote about this unique approach to narrative space. I was introduced to Hou Hsiao-hsien by Angelika Wong, his former assistant director. ${ }^{9}$ She revealed that whenever they worked on a set for the first time, the staff would actually place bets on where Hou would place the camera. This story even surprised Hou himself, who had no idea this was going on behind his back. It suggests how crucial a decision that first placement is, as well as how deliberate a choice it is for the director, as everything in the film will happen there within the limits of that view. This unlikely dynamic between visual repetition and narrative novelty slowly but surely turns spaces into the most familiar kinds of places.

Attending to the calligraphic props helps us see how this works at the most basic level. Recall that red good luck charm from the opening scene. The room was so dark that the two-character charm is one of the few recognizable objects. Much later in the film, Hou returns to the same view, now in the daytime. The ambient light from windows reveals a large work of calligraphy on the back wall. The small charm comes into view with a pan, jogging the viewer's memory-ah, this was the room where the oldest brother listened to the war's end as he awaited the birth of his son. The same dynamic of recognition holds true for the view on mute photographer Wen-ching's living room, where so much joy and sadness takes place. We immediately recognize the space at different times of day and with various configurations of furniture thanks to 


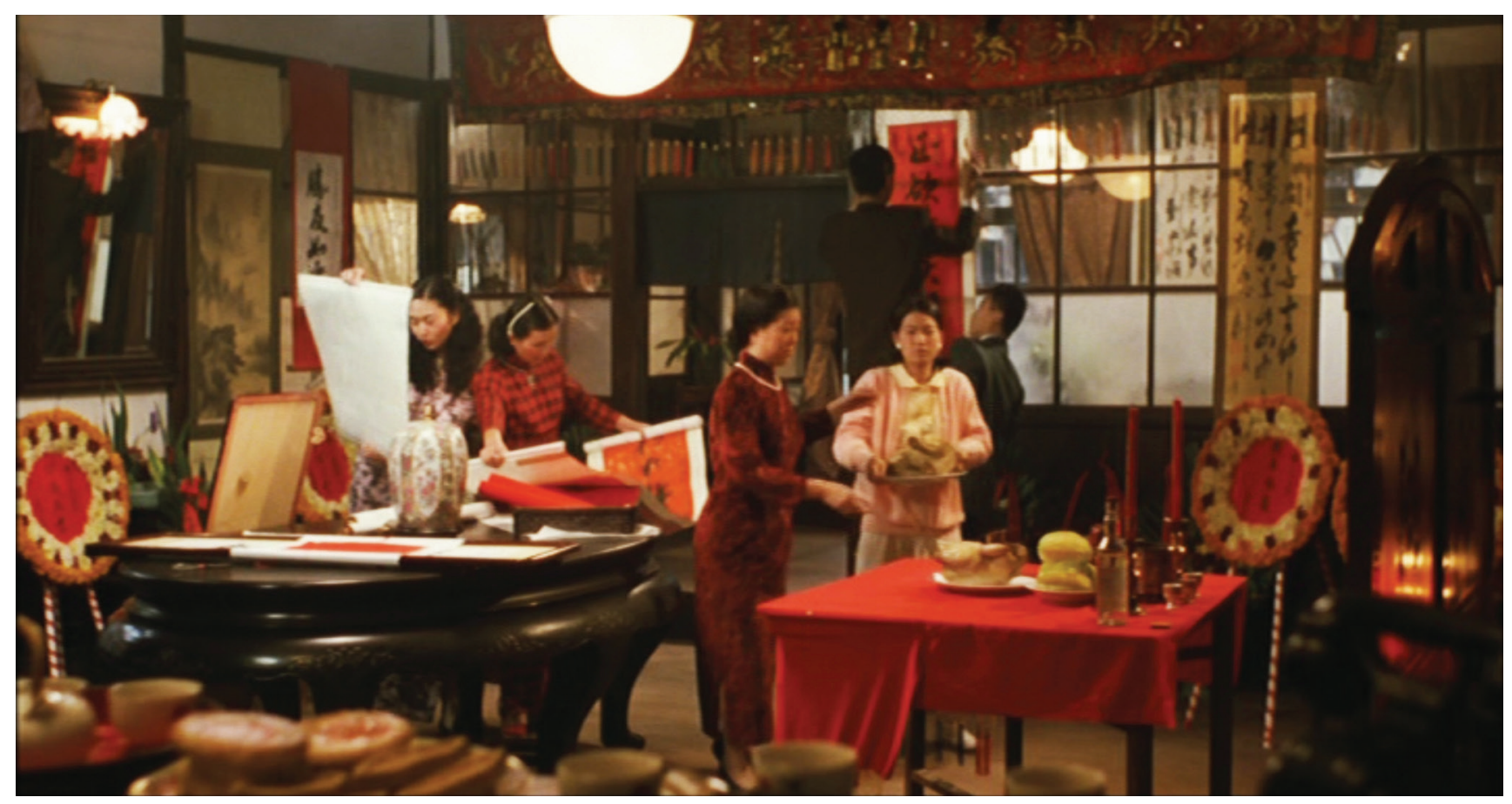

Figure 5.3. Characters mill through the narrative space in an Altmanesque cacophony of action, surrounded by calligraphy.

the calligraphic scroll painting adorning his tokonoma. It is in this patient, deliberate manner that Hou's narrative spaces encumber an overwhelming emotional resonance, where all the events occurring in a given view/place vibrate against each other. ${ }^{10}$ This is quite unlike any cinematic experience I can think of.

At the very same time, a curious parallel process takes place in relation to off-screen spaces. These, too, become narrativized in a gradual process. Since Hou nearly always returns to the initial view on a space, each view slowly establishing it as narrative space, the viewer has only the vaguest sense of the local geography. Hou "activates" or "implements" adjacent spaces whenever a character walks into or out of the camera's view. In this way, he switches between familiar, established views, each with its ener- gized off-screen spaces. Then, every once in a while, Hou will cut on a character walking off into off-screen space, and then into a previously established view in a new, temporally continuous shot; in other words, these are unusual matching shots in Hou's long take style and are designed to stitch contiguous or adjacent views together.

On other occasions, this kind of discovery is inspired by a simple, revelatory pan. One of the most important settings of the film is the Lin family restaurant, The Little Shanghai. Somewhere in the house is the kitchen where the eldest son awaited the birth of a child in the pre-credit scene. After the opening title, we see our first view of the lobby. The shot is striking for its visual disorder (fig. 5.3). Many people mill through the space in an Altmanesque cacophony of action as they prepare for the opening of 


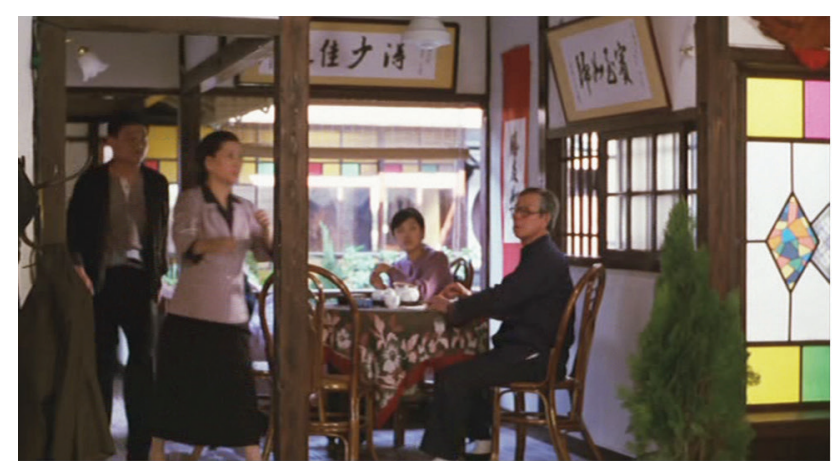

the restaurant. An interior wall of windows adds a profusion of lines; six calligraphic scrolls adorn the walls in three rooms, and women are hand-inspecting two more. A vase, which will soon become the most prominent object in the film, sits on a table, hardly noticeable in all the action and visual clutter. Hou cuts to another room somewhere in the house where the patriarch sits at a table; two scroll paintings grace either side of a shrine in the back room, obscured by plants and yet more windows. A third and final cut takes us to another space with the vase and a striking stained glass wall. Above it, calligraphy on a wood plank identifies the name of the establishment-the Little Shanghai-and another work of calligraphy is half-visible in a back room. The vase returns now, suggesting the camera has tracked back to the first space, but jumped a clean 45 degrees to the right. This is how Hou introduces The Little Shanghai.

However, even the most scrupulous viewer probably requires multiple viewings to make sense of this space. Not until the second half of the film, after Hou has introduced a number of other rooms to the house, does he stitch it all together. This is the scene where the eldest daughterin-law marches past the restaurant table, and the camera

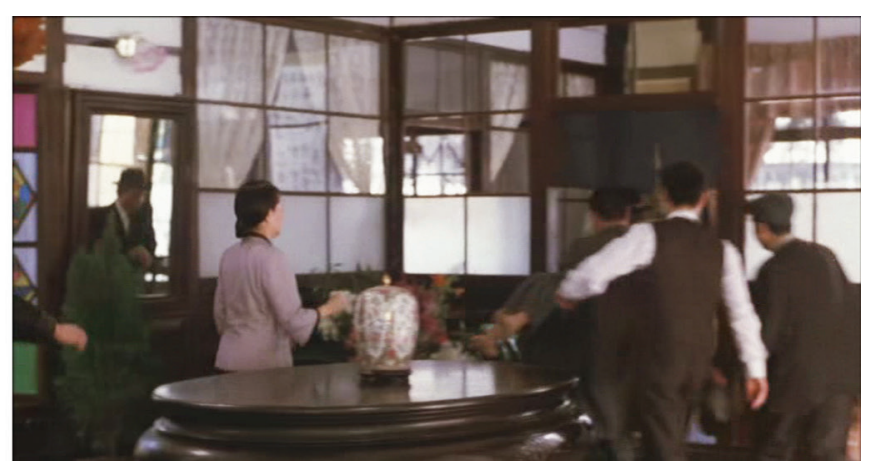

Figure 5.4. Calligraphic ornaments help the viewer navigate Hou's narrative space. This pan from left to right finally stitches together the till-then disconnected spaces of the lobby.

pans to reveal the second brother brought into the shrine room (fig. 5.4). It is only at this point-halfway through the film - that the narrative space of the Little Shanghai is relatively complete. The connective tissue has been provided largely by the works of calligraphy ornamenting this initially bewildering space.

As the various spaces of The Little Shanghai gradually interconnect-mapping out the restaurant while acquiring emotional resonance-the semantics of the calligraphy transform and hold the potential for additional emotional amplification. The most striking piece of calligraphy in the film is in the shrine room. The shrine itself is dedicated to Guan Yu, a favored deity of Taiwanese merchants because he represents trustworthiness and personal loyalty. Adjacent to the shrine's calligraphic couplet and directly above the ancestors' tablet is a large "longevity" (shou 壽) painted on red paper and framed. While not a typical practice, this could be a reference to the ancient The Nine Songs, which refers to the Palace of Longevity. ${ }^{11}$ Wang Yi (王逸 ca. 89$158 \mathrm{CE}$ ), the first commentator on this anthology, wrote:

The Palace of Longevity is the place where people make offerings to the spirits. To construct a shrine (a temple 


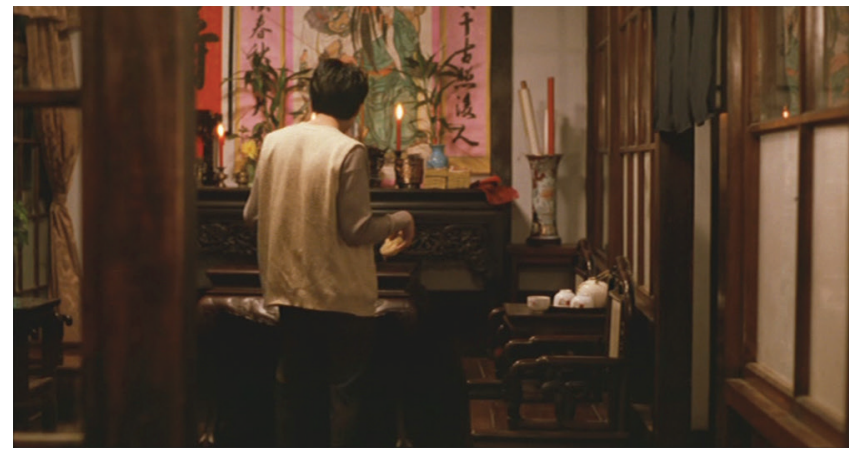

or altar) to worship the spirits and ancestors is nothing but for the purpose of obtaining longevity (for the worshipers). Thus, it is named "the Palace of Longevity."12

This painting next to the shrine makes its first appearance a third of the way into the film at an appropriately celebratory scene when Hinomi visits the house. At this point, it is perfectly lit, the red paper and size of the character calling for attention - though for no particularly evident reason.

However, later in the film, we are introduced to the severity of the second brother's insanity when Hou cuts back to this space. The view is, once again, fractured by window panes, behind which the brother spastically walks (fig. 5.5; left). The "longevity" painting is still brightly lit, but now only its edge is visible. It is enough, just enough, to add a dark commentary on the brother's plight. In the last half of the film, the calligraphic painting floats in the background, obscured by architecture or only half lit. For example, one of the most moving moments of the film is when Hinomi sits alone at the table in the foreground, crying quietly (fig. 5.5; right). She is awaiting the return of photographer Wen-ching, and when he arrives, it is clear

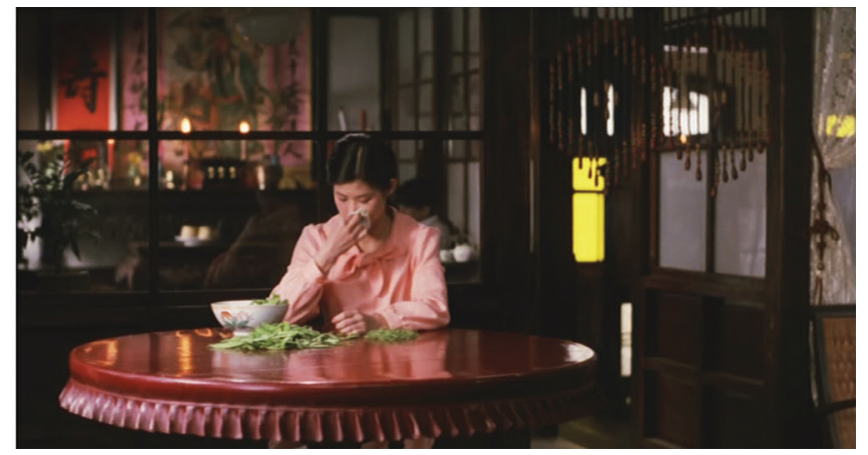

Figure 5.5. Characters endure one loss after another; behind them a bright red scroll painting with the character for "longevity" haunts the background in shadow.

they are in love and bound to be married; he then provides her an account of her brother's capture in the mountains. Appropriately enough, the "longevity" character is halfhidden by a dark shadow.

Only in Hou's cluttered narrative space, where singular views are repeated in long take, could a half-visible prop possess such a devastating effect. It is the combination of repetition and duration that enables viewers to master the clutter and recognize the smallest changes in setting and framing.

\section{Subtitling Calligraphy}

City of Sadness is filled with the delivery of messages and letters. Almost invariably, they bear the worst of tidings. Many report the untimely demise of a loved one due to the political violence. The most unbearable of the messages hovers between crude handwriting and the calligraphic, as when Wen-ching visits the family of a friend he knew in prison and hands the wife a message from her husband: "Father is innocent. You have to live with dignity"scrawled on cloth instead of paper, with the husband's fin- 


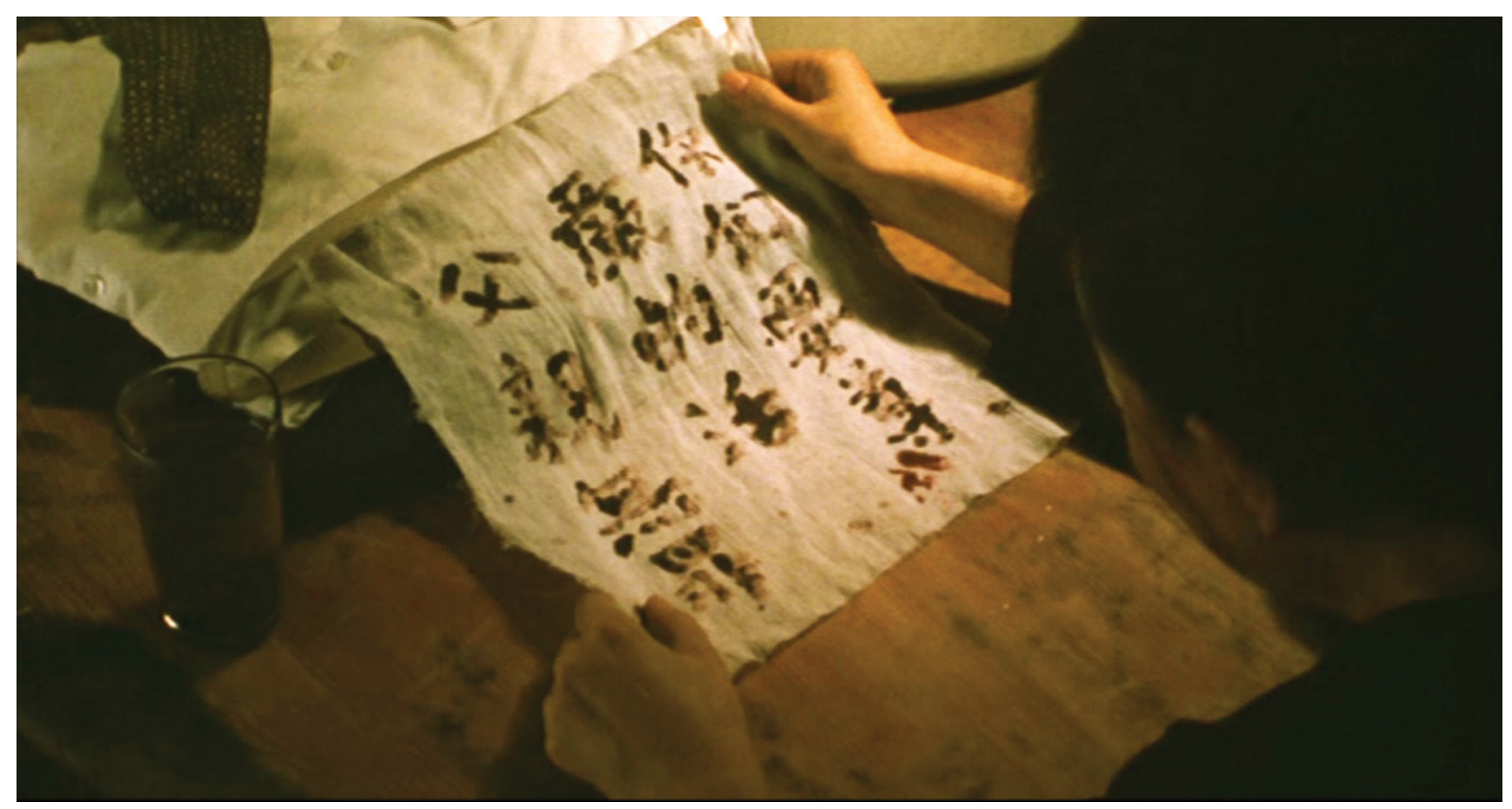

Figure 5.6. A message from prison: "Father is innocent. You have to live with dignity" - scrawled on cloth instead of paper, inscribed with the husband's finger instead of a brush, and not in ink but rather his own blood.

ger instead of a brush, and not in ink but rather his own blood (fig. 5.6).

This intimate connection between writing and the (once moving, once living) human body points us to one more form of writing in City of Sadness: subtitling. With its brilliant cacophony of dialects and languages, even the original film in Taiwanese performances was replete with subtitles. Their particular articulation here, narratively and aesthetically, points us to a set of theoretical problems I shall attend to in the next chapter. In Cinema Babel, I wrote about the frustrations we feel those unusual times when we stop to give subtitles a thought. In considering the translation of calligraphy, I began to speculate about some of the reasons that these occasions are so few and far between. Why is it that we so readily accept the foreign intrusion of this ugly Helvetica text on what are often such beautiful images? When I consider it, I find myself seeing the subtitle as an intrusion, an invasion, or even contagion. But I rarely think about it; and that itself is interesting. Perhaps it is because the subtitle possesses a curiously intimate and fundamental connection to the cinema.

As mentioned in chapter 2, the first subtitles were also calligraphic, however, at that key moment in film history when the coming of sound spelt the suppression of visual text from the cinema, the communicative dimension of calligraphy overwhelmed all else. 
The spectacular materiality of the brushed characterits pictographic qualities and corporeality-fell aside along with linguistic tools of the writing trade like alliteration, onomatopoeia, rhyme, and other forms of heightened language. From the 1930s to the 1990s, their peculiar writing styles maximized legibility while paring away flourishes that would individuate the writing or call "undue" attention to the text. They are graphic elements strangely, if we stop to think about the matter, disconnected from the visual composition they are affixed to. Indeed, this is a form of writing that evacuates the human from the letter.

At the same time, my consideration of calligraphy in East Asian cinema has led me to discover a different kind of linguistic play or excess at work in the subtitle. You see, even if the subtitle seems so cold and indifferent to the image it sits on, there is actually a peculiar intimacy between subtitle and image and sound. To arrive there, we must think through some of the temporal and spatial peculiarities of the calligraph-and its surprising affinity with cinema.

The word for moveable type is the same across the region: 活字 ( $\mathrm{C}=$ huozi; $\mathrm{J}=$ katsuji; $\mathrm{K}=$ hwalja). In contrast to calligraphy-which is accomplished through the Four Treasures of brush, ink, inkstone, and paper-type was produced through metal letter punches, matrixes, and castings. Both calligraphy and type involve the labor of human bodies; however, that labor, and its movement, fades from the glyph in the process between punch cutting and printing. This is a decisive difference.

Be that as it may, recognizing subtitles as calligraphy has led me to reconsider my understanding of subtitling. I have come to conclude that-in one fundamental respect一the 活字 of the subtitle is just that: moving type.

In an essay on film translation, Michael Raine evoked the potshards of Benjamin, arguing that subtitles are like a glaze.
Unlike translated novels, film subtitles do not obliterate the original — they are not, in Benjamin's metaphor, "fragments" of a messianic whole, but a glaze that penetrates the surface of the film, making it transportable even as they change it completely ... (S)ubtitles are both the way and in the way of an encounter with foreign films, an aporia that could not be resolved by the cinephilic art film print, in which titles are burned into the substrate and constrained by the microtemporality of projection. ${ }^{13}$

Raine's glaze trope is actually more appropriate than he thinks. Just as we tend to accept the glaze on a pot as constitutive-even if it's on a shard-we also tend to accept the subtitle without a second thought. Furthermore, glaze may appear to sit on the surface, but it penetrates inside and becomes part and parcel of the pot's structure. I suggest the subtitle diffuses into the shot, weaves its way into the shot via visual space. Raine said, "Subtitles are both the way and in the way." I'm saying they are, in some fundamental sense-part of "it."

In our guts, we know this to be important, because the status of a subtitle for speech and one for graphic text like calligraphy feels different (figs. 4.7, 5.7, and 7.1). This is probably why translators have been so inclined to leave calligraphic text unsubtitled, while being so clearly driven to subtitle every aural utterance as a matter of course.

What is the difference? First, each has a peculiar temporality. When calligraphy appears on screen, whether in a title sequence or decorating a prop, it has a striking immediacy - a self-sufficient thereness, as it were. On first glance, the subtitle has a different status; it is dependent on a temporally absent event-one that is strictly aural.

This is to say, the voice humanizes, breathes life into, the subtitle. It is why we rarely stop to think about subtitles, why we accept them with indifference despite their compromised translations.

The regional term for moveable type一活字—turns 
Figure 5.7. The subtitles for voice and calligraphy feel radically different, but the latter usually goes untranslated. The calligraphic intertitle on the right translates the scroll painting being gifted in figure 5.2 .
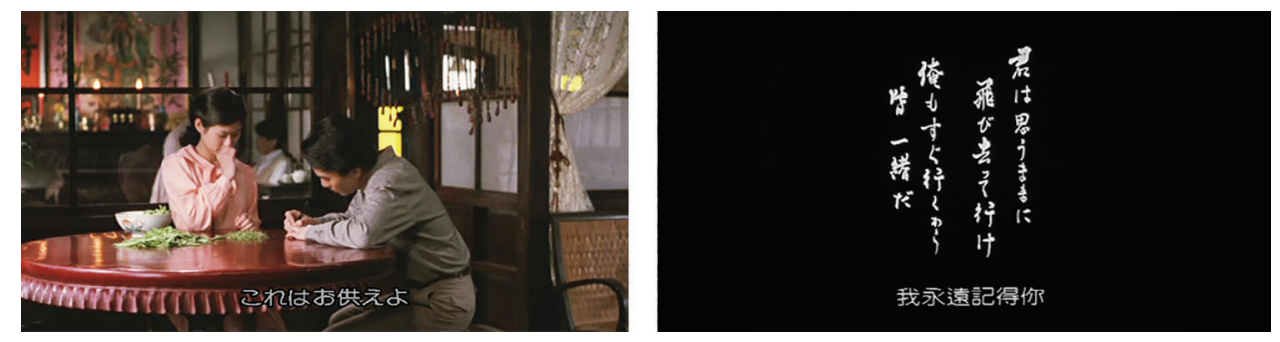

out to be unwittingly apropos here. 字 means character or letter. But 活 has, by contrast, a semantic richness that is provocative. It can mean "lively," "living," or even "resuscitation" and "being helped." The subtitle, no matter the language, is all this. Does all this. It is the reason we tolerate its intrusion into the shot. It is every bit alive as the twenty-four frames per second stream of still images that the apparatus resuscitates and brings back to life.

This animation of the dead letter of the subtitle through its constitutive aural dimension is one of subtitling's greatest paradoxes, and the reason why lovers of the sub hate the dub: for all its icy formalism-its rendering in a non-descript hand, its bolting down at the frame's edge, its elaborate rules controlling time and space, as well as its remarkable limitations as a form of translation-there is something lively and imminently present in the subtitle, and this powerfully avoids the potential uncanniness of dubbing. The effect is deeply dependent upon the vocal utterance, which is a constitutive (and often overlooked) component of subtitle textuality.

This is to say, unlike typography, the human labor invested in the inscription of calligraphy is palpably built into the letter. This evokes an early theorization of calligraphic writing, first articulated by Tang dynasty scholar Chang Huai-kuan (714-760): "Chinese believed that through the act of writing, the artist rediscovered the vital cosmic forces that informed the character's rhythm and structure, forces that had first been revealed to the ancient sages."14 The viewer of a work of calligraphy can similarly tap into these forces marshaled by the being of the calligrapher at the instant of inscription. The work, like the calligraphic prop or the cinematographic subtitle, is a kind of choke point between the viewer's present and a complex set of circumstances in the past. In this respect, the treasures of cinema-light, optics, emulsion, bytes, and the like-are every bit as sensitive as the Four Treasures of calligraphy. Thus, we arrive at the ultimate link between the art of calligraphy and the art of cinema, which we shall explore in the following chapter.

\section{Notes}

1. This is a revised version of my "Hou Hsiao-hsien and Narrative Space."

2. Stephen Heath, "Narrative Space," 86.

3. Ibid., 90.

4. These qualities and more are explored in great depth in Staging Memories: Hou Hsiao-hsien's A City of Sadness, which I wrote with Yeh Yueh-yu.

5. The most spectacular examples may be found in the films of Edward Yang; I analyzed his construction of off-screen space shortly after encountering his first films in Nornes, "Terrorizer."

6. Interview, August 15, 2011.

7. As for Hou, it is likely that he feels a work of calligraphy is a prop like any other. Any object will suffice in the construction of his peculiar narrative space. Depending on the film, it might be a table, or a peculiarly shaped window, or merely some laundry 
hanging out to dry. Indeed, I had a chance to sit down with Hou to talk specifically about calligraphy. Our conversation ranged from fine art calligraphy to traditions of writing to his own filmmaking practice. Most of the things he had to say about calligraphy were a bit obvious, as if he were gamely playing along with the visiting scholar and his unexpected set of questions. His comments concerning calligraphy in his own films revealed that he never really thought about it that much. It was clear that he is an artist that mainly works by instinct. After over an hour of playing the scholar-filmmaker game, Hou stopped, leaned forward with a smile that was at once gracious and mischievous, and said, "You know, in all honesty, I have to admit that your research topic just doesn't interest me that much."

8. We analyze the intertitles at length in Staging Memories, op. cit.

9. This revelation took place at the interview with Hou referenced above.
10. This aspect of Hou's work is also explored in Staging Memories, op. cit.

11. David Hawkes uses "House of Life" in his translation: "He is going to rest in the House of Life./His brightness is like that of the sun and moon." David Hawkes, The Songs of the South, 104. On p. 118, Hawkes notes, "the House of Life: literally "Palace of Longevity" (shou gong) - a chapel specially constructed for the reception of spirits conjured up in shamanistic seances."

12. Translation by Shuen-fu Lin. I am indebted to Prof. Lin for helping me understand the culture and practices around this character. I would also like to thank Akiyama Tamako, who helped me puzzle through this and other scenes, not to mention a small but significant technological problem.

13. Raine, "From Hybridity to Dispersion," 152.

14. Fong, "Chinese Calligraphy: Theory and History," 30. 


\section{CH A P T E R 6}

\section{The Shimmering Smudge}

Calligraphy is simultaneously visual and verbal. It cannot be reduced to verbal representation or to visual experience. After all, is calligraphy a text to see or is a drawing to read? If it is both then how should we understand the kind of seeing that is also reading? Or should we insist that seeing is always reading, so that visual perception is in fact an experience of reading the world?

- Naoki Sakai ${ }^{1}$

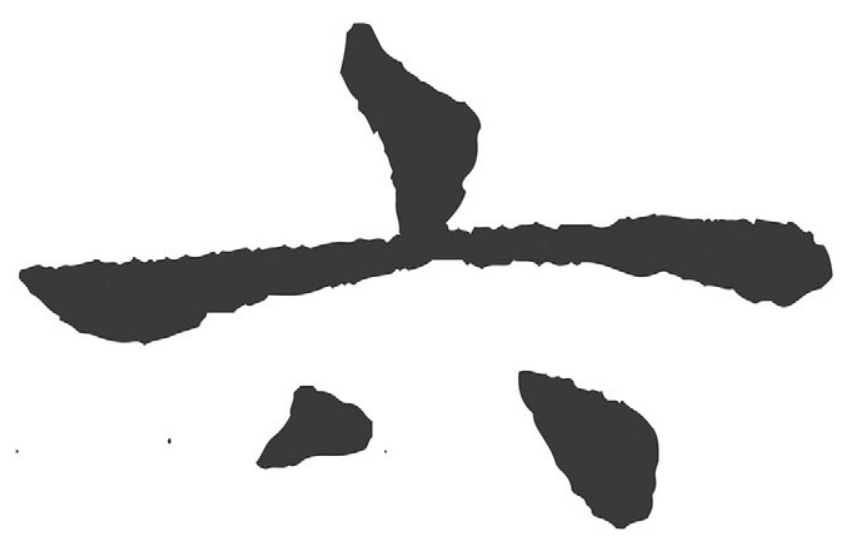

The Knot

Up to this point, we have looked at how calligraphy entered East Asian film in the nineteenth century, tracking how its many uses transformed hand in hand with both narrative, stylistic, and technological innovation. It is now clear how cinema extended the life and possibilities of calligraphy and vice-versa. This chapter considers what cinema and calligraphy are and, in the process, discovers some unexpected and fundamental affinities. It is as if the arts of ink and light were made for each other.

Let us begin with the world outside of the movie theaters-the world in which filmmakers lived in. Although calligraphy is much less present in the daily lives of filmmakers today, it is still true that when writing on important occasions calligraphy is clearly called for. The reasons exceed common sense and the pressure of tradition. The brushed word captures something, or things, which set it apart from other forms of writing and makes its use an automatic reflex.

Consider the cover for the inaugural issue of North- 
west Cinema (fig. 6.1). Warlord Yan Xishan financed the creation of the Northwest Film Studio in Shaanxi. When the Sino-Japanese War broke out, Zhou En-lai enlisted sympathetic filmmakers to move there for the cause. Obviously, this studio was unusually connected, and this studio magazine cover was designed specifically to put these powerful names on display. Including their signatures signals their approval to the establishment of the studio. The names are written in both pen and brush, a choice that says something about their respective characters. Notably, the brushed names especially hint at the personalities and education levels of the writers.

Many of these names are now lost to history, so it may be difficult to appreciate the powerful experience of reading this kind of brushed signature. A better example is the plaque commemorating the creation for the Directors Guild of Japan in 1936 (fig. 6.2). At some point in their inaugural meeting, the attendees fixed their names to a wooden board, one by one. They include the luminaries of Japanese film history: Suzuki Shigeyoshi, Shimizu Hiroshi, Shimazu Yasujiro, Mizoguchi Kenji, Kinugasa Teinosuke, Gosho Heinosuke, Abe Yutaka, Yamanaka Sadao, Yamamoto Kajiro, Uchida Tomu, Ushihara Kiyohiko, Murata Minoru, Naruse Mikio, Tasaka Tomotaka, Ozu Yasujiro, Inoue Kintaro, Ikeda Yoshinobu, and Itami Mansaku. Each signature hints at the personality of the director and even ties into the styles, genres, and stories the directors were known for. Standing before the board, one comes into the very presence of prewar cinema and its greatest artistsand in a specific event in the past when they were all in the same room. These brushed words are auratic.

As these two examples reveal, formal occasions call for the Four Treasures. Even today, the reception desks for film openings, receptions, and funerals will have calligraphy pens, and sometimes actual brushes. Award certificates at film festivals will prominently feature calligraphic writing as a matter of course, as do the diplomas of the region's film schools. Calligraphy is the inscription mode

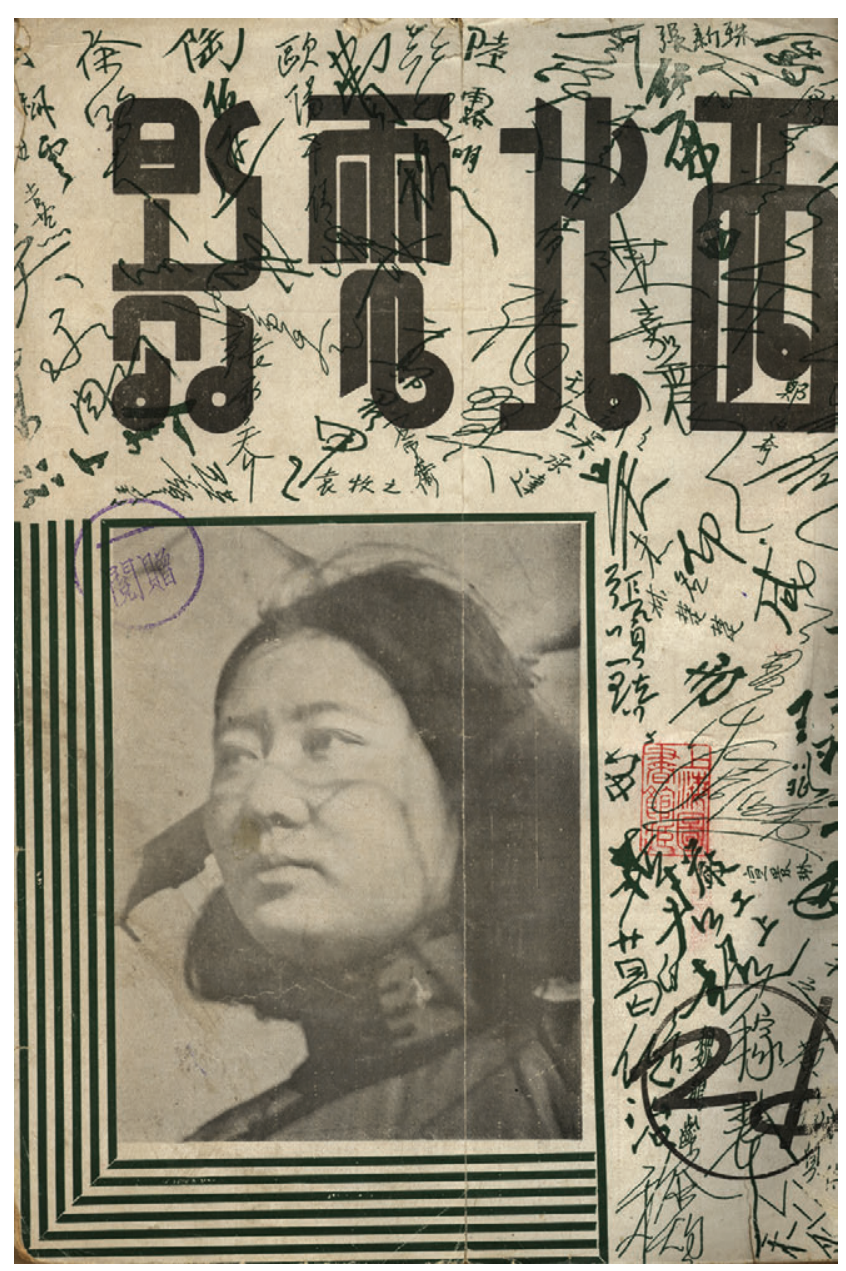

Figure 6.1. The inaugural issue of Northwest Cinema was decorated by calligraphic signatures from powerful people in Japan and China. Courtesy of Shanghai Library.

of choice for formal matters, and this ultimately has to do with its intimate connection to the human body.

We can appreciate the nature of this relationship through a nonlinguistic form of representation-the death mask. When Mizoguchi Kenji died at the young age of fifty-eight on August 24, 1956, his longtime art director Mizutani Hiroshi took a mold of the director's face and cast 


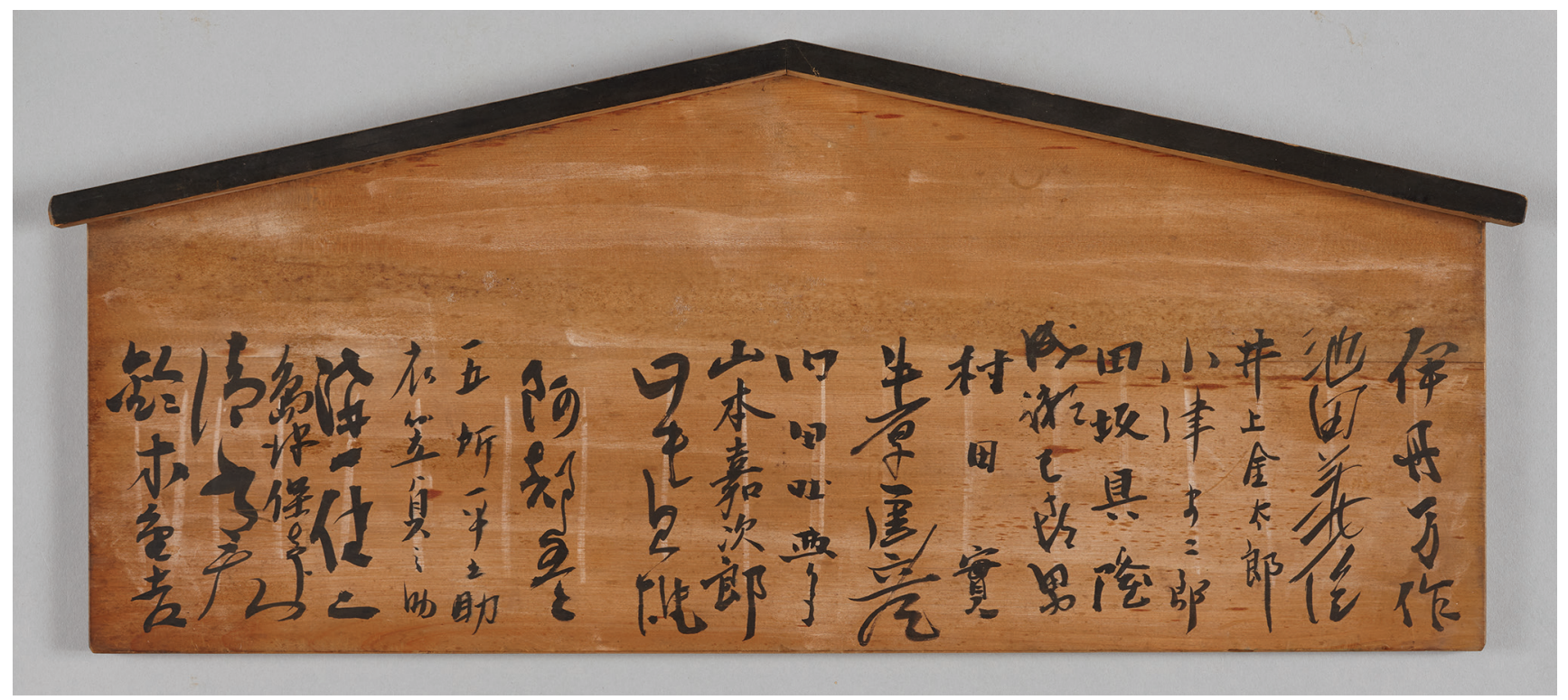

Figure 6.2. These luminaries of the Japanese film world signed this board to commemorate the establishment of the Directors Guild of Japan; from left to right, Suzuki Shigeyoshi, Shimizu Hiroshi, Shimazu Yasujiro, Mizoguchi Kenji, Kinugasa Teinosuke, Gosho Heinosuke, Abe Yutaka, Yamanaka Sadao, Yamamoto Kajiro, Uchida Tomu, Ushihara Kiyohiko, Murata Minoru, Naruse Mikio, Tasaka Tomotaka, Ozu Yasujiro, Inoue Kintaro, Ikeda Yoshinobu, and Itami Mansaku. Courtesy of the Tsubouchi Memorial Theatre Museum of Waseda University.

a death mask (fig. 6.3). Mizutani joined assistant directors Uchikawa Seiichiro and Sakai Tatsuo in placing the mask in a beautiful wooden box-marking the occasion by signing their names by brush. The box now serves as a display case, and the mask is one of the most striking objects exhibited at the National Film Archive of Japan. While the mask is the color of bronze, the stunning details in the skin and hair exert a strange reality effect on the viewer. It may be static as death, but the mask brings one into the presence of Mizoguchi Kenji.

To be specific, one is confronting the long gone corpse of Mizoguchi Kenji. The brushed letter has deep affinities with the ontology of the death mask. Both capture and preserve the artist of the past in powerful ways. However, as a matter of course, one captures death and the other life. Furthermore, as linguistic sign and the inscription of a sentient being, calligraphy's relationship to history can be so dynamic as to make the death mask seem as inert as it actually is.

This is to say, there is a powerful ontological link between a writer and his or her calligraphy. This special kind of authorship is part and parcel of the auteurist dis-

THE SHIMMERING SMUDGE 
courses surrounding filmmakers like King $\mathrm{Hu}$, who wrote the calligraphy for his films' titles and props. King Hu was celebrated for bringing an individual vision to the period film in Chinese cinema, and elevating cinema to the level of literature and other prestigious art forms. He not only sprinkled his films with his calligraphic writing but even affixed his seal to some of his paperscapes (fig. 2.14). This is a literalization of auteur theory within the cultures of East Asian calligraphy.

More typically, calligraphy's ability to somehow capture and preserve the very being of the writer buttresses the common practice of inviting special personages to brush a film's title. Earlier, we saw how novelist Kawabata Yasunori provided the title calligraphy for the adaptation of his Snow Country (fig. 1.12). Likewise, the widow of novelist Tanizaki Jun'ichiro did the calligraphy for the adaption of Makioka Sisters (Sasameyuki, 1983; fig. 6.4). Director Ichikawa Kon designed the title sequences for all of his films; but his own calligraphy was bold and rather stubby, and thus not terribly appropriate for this delicate story about four upper-crust, kimono-clad sisters. During the pre-production, he took up an exchange of letters with Tanizaki's widow, who wrote letters on scrolls of rice paper in stunningly delicate calligraphy. Their correspondence culminated in Ichikawa's request for the title calligraphy gracing the beginning of the film. ${ }^{2}$

Because calligraphic writing has such distinct personal style, props often include homages or appropriations of calligraphy by famous dead people. Is the real writer unavailable? No problem. Bootleg it. By far, the most famous calligraphy in modern East Asia belongs to Mao Zedong. Korean kaelligeurapi artist Kang Byun-in was a great admirer: "It is fascinating. Thin, but with a brush strength (筆力) powerful enough to slice through stone." This is why Mao's calligraphy has been used for The People's Daily and the logos of various ministries, universities, and companies. A 1999 poll conducted by a major calligraphy journal found that, among the top masters of the twentieth century, respondents ranked Mao at number five. ${ }^{3}$

I was unable to ascertain if Mao actually provided calligraphy for any films. But one does run across facsimiles. In the prop department at Shanghai Film Studios, there is a thirty-foot long row of double-sided cabinets chock-full of hundreds of scroll paintings (fig. 3.9). In one drawer, I found a fascinating scroll easily identifiable as Mao's handwriting (fig. 6.5); in fact, it was signed at the top. Naturally, it was executed by a skilled calligrapher working for hire. Curiously enough, this was supposed to be a draft, with mistakes circled and marginalia. This probably made it feel all the more real-purposeful slips as deceptive marks of authenticity. In a nearby drawer, I also stumbled upon a bootleg of the literary giant Lu Xun's writing (fig. 6.6). This forgery used a different strategy for guaranteeing authorship: under the signature, "Lu Xun" left his red fingerprint as substitute for a seal-index upon index, fake certification for the fake-even better than a seal.

This personalization of difference, this identification of the calligraph with the individual, has even been certified by the courts in Korea. The production company Taeheung Picture Co. was accused of pilfering the calligraphy for Im Kwon-taek's Festival (Chukje, 1996; fig. 6.7) from calligrapher Yeo Taemyeong. He was a professor at the Department of Calligraphy at Wonkwang University and the president of the Korea Calligraphy Design Association. Yeo claimed the filmmakers stole two characters from a book he published and the court agreed. They ruled in Yeo's favor and charged the studio 10 million won per character (five times his usual rate). ${ }^{4}$

This scandal of forgery starts with the matter of writing style but does not end there. While all the examples above display writing that somehow expresses the personalities of their makers, they simultaneously capture the writer's being at the moment of inscription in ways that can get wrapped up in magic and superstition. Xu Pengle, a vet- 


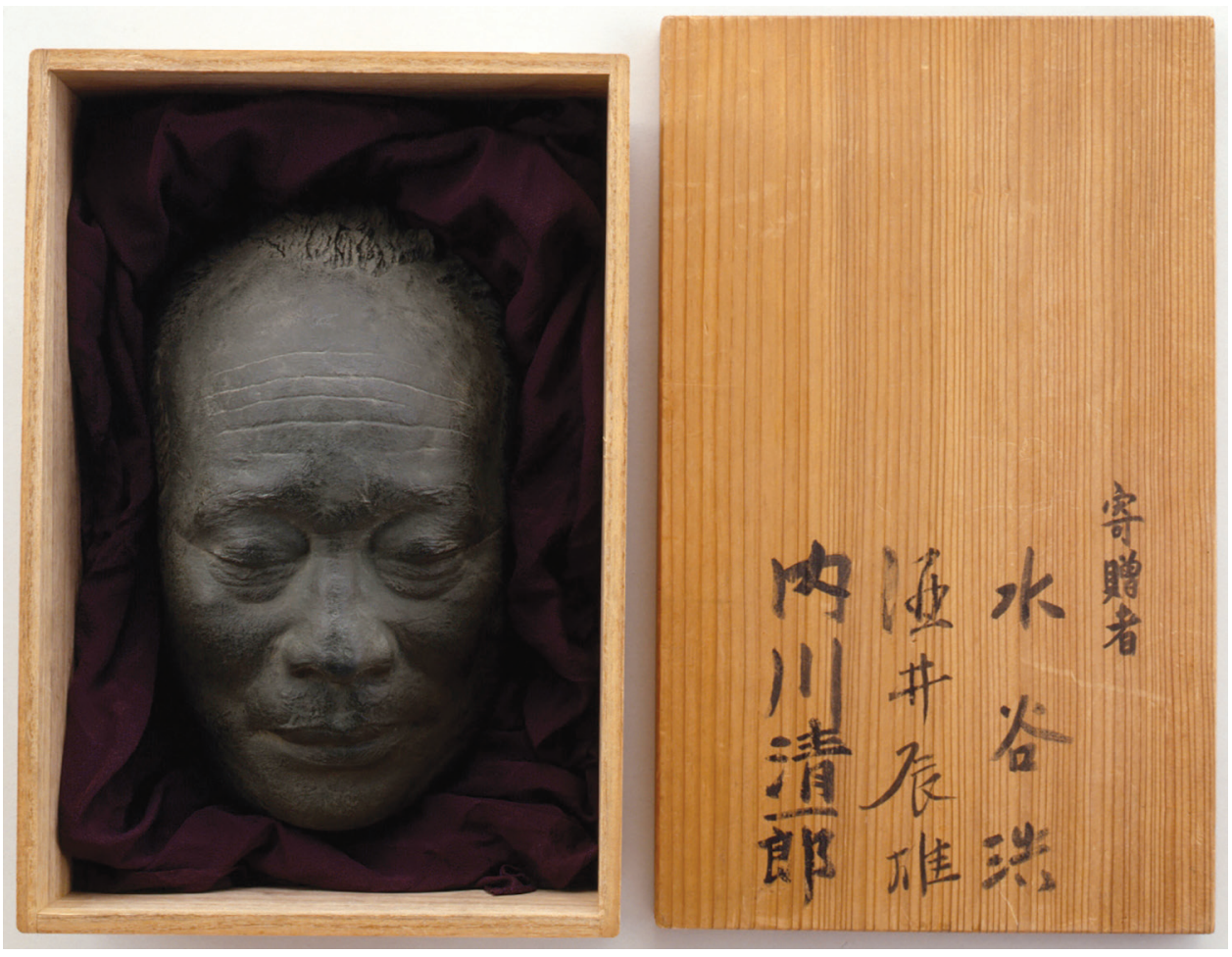

Figure 6.3. The death mask of Mizoguchi Kenji was cast by his long-time art director Mizutani Hiroshi, who signed the display book by brush with assistant directors Uchikawa Seiichiro and Sakai Tatsuo. Courtesy of the National Film Archive of Japan.

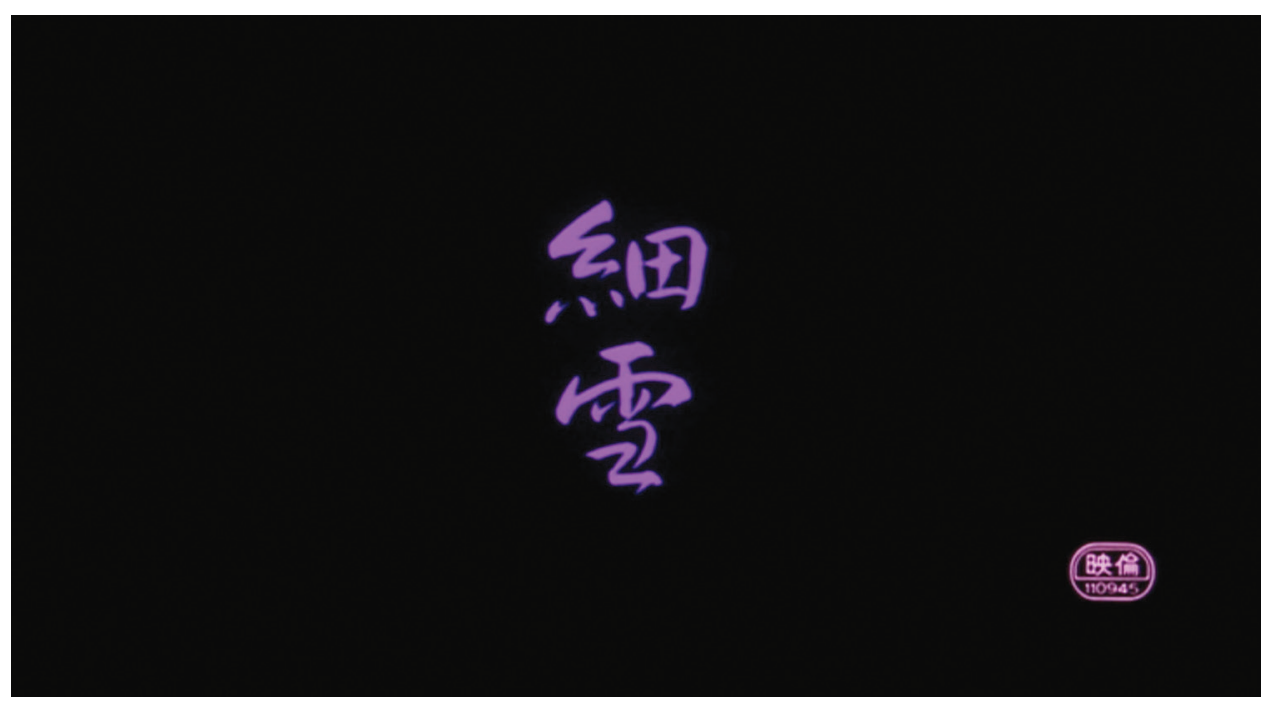

Figure 6.4. The title for Makioka Sisters (Sasameyuki, 1983) was written by the widow of novelist Tanizaki Jun'ichiro. 


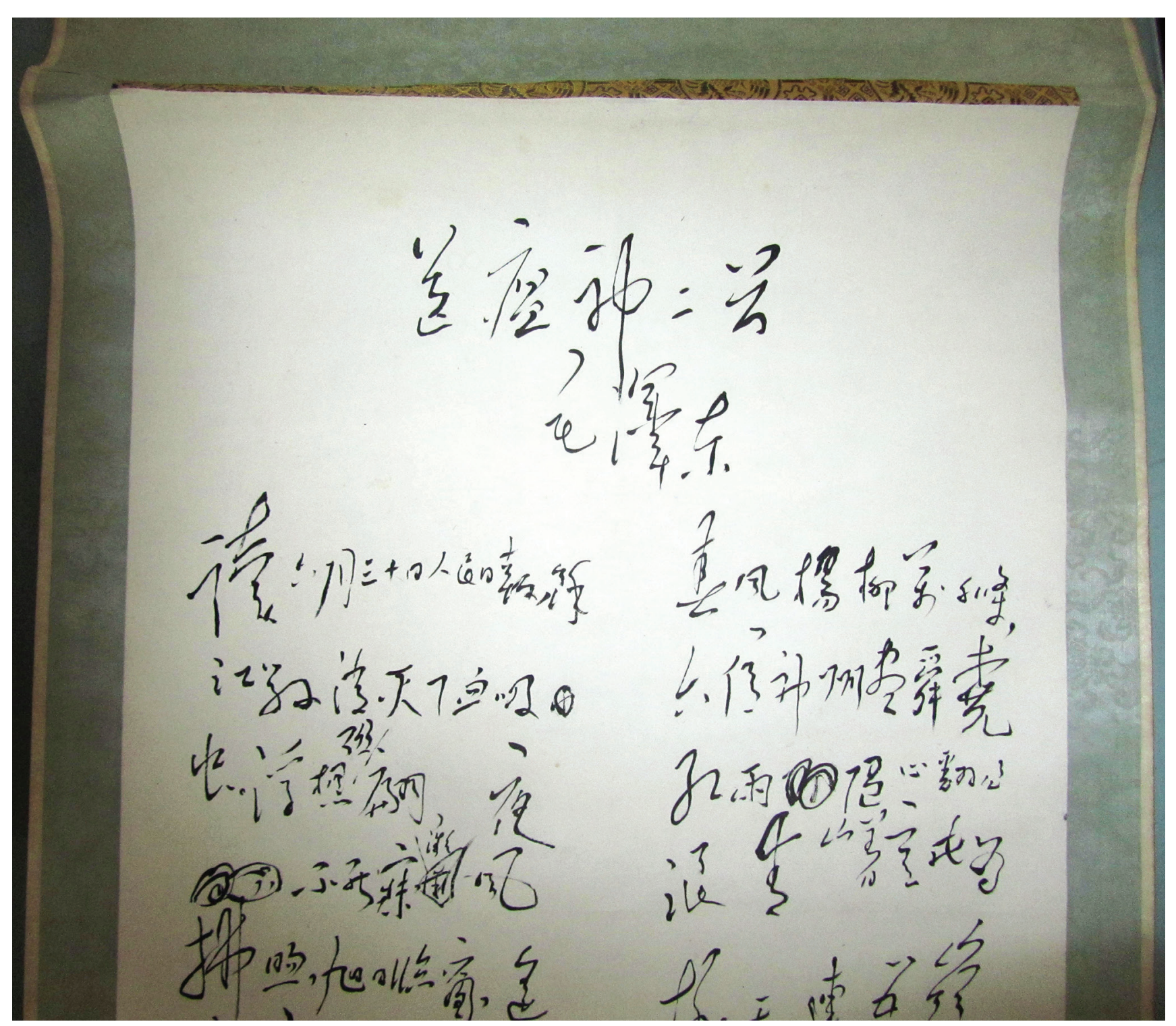

Figure 6.5. A fake Mao Zedong scroll in the props department of Shanghai Film Studio. The second line contains his signature. Mao's calligraphy is instantly recognizable across Asia. 


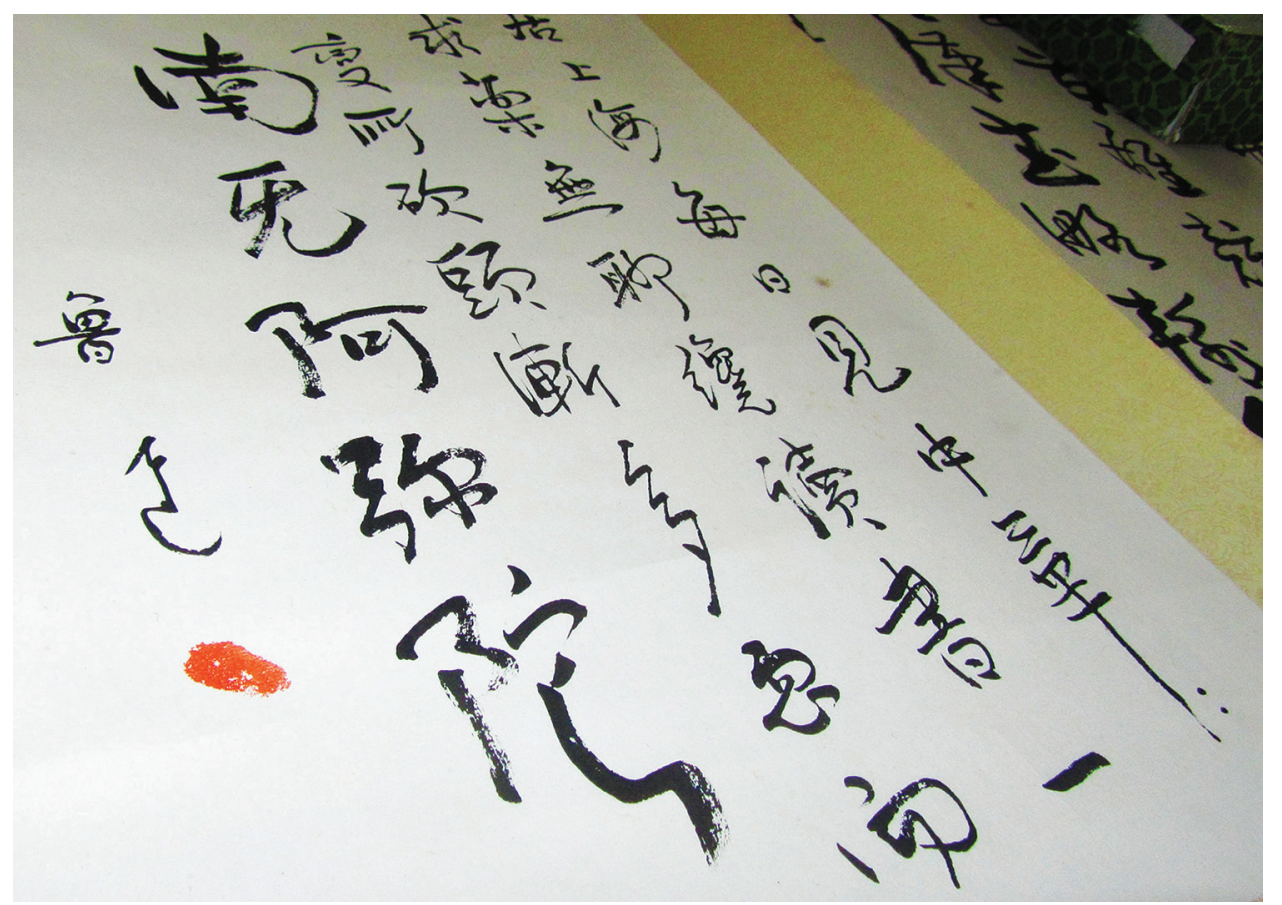

Figure 6.6: A bootleg of the literary giant Lu Xun's writing, this forgery substituted a red fingerprint for a seal next to his signature-index upon index, fake certification for the fake. eran producer and head of the major studio in Shanghai, told me that he often asked his investors to do the titles "for good luck." This is probably why Confucius (Kong Zi, 2010; fig. 6.8) sported a logo made of calligraphy by Kong Demao, a descendent from the seventy-seventh generation following the ancient philosopher (Kong's personal seal affixed to guarantee the authorship).

There is a long backstory to the sense that the linguistic signs of calligraphy are indexes indelibly linked to their creators at the scene of writing. This is why calligraphy substituted for the royal portrait in Asia in the pre- and early modern eras. Jonathan Hay argues that,

for many centuries the functional equivalent to the royal portrait in China has been not a likeness but a trace, a trace left by a brush in the emperor's hand. The imperial presence, in other words, has principally been disseminated by means of calligraphy, on a model that owes nothing to mimesis and is more presentation than representation. Oversimplifying wildly, one might further dramatize the contrast with Western practice by saying that if the portrait is a noun, the calligraphy (re)presentation is a verb. ${ }^{5}$

Even in exterior, public spaces, calligraphy by renowned personages was carved into durable stone. As Chang Tsongzung notes, "These carved texts . . reproduced the original calligraphy of their authors, implying that the powers the inscriptions represented were personal, graced with a human presence. This personal dimension of carved calligraphy differs significantly from the standardized, and therefore impersonal, lettering used for stone monuments and buildings in Europe. . . . With calligraphic writing, civic spaces were being 'civilized."'6 However, in the twen- 


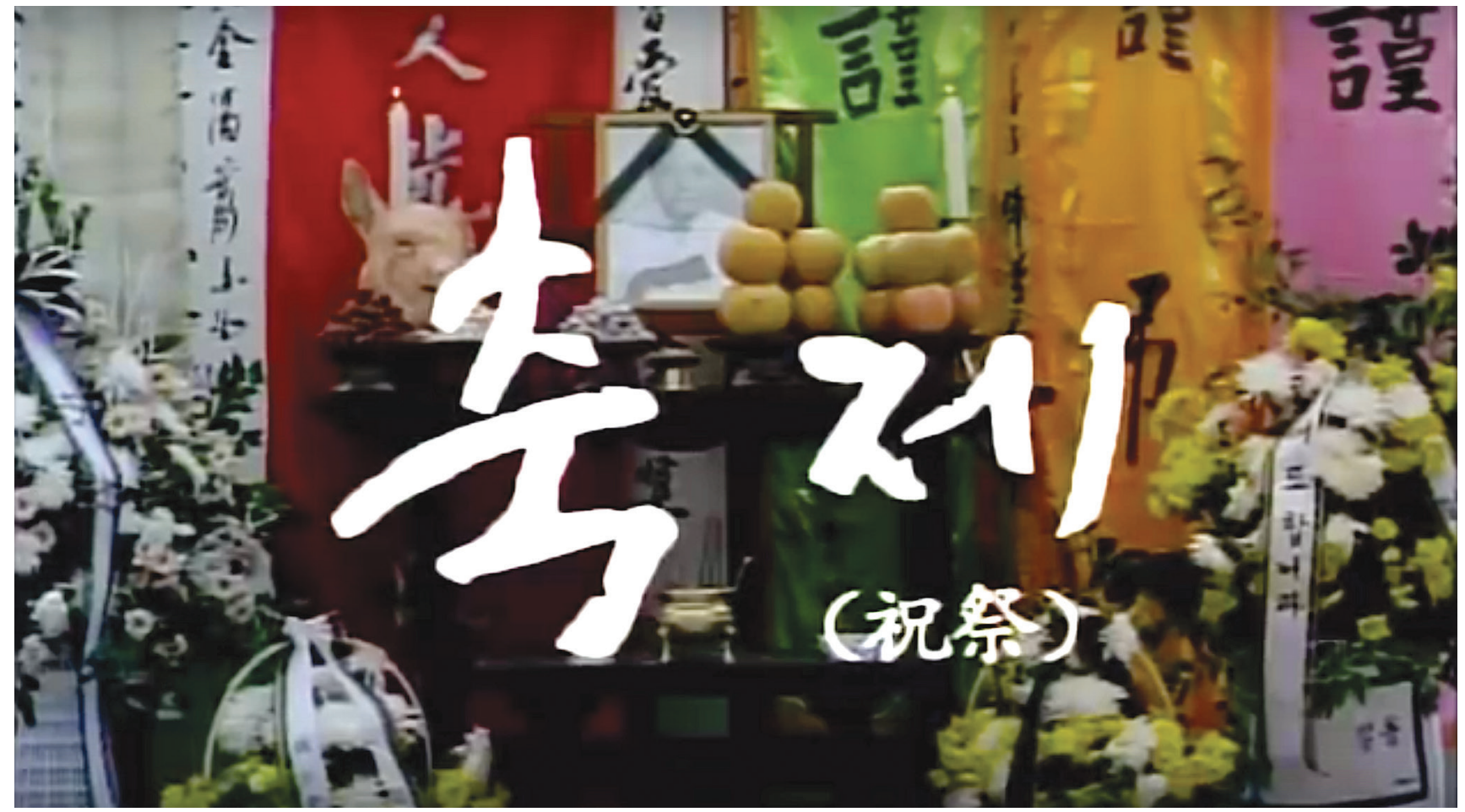

Figure 6.7. Calligrapher Yeo Tae myeong successfully sued the production company of Festival (Chukje, 1996), which stole his calligraphy for their opening title and poster design.

tieth century, calligraphic signs and stones were replaced by lettering and neon. Portraiture took on public dimensions, and political icons appeared on stamps, coins, paper money, posters, and, of course, movie screens.

By the invention of cinema, the emperor's hand had been replaced by the Western practice of the imperial portrait. However, a cinematic hybrid does manifest in the wartime cinema of Japan, where the words of the Meiji emperor were displayed in non-diegetic calligraphy. Examples include Young Soldiers of the Sky (Sora no shonenhei, 1940) and War at Sea from Hawai'i to Malaya (Mare Hawai okikaisen, 1942); the former is a documentary designed to inspire young people to enlist as pilots, and the latter recreated the Pearl Harbor attack on the occasion of its first anniversary through realistic special effects sequences by none other than Godzilla's Tsuburuya Eiji. In both films, the forward progress of the narrative grinds to a halt with cadets lining up in the visual spectacle typical of fascist aesthetics. They begin reciting a poem by the Meiji emperor in unison (fig. 6.9):

\section{Pale pristine expanse:}

more vast than spring's azure fields.

Under royal sky,

inspired by sheer breadth, my

own soul longs to mirror it. ${ }^{7}$ 

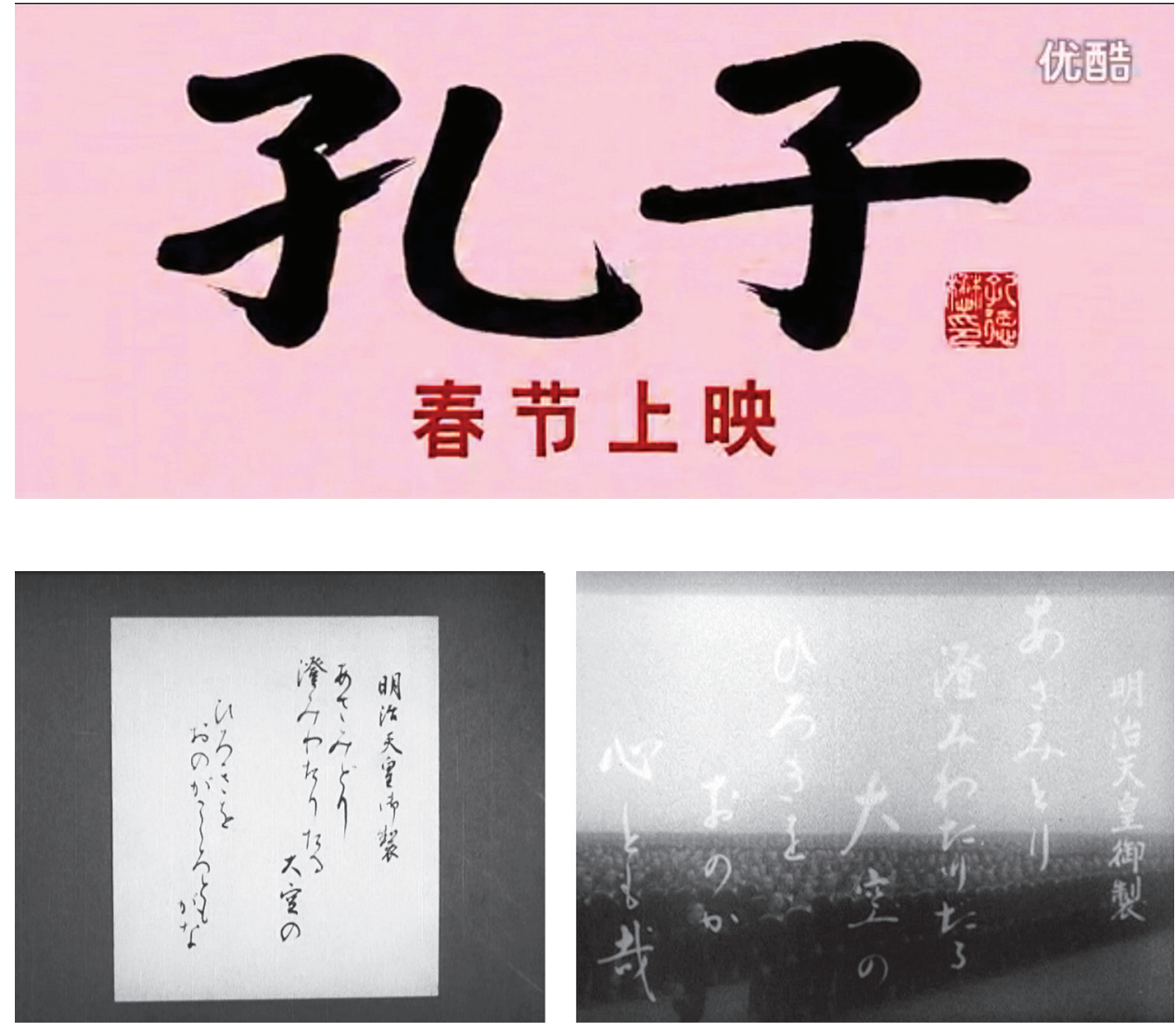

Figure 6.8. A direct relative of Confucius, seventy-seven generations away from the philosopher, drew the calligraphy for Confucius (Kong Zi, 2010).

Figure 6.9. The same poem from the Meiji emperor is prominently featured in two wartime films, War at Sea from Hawai'i to Malaya (Mare Hawai okikaisen, 1942) and Young Soldiers of the Sky (Sora no shonenhei, 1940). This non-diegetic display effectively united the characters and the audience with the presence of the sovereign.
Young Soldiers of the Sky superimposes the calligraphy for the poem over an endless expanse of erect soldiers. War at Sea from Hawai'i to Malaya cuts away from its soldiers to an actual painting of the poem; judging from the hand, it appears to be from Meiji's court calligrapher, Ban Masaomi. ${ }^{8}$ The poem itself plays on space and color, positioning the cadets in relation to both an awesome imperial presence they desire to be absorbed into as well as an empire fertile with possibilities for endless expansion. In this respect, it is significant that both films use nondiegetic calligraphy for the emperor's poem, as it suggests the calligraphy's source is somewhere other than the narrative space. While we see and hear the cadets recite it, the poem itself is sourced from a suitably obscure place. This further amplifies the force of calligraphy we explored in the previous chapter. Through this curious articulation of cinematic calligraphy, audiences were brought into the imperial presence. More specifically, audiences and soldiers pedagogically united through the words of the sovereign.

Kurosawa Akira brought this to a somewhat strange place during the production of Tora Tora Tora (1970), yet another reenactment of the Pearl Harbor attack, this one commemorating the twenty-fifth anniversary of the end of the war. During the production, Kurosawa suffered a mental breakdown that subsequently led to his dismissal from the set. At the height of his insanity, he issued a puzzling 

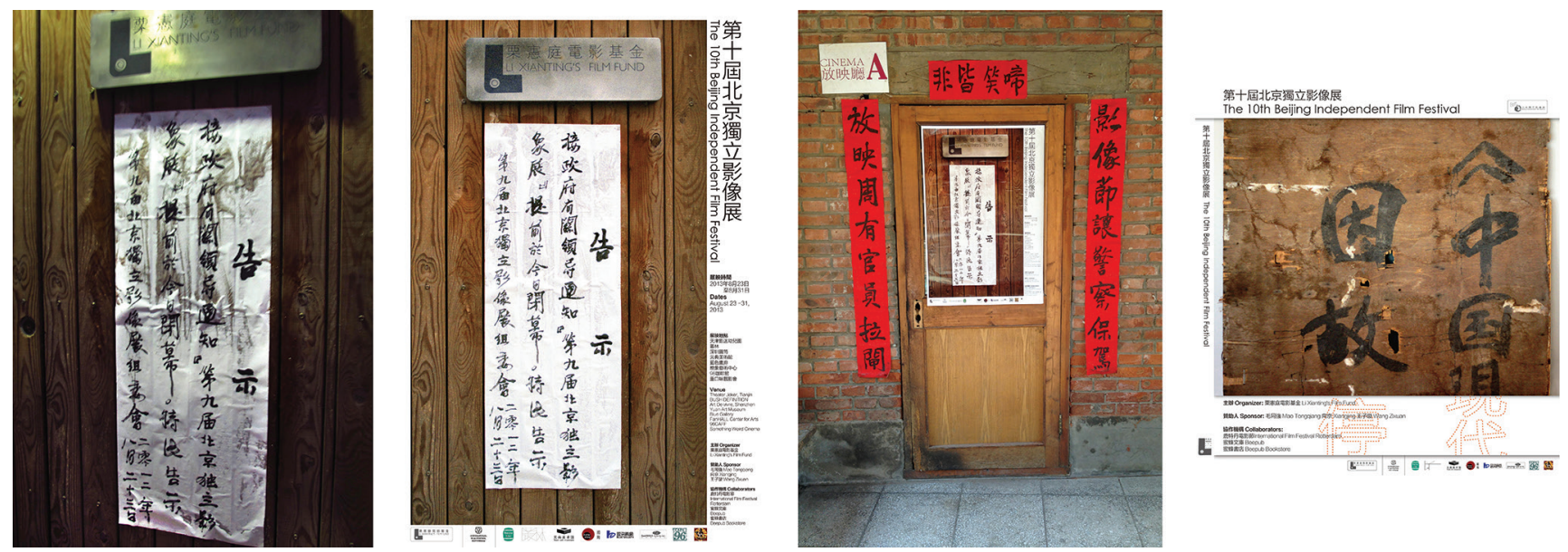

Figure 6.10. Li Xianting wrote a notice (left) announcing the forced closure of his ninth Beijing Independent Film Festival, echoing a similar notice he wrote in 1989 when the first exhibition of postwar modernist work was also shut down. Anticipating more police interference, the poster design for the tenth festival by Wang Wo (middle) integrated the previous year's notice. His catalog cover (right) integrates the notice Li wrote back in the 1980s, making the connection explicit.

command to his staff. Take the calligraphic scroll hanging on the set of Admiral Yamamoto's cabin to the Imperial Palace 500 kilometers away and show it to Hirohito himself for approval. Kurosawa wanted to be sure-by way of the imperial gaze - that the calligraphy was adequate for the Emperor's former charge. ${ }^{9}$ This is essentially the cinematic flip side of what Hay describes; rather than preserving the emperor's hand in an auratic original, Kurosawa wanted to render his fake prop auratic by capturing Hirohito's gaze.

A final, more secular example will point us in a new, complicated direction. This is the set of posters and catalog covers designed by director Wang Wo for the tenth Beijing Independent Film Festival (BIFF) in 2012 and 2013. This festival is organized by art critic and calligrapher Li Xianting, who I have cited in previous chapters. Li made

his reputation by throwing his critical weight behind the modernist artists that emerged after the barren era of the Cultural Revolution. He was at the center of an important incident in Chinese art history, an epoch-making exhibition of modernist art in 1989 that went awry. One installation work, entitled "Dialogue," involved shooting a very real gun, and the police used this as a pretense to shut the entire show down. Li was the one to grab a board and brush to write a calligraphic sign announcing the sudden closure.

Twenty-three years later, his own film festival was shut down by authorities for similarly capricious political reasons. Self-conscious of Li's role in writing the sign in 1989, the festival staff asked him to write a new closure sign (fig. 6.10, left), which they affixed to the front door of their institute. This sign and its connection to the previous event 
were the subject of much on-the-spot historiographic discussion, as it suggested Chinese independent film was at a watershed moment akin to that of the fine arts in 1989. Interestingly enough, Li turned from fine arts to independent film (particularly documentary) specifically because, unlike arts like painting and sculpture, it seemed impervious to commodification; and his film institute and festival was initially bankrolled by those 1980 os artists who subsequently became internationally famous and wealthy. Thus, the festival's request for Li's calligraphy on their sign was both homage to Li for his unflagging support for the arts and an assertion of their place in a Chinese modern art history and the inevitability of their legitimacy.

One year later, (correctly) anticipating another cease and desist order from authorities, the festival produced a festival poster and catalog cover with powerful designs by filmmaker Wang Wo. The poster featured a photograph of Li's 2012 closure notice pasted to the front door (fig. 6.10, middle), and the festival catalog cover displayed Li's calligraphic sign from the 1989 exhibit (fig. 6.10, right), which Li had just discovered in the ruins of an artist's studio (after the 8os exhibit, the artist had filched the sign to plug a hole in his leaking roof). This remarkable tangle of historical resonances was possible not just because the signs were handwritten. It is the fact that they were calligraphic - and that Li is admired for his calligraphy - that gives each sign an increasingly powerful sense of gravity. This all derives from the temporal knot of history built into the very fabric of the calligraphic sign.

\section{Corporeal Calligraphy}

The "knot" of the previous section is ultimately bound to the body of the artist. This is gestured to in the mythology of calligraphy history, starting with Cang Jie's forehead full of eyes. One also thinks of Zhang Xu, the Tang Era poet known as one of the Eight Drunken Immortals.
He is said to have painted his best cursive calligraphy at the end of vigorous drinking sessions - using the tip of his long hair instead of a brush. This also recalls the practice of contemporary fine artist Gu Wenda, who "wrote" uncanny, calligraphy-like characters using human hair. He even created ink sticks out of carbonized human hair. These examples all trade on calligraphy's uncommonly profound connection to the human body.

At the same time, all the examples miss a crucial element. If we were to stop here, we might stop at thinking that calligraphy shares the indexical qualities of the photograph, or the death mask for that matter. It certainly does, but actually calligraphy is far closer to cinema. The latter, according to André Bazin, accomplishes something "strangely paradoxical" in comparison to still photography. In "Theater and Cinema: Part Two," Bazin writes,

The cinema does something [more] strangely paradoxical [than the photograph]. It makes a molding of the object as it exists in time, and furthermore, makes an imprint of the duration of an object. . . . Hence it is no longer as certain as it was that there is no middle stage between presence and absence. It is likewise at the ontological level that the effectiveness of the cinema has its source. It is false to say that the screen is incapable of putting us "in the presence" of the actor. It does so in the same way as a mirror-but it is a mirror with a delayed reflection, the tin foil of which retains the image. ${ }^{10}$

Temporality is constitutive of calligraphy. The longgone material conditions of calligraphic practice, including the human labor of inscription, are captured in every work of calligraphy. It is here where the relationship between calligraphy and cinema is at its most intimate. To explore this, let us step away from the brush and the photochemical image and consider Iimura Takahiko's camera-less experimental film White Calligraphy (1967) and the scratch. 
Iimura is an experimental filmmaker based in Japan and New York whose entire career has explored the language of cinema and language in cinema. He shares my concern for the force visual text can exert on cinema and its spectators. His most compelling exploration of the theme is the protean White Calligraphy, a camera-less film he made in 1967 but in a fundamental sense never completed.

A core member of the Neo-Dada scene along with Akasegawa Genpei, Shinohara Ushio, Tone Yasunao, and others, his first films were strikingly surreal and erotic, such as his collaboration with Yoko Ono entitled Love (1962) and Onan (1963). Around this time, Iimura moved to New York, where he became associated with Fluxus artists like Ono, John Cage, and Nam June Paik, as well as the underground film scene being forged by Jonas Mekas, Andy Warhol, and others. His work then became increasingly schematic and semiotic. We can think of White Calligraphy - which is both rigorously formal and sensuously corporeal—as his transitional film.

Iimura undoubtedly found inspiration in Stan Brakhage's abstract experiments and the scratch films that were appearing on the avant-garde film scene. At the center of White Calligraphy is a text from the literary canon, the opening of the Kojiki (711-712), which contains the origin myth of Japan. He scratched it onto black leader one character at a time (fig. 6.11). Iimura explains:

One day the idea came to me. I was poor and my wife was working at a restaurant so I had to make a cheap film. I had lots of black leader laying around, so I decided to write on that, scratching it with a needle. What to write? Not my own thoughts. The Kojiki was very far from me, but I found a paperback version of a modern translation at a bookstore. I started writing, but it was so boring. Really hard work. So I quit and my wife took over. Her writing style is much better. I'm edgy, wild; she's neater. Where there were embedded

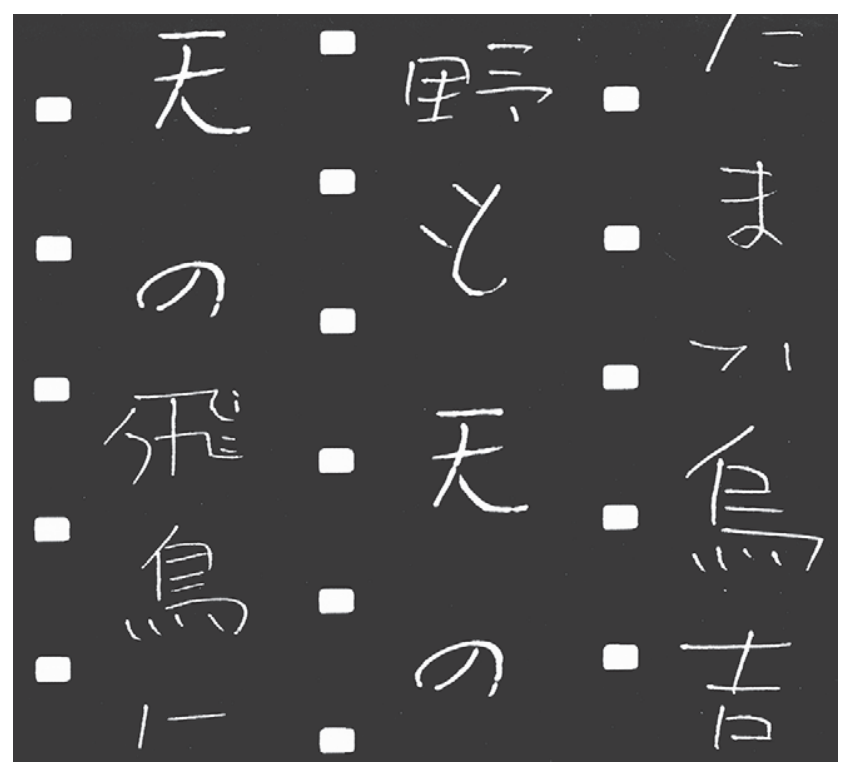

Figure 6.11. Scratched frames from limura Takahiko's White Calligraphy (1967).

poems, I cut them out and left a black space in their place. ${ }^{11}$

In other words, Iimura takes the text on the birth of the universe and transforms it into a set of notations for the performance of his film. As with much of premodern literature, the original manuscript and its first publications are missing. This is text that survived to the present thanks to copies that were made over the centuries, and for most of history, these copies were calligraphic. As Reginald Jackson writes in Textures of Mourning, these brushed copies were performances of the text that served contemporary political and aesthetic sensibilities and ambitions. ${ }^{12}$ This is as true today as it was in the eighth century. Iimura took a translation of the original manyogana text into modernday Japanese to create a classic of the 1960 avant-garde..$^{13}$ It's nothing other than the latest performance of the text to revitalize both the Kojiki and the cinema itself. ${ }^{14}$ Of 
course, his tool was not a brush and scroll of rice paper, but a strip of celluloid, a needle and light.

It is significant that Iimura chose the scratch over the photochemical reproduction of brushwork or woodblock, as Matsumoto did shortly after this for Everything Visible Is Empty. As Steven Heller and Mirko Ilíc argue in Handwritten, the scratch is the most fundamental and embodied of inscriptions:

Everyone has scratched a message in the dirt or onto a stone. It is the most primal of letter-making, more so than graffiti or any other ad-hoc inscription anywhere or anyhow. A scratch is the purest of marks: direct, immediate and unaffected. Skill is unnecessary and artistry is unimportant; it is vernacular's vernacular. ${ }^{15}$

Most handwriting, using pen or pencil, involves the smooth, regular application of lead or ink. As I write this sentence on paper with my fountain pen, every letter receives a steady, automatized flow of ink as the pen's bit glides over the paper. In contrast, Heller and Ilíc remind us that scratching has a special power because it involves pressure and stress. This is precisely why it is used for the horrific credit sequence of the thriller Se7en (1995).

However, the scratch doesn't have to connote violence or dread. In Kim Ki-duk's Spring, Summer, Fall, Winter . . . Spring (Bom yeoreum gaeul gyeoul geurigo bom, 2003), a longlost disciple returns to his remote temple after murdering his wife. His teacher intervenes in a suicide ritual where the man seals his eyes, nose, and mouth with paper brushed with the character 閉, to shut or obstruct. The priest stops him, beats and binds him, and paints the Heart Sutra on the deck of the temple using a cat's tail instead of a brush (fig. 6.12). He makes the disciple carve out each character, using the murder weapon. When two cops show up, guns drawn, they decide to let the murderous disciple finish the carving all night until the sutra is finished. Even then, they help paint in the carved characters with colored ink before

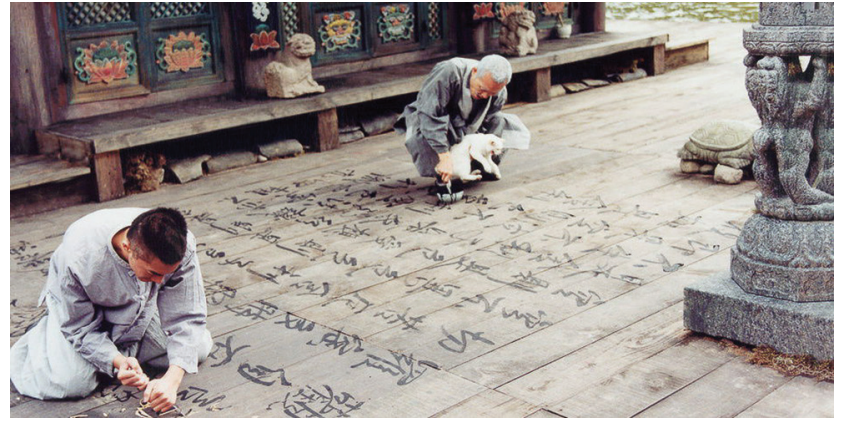

Figure 6.12. In a ritual of contrition, redemption and protection from evil, a murderous disciple carves out the characters of the Heart Sutra written (with a cat's tail) by his master in Spring, Summer, Fall, Winter... and Spring (Bom yeoreum gaeul gyeoul geurigo bom, 2003).

cuffing the student and hauling him away. Like Se7en, the film exploits the physical force behind carving, except here it is therapeutic, redemptive, and apotropaic.

The act of inscription in East Asian calligraphy is far closer to scratching than writing by pen, steel bit, or quill. The calligrapher also uses pressure, but it is fine-tuned and ranges from a feathery glance to a kinetic swipe or jab. In White Calligraphy, Iimura's scratches have wavering, unpredictable strokes that give them a very human feel that typeface omits by design.

In this way, the film invites us to think about the act of writing, especially the tension between traditional protocols and modernist innovation-the treacherous sweet spot that all cinematic calligraphy inhabits. The director chose this title because of the way calligraphy, as a form of writing, is dominated by that rigid set of rules that determine where lines start and end, how long strokes last, their directionality, the angle of the tool, the speed of the writing, the order of application, the grasp of the writing instrument, and more. Iimura states this is why he hates calligraphy and why he is terrible at it. Here he was striving for a performance of both writing and filmmaking free 
of stricture, opening his work to spontaneity, automatism, and the artfulness of accident. "Writing with a needle is hard," said Iimura, "and sometimes the needle slips. The lack of control leads to unexpected movement and effects."

Of course, since every frame of the film contains a single character, the act of projection illuminates the writing while simultaneously activating it; the characters restlessly dance on the screen, a novel kind of illegibility made possible by cinematization. It forces one to contemplate the experience of reading. According to Iimura,

Foreigners see the film differently. When I look at the film, my eye connects to the original characters. Foreigners can approach it much more freely. So foreigners are the ideal audience, because they are free from meaning and don't struggle to pick out characters. For Japanese it is very different. Unlike kana, Chinese characters have meaning. It all overlaps at 24 frames per second, so it is a new and unexpected experience of language.

Scott McDonald called this a "retinal collage."16 It's a compelling description that misses out on the essential element of performance. As we saw earlier, cinema is a multi-staged art with perplexing modes of notation. Most films do not capitalize on the back-end stages like projection, but Iimura does with White Calligraphy. It is with theatrical projection before spectators that the film and its "calligraphic" text comes to yet another life-and sometimes in the most surprising and delightful of ways.

As with calligraphy of the premodern era, Iimura occasionally treats his text as a score for vocal performance. He will recite this passage of the Kojiki as the projector transforms it into beautiful, if largely illegible, calligraphic light. But there are other, even more fascinating, performance strategies. Iimura has an $8 \mathrm{~mm}$ version of the film, which he presents with a projector capable of variable speeds. This enables him to speed the film up, or slow it down to the point that spectators can read the characters. Or he
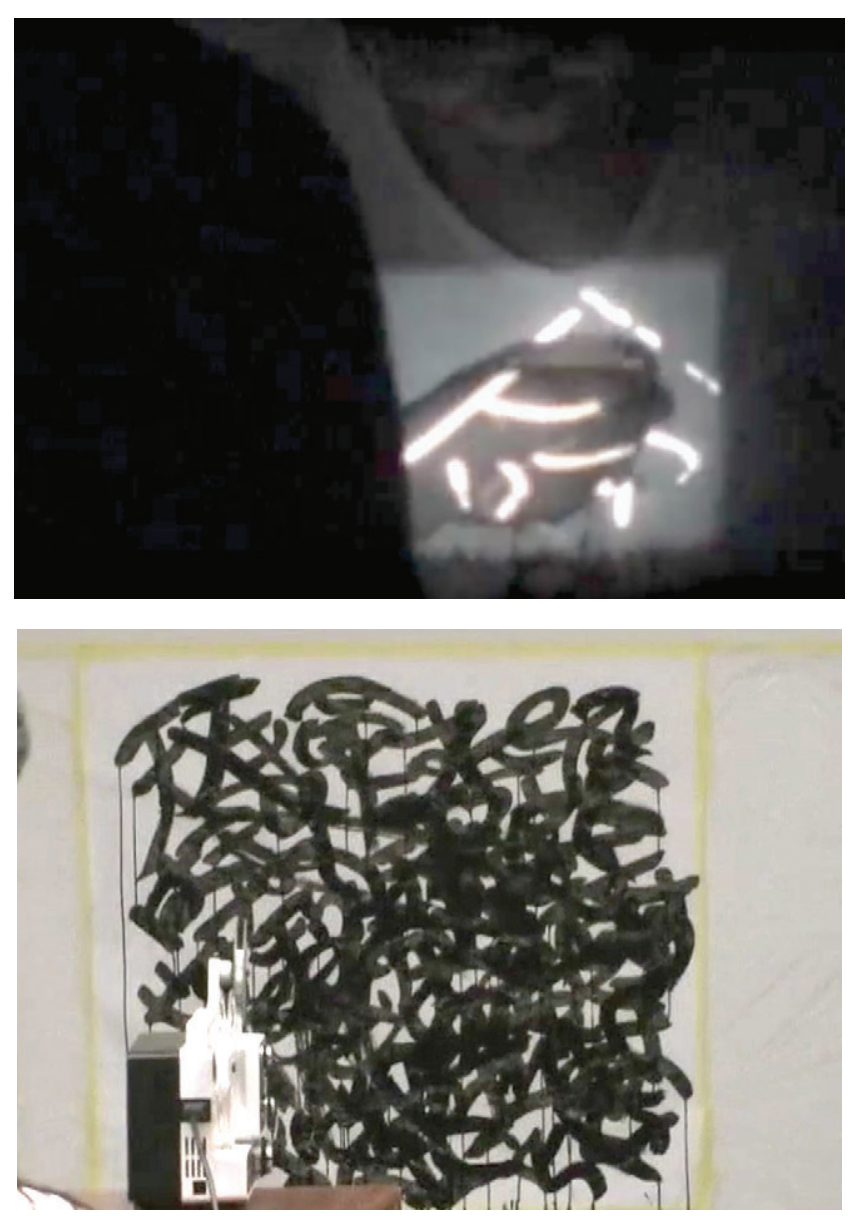

Figure 6.13. Two performances of limura Takahiko's White Calligraphy. On the top, the director writes on a small projected image while the film runs (the character is 命, or "life"). The bottom image shows the theater at the instant the house lights go on, the projector aimed at the screen limura painted on during the film's performance.

can throw the projector into reverse. He has staged performances where a projectionist follows him around the theater while he moves a white board around the audience, paints the text on the screen while the film plays over this supplemental act of writing (fig. 6.13), resulting in a tangle of overlapping strokes reminiscent of Qiu Zhi- 
jie's famous photography sequence "Copying the Orchid Pavilion Preface 1,000 Times." 17 "This," Iimura asserts, "is about animating yourself in the character." Finally, Iimura will sometimes pick up the projector himself, throwing his overlapping characters onto the wall like lively graffiti, onto the floor, and even onto the bodies of the spectators.

Iimura has described White Calligraphy as a film that detaches word from meaning and corporealizes it. ${ }^{18}$ While he meant his film to constitute a rejection of actual calligraphy, we may see that it actually epitomizes what is so special about the calligraphy of the cinema. Calligraphy, whether legible or not, is always already corporealized. The still image of White Calligraphy's slips of scratched celluloid cannot convey the enervating impact of those frames when run through a projector. The initial force of the pin scratching emulsion is immeasurably amplified by the retinal collage, which itself is magnified by both the projector's lens and once again by Iimura's projector performances. Similar events and amplifications occur in the inscription and appreciation of calligraphy. Thus, White Calligraphy brings us to an unexpected convergence of brushing in ink and brushing in light.

\section{Reading the Moment}

In the epigraph beginning this chapter, Naoki Sakai asserts that, in confronting a work of calligraphy, one is both seeing and reading. He concludes that "visual perception is in fact an experience of reading the world." Calligraphy provides a particular rich object for this expanded notion of reading, starting with the fact that its linguistic dimension unleashes the powers of writing in all its communicative and aesthetic dimensions. Cinema extends and amplifies these possibilities through a particularly propitious marriage of art forms. I believe this is related to the profoundly similar temporal qualities of cinema and calligraphy, and especially of cinematic calligraphy.
Moving type and its digital life as font has a remarkable capacity for specifying moments in the history of writing. For example, various decorative typefaces suggest the nineteenth century blackletter print evoking Germanic Europe, or the art deco of the roaring 2os. If typography expresses or indicates an era, calligraphy does that while also preserving an event. What's more, it refers us back to the human being behind the brush. The aesthetic force of calligraphy ultimately taps into the energy expended by that artist back in the painting's past - that human body moving in restricted space for a short span of time, sometimes only an instant.

I came to this realization through a much more unexpected route, a film that is actually about death—although it was not a record but a suicidal fantasy.

The film was Mishima Yukio's Patriotism. I have already discussed the novelist's skilled rendering of the film's title (fig. 4.7) and the monumental scroll decorating his spare set (fig. 4.16). However, what initially struck me about the film was the calligraphy for the intertitles. Mishima produced different sets for English, French, German, and Japanese, all by brushing on a long scroll of rice paper-scrolls that Mishima actually mounted and preserved. ${ }^{19}$ Despite his talent for calligraphy, the English intertitle looks rather amateurish; as this evidences, it is simply impossible to make the Roman alphabet look good with the Four Treasures.

However, what caught my eye were the mistakes. Surely it was difficult to write in the foreign language, and all the more trouble because of the way the Roman letters are so alien to the writing tools. Thus, when Mishima made mistakes, he decided it was too much trouble to start from scratch. Instead, he simply used his thumb to wipe off the ink and plow ahead (fig. 6.14). This is what caught my eye: the smudge. To be specific, Mishima's smudge.

Unlike the letters surrounding it, the smeared ink communicated no semantic meaning. The text itself drew no attention to the calligraphy - unless one noticed its home- 
liness. The viewer is meant to ignore the letter to extract the message propelling the film's narrative. In contrast, the smudge may have no semantics but it does possess somatics. There may be no message, but there is definitely a trace of Mishima himself. The novelist's stumble left a visual glitch, and when the reader arrives at it, there is an instant in which one comes into a curious relation to Mishima and the moment he thought, "Screw it. I'll just rub this out."

Actually, the author's motivation could have been entirely different. There is precedent for an artist retaining his mistakes, starting with one of the most famous works of calligraphy in history, Wang Xizhi's "Preface to the Poems Collected from Orchid Pavilion" (fig. 6.15). The setting was an historical gathering of literati in 353. The poets sat on the banks of a stream. Cups were launched on its surface and whenever a cup caught the bank, the nearest man would have to drink the wine and write a poem on the spot. In the end, they created a collection of thirty-seven

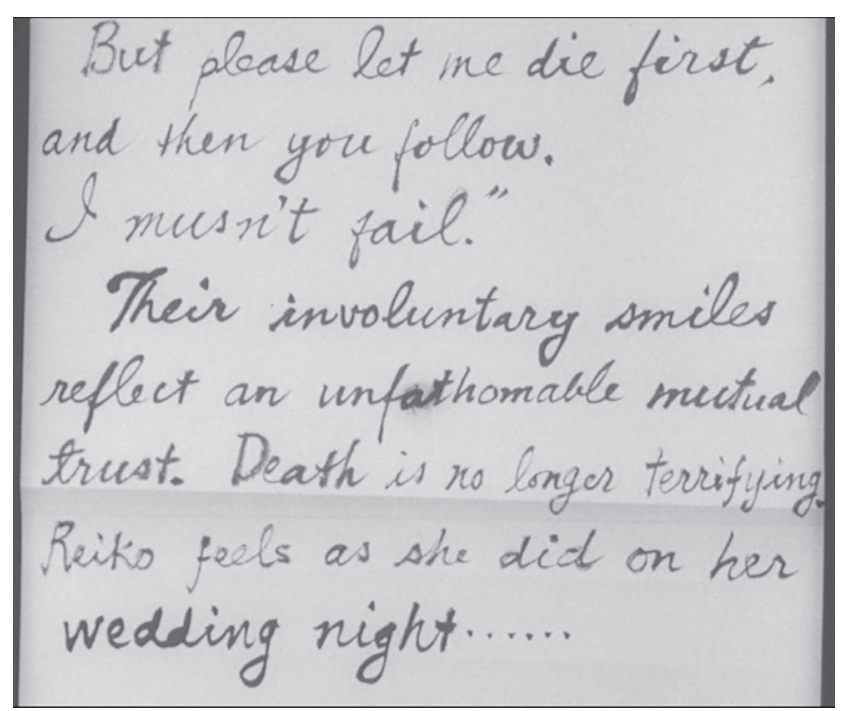

Figure 6.14. Mishima Yukio painted the scrolling intertitles for Patriotism (Yukoku, 1966), smudging out mistakes rather than starting from over again.

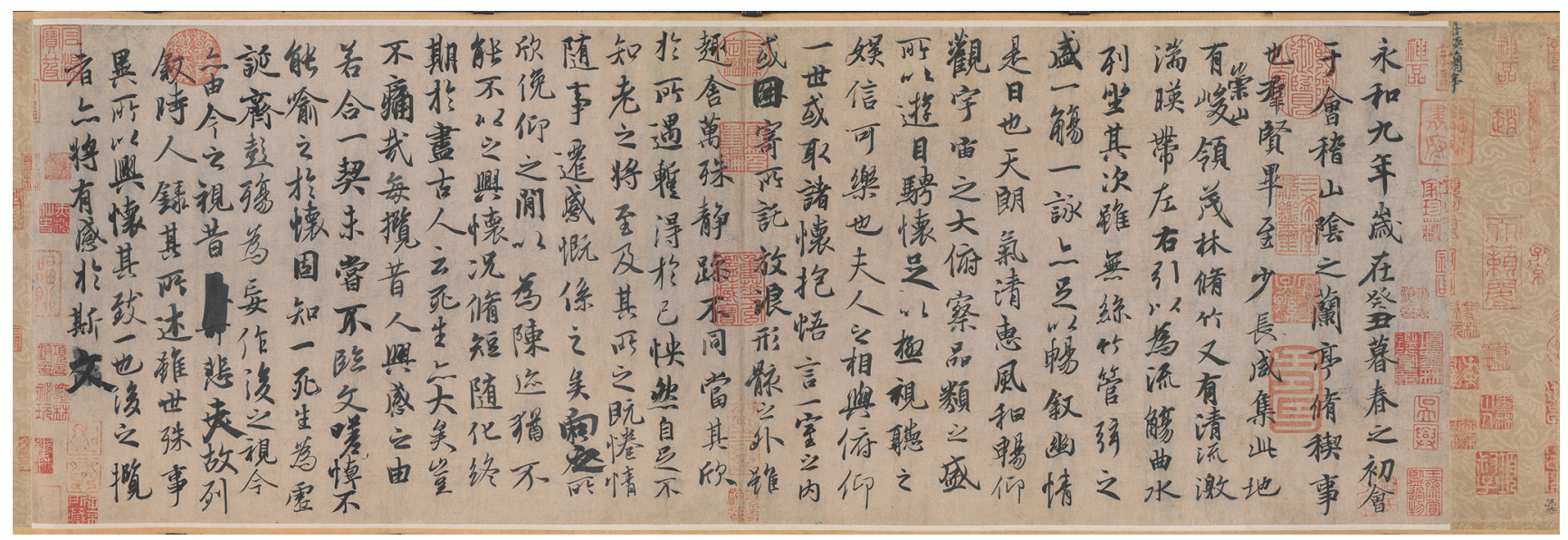

Figure 6.15. The corrections in Wang Xizhi's "Preface to the Poems Collected from the Orchid Pavilion" (Lantingji Xu, 353) are an essential part of the work and copied by collectors over the centuries. Courtesy of the Palace Museum. 
works. When it was all over, Wang Xizhi, in spite of his inebriated state, set brush to paper and composed a beautiful preface to their collection. And thanks to the wine, he kept making mistakes-striking each of them out with a few twirls or strokes of his brush.

Disappointed by his mistakes, Wang returned to the piece and wrote the same preface out with a clear mind. However, his new efforts disappointed him. None of them achieved the beauty of his original drunken calligraphy. So he discarded the new versions and kept the original with all its blunders. Unfortunately, that original is lost; the Tang Emperor Taizong (ca. 598-649 CE) famously tracked down and acquired it, and then demanded that it accompany him to the grave. Happily, many copies were made over the centuries. Today, it is probably no exaggeration to say that it has been copied more than any other work of calligraphy. For over a millennium, it has been used as a model for calligraphers honing their skills. This practice is epitomized by Chinese artist Qiu Zhijie's "Copying the Orchid Pavilion Preface 1,000 Times" (1990-1995), a performance piece where Qiu practices Wang's model on the same sheet of paper until it became an utterly black field.

What is relevant to us is the fact that every copy of the preface, including Qiu's, replicates Wang's smudge from 353 CE. As Martin Kern writes, "every flaw was there to stay, a witness to the very act of performance never to be erase ... While fundamentally non-propositional, calligraphy was still representational: not of its contents but of its singular moment of bodily enactment." ${ }^{20}$ It is less failure than conduit between the ancient artist's present and ours.

It occurs to me that the works of calligraphy decorating Mishima's set-mechanically replicated in the photochemical image-do possess semantic meaning that contributes to the narrative. And as props unlike any others, they certainly anchor the mise-en-scène while organizing cinematic space. At the same time, the bold strokes of this calligraphy reference the undulating body of the writer as he danced over the paper with a brush. And then it struck me: this trace of a moment in the creative life of Mishima Yukio is not unlike the photochemical moving images preserving the novelist rehearsing his suicide.

\section{The Restlessness of the Calligraph}

In the last sequence of this chapter, I want to unpack the theoretical implications of calligraphy's strange temporality, especially with reference to the added complications of its cinematization. And I want to read this unique scene of writing through the film theory of Stanley Cavell and David Rodowick, whose work inspired me to return to this long-neglected project. Let us begin by asking what kind of art calligraphy is, following Rodowick's lead and routing the discussion through Cavell's discussion of Nelson Goodman's Languages of Art (1968). Nelson famously made a distinction between autographic and allographic art.

An art is autographic if it was produced in a unique and singular act in the past. In its purest form, there is also only a single artist responsible for the work. Thanks to the artwork's uniqueness, which is guaranteed by traditions of provenance, it is forever linked to the genius of the artist and the act of creation. It follows that subsequent repetitions or appropriations are seen as either novel creative acts of their own or scandalous forgeries. Autographic arts include painting, sculpture, and literature.

In contrast, allographic art involves creative acts with multiple agents and stages. This is to say, there is a spatial and temporal schism between the initiation of the work and its eventual completion. The final stage that completes the work of art often involves performance. The prototypical examples of allographic art are theater and music. The artistic process for both is similar. The playwright or composer creates a scored object; the work is complete only

THE SHIMMERING SMUDGE 
when performers gather, take up the original score, and complete it through performance. So, as Rodowick puts it, allographic art involves ephemeral acts of creation based on (ideally) inalterable scores, which is to say that notationality is at its very core. ${ }^{21}$

Rodowick, following Cavell's lead, points out that film does not reside comfortably in Goodman's schema. It seems a matter of course that film is not autographic, since the process of its creation has an almost mind-boggling multiplicity of stages. And if, as Cavell describes it, an artlike painting is autographic because it is "totally there"present in its entirety before us - then cinema sets itself apart by directing us to a past that is somehow present in the theater. ${ }^{22}$ But cinema, they remind us, is not precisely allographic either. The key to Goodman's theory of allographic art is notation. Here is how Goodman describes it:

First, a score must define a work, marking off the performances that belong to the work from those that do not ... But that is not all . . Not only must a score uniquely determine the class of performances belonging to the work, but the score (as a class of copies of inscriptions that so define the work) must be uniquely determined, given a performance and the notational system. $^{23}$

Now calligraphy would seem to be an autographic art form fitting Cavell's principle that an autographically produced work of art is "totally there." Using a bound bit of text as raw material, the calligrapher is both artist and author. The final brush stroke completes the work. In a simple sense, the work of calligraphy is nothing but a painting on paper. Furthermore, we view calligraphy like any other autographically produced drawing or painting.

However, on second glance, we can immediately appreciate the fact that calligraphy is far more complicated. First of all, many premodern works of calligraphy we appreciate as artworks today were, in fact, meant to be read during vocal performances of sutras and other religious or poetic texts. Calligraphy displays other curious aspects of notationality. The texts featured in calligraphic works of art are so often inscriptions of texts that, in this context, they are performances of scores. While it is true some texts are original, many-perhaps most-are poems, snatches of famous literary texts, charms, incantations, stock phrases, or single characters like the old standby 壽 (J: kotobuki; C: shou; K: su longevity, felicitations). We saw this character in Hou Hsiao-hsien's City of Sadness in chapter 5 (fig. 5.5); contrast this subtle and exceedingly complex usage to the yakuza film Yakuza's Tale (Tosei ninretsuden, 1969), where a bad guy in black stumbles into the character for longevity and Takakura Ken pins him to it with a samurai sword (fig. 6.16). Both the calligraphic scrolls and the films are like performances of this standard character for calligraphy.

We have already seen these notational qualities of calligraphy and cinematographic calligraphy in chapter 1 with the example of Everything Visible Is Empty, Matsumoto Toshio's performance of the Heart Sutra. Considered from Goodman's point of view, the director produced a new, intermediate score for the sutra (fig. 2.17). He photographically reproduced characters from a woodblock copy of the text he picked up at a temple, literally a score sold to believers to chant in prayer. Yet for half of the film, the director produced his own calligraphic copy of the sutra. Matsumoto's film provocatively reveals that the performance of the Heart Sutra score can be vocal, calligraphic, or cinematic.

There is also the matter of style and pedagogy. Tradition exerts a special, dull weight on most calligraphic art. As I mentioned near the beginning of this book, approaches to calligraphic style were codified by Wang Xizhi and others in the fourth century. The durability of these ancient conventions and rules has been guaranteed mainly by two things. The first is the actual system of notation calligraphy is based on: language itself. The building blocks of the art are characters that have specific shapes, num- 


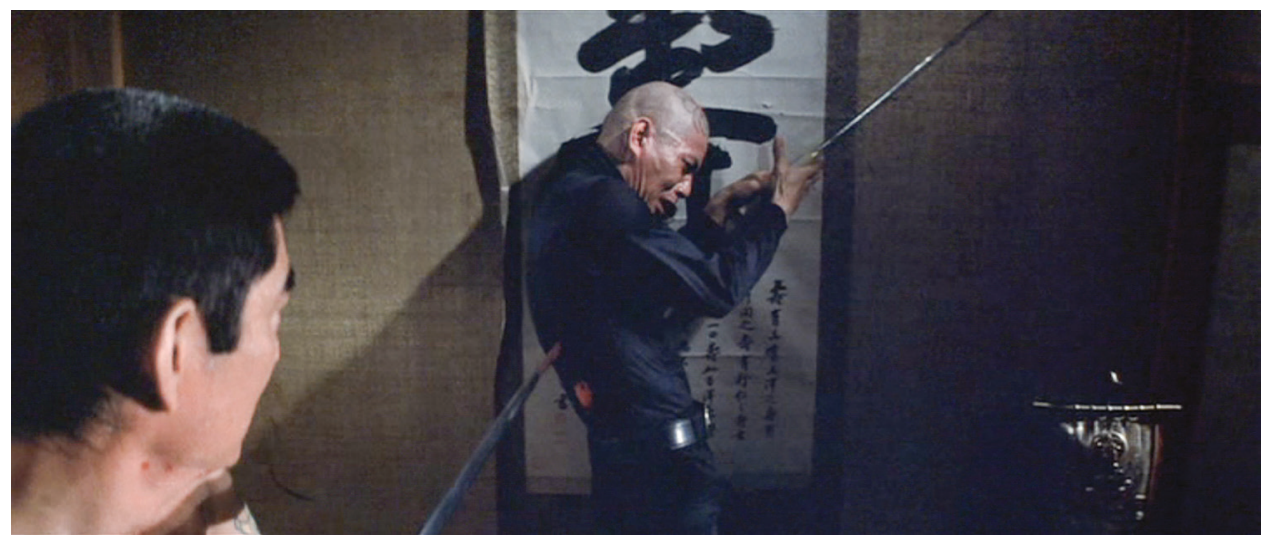

Figure 6.16. In Yakuza's Tale (Tosei ninretsuden, 1969), Takakura Ken pins a bad guy to the character for longevity with a samurai sword.

bers of strokes, line placements, and even the directions the brush must move in. The fact that a single stray stroke completely changes the semantics of a character-or renders it a meaningless abstraction-ensures a transmission of convention from generation to generation.

More importantly for the discussion at hand, calligraphy pedagogy is deeply based on mimicry. Anyone who has studied the art most likely began their training by endlessly imitating a model for the character - (or "one"it's harder than it looks). As artists progress, they carefully imitate the masters' examples. Only after long study is it thought that one can achieve a certain kind of spontaneity and individuation. This is even assumed by modernist artists who make it their business to break from convention. The artists representing the great modernist breaks in the history of calligraphy-artists like Gu Wenda in China or Morita Shiryu in Japan-were committed to tradition, bringing the codified practices of the past into tension with new forms of abstraction. Morita, for example, emphasized calligraphy's “mojisei” (文字性), tying it inextricably to the notational system of language.

It all tends to be so discrete that only other artists and connoisseurs can measure meaningful departures from the norms set out millennia before. However, with all this copying and mimicry, calligraphy compares favorably to allographic arts like music - a calligrapher's brushwork as akin to the rendering of a Mozart score.

Of course, as David Rodowick reminds us, notationality has long been a key concept in the history of film theory. The most important moment was certainly cinestructuralism. In Film Language, Metz sorts out the cinema into a system of codes, which he likened to linguistic structuralism's langue, with the énoncé of all the films made or possible to make. However, Metz discovered the perplexing impossibility of a code that cannot be broken down to its smallest constitutive parts-ultimately demonstrating that despite its demonstrative complexity, there's this paradox that you can't nail down a system of notation. Cinema is "a highly complex, elaborated, and codified system that nonetheless escapes notation," writes Rodowick. ${ }^{24}$

All this is something Kurosawa Akira clearly understood. Over the years, I have been meeting many calligraphers and art directors across East Asia; as I mentioned earlier, one name that repeatedly comes up as a director who cared deeply about art design and "got it" is Kurosawa. I want to tell the story of a gorgeous scroll painting from Kurosawa's Ran (1985). I stumbled upon this object on an obscure bookshelf in the props department on the Toho film studio lot (fig. 6.17-18). It is a major prop and was called out prominently in the initial design sketches 
for the sets. It says Hachiman Daibosatsu, one of those original "scores" that have been "performed" by calligraphers for centuries. The words literally refer to the protective deity of warriors. Their grand rendering in calligraphy, mounted on a scroll with an unconventional black border, and its placement in the innermost room of the lord's castle turn it into an offering to the god. Obviously, in this dark adaptation of King Lear, the painting has a haunting irony amidst the titular chaos and is meant to be a counterpoint to the scroll a blind character drops off the burned ramparts at the end of the film. That scroll displayed an image of Amitabha Buddha of Pure Land Buddhism, implying the world was entering one of the universe's cycles of godless upheaval. The samurai bluster of the first scroll and the eschatological metaphysics of the second are rendered mute for foreigners thanks to the lack of subtitles-as we've seen, most cinematographic calligraphy goes untranslated. Thus, for foreign viewers, the Hachiman Daibosatsu scroll becomes little more than an ornamental prop unburdened of its semantic and thematic role in the narrative. However, its sheer size and careful calligraphy indicates it was meant to be read.

I spoke to the art director who commissioned the calligraphy for this scroll at the behest of Kurosawa. The director told him he saw a hyosatsu name plate in Kyoto and wanted to use that specific calligrapher. The art director found it and tracked down the artist: of course, it ended up being one of the most famous calligraphers in Kyoto. He asked the artist for a sample, which he took back to the studio. Kurosawa liked what he saw and asked for eight more to choose from. After many trips between the two cities, the artist finally finished the task, and the art direc-

Figure 6.17. This massive prop from Ran (1985), seen here in the props department at Toho Studios, was visualized from the beginning as a major feature in the film's design.

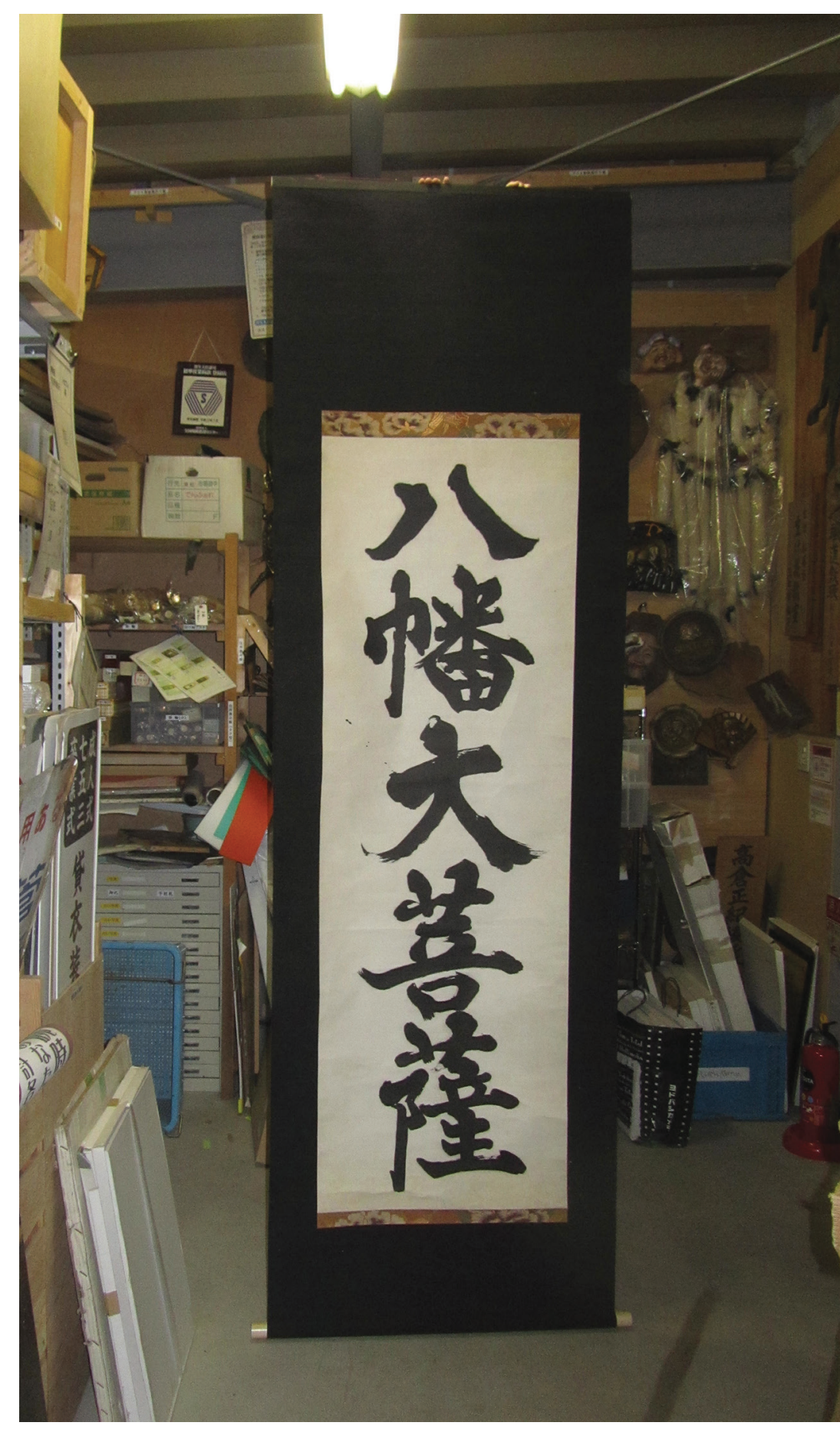




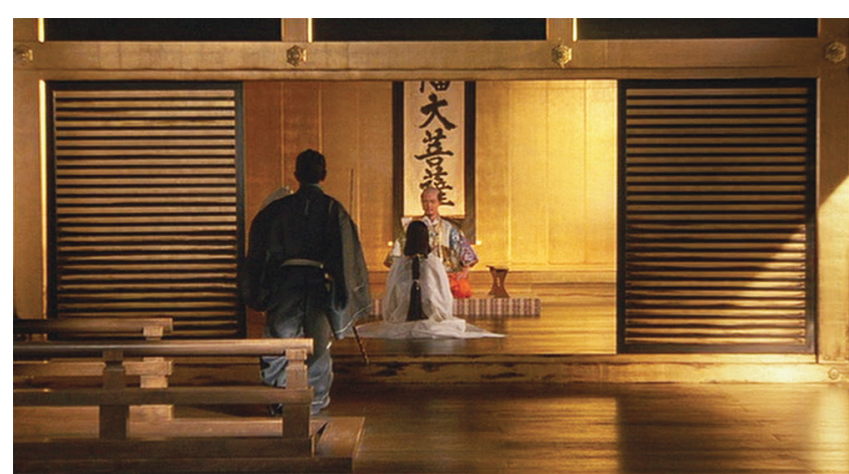

tor hand-carried them back to Tokyo. He put them all on a sound stage wall. Kurosawa came in and perused them. He was known as a director who knew what he wanted, and he immediately singled out the one he would dress his set with: it was the original sample! The art director was crushed. All that hassle, going back and forth, working with a famous artist that demanded obsequiousness. Tail between his legs, he went back to Kyoto and apologized to the calligrapher for wasting his time. The calligrapher thought about it and said, "Hmmm. Interesting. Actually, one or two of the others were better works of art, but it's the sample where the calligraphy best communicates the movement of my body." This calligrapher heard the art director's apology through a framework theorized millennia ago. Kai Yu-kung puts it succinctly:

As lyric experience, calligraphy concentrates on the phase of execution, which is the materialization of the power of the artist. Repeatedly, theorists warned the calligrapher to cleanse his mind before execution. It should not escape our attention that a completely cleansed mind may require the calligrapher to cut himself off from realistic experience. Divorce from the

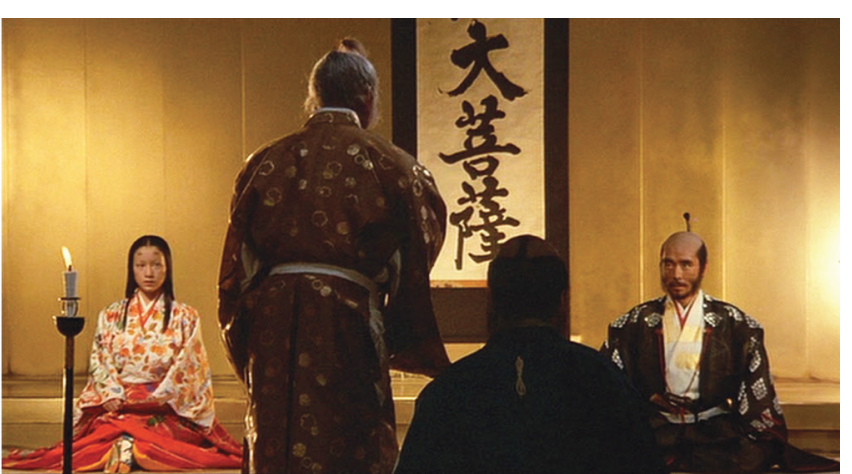

Figure 6.18. The Hachiman Daibosatsu scroll from Ran (1985) on the set. The calligrapher said it was the version that best communicated the movement of his body.

outside world is a necessary condition for great performance, completely dependent as performance is upon the inner reserve the artist can release at the moment. To appreciate calligraphy is to relive the physical action in one's mind. Therefore even the physical aspect of calligraphy can be meaningful only in its mental mode. ${ }^{25}$

Action painting is sometimes approached in ways evocative of ancient theories of calligraphy. For example, Harold Rosenberg writes, "The action painting is of the same metaphysical substance as the artist's existence. The new painting has broken down every distinction between art and life." ${ }^{26}$ This quote is a bit hyperbolic for my taste, but it does indicate the ground upon which the abstract expressionists viewed Asian writing - and misunderstood it. In their own practice, the individual stroke generally did not attract attention.

In contrast, the connection between work and artist is conceptualized in far more elaborate and pervasive ways in the world of calligraphy, beginning with the vocabulary. Brush strokes are said to have flesh (肉 rou, a full broad line), bones (骨 $g u$, middle tip movements, angular, lean and articulated), sinew (腱 jian, from the point of the tuft, 


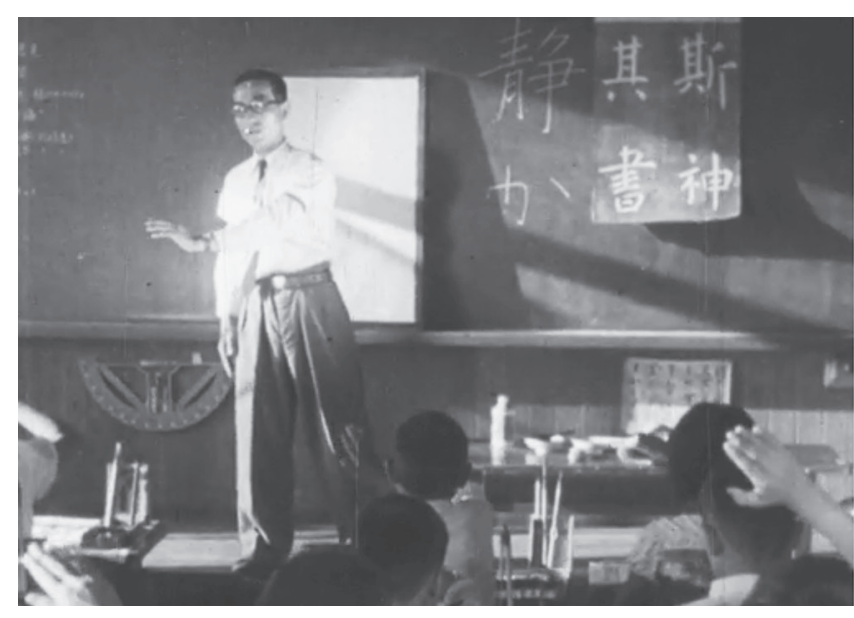

lines separated or linked by a thin line), and blood (血 $x u e$, the quality of the ink). ${ }^{27}$ Calligraphers over the ages have regularly used such bodily metaphors to explain what they are doing. This is because their artistic practice goes far beyond a crude communication model of sender and receiver of messages. As Tom Lamarre writes, "with brushwork, it is a question of sensory interpellation or, rather, embodiment." 28

This emphasis on the somatics of the art form is undoubtedly related to the fundamental conditions underlying the practice of calligraphy. Indeed, the space of the calligraph is intimately interfaced with the space of the human body. Figure 6.18 shows the pedagogical scene, as captured in the Alechinsky documentary. Before putting brush to paper, the teacher rehearses stroke order, waving his arms through the air like a massive brush; students mimic him, then finally pick up the brush. We intuitively measure the limits of the work of calligraphy by the length of the arm. As viewers of a calligraph, we know that a line

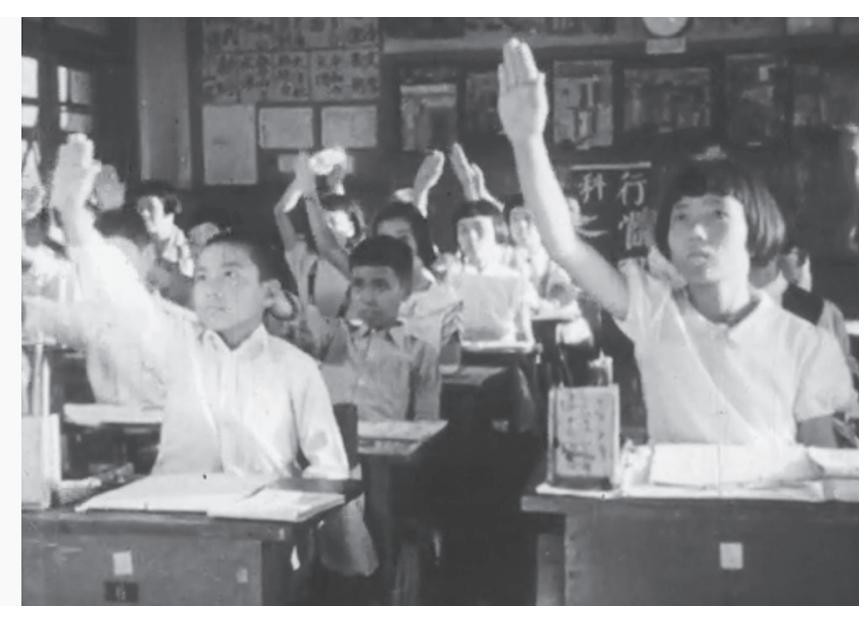

Figure 6.19. The somatics of pedagogy: before taking up the brush, students mimic their teacher's stroke movements while learning calligraphy. From Peter Alechinsky's Calligraphy Japonaise (1956).

shooting off in one direction can only travel so far before it reaches the span of the artist's arm and it must return. This is to say, the spatiality of the calligraph is intimately tied to gesture and the event of creation, and thus has as much to do with time as it does space.

\section{Notes}

1. Sakai, Voices of the Past, 116.

2. The correspondence, but not the title calligraphy, is preserved in the Ichikawa Kon museum in Shibuya (http://www. konichikawa.com/memorial.html).

3. Chang, "Power of the Word," 9. Also see Yen, Calligraphy and Power in Contemporary Chinese Society, 2-3.

4. Lee, "Hangul's Star Is Ascending."

5. Hay, "The Kangxi Emperor's Brush-Traces: Calligraphy, Writing and the Art of Imperial Authority," 310-11. This is a nice discussion of Imperial calligraphy and the "refashioning of public space" through fetishized gifts from the emperor, a practice that 
Mao exploited later. But the practice of imperial calligraphy goes back to the first century.

6. Chang, "Power of the Word," 7.

7. I am grateful to Reginald Jackson, who helped me unpack this poem and provided this translation. The calligraphy reads "Asamidori / sumiwataritaru / Ozora no / Hiroki o / noga kokoro to mogana."

8. The film also displays the calligraphy of Russo-Japanese War hero Admiral Togo . . . cast in bronze for a massive door.

9. We know of the story because a Warner Brothers executive memorialized Kurosawa's behavior on and off the set for the studio's insurance company. I tell the whole sordid story drawing on studio records in Cinema Babel.

10. Bazin, "Theater and Cinema-Part Two," 97.

11. All Iimura quotes come from interviews conducted on September 28-29, 2013, in Ann Arbor.

12. Jackson, Textures of Mourning, n.p.

13. Manyogana (万葉仮名) was the first use of Chinese characters to represent the Japanese language phonetically. It was in use from at least the seventh century. Cursively written manyogana gave rise to hiragana, and katakana was a similar simplification ultimately used for loan words.

14. The oldest extant copies date back to the thirteenth century; a second, slightly different copy established two streams of replication over the centuries. Here is a 1644 woodblock copy of the manyogana text: http://archive.wul.waseda.ac.jp/kosho/ ri05/ri05_04868/

15. Heller and Ilíc, Handwritten: Expressive Lettering in the Digital Age, 56.

16. McDonald, The Garden in the Machine, 71.

17. Examples of this kind of performance are available on the DVD Writing with Light: White Calligraphy, which is available on Iimura's website.

18. Dance News Plus, 5 (2005).

19. One can see the scrolls in a making-of documentary entitled Film: Patriotism Album (Eiga "Yukoku" arubamu, NA), which is on Youtube (https://youtu.be/S8ACN-NBhxs; accessed 10 August 2019).

20. Kern, "Made by the Empire," 131.

21. Goodman, Languages of Art, 212.

22. Cavell, The World Viewed, 109.

23. Goodman, Languages of Art, 128-30.

24. Rodowick, The Virtual Life of Film, 22.

25. Kao Yu-kung, "Chinese Lyric Aesthetics," 80.

26. Rosenberg, 23; quoted in Powers, op. cit.

27. Ecke, Chinese Calligraphy, n.p. Yen, Calligraphy and Power in Contemporary Chinese Society, 75-79.

28. Lamarre, op. cit. 


\section{Conclusion}

BRUSHED IN LIGHT

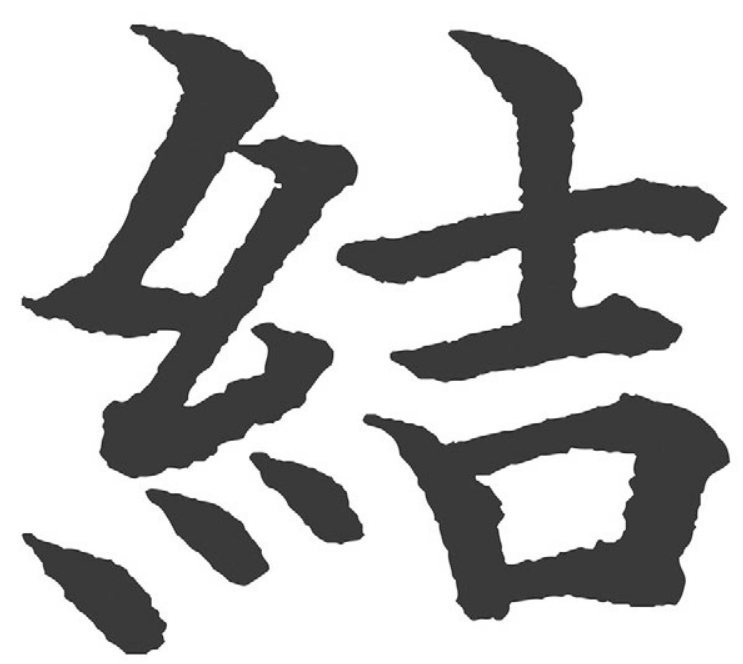

Sometimes extreme examples can help one understand something exquisitely delicate and subtle. Miike Takashi's 13 Assassins (13-nin no shikaku, 2010) presents a horrific scene of writing that manages to perversely flip the logic and sentiment of the following ancient Chinese commentary: "The essence of beauty in writing is not to be found in the written word but lies in response to unlimited change; line after line should have a way of giving life; character

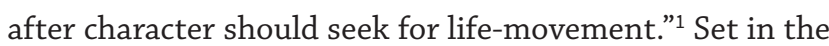
feudal period, the writer in 13 Assassins was a woman tortured and maimed by a sadistic prince. He brutally raped her, and then cut off all her limbs. To encourage 13 assassins to kill the perpetrator, she takes brush into mouth (having no hands) and, poetically crying tears of blood that spatter the paper, brushes out a calligraphic message. When the assassins finally confront the villain and his entourage of samurai, their leader whips out the woman's message and holds it up for the prince to read: "Kill them all" (fig. 7.1). The crudeness of the calligraphy, painted by mouth by the sobbing woman and surrounded by tearful drops of blood, vividly invokes the previous scene of writing, the extremity of the prince's brutality, and her tragic disability, all the while recording and expressing her roiling anger.

This is a narrativization of calligraphy theory's basic premise, which is that this form of writing is uniquely capable of registering individual personality, recording states 
of mind, and creating an indelible link between the scene of writing (in a sometimes very distant past) and the act of viewing in a subsequent present. This is why Buddhist monks would gather around their dying master with the Four Treasures, hoping the master's hand could inscribe, capture, and preserve the traversal from the realm of the living to that of enlightenment (and death). Called yijie (or yuige in Japanese 遺偈), this Chan/Zen custom has been called a "ritual enactment and expression of awakened awareness." 2 Greg Levine points out that modern writers sometimes refer to this as "terminal writing."

In these terms, the autographic death verse is not "calligraphic" because-in the face of death-the writer failed to fulfill, or eschewed, calligraphy's venerable logographic requirements and aesthetic inflections. The writing is characterized by slippage rather than control, mismeasure rather than fluidly gauged placement, stutter rather than momentum, and collapse rather than graceful strength or sustained energy. Thus, the master's final traces of the brush are about death, not art. ${ }^{3}$

There are modern equivalents. Shindo Kaneto's Kenji Mizoguchi: The Life of a Film Director (Aru eiga kantoku no shogai, 1975) ends with his assistant director relating a story about Mizoguchi on his deathbed. The day before his passing, the $\mathrm{AD}$ and screenwriter Yoda Yoshikata gave Mizoguchi a pen and beautiful Japanese paper, upon which the master made his final inscription: "The chill autumn air has already arrived. I want the pleasure of working with all of you at the studio" (fig. 7.2). The message is both hopeful and wistful. But the lack of control with which he wrote clearly belies what he himself knew-that he would never return to the studio. Indeed, while writing, Mizoguchi burst into tears, shattering his characters, and sending one line veering over the other. He passed away the following day.

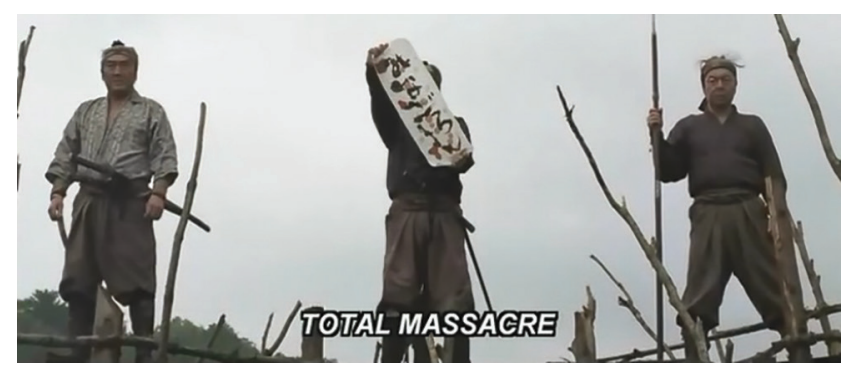

Figure 7.1. 13 Assassins (13-nin no shikaku, 2010): calligraphy written by mouth, by a woman whose arms and legs were cut off by a rival, with tears of blood splashing the page. The assassin displays her message_“Kill them all”/みごろし-before slaughtering the villain.

A similar, but decisively different example, is the yuige of Oshima Nagisa captured in the documentary What's a Film Director? (Eiga kantoku tte nan da?, 2006). And that difference is Oshima's use of the Four Treasures. The film is an argument about copyright and authorship produced by the Directors Guild of Japan. It climaxes with Oshima Nagisa sitting before paper with brush in hand, fighting his own body. It had been ravaged by an intracranial hemorrhage, and he could move only with immense effort. It's hardly masterful calligraphy; indeed, it is likely many calligraphers and art historians would refuse to call it calligraphy for its lack of control and inability to abide by the rules. ${ }^{4}$

However, every wispy line in the resulting painting (fig. 7.3) registers the complexity of the inscription event. Curiously, the ink thins out from the left to the right; this despite the fact that the sentence- "The director is the copyright owner" - starts on the right and ends on the left. In other words, at some point the viewer realizes with astonishment that the great auteur-for a film asserting the authorial rights of directors - started painting from the end: his signature. Oshima wanted to get his name right. The strokes become increasingly shaky with every 


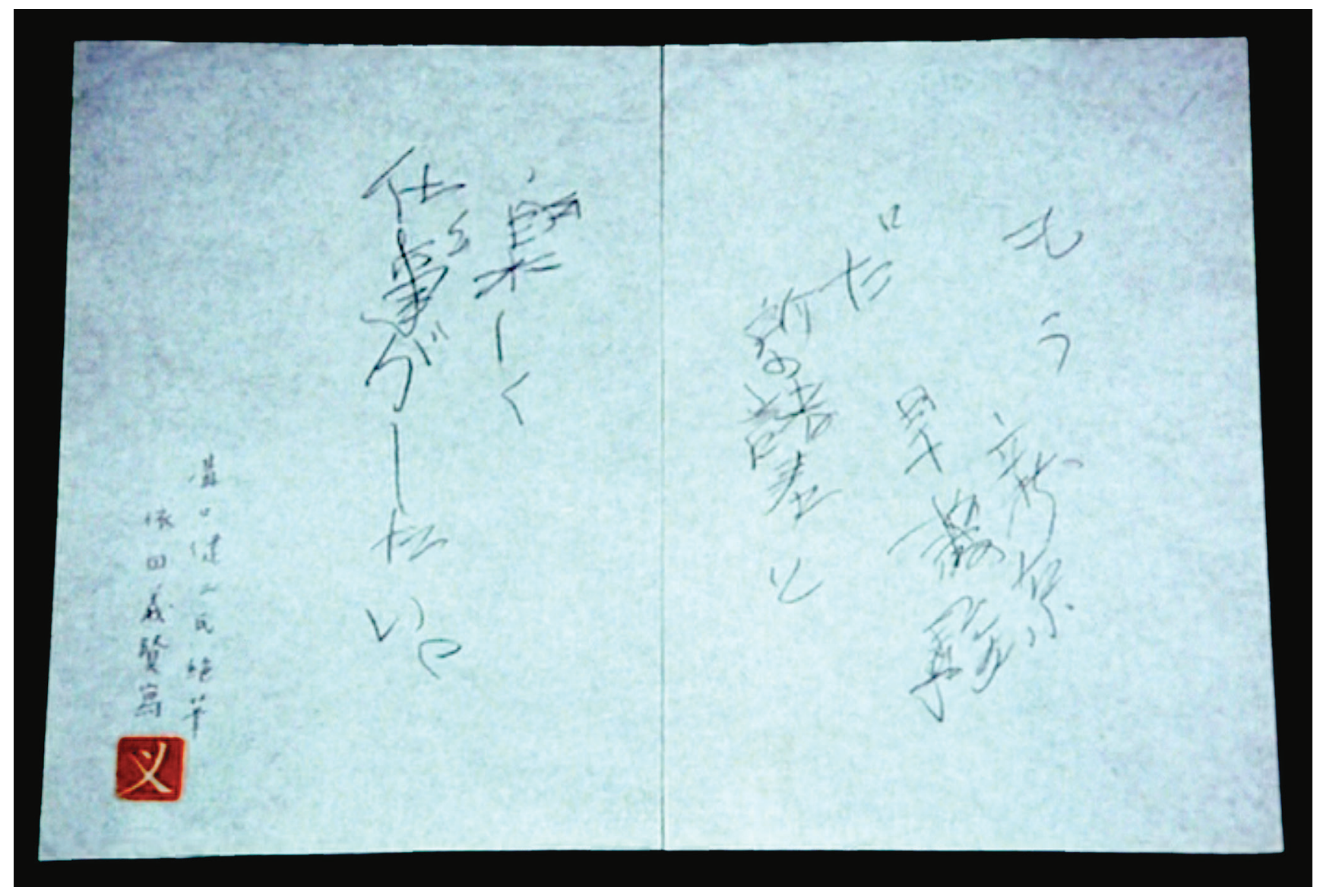

Figure 7.2. The last writing of Mizoguchi, from the documentary Kenji Mizoguchi: The Life of a Film Director (Aru eiga kantoku no shogai, 1975). In the tradition of Buddhist disciples capturing the moment of death of their master through calligraphy, his screenwriter gave him pen and paper the day before he died. The director wrote, "The chill autumn air has already arrived. I want the pleasure of working with all of you at the studio." On the lower left above the seal, it says, "Mizoguchi Kenji's last writing (zeppitsu); recorded by Yoda Yoshikata." The seal has the crushed character for 義, the third character in Yoda's name. 
character he laid down, communicating his growing emotion, collapsing body, and will to finish as he reached the last (first) line.

What makes the scene so emotionally moving is the dynamic between mental and physical states and the particular set of automatisms at work in the production of a work of calligraphy. Whereas the edges of a painting function as a limit that gathers and organizes its elements into what Cavell called a "totally there-ness," the edges that matter in calligraphy are the organic curves and spikes of the brushstrokes. ${ }^{5}$ And they send us to the process that caused the image. They point us to the brush, hand, and the gesticulating body of the transcription-event. And as the artist dances above the paper, any number of automatisms inflect the transcription: the posture of the body, the limits of the surging limbs and trembling fingers, the built-in directionality of the paper fibers, the mixture of water and ink, the temperature of water and ink, humidity of the room, and the ink's absorption from the tip of the brush into the paper. When the artist's body ends its final gesture, what is left is the indexical trace of a past event and existence. As Maxwell K. Hearn suggests, "every trace of the brush carries the autographic handprint or "heartprint' of the individual, reflective of his or her intellect, emotions, and connection with the past." Iida Reigiku compares calligraphy to acting; just as an actor breathes life into a role, a calligrapher enervates and animates the letter-if she doesn't, the characters are "dead."

It is the task of the viewer of these lively characters to tune into the long absent scene of writing. This begins with the saccading of the eye. Viewing a work of calligraphy, one's gaze follows the lines in the order of inscription, sliding, pausing, over the sinuous brushwork. There is a mimetic effect here. John Hay writes,

The physiological metaphors in calligraphy texts are immediately sensible. This in itself is an important indicator. It is immediately effective to ask someone,

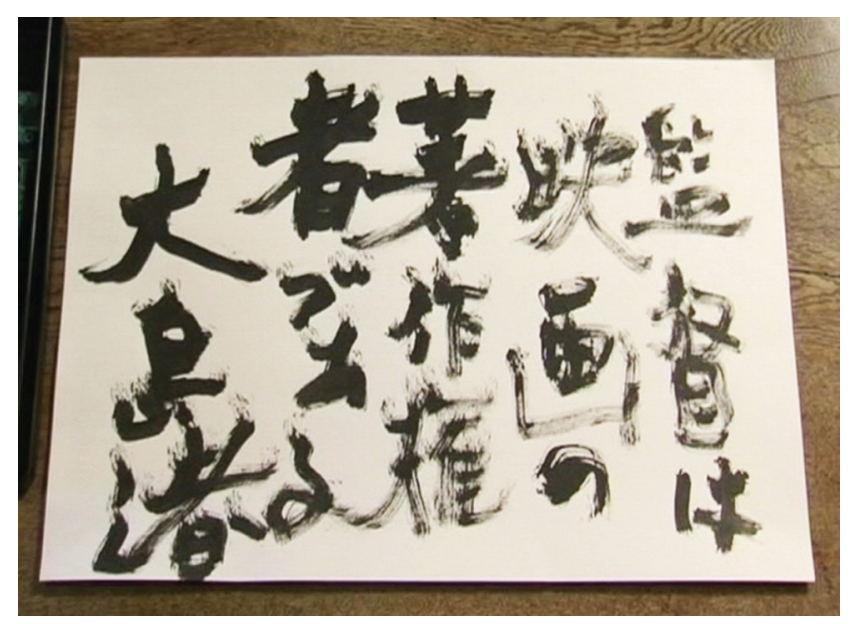

Figure 7.3. In What's a Film Director? (Eiga kantoku tte nan da?, 2006), every wispy line of Oshima Nagisa's painting registers his lack of bodily control and his utter will to finish. From the fading ink, it is clear he wrote backwards (left to right), starting with his name.

in their first meeting with calligraphy, to look at the characters as though they were a body structure- - supporting skeletal structures made beautiful with flesh, and strong with muscle and sinew-to suggest they grasp kinesthetically the implications of movement, so that they can perceive the tensions and balance within the writing through these same functions within their body. $^{7}$

Calligraphy exhibitions can draw massive crowds in East Asia, and clearly one of the pleasures on hand is mimetic. We visited Yan Zhenqing's calligraphy in chapter 2. A 2019 blockbuster exhibition of his life work at the National Art Museum in Tokyo attracted visitors from across the region. In every crowded gallery, one could observe the traveling spectators engaging a work from the eighth century by tracing each brushstroke in the air with a finger. In his influential 1931 essay on calligraphy theory, 
Zhang Yinlin wrote provocatively about the "bodily resonance" of the art form. He described the viewing of calligraphy as an active process where one follows lines with the eye, tracing them in their order of inscription with an energy of attention that ultimately synthesizes them into a whole:

This experience does not only resort to "demands of the eye," but also to the touch of hands ... The shapes of the material objects emulate the traces of bodily movements . . . Our body will have a sense of déja $v u$ if we can touch them and follow their traces with the eye. This is what is called the function of "bodily resonance" ... The locus of a line triggers our bodies' movement towards a homogenous position, resulting in corresponding feelings that we will have in a similar posture. This could be called "bodily mimesis." Viewers recreate while tracing the creative process of the artists. We ourselves, in the imagination once more, may recreate the line after the artist, and feel, just as he must have felt, the mastery, ease, vigor, or delicacy of the execution into the line itself. ${ }^{8}$

Behind this conception of calligraphy lies the core value of mastery. Calligraphy's borders-defining what it is and is not-are deeply informed by the experience of years of mimetic training based on both the work of masters and the conventions they set in play eons ago. This is why the very premise of this book rubbed some art historians and calligraphers the wrong way. It is the stance that produced the pronouncement, "There is no calligraphy in cinema." But this stance is so committed to the ontology of calligraphy that it forecloses how people actually use calligraphywhat it is and, in fact, can be. This charge is similar to the way film theorists often criticized the André Bazin of "The Ontology of the Photographic Image." Only recently has the critic's rich complexity been foregrounded. Dudley Andrew could be talking about calligraphy when he writes,
Cinema here is examined not by looking inward at its cellular makeup, but, rather, outward toward its place relative to the arts around it. Should it position itself in open territory unoccupied by the arts before it, or should it conspire with them in a tangled cultural field? Bazin felt no contradiction in these two directions of his thought. Like any living form, cinema must adapt to conditions around it, sacrificing its putative selfidentity (its ontology) as it matures into the shape it takes on in history (its adaptations). Along the way it acquires affiliations and vocations, just as people do. ${ }^{9}$

I, too, feel no contradictions between appreciating the vertiginous beauty of masterful calligraphy in its most traditional sense and the delightful way that art designers throughout film history have built the brushed work in the fabric of cinema. For me, it all starts with the fact that calligraphy sits in a place as undecidable as cinema. Although language itself is the medium often used for notation in allographic arts, calligraphy-like filmshimmers between the allographic and the autographic. Cinema opens up new horizons for calligraphy, while calligraphy brings novel dimensions to cinema that, even in their diversity, are bound by the historical knots of the brushed and cinematized letter.

I would like to wrap up this book with a remarkable credit sequence only possible in East Asian cinema. Ironically, it comes from Yoshida Kiju, the Japanese director who usually opts for "cool typography." The film is The Human Promise (a.k.a. A Promise, Ningen no yakusoku, 1986), and it opens on a lush screenscape of green rice paper, accompanied by contemplative, slightly dissonant piano chords by Yellow Magic Orchestra's Hosono Haruomi. The dissonance on the soundtrack is matched by the title calligraphy's amalgamation of seal style, cursive grass style, semi-cursive walking style, and standard style on a single line (fig. 7.4). Since Yoshida always concerned himself with the new human and the casting off of convention, it is curi- 
ous that the 人 (person) of 人間 (human) is in the relatively newer semi-cursive walking style, and 間 (between, space, relation) in the ancient seal style. It seems to imply the antiquity of human interaction while signaling a lean forward to the future.

As the credits proceed at a gentle pace, the single character 人 accompanies every list of human names, often in extreme closeups that show only part of the character (fig. 7.5). Now the artist settles on the semi-cursive walking style for each 人; but these are $35 \mathrm{~mm}$, photo-chemical records of the calligraphs so all the automatisms are preserved, from the subtle gradations of grey in the calligra-

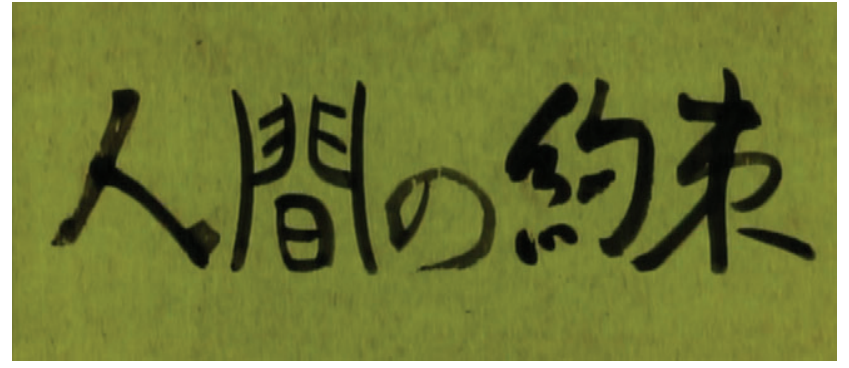

Figure 7.4. The Human Promise (a.k.a. A Promise, Ningen no yakusoku, 1986) starts with a title card that mixes (from left to right) Semi-Cursive Walking Style, Seal Style, Standard Style, and Cursive Grass Style.

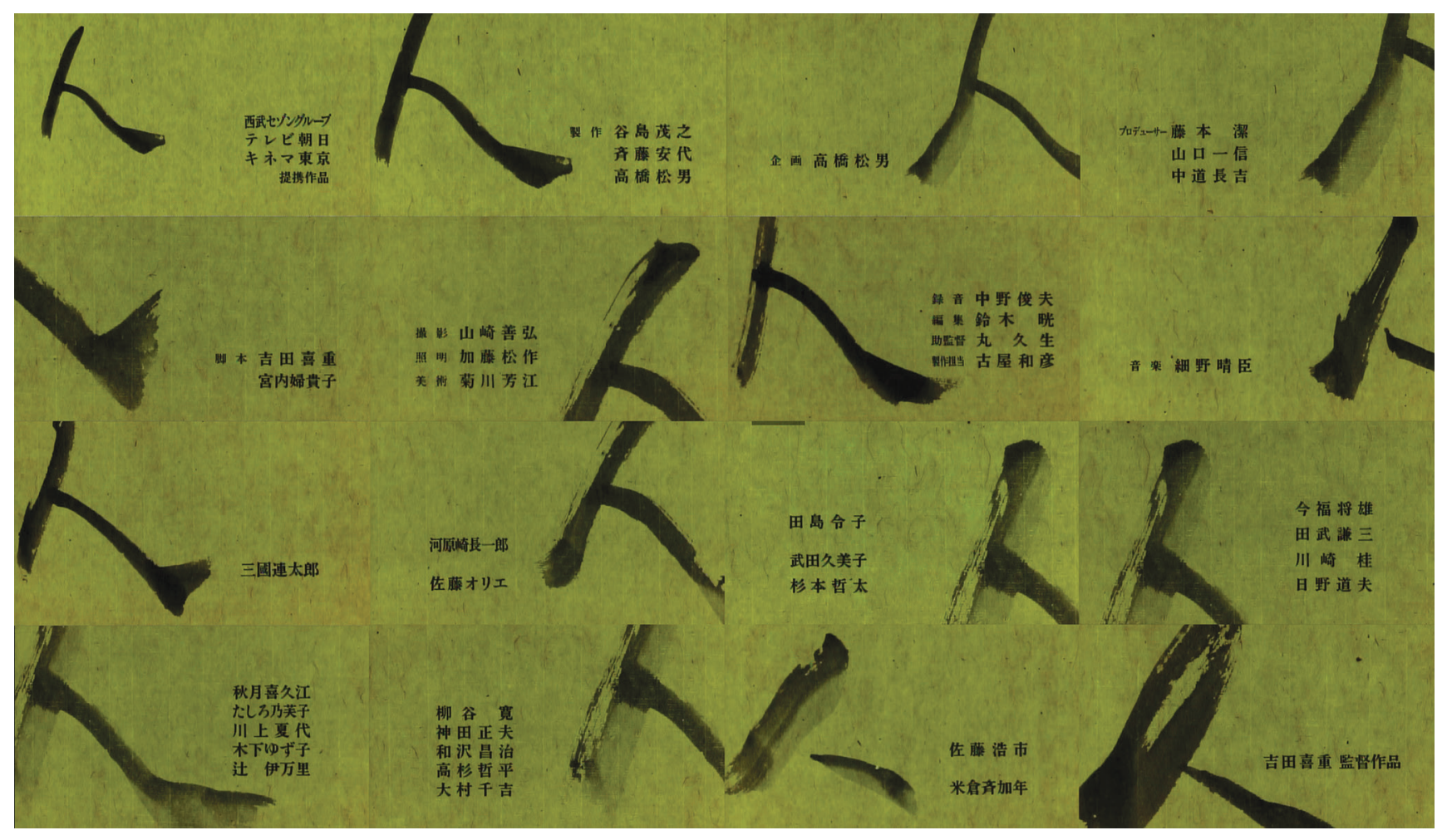

Figure 7.5. Then as the credits for The Human Promise proceed, the character 人 (human) repeats on every single frame; in the manner of a signature, every iteration of the character-like every human in history-is the same but slightly different. 
phy's notan to the delicate micro-strokes of stray brush fibers. Thus, the style is the same, but every iteration of the character-like every human in history-is the same but slightly different.

As Dudley Andrew might put it, these are arts that "traffic with absence." ${ }^{10}$ For its part, calligraphy is a written trace of a past event, made powerfully present and playing with the tensions between legibility and illegibility, black and white, convention and individuation, tradition and innovation, past inscription and present viewing, and most of all between kinetic human force against its deceptively static line and field. Cinema, itself predicated on long-past events made palpably present, makes all this spectacle. It turns calligraphy into brushing with light. Linked to the past gestures of an individual, the calligraph records and expresses personalities and states of mind through a complex interaction of automatisms and evocation of convention. This is why calligraphy lends itself so effortlessly to the multistage art of film-it comes down to this shimmer.
Notes

1. Anonymous; quoted in Lee, "Foreword," n.p.

2. Leighton, "Zazen as an Enactment of Ritual," quoted in Levine, 563.

3. Levine, "The Faltering Brush," 567.

4. Centered on a spectacular analysis of a yuige writing act, Levine's "The Faltering Brush" makes the case for calling this calligraphy, an argument analogous to my own in this book.

5. Rodowick, The Virtual Life of Film, 57.

6. Hearn, "Ink Art: An Introduction," 13.

7. Hay, "The Human Body as Microcosmic Source of Macrocosmic Values in Calligraphy," 183

8. Zhang. "Zhang Yinlin: A Preface to Chinese Calligraphy Criticism (1931)," 21-22.

9. Andrew, What Cinema Is!, 112.

10. Ibid., 37.

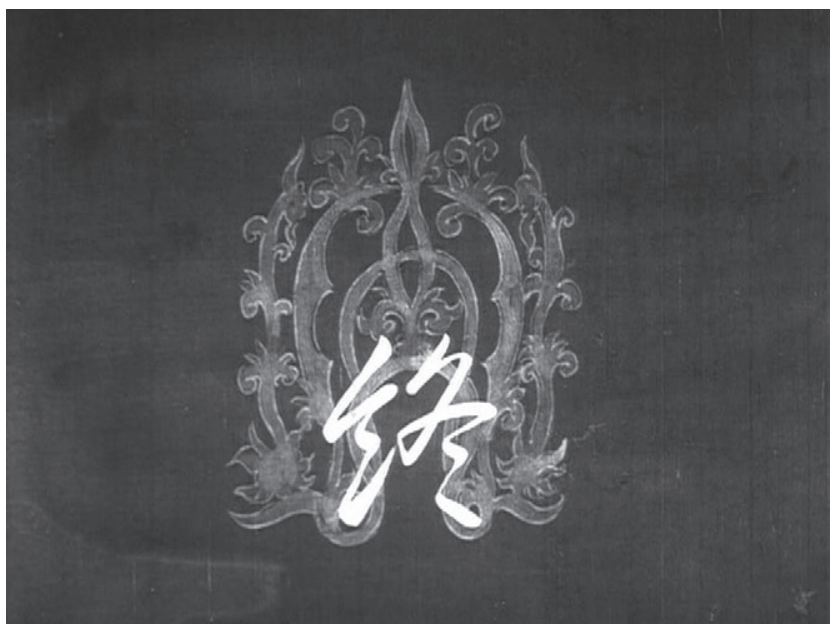




\section{Bibliography}

A Mario. "Nitten: The Shame of Our Nation Nippon," Art iT (21 November 2013) (https://art-culture.world/articles/nit ten-the-shame-of-our-nation-nippon/; accessed 20 August 2019).

Adal, Raja. "Japan's Bifurcated Modernity: Writing and Calligraphy in Japanese Public Schools, 1872-1943," Theory, Culture \& Society 26 no. 2-3 (2009): 233-47.

An Seonyeong. "Kaelligeurapiseuteu Gim Jonggeon" [Calligraphist Kim Zhong-Kun], Neo Atelier (April 2004).

Andrew, Dudley. What Cinema Is! Bazin's Quest and Its Charge (West Sussex: Wiley-Blackwell, 2010).

Astruc, Alexandre. "The Birth of a New Avant-Garde: La CaméraStylo," in The French New Wave: Critical Landmarks, edited by P. J. Graham and Ginette Vencendeau (London: British Film Institute, 2009), 31-36.

Astruc, Alexandre. "The Future of Cinema," translated by Adrian Martin, The Third Rail 9 (http://thirdrailquarterly.org/alexandre-astruc-the-future-of-cinema/; accessed 20 August 2019).

Bak Miseon. "Calligraphy ui pyohyeon bangbeop e gwanhan yeongu" [A Study of Expression Forms of Calligraphy in Movie Posters: With Title Logo in the Center] (master's thesis, Dongyang University, 2004).

Ban Hyeonjeong. "But taiteul logo jeonseong sidae: 'neohui ga kaelligeurapi reul aneunya?" [The Golden Age of Brush Title-Logo “Do You Know Calligraphy?"], FILM 2.o (July 2002).

Barnet, S. and W. Burto. "Some Western Thoughts on Shodo: The Way of Writing," in The Written Image: Japanese Calligraphy 
and Painting from the Sylvan Barnet and William Burto Collection, edited by M. Murase (New Haven, CT: Yale University Press, 2002), 25-38.

Bazin, André. "Theater and Cinema-Part Two," in What Is Cinema? Vol. 1, translated by Hugh Gray (Berkeley: University of California Press, 1967), 76-94.

Blossom of Calligraphy: Calligrapher Kang Byung-In Solo Exhibition Seoul 2011 (Seoul: Workshop Creative Lab, 2011).

Bogdanova, Eugenia. "Negotiating Art Borders: Between AvantGarde Calligraphy and Abstract Painting," in Modernism beyond the West, edited by Majella Munro (Cambridge, UK: The Enzo Press, 2012), 41-63.

Bogdanova-Kummer, Eugenia. "The Line between Calligraphy and Painting: A View from Post-War Japan," The Power of Line (Munich: Hirmer, 2015), 116-25.

Bordwell, David. Figures Traced in Light: On Cinematic Staging (Berkeley, CA: University of California Press, 2005).

Bottéro, Françoise. "Cang Jie and the Invention of Writing: Reflections on the Elaboration of a Legend," in Studies in Chinese Language and Culture: Festrschriftin in Honor of Christoph Harbsmeier, edited by Christoph Anderl and Halvor Bøyesen Eifring (Oslo: Hermes Academic Publishing, 2006), 135-55.

Brass, Gordon S. The Art of Calligraphy in Modern China (Berkeley, CA: University of California Press, 2002).

Carroll, Noel. "Concerning Uniqueness Claims for Photographic and Cinematographic Representation," Dialectics and Humanism 2 (1987): 29-43.

Chang Tsong-zung. "Power of the Word," in Power of the Word (New York: Independent Curators International, 2001), 6-14.

Chang Tsong-zung and Valerie C. Doran, eds. Gu Wenda (Hong Kong: Hanart TZ Gallery, 2014).

Chang Yiguo. Brushed Voices: Calligraphy in Contemporary China (New York: Miriam and Ira D. Wallach Art Gallery, Columbia University, 1998)

Chiang Yee. Chinese Calligraphy: An Introduction to Its Aesthetic and Technique (Cambridge: Harvard University Press, 1973).

Chion, Michel. Words on Screen, translated by Claudia Gorbman (New York: Columbia University Press, 2017).
Choe Byeongman. "Hanguk yeonghwa poseuteo taiteul rogo ui pyohyeon bangsig e gwanhan yeongu." [A Study of the Expression Style for Title Logo in Korean Movies: Focused on the Calligraphy], Dijain yungbokab yeongu [Info Design Issue] 9 (2006): 59-70.

Conley, Tom. Film Hieroglyphs: Ruptures in Classical Cinema, and ed. (Minneapolis: University of Minnesota Press, 2006).

Daniel, Leah. "Morita Shiryu and Artistic Classification: AvantGarde, Abstract Expressionist, or Sho?" (https://www. academia.edu/4697639/Morita_Shiryū_and_Artistic_ Classification_Avant-Garde_Abstract_Expressionist_or_ Sho; accessed 13 August 2017).

de Campos, Haroldo and Maira Lúcia Santaella Braga. "Poetic Function and Ideogram: The Sinological Argument," Disposito 6 no. 17-18 (Summer-Fall 1981): 9-39.

Derrida, Jacques. Limited Inc., translated by Samuel Weber and Jeffrey Mehlman (Evanston, IL: Northwestern University Press, 1988).

Ecke Tseng Yu-Ho. Chinese Calligraphy (Philadelphia: Philadelphia Museum of Art, 1971), n.p.

Eisenstein, Sergei. “The Dramaturgy of Film Form," S. M. Eisenstein: Selected Works (Volume I Writings, 1922-34), edited and translated by Richard Taylor (London: BFI Publishing, 1988), 161-8o.

Fenollosa, Ernest. The Chinese Written Character as a Medium for Poetry: A Critical Edition, edited by Haun Saussy, Jonathan Stalling, and Lucas Klein (New York: Fordham University Press, 2008).

Fong Wen C. "Chinese Calligraphy: Theory and History," in The Embodied Image: Chinese Calligraphy from the John B. Elliott Collection, edited by Robert E. Harris Jr. and Wen C. Fong (Princeton: The Art Museum, Princeton University, 1999), 29-84.

Gim Eunhyeong. "Kaelligeurapi ui seoyejeok dijainseong yeongu: yeonghwa taiteul eul jungsim euro" [A Study of Calligraphy \& Calligraphic Designs: Focused on Movie Titles] (master's thesis, Kyonggi University, 2010).

Gim Eunhyeong. "Yeonghwa poseuteo jejaksa Kkot pineun bom i omyeon Gim Hyejin ssi" [Kim Hye-Jin, the Representative of The Film Poster Production Kkotsbom], CINE21 (14 July 2005). 
Gim, Minyeong. "Geuja ga chum eul chunda" [Dancing Letters: Kim Zhong-Kun, the President of PHILMUK], Book E-daily (1 February 2007).

Gim, Sucheon. "Pilmuk eul iyonghan munja dijain" [Letterdesign Using Brush and Ink Stick], Seoyemunhwa (June 2005).

Gim, Sugyeong. "Taiteul sikwonseu beseuteu ten" [The Best 10 Title Sequences], CINE21 (18 August 2005).

Goodman, Nelson. Languages of Art: An Approach to a Theory of Symbols (New York: Hackett Publishing, 1968).

Greenaway, Peter. "Peter Greenaway on 'The Pillow Book," Sight and Sound 6 no. 11 (November 1996): 15-17.

Gu Gan. The Three Steps of Modern Calligraphy, edited by Hu Yunhuan (Beijing: Chinese Book Publishing House, 1990).

Guo Ruoxu. Kuo Jo-hsü's Experiences in Painting, translated by A. C. Soper (Washington, DC: American Council of Learned Societies, 1951).

Hammers, Roslyn. Socialist Concerns in the Aesthetics of Roger Fry (Ann Arbor, MI: master's thesis, University of Michigan, 1988).

Han Sangim. "But euro pyohyeon haneun dijain ui segye, Pilmuk" [Philmuk, A World of Design Expressed with a Brush], Design Jungle (June 2001).

Hanguk yeongsang jaryowon. Sinmun visa ro bon Hanguk yeonghwa 1945-1957 [Korean Films Seen through Newspaper Articles: 1945-1957] (Seoul: Gonggan gwa saramdeul, 1993).

Hannas, William. Asia's Orthographic Dilemma (Honolulu, HI: University of Hawai'i Press, 1997).

Harrist, Robert E., Jr. "Book from the Sky at Princeton: Reflections on Scale, Sense and Sound," Persistence | Transformation: Text as Image in the Art of Xu Bing, edited by Jerome Silbergeld and Dora C. Y. Ching (Princeton: Princeton University Press, 2006), 25-45.

Harrist, Robert E., Jr. “Look but Don't Read: Chinese Characters and the Translating Drive from John Wilkins to Peter Greenaway," Modern Language Quarterly 6o no. 3 (1999): 353.

Hawkes, David. The Songs of the South: An Anthology of Ancient Chinese Poems by Qu Yuan and Other Poets (New York: Penguin, 1985).

Hay, John. "The Human Body as a Microcosmic Source of Macrocosmic Values in Calligraphy," in Self as Body in Asian
Theory and Practice, edited by Ames Kassulia and Wimal Dissanayake (Albany: State University of New York Press, 1993), 179-212.

Hay, Jonathan. "The Kangxi Emperor's Brush-Traces: Calligraphy, Writing and the Art of Imperial Authority," in Body and Face in Chinese Visual Culture, edited by Wu Hung and Katherine Tsiang Mino (Cambridge, MA: Harvard University Press, 2004), 311-34.

Hearn, Maxwell K. "Ink Art: An Introduction," in Ink Art: Past as Present in Contemporary China (New York: Metropolitan Museum of Art, 2013), 13-18.

Heath, Stephen. “Narrative Space," Screen 17 no. 3 (1976): 68-112. Heller, Steven and Mirko Ilíc. Handwritten: Expressive Lettering in the Digital Age (London: Thames and Hudson, 2004).

Hitonobu Kukita, ed. Japanese Design Calligrapher's Works (Tokyo: Maar, 2018).

Iwabuchi, Koichi. Recentering Globalization: Popular Culture and Japanese Transnationalism (Durham: Duke University Press, 2002).

Jackson, Reginald. Textures of Mourning (Ann Arbor: Center for Japanese Studies Publications Program, 2018).

James, Nick. "Body Talk," Sight and Sound 6 no. 11 (November 1996): 14 .

Jang Mi. "Yeonghwa poseuteo buteo uisang paeteon kkaji, kaelligeurapi ui segye" [The World of Calligraphy: From Film Posters to Patterns on Clothes], CINE21 19 (January 2007).

Jeon Surim. "Hanguk kaelligeurapi ui gaecheokja Yi Sanghyeon: pyojeong dameun geulssi ro sae sijang gaecheok hada" [Lee Sang-Hyeon, the Pioneer of Korean Calligraphy: Exploring the New Market with the Handwriting with Expressions], Joseon ilbo (13 August 2009).

Jeong Useong, "Hangeul ui areumdaum eul son euro dijain hada: Pilmuk Gim Jonggeon daepyo" [Designing the Beauty of Hangul through Hands: President Philmuk Kim Zhong Kun], People in [Reidi gyeonghyang] (March 2007).

Kajiya, Kenji. "Modernized Differently: Avant-Garde Calligraphy and Art in Postwar Japan," M+ Matters: Postwar Abstraction in Japan, South Korea, and Taiwan (28 June 2014) (http:// www.mplusmatters.hk/postwar/\#/en/topic2intro; accessed 20 August 2019).

Kao Yu-kung. "Chinese Lyric Aesthetics," in Words and Images: 
Chinese Poetry, Calligraphy, and Painting, edited by A. Murck and W. C. Fong (Princeton, NJ: Princeton University Press, 1991), 47-90.

Kenner, Hugh. The Pound Era (Berkeley: University of California Press, 1971).

Kern, Martin. "Made by the Empire: Wang Xizhi’s Xinggrangtie and Its Paradoxes," Archives of Asian Art, 65 nos. 1-2 (2015): 117-37.

Kim, Son and Somi Kim. "Typecast: Meaning, Culture, and Identity in the Alphabet Omelet (¿Which Came First?)," in Lift and Separate: Graphic Design and the Quote Vernacular, edited by Barbara Glauber (New York: Herb Lubalin Study Center of Design and Typography, 1993), 30-37.

Kim Zhong-kun (Gim Jonggeon). "Dijiteol gwa anallogeu ui mannam son geulssi" [Hand Writing: A Meeting of Digital and Analog], w.e.b. (April 2006), n.p.

Kim Zhong-kun (Gim Jonggeon). "Sam-Yeo Kim Zhong Kun," in Bling: Power of the People (March 2007).

Kimata Kimihiko. Ino no Nihon Eigashi: Nihon Eiga o Yominaosu [The Extraordinary History of Japanese Cinema: Rereading Japanese Cinema] (Tokyo: Sairyusha, 2019).

Ko, Dorothy. The Social Life of Inkstones: Artisans and Scholars in Early Qing China (Seattle, WA: University of Washington Press, 2017).

Koga Hiroyuki. Sho no Himitsu [The Secret of Writing] (Tokyo: Asahi Shuppansha, 2017).

Koga Hiroyuki. Moji to Sho no Shosoku: Rakugaki kara Kanji made no Bunkashi [The Whereabouts of Letters and Writing: A Cultural History from Graffiti to Chinese Characters] (Tokyo: Kosakusha, 2017).

Kornicki, Peter. The Book in Japan: A Cultural History from the Beginnings to the Nineteenth Century (Leiden: Brill, 1998).

Kraus, Richard Curt. Brushes with Power: Modern Politics and the Chinese Art of Calligraphy (Berkeley: University of California Press, 1991).

Kurosawa Akira. Gama no Abura [Toad's Oil; published in English as Something of an Autobiography] (Tokyo: Iwanami, 1984).

Kurosawa Akira, et al. Zenshu Kurosawa Akira [Complete Writings of Kurosawa Akira] (Tokyo: Iwanami Shoten, 2002).

Kwon Sangmi. "Seoye reul tonghan kaelligeurapi pyohyeon i gamseong dijain e michineun yeonghyang e gwanhan yeongu: Yeonghwa poseuteo reul jungsim euro" [Study of The Influence of Calligraphic Expression to the Emotional Design by the Oriental Calligraphy: Focusing on Film Poster] (master's thesis, Hanyang University, 2005).

Lamarre, Thomas. Uncovering Heian Japan: An Archeology of Sensation and Inscription (Durham, NC: Duke University Press, 2000).

Landy, Marcia. The Folklore of Consensus: Theatricality in the Italian Cinema 1930-1943 (Albany, NY: State University of New York Press, 1998).

Lee Dong Kook. "Language, Code, and the Future: Several Aspects of Decoding the Korean Alphabet," in Korean Alphabet: The Art of Inspiration and Interaction, edited by Kim Hong-hee (Seoul: Seoul Museum of Art, 2013), 18-23.

Lee, Brian. "Hangul's Star Is Ascending," Korea Joongang Daily (22 September 2008) (http://mengnews.joins.com/view. aspx?aId=2895137; accessed 20 August 2019).

Lee, Jean Gordon. "Foreword," in Chinese Calligraphy, edited by Tseng Yu-ho Ecke (Philadelphia: Philadelphia Museum of Art, 1971), n.p.

Leighton, Taigen Dan. "Zazen as an Enactment Ritual," in Zen Ritual: Studies on Zen Buddhist Theory in Practice, edited by Steven Heine and Dale S. Wright (Oxford: Oxford University Press, 2002), 167-84.

Leprohon, Pierre. The Italian Cinema (New York: Praeger, 1972).

Levine, Greg. "The Faltering Brush: Material, Sensory Trace, and Nonduality in Chan/Zen Buddhist Death Verse Calligraphies," in Sensational Religion: Sensory Cultures in Material Practice, edited by Sally M. Promey (New Haven: Yale University Press, 2014), 561-79.

Lindsay, Vachel. Art of the Moving Picture (1915), (New York: Liveright, 1970).

Lopez, Donald, Jr. Elaborations on Emptiness (Princeton, NJ: Princeton University Press, 2016).

Lord, Richard. "Logographic Art," in Power of the Word (New York: Independent Curators International, 2001), 50-53.

Lucken, Michael. Imitation and Creativity in Japanese Arts: From Kishida Ryusei to Miyazaki Hayao (New York: Columbia University Press, 2016).

Lurie, David. "Language, Writing, and Disciplinarity in the 
Critique of the 'Ideographic Myth," Language and Communication 26 (2006): 250-69.

Lurie, David. Realms of Literacy: Early Japan and the History of Writing (Cambridge, MA: Harvard University Asia Center, 2011).

Lurie, David. "The Development of Japanese Writing," in The Shape of Script: How and Why Writing Systems Change, edited by Stephen Houston (Santa Fe: School for Advanced Research Press, 2012), 159-85.

Martin, Adrian. "Introduction to 'The Future of Cinema' by Alexandre Astruc," The Third Rail 9 (http://thirdrailquarterly.org/ adrian-martin-introduction-to-the-future-of-cinema-byalexandre-astruc/; accessed 20 August 2019).

Martini, Andrea. La bella forma: Poggioli, i calligrafici e dintorni [The Beautiful Form: Poggioli, Calligraphers and Surroundings] (Venice: Marsilio, 1992).

McDonald, Scott. The Garden in the Machine: A Field Guide to Independent Films about Place (Berkeley, CA: University of California Press, 2001).

McNair, Amy. "Engraved Calligraphy in China: Recension and Reception," The Art Bulletin 77 no. 1 (1995): 106-14.

Minami Masamori. Eiga to Kodogu [Cinema and Props], edited by Inagaki Hiroshi (Tokyo: Takatsu Soshoku Kabushikigaisha, 1979).

Miyake, Marc Hideo. Old Japanese: A Phonetic Reconstruction (London and New York: Routledge Curzon, 2003).

Mizuhara Sonohiro, ed. Kawabata to Sho [Kawabata and Writing] (Tokyo: Kyuryudo, 2019).

"Mojimoji kafe: Eiga Jimakushi-Sato Hideo no Shigoto to Dejitaruka" [Mojimoji Cafe: Film Subtitling-The Work of Sato Hideo and Digitization], Chikuchiku Nikki (28 August 2013) (https://chiku-chiku-nikki.hatenablog.com/ entry/20130828/1377642076; accessed 12 August 2019).

Morison, Stanley. Early Italian Writing Books: Renaissance to Baroque, edited by Nicolas Barker (Boston: David R. Godine, 1990).

Noland, Carrie, ed. Agency and Embodiment (Cambridge, MA: Harvard University Press, 2009).

Nornes, Abé Mark. Cinema Babel: Translating Global Cinema (Minneapolis: University of Minnesota Press, 2007).

Nornes, Abé Mark, ed. The Pink Book: The Japanese Eroduction and Its Contexts (Kinema Club, 2014; Open Access: https:// kinemaclub.org/pink-book-japanese-eroduction-and-itscontexts).

Nornes, Abé Mark and Emilie Yueh-yu Yeh. Staging Memories: Hou Hsiao-hsien's City of Sadness (Ann Arbor, MI: University of Michigan Press, 2014; Open Access: http://dx.doi. org/10.3998/maize.13469763.0001.001).

Nornes, Markus. “Terrorizer," Film Quarterly 8 no. 2 (Spring 1989): 64-72.

Nornes, Markus. "Hou Hsiao-hsien and Narrative Space," Hou Hsiao-hsien, edited by Richard Suchenski (Vienna: Österreichisches Filmmuseum and New York: Columbia University Press, 2014), 154-68.

Ooka Shin. Sofu no Sho to Chokoku [Sofu's Calligraphy and Sculpture] (Tokyo: Seibu Museum of Art, 1980).

Powers, Martin. "The Cultural Politics of the Brushstroke," Art Bulletin 95 no. 2 (June 2013): 312-27.

Raine, Michael. "From Hybridity to Dispersion: Film Subtitling as Adaptive Practice," in Media and Translation: An Interdisciplinary Approach, edited by Dror Abend-David (New York: Bloomsbury Publishing, 2014), 151-71.

Rodowick, D. N. The Virtual Life of Film (Cambridge, MA: Harvard University Press, 2009).

Rojas, Eira. "Xu Bing's Dialogue with China's Cultural History" (www.eirarojas.com/xu-bings-dialogue-with-chinas-cultur al-history/\#_ftn6; accessed 25 July 2015).

Saenger, Paul. The Space Between Words: The Origins of Silent Reading (Stanford: Stanford University Press, 1997).

Sakai, Naoki. Voices of the Past: The Status of Language in Eighteenth-Century Japanese Discourse (Cornell, NY: Cornell University Press, 1992).

Sato Tadao. "The Art of Yasujiro Ozu," The Study of the History of the Cinema 4 (1974): 80-96.

Schwan, Alexander. "Curving Lines and Morphing Marks: On the Problems of Comparing Chinese Ink-Brush Writing with Dancing," in The Power of Line, edited by Marzia Faietti and Gerhard Wolf (Florence, Italy: Gallerie deli Uffizi, 2015), 128-41.

Seeley, Christopher. A History of Writing in Japan (Leiden: Brill, 1991).

Seton, Marie. Sergei M. Eisenstein: A Biography (New York: Grove Press, 1960).

Shen Fu, "Kaimaila Shiyi Zhibi: Fangwen Jitan Daoyan Jing- 
yan" [Camera as Brush: Visiting the Director's Experience], in Yingxiang Zhonguo: Zhongguo Dianying Yishu, 1945-1949 [Image China: Chinese Film Art, 1945-1949], edited by Ding Yaping (Beijing: Wenhua Yishu Chubanshe, 1998), 479-83.

Shibuya Namiki. "Ningen to Geijutsu" [Humanity and Art], Link Club Newsletter 98 no. 3 (March 2003): n.p.

Silbergeld, Jerome. "Introduction," in Persistence | Transformation: Text as Image in the Art of Xu Bing, edited by Jerome Silbergeld and Dora C. Y. Ching (Princeton: Princeton University Press, 2006), 19-22.

Silbergeld, Jerome. "Cinema and the Visual Arts of China," in Companion to Chinese Cinema, edited by Yingjin Zhang (New York: Wiley-Blackwell, 2012), 400-16.

Sofu. "Sho ni Omou" [Thinking about Writing], in Sho o Kataru 1 [Speaking of Writing] (Tokyo: Nigensha, 1980), 52-56.

Soon, Simon. "Reading Tsang Tsou Choi: Margin, Madness, and a Hong Kong Avant-Garde," in Preservation, Radicalism, and the Avant-Garde Canon, edited by Rebecca Ferreboeuf, Fiona Noble, and Tara Plunkett (New York: Palgrave Macmillan US, 2016), 193-214.

Takeda Soun. Kanji-Power (Tokyo: BNN, 2009).

Tseng Yuho. A History of Chinese Calligraphy (Hong Kong: Chinese University of Hong Kong, 1993).

Tsujimoto, Masashi. "Formation and Growth of an EducationBased Society 1600-1868," edited by Masashi Tsujimoto and Yoko Yamasaki (London: Routledge, 2017), 5-33.

Tylim, I. "Body as Text, Text as Body: The Pillow Book," Psychoanalytic Review 85 no. 3 (1998): 449.

Venuti, Lawrence. The Translator's Invisibility: A History of Translation (London: Routledge, 1995).

Welch, Christine, trans. Chun Qiu Yuan Ming Bao, in Ancient Chinese Mythology (26 August 2013) (http://ancientchine- semythology.blogspot.jp/2013/08/cangjie-chinese-god-ofwriting.html; accessed 20 August 2019).

White, Duncan. "Artists at Work: Takahiko Iimura," Afterall/ Online (9 October 2010) (https://www.afterall.org/online/ artists-at-work-takahiko-iimura\#.XZejty2ZPOQ; accessed 1 October 2019).

Wong, Frederick. The Complete Calligrapher (New York: Dover, 1980).

Wu Hong. "Transcending the East/West Dichotomy: A Short History of Contemporary Ink Painting," in Ink Art: Past as Present in Contemporary China (New York: Metropolitan Museum of Art, 2013), 19-33.

Yen Yuehping. Calligraphy and Power in Contemporary Chinese Society (New York: Routledge, 2005).

Yi Yeongjin. "Haseok Pak Wongyu Chwihwaseon seoyega" [The Calligrapher of Chihwaseon, Ha-seok Park Won-Kyu], CINE21 (31 October 2001).

Yi Yeongjin. "Yeonghwa poseuteo reul mandeuneun saramdeul [1]: Kkot pineun bom i omyeon" [People Who Make Film Posters (1)-Kkotsbom], CINE21 (22 March 2005).

Yoshida Kiju. "My Theory of Film: A Logic of Self-Negation," Review of Japanese Culture and Society (December 2010): 104-9.

Yun Seohyeon. "Son geulssi ga yeonghwa reul malhanda" [Calligraphy Tells the Film], Movie Week (June 2007).

Zhang Yinlin. "Zhang Yinlin: A Preface to Chinese Calligraphy Criticism (1931)," translated and introduction by Shi Xiongbo, Journal of Art Historiography 13 (December 2015): 1-29.

Zito, Angela. "Writing in Water, or, Evanescence, Enchantment and Ethnology in a Chinese Urban Park," Visual Anthropology Review 30 no. 1 (2014): 11-22. 


\section{Index}

13 Assassins (13-nin no shikaku, 2010), 139-140

24 Eyes (Nijushi no hitomi, 1954), 92, 94

495,63 (2007), 100

Abe Sada, 6o, 61

Abe Yutaka, 116-117

Adachi Masao, vii

Affair, The (Joen, 1967), 58, 67-68, 84

Afraid to Die (Karakkaze yaro, 1960), 12-13

Ai no koriida. See In the Realm of the Senses

Akamatsu Hikozo, 5

Akamatsu Hikozo, vii, 6-7, 8, 28

Akasegawa Genpei, 126

Akitsu Onsen (1962), 63-64

Akiyama Tamako, vii

Aknyeo. See Villainess, The

Alechinsky, Pierre, 25-26, 87, 136

allographic art, 131-132

Amai yoru no hate. See Bitter End of a Sweet Night

Anderson, Wes, 94

Ando Atsushi, vii

Andrew, Dudley, 143, 145

Anma to onna. See Masseurs and a Woman, The

Arabic calligraphy, 18, 21, 75

Ardor (Mirae, 2002), 61

Arita Koho, 87

Arnold, Michael, viii

art deco, 38

art nouveau, 19

Artist of the Floating World, An (Ukiyo no gaka, 2019), 6

Arts and Crafts Movement, 19

Aru eiga kantoku no shogai. See Kenji Mizoguchi: The Life of a Film Director

Astruc, Alexandre, 10-11

Auerbach, Micah, viii

autographic art, 131-132

Autumn Afternoon, An (Sanma no aji, 1962), 71-73, 75-76

Awazu Kiyoshi, 43-44 
Bachner, Andrea, 68, 81n12

Backward Flow (Gyakuryu, 1924), 71

Ban Hyeonjeong, 49, 60

Ban Masaomi, 123

Bando-ui bom. See Spring of Korean Peninsula

Banquet, The (Ye yan, 2006), 51

Battles Without Valor or Humanity (Jingi naki tatakai, 1973), 41

Bazin, André, 125, 143

Beiqing chengshi. See City of Sadness

Benjamin, Walter, 111

benshi, 12

Bertellini, Giorgio, viii

Binyon, Laurence, 87

Bissier, Julius, 87

Bitter End of a Sweet Night (Amai yoru no hate, 1961), 58

Black Sun (Hei tai yang nan jing da ceng sha, 1995), 97

blackletter, 17, 20

Blind Woman's Curse (Kaidan nobori ryu, 1970), 12

blood, 41, 48, 51, 53, 60, 106, 109-110

Blue Kite (Lan fengzheng, 1993), 97

Boksu neun na ui geot. See Sympathy for Mr. Vengeance

Bokubi, 25, 87

Bokujinkai ("Group of People of Ink"), 25

bokuseki, 24-25

Bom yeoreum gaeul gyeoul geurigo bom. See Spring, Summer, Fall, Winter . . Spring

Book from the Sky (Tianshu, 1981-1991), 85

Bordwell, David, 11

Bow, The (Hwal, 2005), 28-29

Brakhage, Stan, 126

Brave Archer (She diao yingxiong zhuan, 1977), 62

Brightwell, Erin, viii

Brother (2000), 7, 60, 93, 95

brush, 42, 48, 6o, 71, 73-75, 80, 87-89

Buddhism, 24-25, 45-46, 62, 124, 127, 132, $133-134,140$

Buñuel, Louis, 94

Busan. See Goodbye Dragon Inn

byeongpung. See screen

Byung Youngjoo, viii, 61

Cage, John, 45, 126

Calligraphie Japonaise (1956), 25

callipackage, 50-51

caméra-stylo, 10-11

Cang Jie, 14-15, 22

Capra, Frank, 19

Carr, Kevin, viii carving, 2, 3, 21, 44, 46, 60, 69, 121, 127

Cavell, Stanley, 8

Cavell, Stanley, viii, 131-132, 142

Chan, Wallace Chi Ieong, viii, 3

Chang Huai-kuan, 112

Chang, Haely, viii

Chang, Johnson (Chang Tsong-zung), viii, 2, 22, 121

Chang, Sylvia, 43

Chao Yu-hsiu, vii, 51, 75

Chaplin (1992), 18

Charlie Chan films, 19

Chauncery, 18

Cheat, The (1915), 19

Chen Kaige, 70-71, 96-97

Chen Shih-hsien, vii

Chen, Rose Kuo-chen, vii

Chen, Ru-Shou Robert, vii

cheonjiin, 28

Cheung, Tit Leung, viii

Chi bi Part II: Juezhan tianxia. See Red Cliff 2

Chiang, Vivian Tsu-i, vii

Chinese Ghost Story I (Qing nu You hun, 1987), 97

Chion, Michel, 11

Choi Ji-Woong, 50

Choi Ji-Woong, viii

Choi, Emily SY, viiii

chopsticks, 7, 48, 50, 60, 80

Christopher Columbus (1949), 18

Chrysanthemum and the Guillotine, The (Kiku to girochin, 2018), 6, 24

Chu, Shinae, vii

Chukje. See Festival

Chun Qiu Yuan Ming Bao, 14

Chung Chonghwa, viii

Chung Kuo-hua, vii

Chunhyang (Chunhyangjeon, 2000), 92

Chushingura (1903), 37

Chushingura (1910-1915), 71

Chushingura (1941), 63-64

Chushingura: Heaven and Earth Episodes

(Chushingura: ten no maki, chi no maki, 1938), 35

Chwihwaseon. See Painted Fire

cinema calligrafico, 19

cinematography, 14, 38, 58, 71, 89-99

City of Sadness (Beiqing chengshi, 1989), 11, 101-113, 132

clerical script, 22, 69, 70-71

Cloud Gate Dance Theater, 24, 76

Cold Life (Tsumetai seimei, 2014), 53-55

collage. See montage color, 28-29, 41

Confucious (Kong Zi, 2010), 121, 123

Cong Feng, viii

Conley, Tom, 11

Contact, The (Jeopsok, 1997), 48

Cooper, Stanley, 94

copperplate, 19

"Copying the Orchid Pavilion Preface 1,000

Times," 128-129, 131

Coup d'état (Kaigenrei, 1973), 94

couplet, 62-63, 96-99, 103

Crane and Turtle (Tsurukame), 71-72

Crouching Tiger, Hidden Dragon (2000), 78, 80

Crows and Sparrows (Wuya yu maque, 1949), 10

cursive, 18, 22, 51, 68-69, 71-72, 83-85, 143-144

Davis, Darrell, viii

de Koonig, Willem, 64

Demko, Tony, viii

Die Bad (Jukgeona hogeun nappeugeona, 2000), 48-49, 60

Die Nibelungen: Siegfried (1924), 17-18

digital technology, 3, 39, 46-55, 59, 75, 103

Dolan, Xavier, 94

Dolls (2002), 6

Dongdong de jiaqi. See Summer at Grandpa's, A

Doran, Valerie C., viii

Double Suicide (Shinju ten no amijima, 1969), $43-44,46$

Downfall of Osen (Orizuru Osen, 1935), 145

Dr. Zhivago (1965), 46

Dragon Inn (Long men xia zhang, 1992), 97

Dreyer, Christopher, viii

Drug War (Du zhan, 2012), 51, 53

Du zhan. See Drug War

duilian. See couplet

Duk bei dou. See One-Armed Swordsman

Eel, The (Unagi, 1997), 6, 24

Eguchi Sogen, 25-26

Eiga kantoku tte nan da? See What's a Film Director?

Eight Drunken Immortals, 21-22, 125

Eisenstein, Sergei, 8, 9, 15

Emperor Gojong, 28

Emperor Taizong, 131

Emperor's Naked Army Marches On, The (Yuki yukite shingun, 1986), 6

English roundhand, 19

Eros Plus Massacre (Erosu purasu gyakusatsu, 1969), 58

Erosu purasu gyakusatsu. See Eros Plus Massacre Esperanto, 8 
Everything Visible is Empty (Shiki soku ze ku, 1975), 45-46, 127, 132

expressionism, 38

Face (2000), 8

Face (Kao, 200o), 6

Face (Visage, 2009), 8-9, 24

Face of Another (Tanin no kao, 1966), 13, 25-26

Failan (2001), 60

fantôme de la liberté, Le. See Phantom of Liberty

Farewell to the Summer Light (Saraba natsu no hikari, 1968), 58

Faust (1926), 17-18

faux-calligraphy, 19

Feng sheng. See Message, The

Festival (Chukje, 1996), 118, 122

Fight Back to School (Tao Xue Wei Lung, 1991), 97

Fireworks (Hanabi, 1997), 6

five styles, 69-73

Flame and Women (Hono to onna, 1967), 58

Fluxus, 126

Fong Sai Yuk I (Fong Sai Yuk, 1993), 97

Fong Sai Yuk. See Fong Sai Yuk I

Fonting the City (Zi li chengjian, 2015), 3

fonts, 47-48, 59

Four Treasures, 59-69, 80, 140

Fry, Roger, 87

Fu Syou-ling, vii

Fu, Winnie Wy, viii

Fudan University, viii

Fujioka, Sanako, viii

Fukazawa, Yuri, viii

Fung Ming-chip, 75

Fung wan: Hung ba tin. See Storm Riders

Futagawa Buntaro, 38, 71

Gama no Abura. See Toad Oil

Game of Thrones (2011-2019), 77

Gebarutopia yokokuhen. See Gewaltopia Trailer

Genealogy (Jokbo, 1979), 12, 93

Geomsa-wa yeoseonsaeng. See Public Prosecutor and a Female Teacher, $A$

Gerow, A. A., viii

Gewaltopia Trailer (Gebarutopia yokokuhen, 1968), 44-45

Gilbert and Sullivan, 19

Gim Hogil, viii, 91-92

Ginpei from Koina (Koina no Ginpei, 1933), 92, 94

Godard, Jean-Luc, 102

Goddess, The (Shennu, 1934), 37

Golum, The (1915), 45

Good for Nothing (Rokudenashi, 1960), 58
Good Men, Good Women (Haonan haonu, 1995), 102-103

Goodbye Dragon Inn (Busan, 2003), 21-22, 23, 97

Goodman, Nelson, 131-132

Gosho Heinosuke, 116-117

graffiti, 22-23

Grandmaster (Yidai zongshi, 2013), 76-77

graves, 2, 3

Greenaway, Peter, 2

Griffith, D. W., 8

Group of People of Ink. See Bokujinkai

Gu Gan, 7, 133

Gu Wenda, 23, 85

Guang Yu, 108

Gyakuryu. See Backward Flow

Hanabi. See Fireworks

Hanart TZ Gallery, viii, 81n5

handwriting, 28, 80, 104-105

Hanging Tree (Janyeomok, 1985), 62

hangul, 28-30, 47-51

Hannas, William, 9-10

Haonan haonu. See Good Men, Good Women

Happy Day of Maeng Jin-sa, The (Maeng Jinsadaek gyeongsa, 1962), 93

Hara Kazuo, vii, 5, 6

Harakiri (Seppuku, 1962), 24-25

Harrist, Robert E. Jr., 85

Hay, John, 98, 142

Hay, Jonathan, 121

Hayakawa, Sessue, 19

He liu. See River

Hearn, Maxwell K., 142

Heart Sutra, 45-46, 127, 132

Heath, Stephen, 102

Hegel, Georg Wilhelm Friedrich, 31

Hei tai yang nan jing da ceng sha. See Black Sun

Heller, Steven, 127

Helvetica, 40, 50, 85, 110

Hero (Yingxiong, 2002), 68

Heroic Purgatory (Rengoku eroika, 1970), 58

hieroglyphs, 8

High and Low (Tenkoku to jigoku, 1963), 43

Hijikata Tatsumi, 126

Hikari (2017), 6

Hindenberg, The (1975), 17

hiragana, 24

Hissatsu shigotonin. See People Whose Work is Necessary Murder

Hitler's Children (1943), 17

Ho Kim Hung, Cyrus, viii

Ho, Emily, viii

Hono to onna. See Flame and Women
Hosono Haruomi, 143

Hou Hsiao-hsien, vii, 101-113, 132

House of Flying Daggers (Shi mian mai fu, 2004), 76

Huang tudi. See Yellow Earth

Huang, Frances, vii

Hugo, Victor, 59

Huillet, Danièle, 102

Human Promise, The (Ningen no yakusoku, 1986), 143-145

humanistic hand, 18

Hung, Sammo, 13-14, 91

Hurricane, The (1999), 46

Hwal. See Bow, The

Ichikawa Kon, 118

Ichiyanagi Toshi, 45

Iida Reigiku, vii, 28, 142

Iimura Takahiko, vii, 125-127

Ikeda Yoshinobu, 116-117

Ilíc, Mirko, 127

illegibility, 67-68, 83-87

Im Kwon-taek, 12, 31, 43, 92

Imai Ryosetsu, 43

Imai Takashi, vii

In the Realm of the Senses (Ai no koriida, 1976), 60

ink stick, 48, 6o, 64, 125

ink, 2, 5, 7, 12, 21, 22, 28, 34, 38, 40, 43, 47, 48, $54,59-60,62,64,67,68,72,76,78-80,87$, 105, 111, 127, 129-130, 136, 137-138

Inkstone (Yantai, 1996), 65-67

inkstones, 42, 59, 64-67, 68-69, 88, 105, 111

Inoue Kintaro, 116-117

Inoue Yuichi, 25

International Military Tribunal for the Far East

(Tokyo saiban, 1983), 6

intertitles, 2, 8, 9, 33-39, 45, 70-72, 83, 85, 104$105,112,129-130$

Intolerance (1916), 18

ioriten, 12

Itami Juzo, 85-86, 101

Itami Mansaku, 116-117

Itomi Keinan, vii, 5, 6o-61

Jackson, Reginald, viii, 126, $137 n 7$

Jane Eyre (1943), 50

Jang huibin. See Lady Jang

Janyeomok. See Hanging Tree

Japanese Girls at the Harbor (Minato no Nihon musume, 1933), 9

Jayu buin. See Madame Freedom

Jefferson in Paris (1995), 18-19 
Jeopsok. See Contact, The

Jia Zhangke, 62-63

Jiang Kui, 89

Jiangshi xiansheng. See Mr. Vampire

Jing Shijiang, 51

Jingi naki tatakai. See Battles Without Valor or Humanity

Jitsuroku Abe Sada. See Woman Named Abe Sada, A

Jobs, Steve, 59

Joen. See Affair, The

Jokbo. See Genealogy

Jonouchi Motoharu, 44-45

Jukgeona hogeun nappeugeona. See Die Bad

Jung Hyunchang, viii

\section{kaelligeurapi, 48-51}

Kagemusha (1980), 31

Kai Yu-kung, 135

Kaidan (1964), 61-62

Kaidan nobori ryu. See Blind Woman's Curse

Kaigenrei. See Coup d'état

Kamiya Makiko, vii

kanbun, 24

Kaneko Otei, 43

Kang Byung-in, viii, 54, 118

Kao. See Face

Karakkaze yaro. See Afraid to Die

Karisuma. See Charisma

katakana, 24

Kataoka Ichiro, vii, 37

Kawabata Yasunari, 30, 118

Kawakita Memorial Film Institute, vii

Kenji Mizoguchi: The Life of a Film Director (Aru eiga kantoku no shogai, 1975), 140-141

Kern, Martin, 131

Kids Return (1996), 6

Kiku to girochin. See Chrysanthemum and the Guillotine, The

Kill! (Kiru, 1968), 90, 95

Kim Dongwon, viii

Kim Hye-jin, viii, 48, 60

Kim Ki-duk, viii, 27-29, 50, 127

Kim Soon-mo, viii

Kim Soyoung, viii

Kim Tae-Uk, viii

Kim Zhong-kun, 48-49, 67

Kim, Hansang, vii

Kim, Jini, viii

Kim, Sue, viii

Kimata Kimihiko, 5

King $\mathrm{Hu}, 43$

King Kong (1933), 45
King Lear, 134

King of Kowloon (1998), 32n7

King of Kowloon, 22-23, 32n7

King Sejong, 28

Kinoshita Keisuke, 92

Kinugasa Teinosuke, 116-117

Kiru. See Kill!

Kitano Takeshi, 6, 7, 50, 93, 95

Kkotsbam, 48

Kline, Franz, 1, 2

Kline, Franz, 64

Kline, Franz, 87

Ko, Dorothy, 65

Kobayashi Masaki, 24, 61-62

Koina no Ginpei. See Ginpei from Koina

Koizumi Hiroyasu, vii

Kojiki, 126-127

Kong Demao, 121, 123

Kong Zi. See Confucious

Kono michi. See This Road

Koran, 19

Kumo no sujo. See Throne of Blood

Kumo no sujo. See Throne of Blood

Kuroki Kazuo, 6

Kurosawa Akira, 31, 42-43, 70, 123-124, 133-135

Kurosawa Kiyoshi, 6

Kwan Tak-hing, 68-69

Lady Jang (Jang huibin, 1961), 71-72

Lam Sai-wing. See Magnificent Butcher

Lamarre, Thomas, viii, 23, 63, 64, 84

Lan fengzheng. See Blue Kite

Law Kar, viii

Lee Dong Kook, 47

Lee Myungse, viii

Lee Sangjoon, viii

Lee Yu-hwa, vii

Lee, Juyeon, viii

Legend of the Mountain (Shanzhong chuanqi, 1979), 43

Leprohon, Pierre, 19

lettering, 2, 3, 9, 19, 29, 33, 34, 36, 41, 59, 75, 77, 81n5, 121-122

Levine, Greg, 140

Li Gangtian, viii, 55

Li Liufang, 51

Li Xianting, viii, 7, 8, 73-76, 96, 124-125

Liao Hsien-hao Sebastian, vii

Lin, Shuen-fu, viii

Lin, Wood, vii

Lin Wen-chi, vii

Lindsay, Vachel, 8, 9

Long men xia zhang. See Dragon Inn
Lopez, Jr., Donald, vii

Lord, Richard, 75

Love (1962), 126

Love Letter (1996), 60

Lu Xinyu, viii

Lu Xun, 118, 121

Lun Shu, 32

Lunheng, 14

Lurie, David, 9

Maadadayo (1993), 43

Macbeth, 43

Madame Freedom (Jayu buin, 1956), 93

Maeng Jin-sadaek gyeongsa. See Happy Day of Maeng Jin-sa, The

Magnificent Butcher (Lam Sai-wing, 1979), 68-69

Makino Masahiro, 35

Makino Shozo, 71

Makioka Sisters (Sasameyuki, 1983), 118-119

Malu tianshi. See Street Angel

Man Kit Wah Eva, viii

manyogana, 24, 126, 137n13

Mao Zedong, 118, 120, 136-137n5

Mare Hawai okikaisen. See War at Sea from Hawai'i to Malaya

martial arts, 23, 68-69, 76, 81n5, 90

Masseurs and a Woman, The (Anma to onna, 1938), 38

Matrix, The (1999-2003), 68

Matsumoto Toshio, vii, 45-46, 127, 132

McDonald, Scott, 128

Mekas, Jonas, 126

Message, The (Feng sheng, 2009), 51

Metz, Christian, 133

Miike Takashi, 139-140

Mikado, The (1885), 19

Minato no Nihon musume. See Japanese Girls at the Harbor

Ming jian. See Sword, The

Mirae. See Ardor

mirror neurons, 100

Mishima Yukio, 90-91, 93, 96, 129-130, 131

Mizoguchi Kenji, 11-12, 38, 62-63, 83-84, 116117, 119, 140-141, 145

Mizu de kakareta monogatari. See Story Written on Water, A

Mizutani Hiroshi, 116-117, 119

models, 21, 22, 27-28, 47, 51, 72-73, 80, 84, 86, $89,131,133$

Mok, Elvis, viii

Molecular Music (1982), 100

montage, 8, 28-29, 51-53, 78-80 
Moribito: Guardian of the Spirit (Seiei o mamoribito, 2016), 6

Morita Shiryu, 25, 133

Morsman, Do-hee, viii

Mr. Vampire (Jiangshi xiansheng, 1985), 84-85, 97

Munchhausen (1943), 18

Murata Minoru, 116-117

Myriad of Lights (Wanjia denghuo, 1948), 10

Nakajima Seio, vii

Nakayama, Yuki, viii

Name of the Rose (1986), 77

Nan quan wang. See South Shaolin Master

Naruse Mikio, 116-117

National Film Archive of Japan, vii

National Palace Museum, vii

nationalism, 29-31, 55, 6o, 80, 104

neon, 2, 3, 96, 98, 122

neuroscience, 100

$\mathrm{Ng}$, Justin, viii

$\mathrm{Ng}$, May Kwan Yuk, viii

Ni nabian jidian. See What Time is it Over There?

Nijushi no hitomi. See 24 Eyes

Nine Songs, The, 108-109

Ningen no yakusoku. See Human Promise, The

Nishigaito Koshun, vii

Nishikawa Yasushi, 43

Nitta Takayuki, vii

No Blood No Tears (Pi do nunmul do eopsi, 2002), 49

Noh theater, 12

Northwest Cinema, 115-116

Nosferatu (1922), 45

official script. See clerical script

Oh Seung-wook, 62

Oh Seunguk, 61

oie-ryu style, 44

Okada Hidenori, vii

Okada Mariko, vii

Okada Mariko, vii, 63-64

Okamoto Kihachi, 90

Onan (1963), 126

One More Time, One More Chance (Tsuki to kabetsu, 1996), 6

One-Armed Swordsman (Duk bei dou, 1967), 97

Onibaba (1965), 73

Ono Yoko, 126

Onoe Monya, 37

Orizuru Osen. See Downfall of Osen
Orochi (1925), 38, 92

Oshima Nagisa, 6o, 140-141

Oyama Yuki, vii

Oyobe, Natsu, viii

Ozu Yasujiro, 4, 71-73, 75-76, 89, 102

Paik, Nam June, 126

Painted Fire (Chwihwaseon, 2002), 49

Painting in the Far East (1908), 87

paper, 6o-64, 71, 78-80

paperscape, 63-64, 91

Park Chan-Wook, 48-49

Park Si-Young, viii, 89

Park Sun-Young, vii-viii

Patriotism (Yukoku, 1966), 90-91, 93, 96, 129-130

Pei jiangjun shi. See Poem for General Pei

People Whose Work is Necessary Murder (Hissatsu shigotonin, 1979-1981), 5, 60-61

Petition (Shang fang, 2009), 73-74

Phantom of Liberty (Le fantôme de la liberté, 1974), 94

Philmuk, 48

Pi do nunmul do eopsi. See No Blood No Tears

Picasso, Pablo, 1

pictographic characters, 8-10, 28-29

Pieta (2012), 50

Pillow Book, The (1996), 2

Platform (Zhantai, 200o), 62-63, 97

Plutarch, 17

Poem for General Pei (Pei jiangjun shi), 51-52

Pollack, Jackson, 64

Pollack, Jackson, 87

Pound, Ezra, 8

Powers, Martin, viii, 87

Prelude to War (1942), 19-20

Promise, A. See Human Promise, The

props, 41-42, 44, 62-63, 84, 91, 106-107, 112$113 n 7,133-135$

Public Prosecutor and a Female Teacher, A (Geomsa-wa yeoseonsaeng, 1948), 37

Qian li zou dan qi. See Riding Alone for Thousands of Miles

Qing nu You hun. See Chinese Ghost Story I

Qiu Zhenzhong, viii, 31, 54

Qiu Zhijie, 128-129, 131

Raine, Michael, 111

Ran (1985), 43, 133-135

Rashomon (1950), 42

Realm of the Senses. See In the Realm of the Senses
Red Cliff 2 (Chi bi Part II: Juezhan tianxia, 2009), 51-52, 78-80

Rengoku eroika. See Heroic Purgatory

Riding Alone for Thousands of Miles (Qian li zou dan qi, 2005), $81 \mathrm{n} 19$

Riefenstahl, Leni, 94

River (He liu, 1997), 77

Riverstone, viii

Robinson Crusoe (1954), 18

Rodowick, D. N., viii, 8, 131-133

Rokudenashi. See Good for Nothing

Rolston, David, viii

Rosenberg, Harold, 135

running script, 22, 69, 71-72, 143-144

Ryoo Seung-wan, 48

Ryoo Seung-Wan, 49

Ryu, Youngju, viii

Saenger, Paul, 23

Sakai Tatsuo, 117, 119

Sakai, Naoki, 115

Sakamoto Hirofumi, vii

Sakamoto Junji, 8-9

Sanma no aji. See Autumn Afternoon, An

Saraba natsu no hikari. See Farewell to the Summer Light

Sasameyuki. See Makioka Sisters

Sasatake Yoshiyuki, vii

Sato Hideo, 46-47

Schlorf, Ena, viii

scratching, 125-127

screen, 42, 91-92

screenscape, 59, 64, 73, 75, 91-93. 99, 143

scroll, 133-135

Se7en (1995), 127

seal script, 22, 68, 69-70, 143-144

seal, 30, 32n18, 43, 55, 70, 118, 121, 141

Seiei o mamoribito. See Moribito: Guardian of the Spirit

Sekigahara (2017), 6

semi-cursive walking script. See running script

Seppuku. See Harakiri

Shang fang. See Petition

Shanzhong chuanqi. See Legend of the Mountain

She diao yingxiong zhuan. See Brave Archer

She-Wolf of London (1946), 18

Shen Fu, 10

Shennu. See Goddess, The

Shiki soku ze ku. See Everything Visible is Empty

Shimazu Yasujiro, 116-117

Shi mian mai fu. See House of Flying Daggers

Shimizu Hiroshi, 38, 116-117

Shindo Kaneto, 140-141 
Shing, Angel On Ki, viii

Shinju ten no amijima. See Double Suicide

Shinoda Masahiro, 43-44

Shinoda Toko, 25, 63-64

Shiri (Swiri, 1999), 48

shoren'in style, 44

Shu Kei, viii

signs, 2, 3, 25, 35, 42, 48, 85-87, 122, 124-125

Silbergeld, Jerome, $81 \mathrm{n} 16$

silent cinema, 33-39, 59, 71, 83, 85, 92, 104, 105

simplified characters, 23

Sisyu, vii, 53-55

skin, 45, 6o, 61-62, 65

sliding door, 42, 62, 84, 92, 103

Snow Country (Yukiguni, 1957), 30, 118

Sohn, Irhe, viii

somatics, 14-15, 28, 6o, 67-69, 75, 80, 87-88, 100, 125-130, 133-136, 139-145

Sora no shonenhei. See Young Soldiers of the Sky

Soulages, Pierre, 1, 87

sound, 28, 39, 41, 43, 67-68, 69, 10on10, 105, 110-112

South Shaolin Master (Nan quan wang, 1984), 97

Spring of Korean Peninsula (Bando-ui bom, Korea, 1941), 40

Spring, Summer, Fall, Winter ... Spring (Bom yeoreum gaeul gyeoul geurigo bom, 2003), 27, 127

standard script, 22, 69, 71-73, 143-144

Storm Riders (Fung wan: Hung ba tin ha, 1998), 97

Story Written on Water, A (Mizu de kakareta monogatari, 1965), 58

Straub, Jean-Marie, 102

Street Angel (Malu tianshi, 1937), 40-41

Su Dongpo, 51

subtitles, 13, 19-20, 39-41, 46-47, 71, 80, 110112, 134

Suk, Jihun, viii

Summer at Grandpa's, A (Dongdong de jiaqi, 1984), 96-97

Sun Guoting, 85

Sun Qianli. See Sun Guoting

Suo Masayuki, 6

Suzuki Shigeyoshi, 116-117

Swiri. See Shiri

Sword, The (Ming jian, 1980), 97

Swordsman, The (Xiao ao jiang hu, 1990), 43, 97 symmetry, 62-63, 91, 94-99

Sympathy for Mr. Vengeance (Boksu neun na ui geot, 2002), 48-49

Tachisme, 25, 87

Takahashi Ken, vii
Takakura Ken, 132

Takeda Soun, vii, 16n15, 54

Taki no shiraito. See Water Magician, The

Tamura Yukihiko, 39

Tang Xiaobing, viii

Tanin no kao. See Face of Another

Tanizaki Jun'ichiro, 118-119

Tao Xue Wei Lung. See Fight Back to School

Tasaka Tomotaka, 116-117

Teahouse of the August Moon (1956), 19

teamLab, 53-55

Tenkoku to jigoku. See High and Low

Teshigawara Hiroshi, 13, 25-27, 43

Teshigawara Sofu, 13, 24-27, 43

This Road (Kono michi, 2018), 6

three irreplaceables, 73-76, 80

three perfections, 29

threefold rule, 71-72

Throne of Blood (Kumo no sujo, 1957), 43

Tianbian yi duo yun. See Wayward Cloud, The

Titanic (1997), 46

To, Johnnie, 51, 53

Toad Oil (Gama no Abura, 1984), 43

Tobey, Mark, 87

tokonoma, 92, 94, 107

Tokyo March (Tokyo koshinkyoku, 1929), 38

Tokyo saiban. See International Military Tribunal for the Far East

Tone Yasunao, 100, 126

Tong Yang-tze, vii, 8, 22, 24, 76-77

Tora Tora Tora (1970), 123

Tosei ninretsuden. See Yakuza's Tale

Touming zhuang. See Warlords, The

Tower of London (1962), 18

Toyoda Shiro, 30

tradition, 7, 8, 22, 28-29

translation, 13, 39-41, 105, 110-112, 126,

Treasure Island (1975), 18

Tristan und Isolde, 90

Tsai Ming-liang, 8-9, 22, 76-77, 96, 99

Tsang Tsou-choi. See King of Kowloon

Tsuburuya Eiji, 122

Tsuchikane, Yasuko, viii

Tsuki to kabetsu. See One More Time, One More Chance

Tsumetai seimei. See Cold Life

Tsurukame. See Crane and Turtle

typography, 13-14, 28, 39, 41, 47, 55, 57-59, 8o, 81n1, 102, 111-112, 127, 129,

Uchida Tomu, 116-117

Uchikawa Seiichiro, 117, 119

Ueda Sokyu, 27
Ueno Toshiya, vii

Ugetsu (Ugetsu monogatari, 1953), 62

Ukiyo no gaka. See Artist of the Floating World, An

Umehara Seizan, 31

Unagi. See Eel, The

Ushihara Kiyohiko, 116-117

van Gogh, Vincent, 25

Villainess, The (Aknyeo, 2017), 93

Visage. See Face

Voice and Phenomenon (1976), 100

von Moltke, Johannes, viii

Wachi Yukiko, vii

Wagner, Richard, 90

Wakamatsu Koji, 5

Wang Delong, 76

Wang Duo, 51

Wang Gerui, viii

Wang Hongwei, viii

Wang Paizhang, vii

Wang Wo, viii, 87-88, 124-125

Wang Xianzhi, 21

Wang Xizhi, 21-22, 24, 130-131, 132

Wang Yi, 108

Wanjia denghuo. See Myriad of Lights

War at Sea from Hawai'i to Malaya (Mare Hawai okikaisen, 1942), 122-123

Warhol, Andy, 126

Warlords, The (Touming zhuang, 2007), 51

Warriors 2 (Zan xiansheng yu zhaoqian hua, 1978), 13-14, 91, 97

Water Boys (Wata boizu, 2001), 6, 24

Water Magician, The (Taki no shiraito, 1933), 11-12, 83-84

Wayward Cloud (Tian bian yi duo yun, 2005), 24, 77

Western calligraphy, 15, 17-21, 50, 75, 77, 8o, 121

What Time is it Over There? (Ni nabian jidian, 2003), 77

What's a Film Director? (Eiga kantoku tte nan da?, 2006), 140-141

White Calligraphy (1967), 125-127

Whitman, Walt, 8

Woman Named Abe Sada, A (Jitsuroku Abe Sada, 1975), 60

Wong Fei-hong, 68-69

Wong Kar-wai, 76-77

Wong, Angelika, vii, 106

Wong, Edmond Kin-yip, vii

woodblock prints, 43-45, 85, 127, 132 
World According to Garp, The (1982), 19 Wrath of the Gods, The (1914), 18, 20 Wu, John, 51

Wuthering Heights (Arashi no oka, 1988), 58 Wuya yu maque. See Crows and Sparrows

Xiao ao jiang hu. See Swordsman, The

Xiong Qi, viii

Xu Bing, viii, 85, 97

Xu Pengle, viii, 118, 121

Yabe Chosho, vii

Yakuza's Tale (Tosei ninretsuden, 1969), 132133

Yamada Yoji, 89

Yamamoto Kajiro, 116-117

Yamanaka Sadao, 116-117

Yan Xishan, 116

Yan Zhenqing, 51-53, 142

Yang Ji, viii

Yang, Edward, 102, 112n5

Yantai. See Inkstone

Ye yan. See Banquet, The

Yeh, Emily Yueh-yu, viii, 104
Yellow Earth (Huang tudi, 1984), 70-71, 96, 98 Yellow Emperor, 14

Yellow Magic Orchestra, 143

Yeo Taemyeong, 118, 122

Yeoh, Michelle, 78

yi jie, 140-141

Yi Ye-Ho, viii

Yidai zongshi. See Grandmaster

Yingxiong. See Hero

Yoda Yoshikata, 140-141

Yomota Inuhiko, vii

Yoshida Kiju, vii, 57-59, 63-64, 67-68, 84, 89, 93-94, 143-145

Yoshimi Shunya, vii

Young Soldiers of the Sky (Sora no shonenhei, 1940), 122-123

Yu Kuo-ching, vii

Yu Yuanwei, 32n5

Yuen Woo-ping, 68-69

yuige. See yi jie

Yuki yukite shingun. See Emperor's Naked Army Marches On, The

Yukiguni. See Snow Country

Yukoku. See Patriotism
Zahlten, Alexander, viii

Zan xiansheng yu zhaoqian hua. See Warriors 2

Zatoichi (2003), 50

Zatoichi Meets Yojimbo (Zatoichi to Yojinbo, 1970), 95

Zen (2009), 6

Zhang Huaiguan, 85

Zhang Shujuan, viii

Zhang Xu, 21-22, 125

Zhang Yimou, 31, 68, 70, 76, 96-97, 99

Zhang Yinlin, 143

Zhang Ziyi, 78

Zhantai. See Platform

Zhao Liang, viii, 73-74

Zhao Mengfu, 51, 53

Zhao Xiaoding, 96-97

Zhe Teng: According to China (Zhe Teng, 2010), 87-88

Zhou En-lai, 116

Zi li chengjian. See Fonting the City

$\mathrm{Zu}$ Xiaobing, 23, 84 


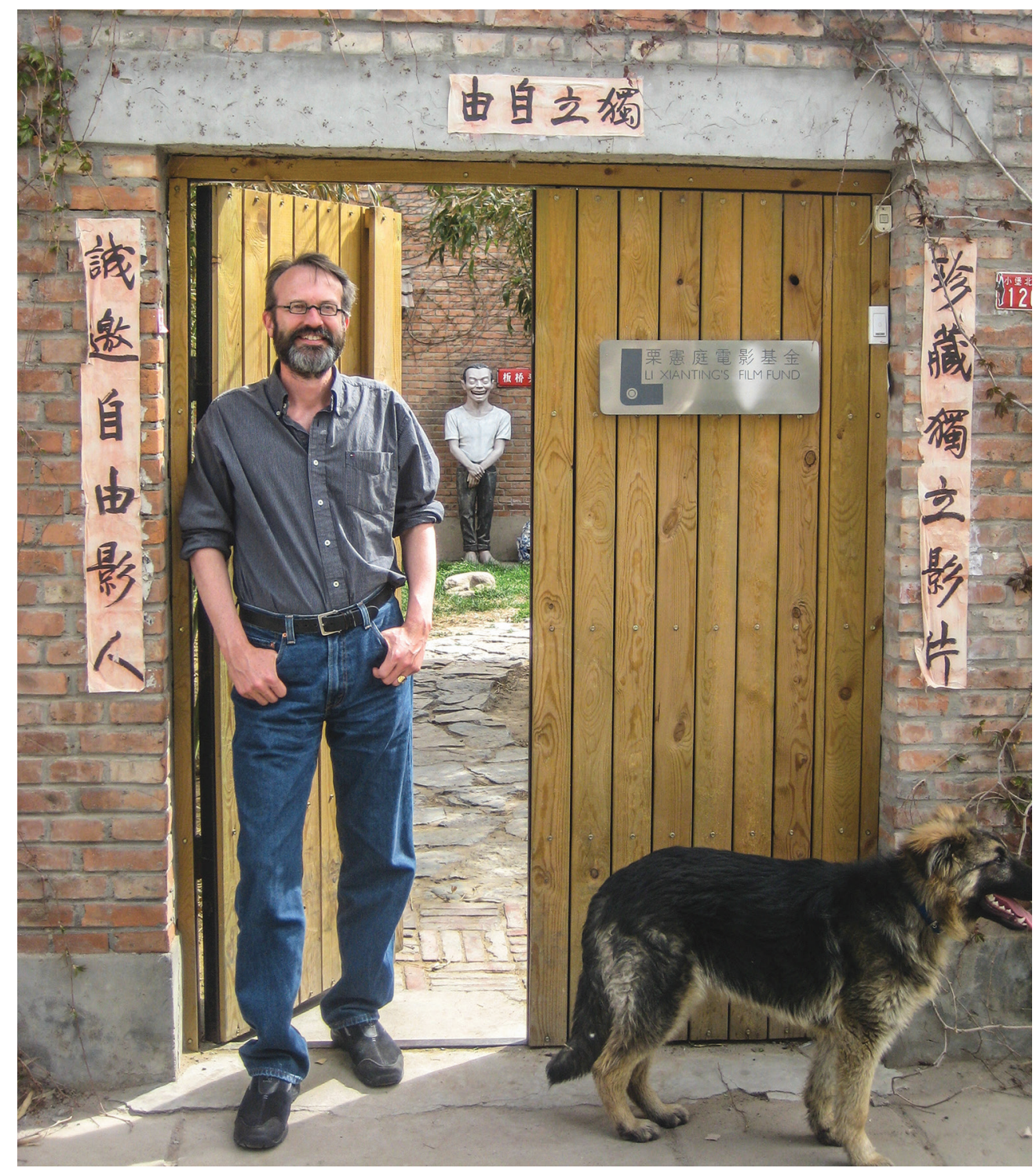

Markus Nornes is Professor of Asian Cinema at the University of Michigan, where he specializes in Japanese film, documentary and translation theory. He has done extensive programming on the international film festival circuit, especially at the Yamagata International Documentary Film Festival. He has written books on Japanese documentary, City of Sadness, film translation, and a critical biography of director Ogawa Shinsuke. Nornes has also co-directed a number of films, including The Big House (2018). He is currently working on a biography of filmmaker Adachi Masao. 
